Universidade de São Paulo

Faculdade de Filosofia, Ciências e Letras de Ribeirão Preto

Departamento de Química

Programa de Pós-Graduação em Química

\title{
“Modificação de superfícies metálicas por meio da deposição de filmes finos orgânicos LB/LbL e filmes híbridos contendo $\mathrm{CaCO}_{3}{ }^{\prime \prime}$
}

\author{
Ana Paula Ramos
}

Tese apresentada à Faculdade de

Filosofia, Ciências e Letras de Ribeirão Preto da Universidade de São Paulo, como parte das exigências para a obtenção do título de Doutor em Ciências, Área: Química 
Universidade de São Paulo

Faculdade de Filosofia, Ciências e Letras de Ribeirão Preto

Departamento de Química

Programa de Pós-Graduação em Química

\title{
"Modificação de superfícies metálicas por meio da deposição de filmes finos orgânicos LB/LbL e filmes híbridos contendo $\mathrm{CaCO}_{3}{ }^{\prime \prime}$
}

\author{
Ana Paula Ramos
}

Orientadora: Profa. Dra. Maria Elisabete Darbello Zaniquelli

Tese apresentada à Faculdade de

Filosofia, Ciências e Letras de Ribeirão Preto da Universidade de São Paulo, como parte das exigências para a obtenção do título de Doutor em Ciências, Área: Química

RIBEIRÃO PRETO -SP 


\section{FICHA CATALOGRÁFICA}

Ramos, Ana Paula

Modificação de superfícies metálicas por meio da deposição de filmes finos orgânicos $\mathrm{LB} / \mathrm{LbL}$ e filmes híbridos contendo $\mathrm{CaCO}_{3}$ Ribeirão Preto, 2009.

176 p. : il. ; $30 \mathrm{~cm}$

Tese de doutorado, apresentada à Faculdade de Filosofia, Ciências e Letras de Ribeirão Preto/USP - Área de concentração: Química.

Orientadora: Zaniquelli, Maria Elisabete Darbello.

1. Carbonato de Cálcio. 2. Filme LbL. 3. Filme LB 4. Biomineralização 
"O que ninguém nunca viu nem ouviu, e o que jamais alguém pensou que podia acontecer, foi isso que Deus preparou para aqueles que o amam"

(Primeira carta de Paulo aos Corintios 2:9) 
À minha mãe Ana Maria e aa meu pai Carlas Antania As minhas irmâs Ana Carla e Ana Claudia A minha arientadora Maria Elisabete Parque sem a apoia de vacês nada seria passível! 


\section{Agradecimentos}

Em primeiro lugar a Deus por ter sido sempre meu methor amigo e ter me abençoado com presentes maravithosos. Obrigada pela caminhada segura!

À minha orientadora e amiga Profa. Dra. Maria Elisabete D. Zaniquelli. Cientista e pessoa admirável, referêncía não só para mím, mas como para todos que a cercam. Bete, obrigada por me auxiliar desde os prímeiros passos na ciêncía, obrigada também pela amizade, pelas longas conversas que me fizeram crescer como cientista e, principalmente, como pessoa.

À amiga e colaboradora Profa. Dra. Rogéría Rocha Gonçalves. Pelas discussões, pela ajuda no desenvolvimento do projeto e artígos e também pela amizade. Sinto-me privílegiada por ter pessoas como você ao meu lado.

À Dra. Fiona C. Meldrum, Dra. Yi-Yeoun e Nicola Hetherington por me receberem tão bem durante o estágio em Bristol-UK. Obrigada pela ajuda nas discussões sobre a formação de carbonato de cálcio.

À minha família por sempre ter me apoíado e me incentivado. Vó Octacílía, tío Sérgío, tío $\mathcal{E} d i ́ l s o n$, tio Carlos, tio $\mathcal{N} e i$, as tías Sílvía, Lourdes e Lucíana, aos meus primos e meu cunhado Marino. À família que Deus me permitiu escolher: tía Irana e tío Cecí. Sinto orgulho por ter uma familía como vocês, a melhor que Deus podería ter me dado.

Ao Jorge Antonio Gómez pelo amor e pela força para seguir em frente.

À Ana Cecília por todos os momentos de dedicação, companheirísmo, pelo ombro e ouvido amigo.

Ao amígo Amadeu Bernardi pelo apoío e por sempre trazer um pouco mais de alegria à minha vida.

Às amigas Tati Minorin e Mariana Guzzo. Pela amizade sincera em todos os momentos que passamos e ainda vamos passar juntas.

Aos amigos e companheiros de todos os dias: Marina, Jamanta, Andréa, Sílvio, Bruno, Luciana, Jefferson, Chíco, Fausto e André Stoppa. Obrigada pelas festas, pela companhia agradável, pelas risadas e conversas úteís e inúteís. Guardo vocês no meu coração! 
Aos companheiros atuais e aos que já se foram do Laboratório de Físico-Químíca de Superfícies e Colóides: Luciano Caseli, Thais, Mirian, Adriano, Leonardo (Tchau), Rafael Malpeli, Matheus, Tati, Thaty, João, Isabel e Douglas. Im especial ao César, Walter, Daniela e Fernanda pela amizade, pelas conversas, pelas piadas e por terem tornado, com isso, o trabalho mais prazeroso.

Ao amigo Maureen Lagos pelo auxílio com as discussões relacionadas à microscopia eletrônica de transmissão. Obrigada pela atenção, pela disponíbilidade e sugestões valiosas!

$\mathcal{A}$ o Sr. José Humberto Lopes da empresa $3 \mathcal{M}$ por disponibilizar o equipamento para os testes de adesão.

$\mathcal{A}$ os todos os professores e funcionários do departamento de química da $\mathcal{F F C L \mathcal { R }}$ e aos colaboradores deste trabalho. $\mathcal{E}$ m especial agradeço ao $\mathcal{D} r$. Luciano $\mathcal{A}$. Montoro por toda a ajuda e ricas sugestões. Obrigada por sempre estar disposto a auxiliar, o mundo precisa de cientistas como você! Aos técnicos Lourivaldo, Rodrígo, Ivana e Vitor.

Aos colegas do Laboratório de Terras Raras e Bio-inorgânica, em especial à Fernanda e Christiane.

$\dot{\mathcal{A}} \mathcal{F A P E S P}$ pelo apoio financeiro (processo 05/51220-4).

$\mathcal{A}$ todas as pessoas que direta ou indiretamente contribuíram para a realização desse trabalho. Meu MUITO OBRIGADA'!!! 
"Os químicos são uma estranha classe de mortais, impelidos por um impulso quase insano a procurar seus prazeres em meio a fumaça e vapor, fuligem $e$ chamas, venenos e pobreza, e no entanto, entre todos esses males, tenho a impressão de viver tão agradavelmente que preferiria morrer a trocar de lugar com o rei da Pérsia."

(Johann Joachim Becher, Physica Subterranea, 1667) 


\section{Índice}

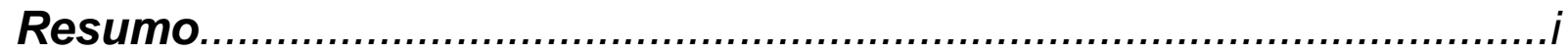

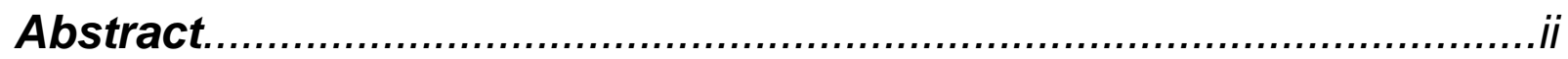

Índice de figuras.........................................................................ii

Índice de Tabelas..........................................................................

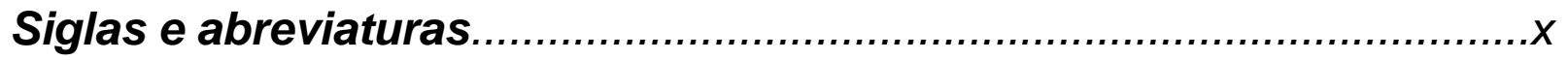

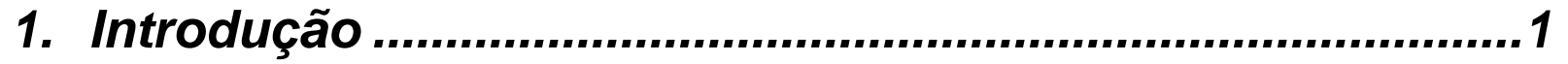

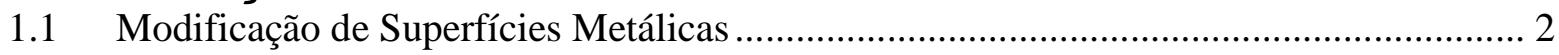

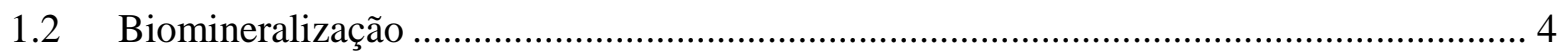

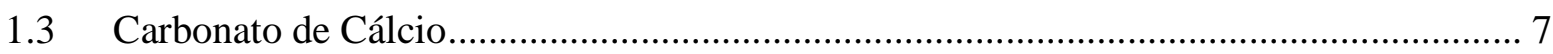

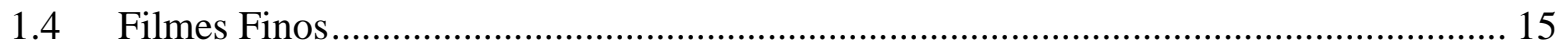

1.4.1 Monocamadas de Langmuir e Filmes Langmuir-Blodgett.................................. 15

1.4.2 Filmes de Langmuir -Blodgett e microbalança a cristal de quartzo ..................... 19

1.4.3 Comportamento de polieletrólitos em solução: adsorção em superfícies sólidas e

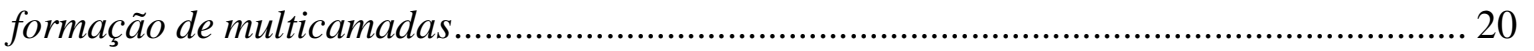

1.4.4 Formação de Filmes Finos Poliméricos: Filmes automontados ou layer-by-layer......... 30

2. Parte Experimental ...........................................................34

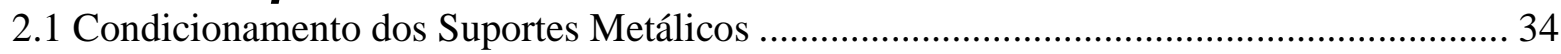

2.2 Formação dos filmes LbL e filmes mistos LB/LbL sobre suportes metálicos .................... 34

2.3 Formação do Filme Inorgânico de $\mathrm{CaCO}_{3}$ sobre suportes planares .............................. 39

2.4 Crescimento de $\mathrm{CaCO}_{3}$ em meio confinado tridimensional ........................................ 41

2.5 Caracterização dos Filmes Orgânicos e Híbridos ............................................................... 43

2.5.1 Teste de adesão dos filmes sobre os suportes ......................................................... 43

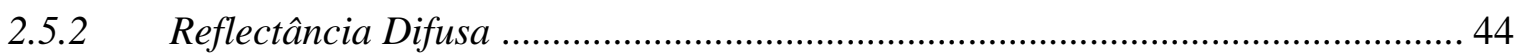

2.5.3 Espalhamento de Raios-x a baixo ângulo $(S A X S)$............................................. 45

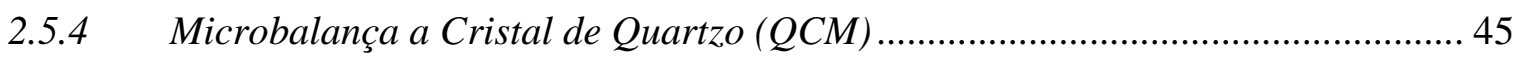

2.5.5 Espectroscopia na Região do Infravermelho com reflexão total atenuada (ATR-

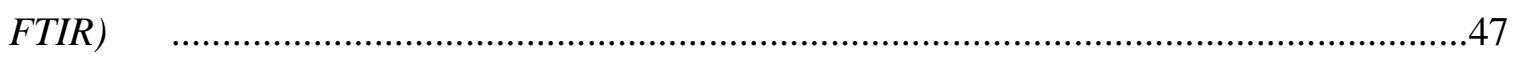




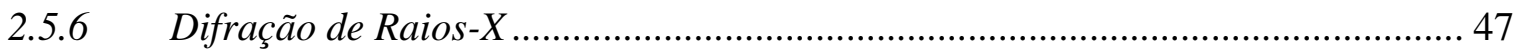

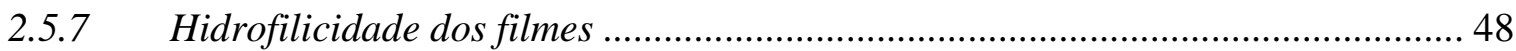

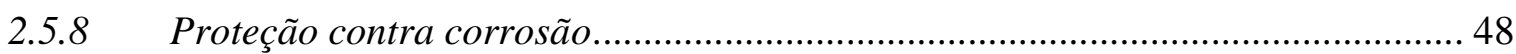

2.5.9 Análises Morfológicas .................................................................................................. 49

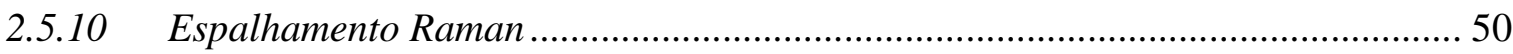

3. Resultados e Discussão ................................................52

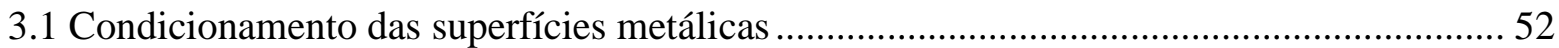

3.2 Formação das matrizes orgânicas de PAA e crescimento de $\mathrm{CaCO}_{3}$ sobre filmes de $\mathrm{LbL}$ de

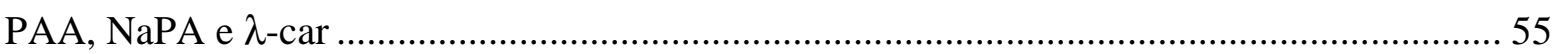

3.2.1 Espectroscopia eletrônica na região UV-vis: análise da deposição dos filmes LbL ... 55

3.2.2 Espalhamento de luz a baixo ângulo (SAXS): Efeito do ordenamento da matriz orgânica de filmes LbL e LB/LbL depositados sobre alumínio........................................... 56

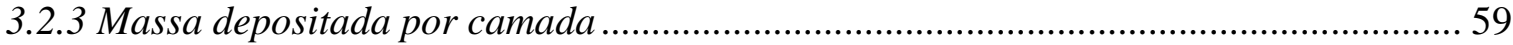

3.2.4 Análise dos grupos químicos presentes na superfície ................................................ 63

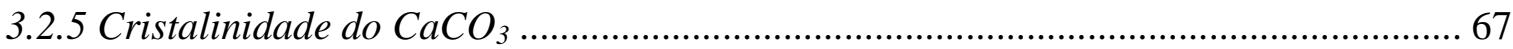

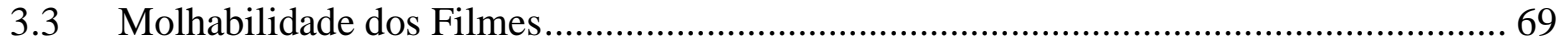

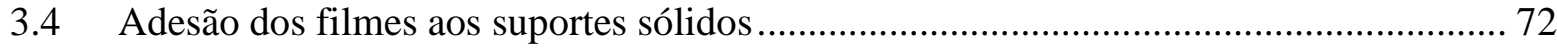

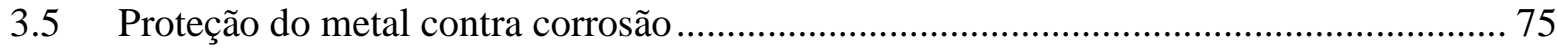

3.6 Formação de $\mathrm{CaCO}_{3}$ sobre filmes de PAA e NaPA pelo método "a seco": comparação

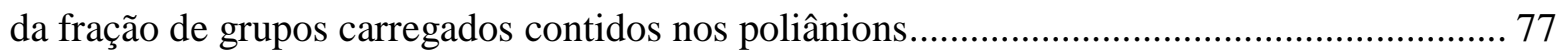

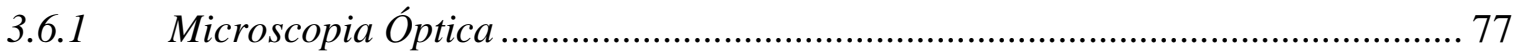

3.6.2 Microscopia Eletrônica de Varredura (MEV) ....................................................... 78

3.7 Crescimento de partículas de $\mathrm{CaCO}_{3}$ sobre filmes $\mathrm{LB} / \mathrm{LbL}$ usando um poliânion capaz

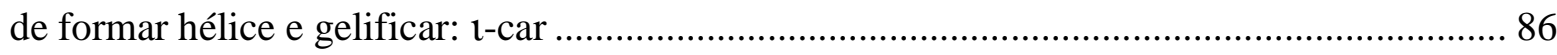

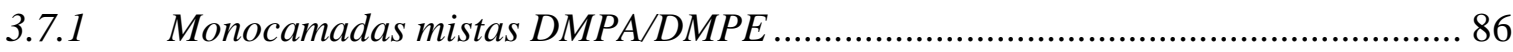

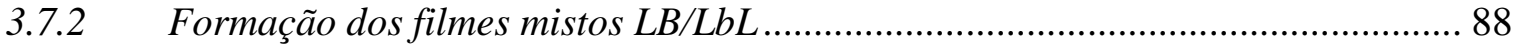

3.7.3 Formação de $\mathrm{CaCO}_{3}$ sobre filmes híbridos contendo t-carr ................................ 91

3.7.4 Variação no tempo de exposição da matriz orgânica a $\left(\mathrm{NH}_{4}\right)_{2} \mathrm{CO}_{3}$ : acompanhamento do crescimento dos cristais 96 
3.8 Crescimento de filmes de $\mathrm{CaCO}_{3}$ sobre matrizes orgânicas mistas $\mathrm{LB} / \mathrm{LbL}$ usando poliânions que apresentam conformação de novelo-ao-acaso: poli(ácido acrílico), PAA, e lambda-carragenana ( $\lambda$-car)- Efeito do tipo de fosfolipídeo no filme LB............................... 98 3.9 Efeito do microambiente na deposição de $\mathrm{CaCO}_{3}$ : suportes planares em solução de

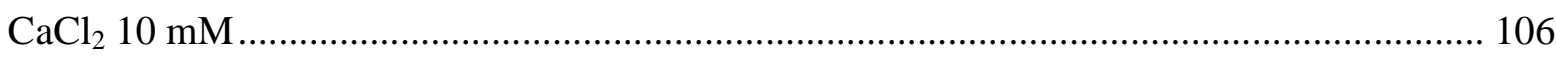

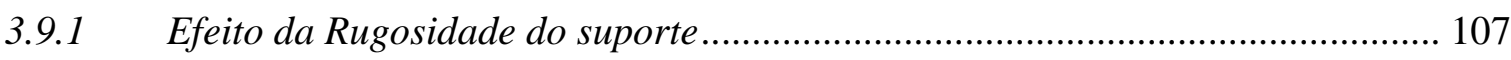

3.9.2 Tipo de poliânion formador do filme LbL: suportes planares em solução 0,01 mol $\mathrm{L}^{-1} \mathrm{CaCl}_{2}$

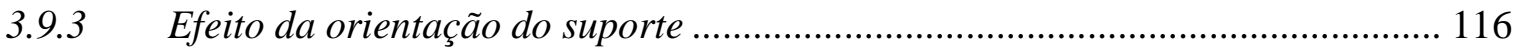

3.10 Identificação dos polimorfos de $\mathrm{CaCO} 3$ formados: Espectroscopia Raman ............ 119

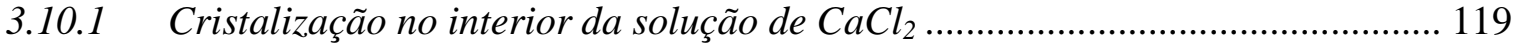

3.10.2 Cristalização fora da solução pelo método "a seco" .......................................... 123

3.11 Crescimento de $\mathrm{CaCO}_{3}$ em meio confinado tridimensional................................... 127

4. Conclusões ..................................................................143

5. Referências ...................................................................149 


\section{Resumo}

Muitos organismos vivos, tal como seus constituintes, são formados por sistemas químicos complexos que envolvem a interação entre compostos orgânicos e inorgânicos ligados química e/ou fisicamente. Nestes sistemas as matrizes orgânicas são geralmente compostas por macromoléculas como polissacarídeos e proteínas. Essas moléculas têm o papel de direcionar a nucleação e o crescimento da porção inorgânica. $O$ uso de superfícies metálicas adequadas recobertas por este tipo de filme híbrido tem potencial aplicação em implantes de substituição óssea, no qual são requeridas superfícies quimicamente inertes, mas que ao mesmo tempo estimulem processos de calcificação. Nesta tese estudou-se o crescimento de $\mathrm{CaCO}_{3}$ sobre superfícies metálicas de alumínio e aço inox recobertas por matrizes orgânicas compostas por diferentes poliânions e pelo policátion quitosana, na forma de filmes montados camada-acamada (do inglês LbL), na presença ou não de fosfolipídeos (filmes Langmuir-Blodgett), formando um meio confinado para o crescimento do mineral. Diferentes técnicas foram utilizadas: microscopia eletrônica, microscopia de força atômica, espectroscopias de reflexão nas regiões do Uv-vis, e do infravermelho, Raman, espalhamento e difração de raios-X. Estudou-se a influência de diferentes grupos carregados dos fosfolipídeos e dos poliânions, tal como sua conformação, no crescimento de $\mathrm{CaCO}_{3}$. O tipo de interação entre o poliânion e a quitosana leva ao crescimento de matrizes poliméricas com diferenças em suas espessuras e capacidade de retenção de líquido, modificando as condições de supersaturação local e influenciando no tipo de estrutura de $\mathrm{CaCO}_{3}$. Puderam ser identificados dois polimorfos formados sobre os filmes orgânicos de poli(ácido acrílico) e quitosana, sugerindo que existem dois diferentes sítios onde a nucleação pode ser iniciada: a partir da solução de $\mathrm{CaCl}_{2}$ aprisionada na matriz polimérica e o outro a partir dos íons cálcio ligados como contra-íons aos grupos negativamente carregados do poliânion. Na presença do pré-recobrimento LB, a natureza da cabeça polar do fosfolipídeo direciona o tipo de ligação e crescimento da matriz polimérica, que levam ao crescimento de partículas de $\mathrm{CaCO}_{3}$ com morfologia e tamanho variados, explicados em termos da presença de ambientes com diferenças de concentrações locais de $\mathrm{Ca}^{2+}$. Além disso, verificou-se que a rugosidade superficial dos suportes metálicos pode favorecer a formação do polimorfo de $\mathrm{CaCO}_{3}$ cineticamente mais estável, mostrando que o processo de cristalização sobre estes suportes é um processo governado por difusão. A hidrofilicidade dos suportes é aumentada pela presença da matriz orgânica e pela presença de $\mathrm{CaCO}_{3}$ sobre as matrizes. $\mathrm{O}$ crescimento de $\mathrm{CaCO}_{3}$ em meios confinados tridimensionais, formados por membranas de policarbonato modificadas com filme finos de polieletrólitos, também foi estudado. Este tipo de molde leva à formação de estruturas cilíndricas que seguem a morfologia dos poros da membrana. A presença de poli(ácido acrílico) leva a formação de estruturas cilíndricas ocas, enquanto que cilindros completamente preenchidos foram formados nos poros contendo quitosana na última camada. Estes resultados foram explicados com base em diferenças na etapa de nucleação: na presença de PAA a nucleação de $\mathrm{CaCO}_{3}$ deve iniciar-se a partir dos íons $\mathrm{Ca}^{2+}$ ligados ao poliânion que, por sua vez, está ligado diretamente às paredes do molde; já na presença que quitosana, com maior capacidade de retenção de liquido e sem interação específica com $\mathrm{Ca}^{2+}$ a nucleação e seqüente cristalização devem ocorrer por todo o poro da membrana. As estruturas formadas são em sua maioria monocristais de calcita hexagonal orientadas na direção cristalográfica $<2$-2 1>. 


\section{Abstract}

Some living organisms as well as their constituents are formed by complex chemical systems which involves the interaction among organic and inorganic compounds bounded physically or chemically. In these systems the organic matrices are usually composed by macromolecules like polysaccharides and proteins. These molecules have an important hole in tailoring the nucleation and the sequent growth of the inorganic portion. Metallic surfaces coated with these hybrid films have potential application as implants for bone substitution for which the surfaces must be chemically inert but at the same time they should stimulate calcification processes. In this present thesis we studied the growth of $\mathrm{CaCO}_{3}$ over aluminium and stainless steal surfaces coated with layer-by-layer films composed by different polyanions and chitosan as polycation, in the presence or not of phospholipids (Langmuir-Blodgett films). These organic matrices formed a confined medium within which $\mathrm{CaCO}_{3}$ particles were growth. Different techniques were applied in order to understand these systems: electronic microscopy, atomic force microscopy, UV-Vis and infrared reflection spectroscopy, Raman, and X-ray scattering and diffraction. We studied the influence of the different charged groups of the phospholipids and the polyanion as well as their conformation on $\mathrm{CaCO}_{3}$ growth. The type of interaction between the polycation and the polyanions tailors the growth of the organic matrices, forming films with different thickness and different water retention abilities which change the local supersaturation conditions changing the structure of the $\mathrm{CaCO}_{3}$ formed. Two types of $\mathrm{CaCO}_{3}$ polymorphs were growth over poly(acrylic acid) (PAA) and chitosan films suggesting that there are two sites where the nucleation can be started: the $\mathrm{CaCl}_{2}$ solution retained in the gel-like organic films and the $\mathrm{Ca}^{2+}$ ions bounded to the negative groups of the polyanion. In the presence of the LB pre-coating, the nature of the phospholipid polar head tailors the binding and the growth of the polymeric matrices leading to the formation of $\mathrm{CaCO}_{3}$ particles with difference in their sizes and morphologies. This result was explained in basis of the differences in the $\mathrm{Ca}^{2+}$ local concentrations in each situation. Moreover, it was observed that the surface roughness of the supports can favour the formation of vaterite, the kinetically most stable $\mathrm{CaCO}_{3}$ polymorph, showing that the crystallization may be guided by diffusion processes. The hidrophilicity of the supports was improved by the presence of both organic and hybrid films. The growth of $\mathrm{CaCO}_{3}$ in tridimentional confined mediums was done using LbL modified polycarbonate membranes as template. This template leads to the formation of cylindrical $\mathrm{CaCO}_{3}$ particles following the morphology of the membrane pores. $\mathrm{CaCO}_{3}$ tube-like structures were formed in presence of PAA, while rod-like structures were formed in presence of chitosan in the top LbL layer. These results were explained on basis of the difference in the nucleation stages: in the presence of PAA the nucleation starts on the $\mathrm{Ca}^{2+}$ ions bounded to the polyanion that is linked to the walls of the template; in the presence of chitosan that presents higher water retention ability and has no specific interaction with $\mathrm{Ca}^{2+}$ ions, the nucleation and sequent crystallization should occur through the entire pore of the membrane. The electron diffraction patterns showed that the $\mathrm{CaCO}_{3}$ structures are single crystals of the calcite polymorph oriented in $<2-21>$ crystallographic direction. 


\section{Índice de Figuras}

Figura 1: Imagens de microscopia eletrônica de varredura dos três diferentes polimorfos de $\mathrm{CaCO}_{3}$ ressaltando as diferenças nas suas morfologias ............................................................... 7

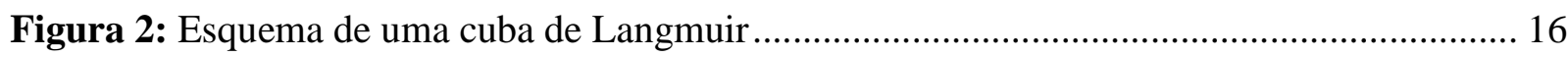

Figura 3: Esquema de um experimento na cuba de Langmuir, topo: vista lateral da cuba, mostrando as moléculas do tensoativo formando a monocamada; meio: vista de cima da cuba, evidenciando a compressão da monocamada com a barreira móvel e, por último um exemplo de

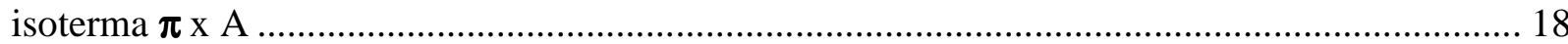

Figura 4: Transferência de moléculas anfifílicas para suporte sólido formando um filme fino .. 19 Figura 5: Filmes tipos $\mathrm{X}, \mathrm{Y}$ e Z obtidos pelo método de Langmuir-Blodgett. .............................. 20 Figura 6: Distância ponta-a-ponta de uma cadeia polimérica Gaussiana.................................... 21

Figura 7: Polieletrólito estendido devido à repulsão entre as cargas de mesmo sinal. ................ 23

Figura 8: Cadeia de polieletrólito fracamente carregada. ...................................................... 24

Figura 9: Decaimento do campo elétrico em função da distância à superfície, com e sem

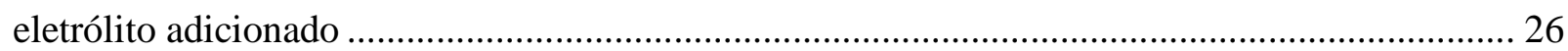

Figura 10: Conformações de um polieletrólito depositado sobre um substrato sólido ................. 27

Figura 11: Perfil de decaimento da concentração de poliânion e policátion em função da

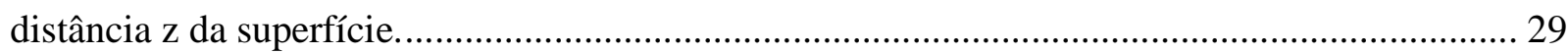

Figura 12: Ilustração da deposição alternada de dois polieletrólitos de cargas opostas e o

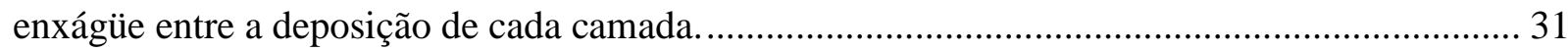

Figura 13: Estrutura dos fosfolipídeo e dos polieletrólitos utilizados........................................ 36

Figura 14: Representação esquemática da estrutura dos filmes mistos LB/LbL. ...................... 38

Figura 15: Esquema da montagem experimental para deposição de $\mathrm{CaCO}_{3}$ em membranas de policarbonato.

Figura 16: Esquema da montagem típica de uma QCM evidenciando o cristal piezelétrico de quartzo, recoberto pelos eletrodos de ouro. 46

Figura 17: Equipamento Raman instalado na Universidade de Bristol- School of Chemistry.... 51 Figura 18: Imagens de AFM das superfícies dos metais e silício antes e após o tratamento de polimento e limpeza. 
Figura 19: Variação da quantidade de luz refletida em função do número de camadas de PAA e Qt depositadas. 55

Figura 20: Curvas de intensidade de luz espalhada $v s$ vetor de espalhamento $(\mathrm{Q})$ para os filmes orgânicos e mistos. 57

Figura 21: Variação da massa adsorvida em função do número de bicamadas de (PAA/Qt) depositadas

Figura 22: Variação de freqüência do cristal de quartzo contendo filme LbL PAA/Qt exposto à $\mathrm{CO}_{2}$ 62

Figura 23: Espectro ATR-FTIR para suportes de alumínio contendo matriz polimérica $(\mathrm{PAA} / \mathrm{Qt})_{6} \mathrm{PAA}$ 64

Figura 24: Espectros ATR-FTIR de padrões quitosana, carbonato e poli(ácido acrílico) 65

Figura 25: Espectros ATR-FTIR filme LbL 1-carr/Qt em suporte de alumínio após exposição à $\left(\mathrm{NH}_{4}\right)_{2} \mathrm{CO}_{3}$ por 15 horas. 66

Figura 26: Picos de difração do filme híbrido (PAA/Qt) ${ }_{6} \mathrm{PAA} / \mathrm{CaCO}_{3}$. 68

Figura 27: Espalhamento de uma gota de água sobre: a) suporte de alumínio; b) suporte de alumínio contendo matriz polimérica (PAA/Qt) ${ }_{3} \mathrm{PAA}$ seguido por exposição a carbonato de amônio por 13 horas 69

Figura 28: Evolução de $\theta$ com o tempo para suporte de almínio recoberto por filme LbL (PAA/Qt $)_{5} \mathrm{PAA}$ com $\mathrm{CaCO}_{3}$ depositado na ultima camada. 70

Figura 29: Curvas de densidade de corrente $(j)$ vs potencial para: suporte de aço (linha traço e ponto), suporte de aço contendo filme híbrido (DMPA) $4 /(\mathrm{Qt} / \mathrm{PAA})_{2} / \mathrm{CaCO}_{3}$ (linha sólida), suporte de alumínio (linha tracejada), suporte de alumínio contendo filme híbrido $(\mathrm{DMPA})_{4} /(\mathrm{Qt} / \mathrm{PAA})_{2} / \mathrm{CaCO}_{3}$ (linha pontilhada). 76

Figura 30: Microscopia ótica com luz polarizada dos filmes PAA/Qt depositados sobre suportes de alumínio: A) (PAA/Qt) $\left.{ }_{3} \mathrm{PAA} ; \mathrm{B}\right)(\mathrm{PAA} / \mathrm{Qt})_{6} \mathrm{PAA}$ e C) (PAA/Qt) ${ }_{6} \mathrm{PAA}$ após exposição por 15 horas a $\left(\mathrm{NH}_{4}\right)_{2} \mathrm{CO}_{3}$ em recipiente fechado. 78

Figura 31: Microscopia ótica com luz polarizada dos filmes PAA/Qt depositados sobre suportes de aço inox 316L a) (PAA/Qt) ${ }_{6} \mathrm{PAA}$ e b) (PAA/Qt) ${ }_{6} \mathrm{PAA}$ após exposição por 15 horas a $\left(\mathrm{NH}_{4}\right)_{2} \mathrm{CO}_{3}$ em recipiente fechado. 78 
Figura 32: Micrografias de filmes LbL (PAA/Qt) ${ }_{6} \mathrm{PAA}$ depositados sobre a,b)suportes de alumínio c,d) suportes de aço inox 316L. As imagens (b) e (d) foram obtidas após exposição dos suportes contendo a matriz polimérica a $\left(\mathrm{NH}_{4}\right)_{2} \mathrm{CO}_{3}$ por 13 horas. 80

Figura 33: Filme $\mathrm{LbL}$ de $(\mathrm{PAA} / \mathrm{Qt})_{6} \mathrm{PAA}+\mathrm{CaCO}_{3}$ depositados sobre suporte de silício 81

Figura 34: Micrografias de filmes LbL (PAA/Qt) ${ }_{6} \mathrm{PAA}$ depositados sobre suportes de aço inox 316 L (inclinação de $60^{\circ}$ ). 82

Figura 35: Micrografias dos filmes (PAA/Qt) ${ }_{6} \mathrm{PAA}$ depositados sobre suportes de aço inox 316L. As imagens foram obtidas variando-se a inclinação das amostras.. 83

Figura 36: Filmes LbL (NAPA/Qt) ${ }_{6} \mathrm{NaPA}$ depositados sobre suporte de alumínio a, c) sem exposição à $\left.\left(\mathrm{NH}_{4}\right)_{2} \mathrm{CO}_{3} ; \mathrm{b}, \mathrm{d}\right)$ após exposição à $\left(\mathrm{NH}_{4}\right)_{2} \mathrm{CO}_{3}$ por 13 horas. 84

Figura 37: Filmes LbL (NaPA/Qt) ${ }_{6} \mathrm{NaPA}$ depositados sobre suporte de aço inox 316L a, c) sem exposição à $\left(\mathrm{NH}_{4}\right)_{2} \mathrm{CO}_{3} ;$ b,d) após exposição à $\left(\mathrm{NH}_{4}\right)_{2} \mathrm{CO}_{3}$ por 13 horas. 85

Figura 38: Isotermas de pressão superficial obtidas sobre água pura para monocamadas mistas DMPA/DMPE com diferentes frações molares de DMPA. 87

Figura 39: Efeito da adição de quitosana $0,05 \%(\mathrm{p} / \mathrm{p})$ sobre as isotermas $\pi$-A do DMPA (匹) $\operatorname{DMPE}(\bullet)$ e monocamadas mistas com diferentes frações molares de DMPA 0,5 ( $\mathbf{\Delta}), 0,3(\boldsymbol{\nabla})$ e $0,7(*)$. 88

Figura 40: Representação esquemática da influência da carga do fosfolipídeo na conformação dos polieletrólitos depositados. 91

Figura 41: Imagens de MEV de cristais de $\mathrm{CaCO}_{3}$ crescidos sobre: a) 2-bicamadas de filme LbL (Qt/l-car) depositado sobre filme LB de DMPA e b) 2-bicamadas de filme LbL (Qt/ l-car) depositados sobre suporte de alumínio. 92

Figura 42: Imagens de MEV dos cristais de $\mathrm{CaCO}_{3}$ crescidos sobre filmes $\mathrm{LB} / \mathrm{LbL}$ formados sobre suportes de alumínio recobertos com filmes LB DMPA/DMPE e filmes LbL Qt/l-car utilizando-se diferentes frações molares de DMPA (a) 1, (b) 0,7, (c) 0,5, (d) 0,3 and (e) 0 (DMPE puro). 93

Figura 43: Formação de $\mathrm{CaCO}_{3}$ sobre matriz orgânica depositada sobre alumínio exposta a $\left(\mathrm{NH}_{4}\right)_{2} \mathrm{CO}_{3}$ por um minuto. 97

Figura 44: Evolução no crescimento de cristais de $\mathrm{CaCO}_{3}$ em função do tempo de exposição à $\left(\mathrm{NH}_{4}\right)_{2} \mathrm{CO}_{3}$. 98 
Figura 45: imagens de MEV de filmes de $\mathrm{CaCO}_{3}$ crescidos sobre matriz (LbL) ${ }_{13}$ formadas com a) $(\lambda \text {-car/Qt })_{6} \lambda$-car; b) $(\mathrm{PAA} / \mathrm{Qt})_{6} \mathrm{PAA}$. Abaixo, aumento da imagem correspondente. 101

Figura 46: imagens de MEV de filmes de $\mathrm{CaCO}_{3}$ crescidos sobre matriz orgânica mista DMPA/ $\mathrm{LB}-(\mathrm{LbL})_{3}$ formadas com a,b) $\lambda$-carr; c,d) PAA. 102

Figura 47: imagens de MEV de filmes de $\mathrm{CaCO}_{3}$ crescidos sobre matriz orgânica mista DMPA/ LB-(LbL) ${ }_{13}$ formadas com a,b) $\lambda$-carr; c,d) PAA 103

Figura 48: Imagens de MEV de filmes de $\mathrm{CaCO}_{3}$ crescidos sobre matriz orgânica mista DMPE/ LB-(LbL) $)_{3}$ formadas com quitosana e $\lambda$-car $(a, b)$; PAA $(c, d)$. 104

Figura 49: Imagens de AFM dos filmes (a) DMPA $\mathrm{LB} /(\mathrm{LbL})_{13}$ sem $\mathrm{CaCO}_{3}$, (b) DMPA $\mathrm{LB} /(\mathrm{LbL})_{13}$ com $\mathrm{CaCO}_{3}$, (c) vista de cima, $(\mathrm{LbL})_{13}$ com $\mathrm{CaCO}_{3}$, (d) (LbL) $)_{13}$ com $\mathrm{CaCO}_{3}$....... 105

Figura 50: Filme híbrido (PAA/Qt) ${ }_{6} \mathrm{PAA} / \mathrm{CaCO}_{3}$ depositado sobre suporte de alumínio. ....... 108 Figura 51: Filme híbrido $(\mathrm{PAA} / \mathrm{Qt})_{6} \mathrm{PAA} / \mathrm{CaCO}_{3}$ depositado sobre suporte de aço-inox. O filme polimérico foi imerso em solução de $\mathrm{CaCl}_{2} 0,01 \mathrm{~mol} \cdot \mathrm{L}^{-1}$. As micrografias a, b e c diferem apenas quanto ao aumento. 109

Figura 52: Difratograma de filmes $\mathrm{LbL}$ de $(\mathrm{PAA} / \mathrm{Qt})_{6} \mathrm{PAA}+\mathrm{CaCO}_{3}$ depositados sobre diferentes suportes, imersos em solução de $\mathrm{CaCl}_{2}$ 0,01 mol L $\mathrm{L}^{-1}$. Alumínio (linha preta), aço-inox (linha vermelha) e silício (linha verde).

Figura 53: Filme LbL de (PSS/Qt) ${ }_{6} \mathrm{PSS}+\mathrm{CaCO}_{3}$ depositados sobre suporte de alumínio imerso em solução de $\mathrm{CaCl}_{2}$ 0,01 mol L ${ }^{-1}$, orientado com a face para cima

Figura 54: Filme LbL de (PSS/Qt) ${ }_{6} \mathrm{PSS}+\mathrm{CaCO}_{3}$ depositados sobre suporte de silício imerso em solução de $\mathrm{CaCl}_{2}$,, $01 \mathrm{~mol} \mathrm{~L}^{-1}$, orientado com a face para cima

Figura 55: Filme $\mathrm{LbL}$ de (PSS/Qt) ${ }_{6} \mathrm{PSS}+\mathrm{CaCO}_{3}$ depositados sobre suporte de aço-inox imerso em solução de $\mathrm{CaCl}_{2}$ 0,01 mol L $\mathrm{L}^{-1}$, orientado com a face para cima. 113

Figura 56: Difratograma de filmes $\mathrm{LbL}$ de $(\mathrm{PSS} / \mathrm{Qt})_{6} \mathrm{PSS}+\mathrm{CaCO}_{3}$ depositados sobre diferentes suportes, imersos em solução de $\mathrm{CaCl}_{2}$ 0,01 mol L ${ }^{-1}$. Alumínio (linha preta), aço-inox (linha vermelha) e silício (linha verde) 114

Figura 57: Filme $\mathrm{LbL}$ de $(\mathrm{PAA} / \mathrm{Qt})_{6} \mathrm{PAA}+\mathrm{CaCO}_{3}$ depositados sobre suporte de aço-inox imerso em solução de $\mathrm{CaCl}_{2} 0,01 \mathrm{~mol} \mathrm{~L}{ }^{-1}$, com a face para baixo. 117

Figura 58: Filme $\mathrm{LbL}$ de $(\mathrm{PAA} / \mathrm{Qt})_{6} \mathrm{PAA}+\mathrm{CaCO}_{3}$ depositados sobre suporte de silício imerso em solução de $\mathrm{CaCl}_{2}$ 0,01 mol L ${ }^{-1}$, com a face para baixo. 118 
Figura 59: Filme $\mathrm{LbL}$ de $(\mathrm{PSS} / \mathrm{Qt})_{6} \mathrm{PSS}+\mathrm{CaCO}_{3}$ depositados sobre suporte de silício imerso em solução de $\mathrm{CaCl}_{2} 0,01 \mathrm{~mol} \mathrm{~L}^{-1}$, com a face para baixo.

Figura 60: Espectros Raman de partículas de $\mathrm{CaCO}_{3}$ formadas sobre filme $\mathrm{LbL}$ (PAA/Qt) ${ }_{6} \mathrm{PAA}$ depositados sobre alumínio (linha preta) e aço-inox (linha vermelha).

Figura 61: Espectros Raman de amostras de filmes $\mathrm{LbL}(\kappa \mathrm{I}-\mathrm{car} / \mathrm{Qt})_{6} \mathrm{KI}-\mathrm{car}+\mathrm{CaCO}_{3}$, depositados sobre alumínio.

Figura 62: Espectros Raman de amostras de filmes $\mathrm{LbL}(\lambda \text {-car/Qt })_{6} \lambda$-car $+\mathrm{CaCO}_{3}$, depositados sobre alumínio. 124

Figura 63: Espectros Raman de amostras de filmes $\mathrm{LbL}(\mathrm{PAA} / \mathrm{Qt})_{6} \mathrm{PAA}+\mathrm{CaCO}_{3}$, depositados sobre alumínio. 125

Figura 64: Filme LbL de (PAA/Qt) ${ }_{6} \mathrm{PAA}$ formado no interior de membrana de policarbonado com poros de $4 \mu \mathrm{m}$.

Figura 65: Estruturas de $\mathrm{CaCO}_{3}$ obtidas utilizando-se membranas de policarbonato, com tamanho de poros de $200 \mathrm{~nm}$, como template. A membrana foi modificada com 4 camadas de filme LbL, alternando-se quitosana e PAA. Enxágüe 3 vezes com $\mathrm{CH}_{2} \mathrm{Cl}_{2}$.

Figura 66: Estruturas de $\mathrm{CaCO}_{3}$ obtidas utilizando-se como molde membranas de policarbonato, com tamanho de poros de $200 \mathrm{~nm}$. A membrana foi modificada com (Qt/PAA) $)_{2}$ antes da deposição de carbonato de cálcio. A lavagem para a remoção da parte orgânica foi feita com 5 enxágues com $\mathrm{CH}_{2} \mathrm{Cl}_{2}$. 131

Figura 67: Estruturas de $\mathrm{CaCO}_{3}$ obtidas utilizando-se como molde membranas de policarbonato, com tamanho de poros de $200 \mathrm{~nm}$. A membrana foi modificada com (Qt/PAA) $)_{2}$ antes da deposição de carbonato de cálcio. A remoção da parte orgânica foi feita por decomposição a altas temperaturas $\left(480^{\circ} \mathrm{C}\right)$.

Figura 68: Estruturas de $\mathrm{CaCO}_{3}$ obtidas utilizando-se como molde membranas de policarbonato, com tamanho de poros de $200 \mathrm{~nm}$. A membrana foi modificada com (Qt/PAA) ${ }_{2}$ antes da deposição de carbonato de cálcio. A lavagem para a remoção da parte orgânica foi feita com 5 enxágues com $\mathrm{CH}_{2} \mathrm{Cl}_{2}$, seguida por decomposição a altas temperaturas $\left(480^{\circ} \mathrm{C}\right)$. 132

Figura 69: Estruturas de $\mathrm{CaCO}_{3}$ obtidas utilizando-se membranas de policarbonato, com tamanho de poros de $200 \mathrm{~nm}$, como template. A membrana foi modificada com 5 camadas de filme LbL, alternando-se quitosana e PAA. Lavagem para a remoção da parte orgânica 5 vezes $\operatorname{com~} \mathrm{CH}_{2} \mathrm{Cl}_{2}$. 
Figura 70: Estruturas de $\mathrm{CaCO}_{3}$ obtidas utilizando-se membranas de policarbonato, com tamanho de poros de $200 \mathrm{~nm}$, como template. A membrana foi modificada com 5 camadas de filme LbL, alternando-se quitosana e PAA. Remoção da parte orgânica por decomposição a altas temperaturas $\left(480^{\circ} \mathrm{C}\right)$. 135

Figura 71: Estruturas de $\mathrm{CaCO}_{3}$ obtidas utilizando-se como molde membranas de policarbonato, com tamanho de poros de $200 \mathrm{~nm}$. A membrana foi modificada com filme LbL (Qt/PAA) ${ }_{2} \mathrm{Qt}$, não utilizando-se PAA como aditivo na solução de $\mathrm{CaCl}_{2}$ do último enxágue. A remoção da parte orgânica foi feita com 5 enxágues com $\mathrm{CH}_{2} \mathrm{Cl}_{2}$ 136

Figura 72: Estruturas de $\mathrm{CaCO}_{3}$ obtidas utilizando-se membranas de policarbonato, com tamanho de poros de $50 \mathrm{~nm}$, como template. A membrana foi modificada com 4 camadas de filme LbL, alternando-se quitosana e PAA. Lavagem para a remoção da parte orgânica 5 vezes com $\mathrm{CH}_{2} \mathrm{Cl}_{2}$. 137

Figura 73: Estruturas de $\mathrm{CaCO}_{3}$ obtidas utilizando-se membranas de policarbonato, com tamanho de poros de $50 \mathrm{~nm}$, como template. A membrana foi modificada com 4 camadas de filme LbL, alternando-se quitosana e PAA. Remoção da membrana e do filme LbL inicialmente com $\mathrm{CH}_{2} \mathrm{Cl}_{2} \mathrm{e}$ em seguida por decomposição à altas temperaturas $\left(480^{\circ} \mathrm{C}\right)$ 138

Figura 74: Estruturas de $\mathrm{CaCO}_{3}$ obtidas utilizando-se membranas de policarbonato, com tamanho de poros de $50 \mathrm{~nm}$, como template. A membrana foi modificada com 5 camadas de filme LbL, alternando-se quitosana e PAA. Lavagem para a remoção da parte orgânica 5 vezes $\operatorname{com~} \mathrm{CH}_{2} \mathrm{Cl}_{2}$. 139

Figura 75: Padrões de difração de elétrons obtidos para as áreas selecionadas mostradas correspondentes às figuras XX. O padrão corresponde a um monocristal de calcita orientado em eixo de zona $<2-21>$. 140

Figura 76: Estrutura hexagonal de $\mathrm{CaCO}_{3}$ orientado na direção cristalográfica $<2-2$ 1>. As esferas representam os átomos em suas posições: vermelho: cálcio, cinza: carbono, verde: oxigênio. 


\section{Índice de Tabelas}

Tabela 1: Pré-tratamentos realizados em superfícies metálicas ................................................ 52

Tabela 2: Freqüências e massas de polieletrólitos (NaPA, Qt) adsorvidos ................................. 61

Tabela 3: Picos padrão e experimentais e seus deslocamentos correspondentes ......................... 68

Tabela 4: Tempo e valores de $\theta$ equilíbrio para diferentes tipos de filmes depositados sobre

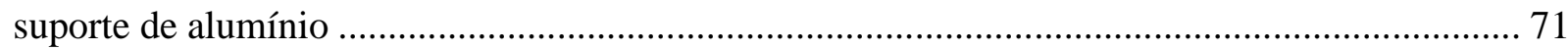

Tabela 5: Força de adesão dos filmes orgânicos e híbridos aos suportes metálicos estudados. A

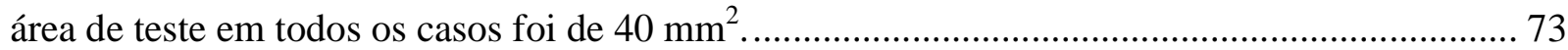

Tabela 6: Massas depositadas de fosfolipídeo, quitosana, iota-carragenana e $\mathrm{CaCO}_{3}$............... 90

Tabela 7: Razão entre as áreas dos picos correspondentes aos polimorfos calcita (C) e vaterita (V) para amostras de $\mathrm{CaCO} 3$ formadas sobre filmes LbL de quitosana e PAA, depositados sobre suportes de diferentes rugosidade 111

Tabela 8: Razão entre as áreas dos picos em $29,1^{\circ}$ e $27^{\circ}$ correspondentes aos polimorfos calcita (C) e vaterita (V), respectivamente, para amostras de $\mathrm{CaCO} 3$ formadas sobre filmes LbL de quitosana e PSS, depositados sobre suportes de diferentes rugosidades. 115

Tabela 9: Bandas presentes no espectro Raman de amostras de filmes $\mathrm{LbL}$ contendo $\mathrm{CaCO}_{3} .122$

Tabela 10: Bandas referentes ao $\mathrm{CaCO}_{3}$ no espectro Raman de amostras de filmes LbL contendo $\mathrm{CaCO}_{3}$ depositado sem uso de solução 126 


\section{Siglas e abreviaturas}

\begin{tabular}{|l|l|}
\hline ACC & Carbonato de cálcio amorfo \\
\hline AFM & Microscopia de força atômica \\
\hline DMPA & Ácido dimiristoil fosfatídico \\
\hline DMPE & Dimiristoil fosfatidil etanolamina \\
\hline $\mathbf{l}_{\mathbf{B}}$ & Comprimento de Bjerrum \\
\hline LB & Langmuir-Blodgett \\
\hline LbL & layer-by-layer \\
\hline MET & Microscopia eletrônica de transmissão \\
\hline MEV & Microscopia eletrônica de varredura \\
\hline PAA & Poli(ácido acrílico) \\
\hline PSS & Poli(estireno sulfonato) \\
\hline Qt & Quitosana \\
\hline K & Comprimento de Blindagem de Debye \\
\hline $\boldsymbol{\lambda}$ & Distância contra-íons/superfície \\
\hline $\boldsymbol{\delta}$ & Distância cadeia de polieletrólito/superfície \\
\hline $\boldsymbol{\lambda}$-car & Lambda carragenana \\
\hline $\boldsymbol{l}$-car & Iota carragenana \\
\hline $\boldsymbol{\kappa I - c a r}$ & Kappa-I carragenana \\
\hline
\end{tabular}




\section{Introdução}

A motivação deste trabalho está no estudo de sistemas biomiméticos formados por moléculas orgânicas, como fosfolipídeos e polímeros, e minerais, neste caso o carbonato de cálcio, depositados sobre superfícies metálicas. Superfícies metálicas modificadas com este tipo de material têm potencial aplicação em implantes de substituição óssea. Muito já foi estudado sobre o crescimento de $\mathrm{CaCO}_{3}$ em sistemas auto-suportados, como membranas de quitosana, porém não existiam trabalhos na literatura que abordassem seu crescimento sobre filmes finos, explorando as variações nas suas características em função de variações nas propriedades das matrizes orgânicas.

Desta forma, o objetivo geral deste trabalho de tese é estudar o crescimento de carbonato de cálcio sobre matrizes orgânicas depositadas sobre suporte de alumínio e aço-inox 316L, utilizando-se um novo método proposto por nosso grupo no qual o suporte contendo a parte orgânica não é imerso em solução para a seqüente deposição de $\mathrm{CaCO}_{3}$. A condição de saturação é obtida apenas na superfície da matriz orgânica, uma vez que carbonato é gerado a partir da decomposição na fase vapor do carbonato de amônio e os íons cálcio são supridos pela solução aprisionada nos interstícios do gel formado pela matriz, bem como aqueles ligados como contraíons na matriz orgânica. A vantagem deste método está na manutenção das informações estruturais da matriz durante o crescimento do mineral, prevenindo precipitações a partir do interior da solução.

Os objetivos específicos podem ser enumerados da seguinte forma:

a) Obtenção e caracterização de matrizes orgânicas, na forma de filmes finos, formadas por fosfolipídeos, utilizando-se a técnica Langmuir-Blodgett (LB) e por 
polieletrólitos, utilizando-se a técnica de formação de filmes automontados layer-bylayer (LbL), sobre superfícies metálicas.

b) Avaliação da capacidade das matrizes orgânicas em promover o crescimento de $\mathrm{CaCO}_{3}$ utilizando-se o método "a seco".

c) Verificação da influência de propriedades dos suportes, da matriz orgânica e da solução no crescimento de $\mathrm{CaCO}_{3}$.

d) Uso de meios confinados tridimensionais modificados com as matrizes orgânicas no crescimento de $\mathrm{CaCO}_{3}$.

\subsection{Modificação de Superfícies Metálicas}

De uma maneira geral a modificação de superfícies é empregada em situações nas quais se deseja melhorar as características físico-químicas das superfícies em questão para determinadas aplicações com os objetivos de: promover ou melhorar as propriedades adesivas de filmes às superfícies, permitir a ancoragem de substâncias ativas (sensores, bio-reatores, etc), tornar a superfície hidrofóbica ou hidrofílica.

No caso de superfícies metálicas, em geral os tratamentos superficiais têm por objetivo modificar a rugosidade e impedir ou diminuir a oxidação do material ${ }^{1}$. As aplicações destas superfícies quimicamente modificadas vão desde o uso em indústrias automotivas e de eletrodomésticos, até aplicações in-vivo no caso de implantes de substituição óssea. Porém, no caso de aplicações biológicas é desejável o uso de metais como titânio ${ }^{2}$ e aço inox $316 \mathrm{~L}^{3}$. As excelentes propriedades mecânicas e a natureza inerte desses materiais fazem deles os mais utilizados nas reestruturações relacionadas com traumas físicos ou patogênicos. Porém, existe 
$\underline{\text { Introdução }}$

uma desvantagem na baixa reatividade desses metais que faz com que exista necessidade de modificação dos mesmos. Como o metal não interage com a vizinhança onde é implantado, é baixa a sua integração com a parte óssea e as modificações visam manter suas características de baixa oxidação, porém melhorando as suas características em promover a osteointegração ao seu redor. Estas superfícies depois de modificadas devem ter afinidade por substâncias polares ${ }^{4,5,6}$ para que seja permitido o crescimento celular ou ainda o crescimento de minerais como, por exemplo, hidroxiapatita já conhecida como bom promotor de osteointegração, facilitando o crescimento ósseo contíguo à peça implantada. Desta forma, materiais considerados como não integráveis a ossos, podem vir a sofrer osteointegração através da formação de uma interface apropriada.

Ainda na área médica, podemos observar também um grande número de trabalhos publicados sobre a modificação de aço inox 316L utilizando-se filmes e complexos imobilizados, com capacidade de liberar óxido nítrico para o tratamento de problemas cardíacos. ${ }^{7,8}$

Outros tipos de problemas práticos relacionados com a modificação de superfícies metálicas podem ser citados, dentre eles está a prevenção do crescimento de minerais sobre cascos de navios e em tubulações utilizadas na extração de petróleo do fundo do mar. Nestes casos, é desejável que a modificação das superfícies previna a incrustação de minerais como $\mathrm{CaCO}_{3}$ nos sistemas. Podemos também citar a modificação de superfícies metálicas no desenvolvimento de metodologia de transporte de óleos pesados com auxílio de filme lubrificante, no qual o transporte do óleo ocorre na parte central do duto, enquanto que a água, ou salmoura, menos viscosa, formam um anel hidráulico circundando a parte central, (fluxo central anular). Para esta última aplicação, é desejável também, como no caso dos implantes, que a superfície modificada possua hidrofilicidade elevada. 
$\underline{\text { Introdução }}$

Nos casos citados, além de aumentar a afinidade da superfície pela água, requer-se que a modificação superficial leve à formação de película estável quimicamente. As modificações superficiais que vêm sendo empregadas envolvem, respectivamente: 1) simples aumento da rugosidade da superfície por lixamento ou jateamento com partículas de óxido, até deposição de filmes sobre os metais, 2) deposição de partículas inorgânicas e a deposição de filmes poliméricos orgânicos.

Nesta tese estudou-se a modificação de superfícies de alumínio e aço inox 316L com filmes orgânicos sobre os quais foi depositado carbonato de cálcio sobre a forma de partículas ou filmes contínuos. Estudos ${ }^{9}$ mostram que o $\mathrm{CaCO}_{3}$, assim como a hidroxiapatita, também pode promover o crescimento de células ósseas. Fatores que afetam o crescimento desse mineral, relacionados com a presença da matriz orgânica, foram estudados. Desta forma, também é possível inferir sobre a prevenção do crescimento.

\subsection{Biomineralização}

Muitos organismos vivos, tal como seus constituintes, são formados por sistemas químicos complexos que envolvem a interação entre compostos orgânicos e inorgânicos ligados química e/ou fisicamente. O processo por meio do qual ocorre a formação da parte mineral desses organismos é chamado biomineralização ${ }^{10}$. Alguns exemplos desses organismos e constituintes podem ser citados e incluem pérolas, conchas e ossos. As moléculas orgânicas formam uma matriz que oferece à parte inorgânica a informação estrutural inicial para direcionamento da nucleação e crescimento ${ }^{11,12}$. 
$\underline{\text { Introdução }}$

Esta matriz, geralmente, é constituída por macromoléculas como polímeros e proteínas, enquanto a parte inorgânica é normalmente constituída por minerais como hidroxiapatita (fosfato de cálcio) e carbonato de cálcio. A resistência mecânica desses sistemas pode ser atribuída à forma e à interação entre as partes orgânica e inorgânica. Pode-se citar como exemplo a grande diferença de resistência mecânica entre o giz e as conchas do mar. Ambos são formados por carbonato de cálcio, porém, nas conchas a presença da matriz orgânica faz com que sua resistência mecânica seja muito maior quando comparada à natureza friável do giz. Portanto, estudando-se o processo pelo qual esses sistemas são formados, ou seja, estudando-se a biomineralização, podem-se desenvolver estratégias para a síntese de materiais compósitos orgânico-inorgânicos com diferentes propriedades.

Se, por um lado, existe um avanço considerável no entendimento da biomineralização, por outro, muito tem sido feito no sentido de desenvolver novos materiais inspirados nos processos de biomineralização ${ }^{13}$. O crescimento de cristais em meios confinados resultando em macroestruturas com geometrias definidas ${ }^{14}$ é um exemplo deste tipo de estudo. Meldrum ${ }^{15}$ e colaboradores recentemente estudaram o crescimento de monocristais de diferentes minerais como $\mathrm{SrSO}_{4}$ e $\mathrm{PbSO}_{4}$, utilizando como matrizes membranas poliméricas que permitiram a formação de cristais com macro-poros e estruturas tipo esponja. O mesmo grupo também ${ }^{16}$ já havia estudado o crescimento de cristais de $\mathrm{CaCO}_{3}$ na forma cristalina calcita utilizando-se templates naturais obtidos de organismos marinhos. Visando-se aplicações biológicas, sistemas de biominerais que mimetizam ossos ${ }^{17}$, dentes ${ }^{18}$ e pérolas ${ }^{19}$ são estudados. Estes filmes híbridos quando depositados sobre superfícies metálicas como titânio e aço inox 316L podem ser potencialmente aplicados como próteses em implantes de substituição óssea ${ }^{20,21}$. Westbroek e Marin ${ }^{9}$ estudaram a relação entre o crescimento de células formadoras de ossos e madrepérolas verificando que a estrutura e composição destes organismos marinhos podem auxiliar no 
Introdução

crescimento e manutenção da estrutura óssea. Beppu, M. M. ${ }^{22}$ mostrou que membranas de quitosana modificadas com poli(ácido acrílico) favorecem processos de calcificação quando mergulhadas em soluções que simulam as concentrações de sais observadas em fluidos corpóreos reais.

As propriedades de sistemas biológicos podem ser estudadas por sistemas miméticos formados a partir de matrizes orgânicas contendo proteínas, polímeros ${ }^{23,24,25}$, ácidos graxos ${ }^{26,} \mathrm{e}$ carboxílicos ${ }^{27,28,29}$ ou tensoativos solúveis ${ }^{30}$. O uso de alguns tipos de proteínas, como a fibroina de seda ${ }^{31}$, pode auxiliar na inibição do crescimento de microorganismos sobre os filmes híbridos (orgânico-inorgânico) formados, resultando em biomateriais aptos a serem utilizados in vivo como mostram os trabalhos de Kino ${ }^{32}$ e co-autores e Falini ${ }^{33}$ e co-autores. Shen ${ }^{34}$ e colaboradores estudaram, recentemente, a influência de um tensoativo catiônico na presença de um álcool na orientação e agregação de cristais de carbonato de cálcio na forma cristalina vaterita. Porém, vale a pena lembrar que polímeros inorgânicos, como sílica ou silanos, também podem ser utilizados como matrizes para o crescimento de cristais ${ }^{35}$.

A escolha do tipo de matriz polimérica é de vital importância, uma vez que será essa quem direcionará os processos de nucleação e crescimento dos cristais. Diferentes tipos de polímeros têm sido utilizados ${ }^{36,37,38}$, porém, para o crescimento de carbonato de cálcio, a maioria faz uso de membranas de quitosana ${ }^{39}$ tendo, ou não, ligados a ela poliânions como poli(ácido

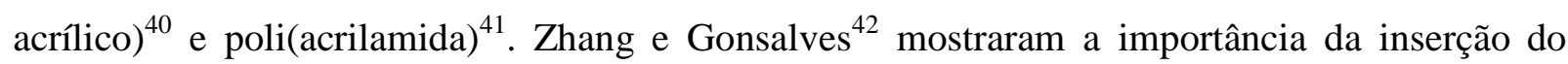
poli(ácido acrílico) nas membranas de quitosana para crescimento de filmes de carbonato de cálcio homogêneos, sendo que na ausência do poliânion observa-se apenas a formação de cristais isolados. Para o crescimento dos cristais estas membranas são geralmente imersas em soluções supersaturadas de bicarbonato ${ }^{43}$ ou carbonato ${ }^{44}$. Também se utilizam soluções de cloreto de cálcio que formam $\mathrm{CaCO}_{3}$ a partir da difusão de $\mathrm{CO}_{2}$ em recipientes fechados ${ }^{14}$. 
$\underline{\text { Introdução }}$

Unindo-se a técnica LbL para formação da matriz orgânica e tais métodos de precipitação de $\mathrm{CaCO}_{3}$, podem-se obter filmes híbridos orgânico-inorgânico e tais filmes, como citado anteriormente, quando depositados sobre superfícies metálicas podem ser potencialmente aplicados como prótese em implantes de substituição óssea.

\subsection{Carbonato de Cálcio}

Carbonato de Cálcio $\left(\mathrm{CaCO}_{3}\right)$ é um mineral vastamente encontrado na natureza em conchas marinhas, cascas de ovos e, no corpo humano, é o quinto mineral em abundância. $\mathrm{CaCO}_{3}$ pode ser encontrado na forma de três polimorfos cristalinos anidros: calcita (o mais estável), vaterita (o menos estável) e aragonita. Geralmente estes três polimorfos cristalizam com diferentes hábitos cristalinos permitindo distinção visual de imagens de microscopia entre os mesmos, sendo que a calcita apresenta geometria romboédrica, aragonita estrutura alongada tipo agulha e vaterita estrutura esferulítica (Figura 1). Ainda, três formas metaestáveis podem ser encontradas: $\mathrm{CaCO}_{3}$ amorfo e $\mathrm{CaCO}_{3}$ mono e hexahidratados. Estes três últimos polimorfos além de serem instáveis e facilmente convertidos nos outros polimorfos, são também altamente solúveis em água.

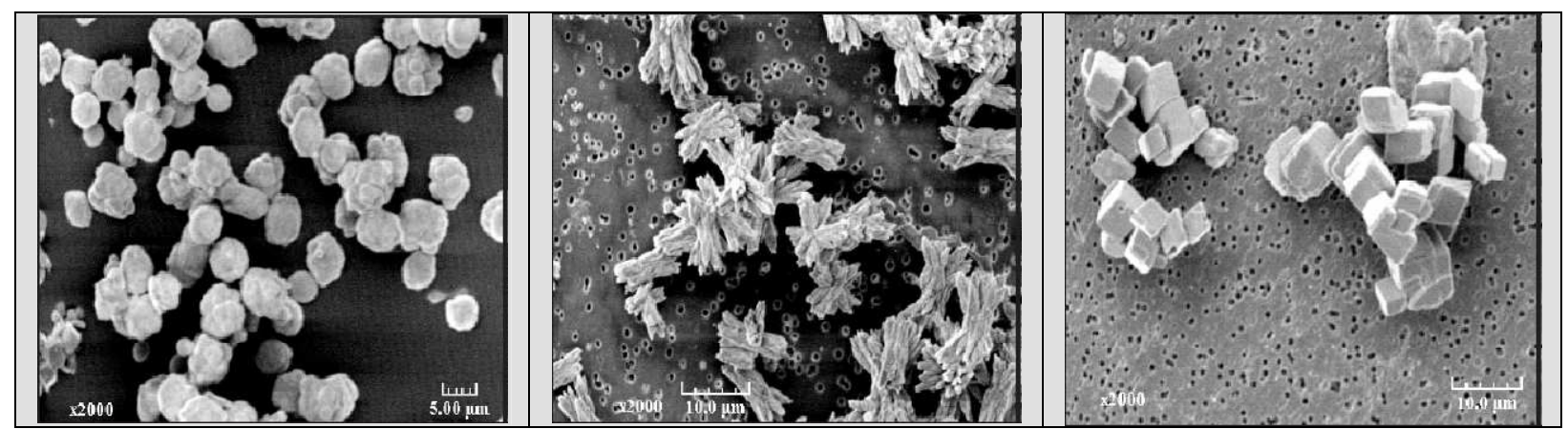

Figura 1: Imagens de microscopia eletrônica de varredura dos três diferentes polimorfos de $\mathrm{CaCO}_{3}$ ressaltando as diferenças nas suas morfologias: a) partículas esferulíticas de vaterita; b) 
$\underline{\text { Introdução }}$

partículas tipo agulha de aragonita e c) partículas romboédricas de calcita. (figura extraída da referência 144).

Diferentes minerais têm sido estudados para o entendimento de processos de biomineralização $^{11,12,13,45}$. Entretanto, neste trabalho de tese, devido à sua abundância e importância em sistemas biológicos, focamos nossos estudos na formação de carbonato de cálcio sobre diferentes matrizes orgânicas. Uma revisão recente sobre materiais híbridos contendo $\mathrm{CaCO}_{3}$ foi apresentada por Kato et. al. ${ }^{46}$ Mais ainda, deve ser enfatizado que estudos sobre a formação de $\mathrm{CaCO}_{3}$ na presença de moléculas orgânicas não estão sempre relacionados à formação de materiais híbridos, mas também relacionam-se com o crescimento do mineral puro em forma de partículas ou filmes inorgânicos exibindo características peculiares devido à presença de uma matriz orgânica ou certos aditivos. Em uma visão geral, podemos dividir estes estudos em diferentes classes baseados em: i) importância dada ao local onde o crescimento da parte inorgânica ocorre (solução ou interface); ii) tipo de moléculas que participam do processo (moléculas orgânicas de baixa massa molar, macromoléculas solúveis, moléculas orgânicas insolúveis ou matriz inorgânica ${ }^{35}$ ) e iii) organização do meio (molecularmente organizado ou randômico). Naturalmente, esta classificação apresenta pontos de intercruzamento. Podem ser citados os estudos sobre a importância da interface no crescimento de $\mathrm{CaCO}_{3}$ utilizando-se membranas poliméricas, ${ }^{36,39,47,48}$ deposição de biomacromoléculas ${ }^{12,31,32,38}$ sobre suportes sólidos, monocamadas de Langmuir lipídicas ${ }^{26,49,50}$ na interface ar/líquido tão bem como monocamadas auto-montadas $^{51,52,53}$ sobre suportes sólidos. Com relação à natureza química das moléculas presentes nos sistemas, são exemplos: moléculas pequenas não-iônicas como glicerol, ${ }^{54,55}$ etileno glicol, ${ }^{55,56,57}$ e etanol ${ }^{55}$. Estas moléculas influenciam a nucleação e crescimento de carbonato de cálcio, que também pode ser influenciado pela presença de sais inorgânicos como, por exemplo, 
$\underline{\text { Introdução }}$

$\mathrm{MgCl}_{2}$. Considerando-se o crescimento de $\mathrm{CaCO}_{3}$ na presença de macromoléculas, estudos utilizando-se ambas, naturais e sintéticas podem ser encontrados. No primeiro grupo podemos considerar separadamente polissacarídeos ${ }^{25,42,58,59,60}$ e proteínas, ${ }^{61,62,63}$ e no segundo, especialmente poli(ácido acrílico), ${ }^{40,44,64}$ poli(acrilatos), ${ }^{48,65}$ e poli(iminas). ${ }^{66} \mathrm{Um}$ aspecto que deve ser levado em conta é que estas moléculas solúveis podem formar filmes insolúveis quando em condições apropriadas, como por exemplo de $\mathrm{pH}$. Por exemplo, sistemas preparados a partir de quitina, ${ }^{47,67}$ celulose ${ }^{67,68,69}$ e quitosana ${ }^{40,42,44,67}$ foram utilizados como matrizes insolúveis, embora, somente as duas primeiras serem, de fato, insolúveis em água. O crescimento de carbonato de cálcio sobre membranas de quitosana ${ }^{40,42}$ resulta em filmes inorgânicos homogêneos quando em presença de poli(ácido acrílico), entretanto, quando o poliânion não é adicionado ao sistemas, observa-se apenas a formação de cristais isolados. ${ }^{42}$ Por outro lado, é esperado que a formação controlada de cristais nos leve à idéia da utilização de meios organizados, e de fato, isto tem sido testado em diferentes estudos utilizando-se: matrizes baseadas em tensoativos ${ }^{30,70,71,72}$ incluindo cristais líquidos liotrópicos, ${ }^{72,73}$ filmes auto-montados ou layer-by-layer (LbL), ${ }^{64}$ meios confinados consistindo de membranas naturais porosas ${ }^{14,15}$, e monocamadas de Langmuir. ${ }^{49,74,75,76}$ Considerando-se este último sistema, estudos teóricos ${ }^{77,78}$ também têm sido desenvolvidos. Não é uma tarefa fácil racionalizar todos os resultados apresentados na literatura, entretanto, podemos enumerar alguns dos principais aspectos e explicações para as peculiaridades envolvidas no crescimento de cristais de $\mathrm{CaCO}_{3}$, as quais podem também ser aplicadas a outros tipos de cristais inorgânicos.

Quando monocamadas de Langmuir são utilizadas ${ }^{26,57-59,47-49,79}$ como molde molecularmente organizado na mimetização de processos de biomineralização, alguns fatores podem afetar a cristalização, como: organização dos domínios lipídicos, ${ }^{50,80}$ comprimento da cadeia apolar do tensoativo, ${ }^{26}$ assim como o tipo de grupo polar. ${ }^{75}$ Diferentes hipóteses são 
$\underline{\text { Introdução }}$

apresentadas para explicar os resultados obtidos. Após observar os diferentes efeitos na cristalização de $\mathrm{CaCO}_{3}$ em contato com monocamadas de tensoativos contendo grupos carboxilato, sulfato e fosfonato na cabeça polar, Heywood e Mann ${ }^{75}$ sugeriram como explicação a complementaridade estereoquímica entre os átomos de oxigênio dos grupos aniônicos da cabeça polar e os átomos de oxigênio dos íons carbonato localizados no retículo cristalino dos cristais nucleados e crescidos na interface monocamada/solução. O mesmo grupo ${ }^{49}$ também teve êxito na obtenção de partículas maiores e mais monodispersas em tamanho formadas sob monocamadas expandidas quando comparadas com as partículas formadas sob monocamadas mais comprimidas. Ainda, os autores concluíram que a ligação dos íons cálcio não deve ser um prérequisito na cristalização orientada, uma vez que observaram este efeito para $\mathrm{CaCO}_{3}$ crescidos sob monocamadas formadas por tensoativos catiônicos, e afirmaram que monocamadas nãoiônicas causam inibição do crescimento do carbonato de cálcio. Além disso, aparentemente, os autores não levaram em consideração a importância da densidade superficial de carga e da orientação dos dipolos na interface. Estas questões foram consideradas no trabalho realizado por Müller et. al. ${ }^{79}$ no qual monocamadas mistas contendo ácido esteárico e um monômero polimerizável contendo grupo éster em sua cabeça polar, contendo $\mathrm{CaCO}_{3}$ foram transferidas para suportes sólidos por meio da técnica de Langmuir-Blodgett (LB). Eles concluíram que $\mathrm{CaCO}_{3}$ foi formado apenas sobre domínios de ácido esteárico no estado sólido enquanto que a cristalização foi inibida nos domínios do éster graxo ainda no estado líquido. Ainda, observou-se a inibição do crescimento tridimensional de cristais de $\mathrm{CaCO}_{3}$ através da subfase por meio da adição de poli(ácido acrílico). A formação de carbonato de cálcio, sob monocamadas de Langmuir formadas a partir de ácidos graxos com diferentes tamanhos de cauda apolar, provou ser principalmente influenciada pela taxa de difusão de $\mathrm{CO}_{2}$ através dos filmes com diferentes espessuras e grau de compactação. ${ }^{26}$ 
$\underline{\text { Introdução }}$

Assim, existe um entendimento geral que mostra que a matriz orgânica direciona a cristalização de $\mathrm{CaCO}_{3}$ agindo não somente como molde. De fato, estudos de simulação molecular ${ }^{77,78}$ indicam que no caso matrizes orgânicas com maior mobilidade e relativamente mais flexíveis, o deslocamento de moléculas de água pelos cristais inorgânicos é bastante importante, combinado com o grau de ionização das monocamadas.

Pode-se perceber que estudos sobre a formação de $\mathrm{CaCO}_{3}$ sob monocamadas de Langmuir utilizando-se solução aquosa ou difusão de $\mathrm{CO}_{2}$ são bem documentados. $\mathrm{O}$ mesmo pode-se afirmar com respeito à cristalização sobre filmes poliméricos, membranas espessas ou mais finas preparadas pela técnica LbL; ambos sistemas são inspirados em processos de biomineralização. Entretanto, estudos utilizando-se filmes LB como matrizes são praticamente inexistentes. Filmes LB constituem uma estrutura que mimetiza aquelas encontradas em biomembranas e também possibilitam controle da carga elétrica do suporte sólido sobre o qual o filme está depositado. Por outro lado, em uma mesma força iônica a densidade superficial de carga pode modificar a conformação das cadeias de polímeros, depositados sobre estes suportes a partir da técnica LbL. Levando-se em conta estas considerações estudou-se, nesta tese, a formação de $\mathrm{CaCO}_{3}$ sobre matrizes orgânicas mistas, depositadas sobre suportes metálicos de alumínio, formadas com filmes depositados a partir da técnica LB com diferentes proporções de lipídeos negativamente carregados e zwiteriônicos. Estes filmes foram recobertos com filmes LbL de polissacarídeos, com objetivo de observamos se a densidade superficial de cargas e o tipo de cabeça polar do prérecobrimento LB podem afetar o crescimento e a morfologia das partículas formadas sobre os filmes dos polissacarídeos.

Estudos sobre o crescimento bio-inspirado de carbonato de cálcio podem ser divididos, principalmente, em dois eixos com relação ao meio no qual tal processo ocorre: crescimento em solução ("bulk") e crescimento em confinamento. O princípio da cristalização controlada e 
$\underline{\text { Introdução }}$

morfossíntese, utilizando-se polímeros solúveis, naturais ou sintéticos, como modificadores em solução, não formando estruturas organizadas, é completamente diferente dos métodos que se baseiam em efeitos de matriz (template), como interfaces artificiais, no caso de crescimento em meio confinado e/ou matrizes planares modificadas. Ainda que estas matrizes sejam modificadas com polímeros, o crescimento em interfaces difere do crescimento em solução. Meios confinados podem direcionar o crescimento de cristais a compartimentos, limitando-os à geometria do template. Em solução, a quantidade de íons presentes no interior da mesma promove um crescimento, sem restrição espacial. Porém, um ponto em comum entre os dois métodos, é o efeito de interações mútuas (p.e. interações eletrostáticas e ligações de hidrogênio) entre os grupos funcionais do polímero e as espécies inorgânicas do mineral e a sua subseqüente reconstrução em um processo automontado.

$\mathrm{O}$ crescimento de $\mathrm{CaCO}_{3}$ no interior de soluções em presença de aditivos pode ser subdividido levando-se em consideração a natureza do aditivo. Por exemplo, sabe-se que polieletrólitos podem estabilizar eletrostaticamente colóides inorgânicos e por isso são vastamente utilizados como aditivos. Gower et. al ${ }^{81}$ estudaram o crescimento de $\mathrm{CaCO}_{3}$ obtendose estruturas não usuais como calcita helicoidal em presença de pequenas quantidades de poliaspartato quiral $\left(\mu \mathrm{g} . \mathrm{L}^{-1}\right)$. Este método foi nomeado PILP, do inglês "Polymer-induced liquid precursor". A adição de gotas da solução de poliaspartato à solução precursora resulta na formação de uma separação de fases líquido-líquido nas gotículas precursoras à cristalização, as quais podem adotar estruturas complexas antes do início da cristalização, como hélices, neste estudo. Em presença de colágeno, utilizando-se o mesmo método, foram obtidos agregados fibrosos de $\mathrm{CaCO}_{3}{ }^{82}$. Pode-se notar por estes dois estudos que o crescimento de inorgânicos pode ser direcionado por meio da conformação dos polieletrólitos em solução, utilizando-se um "auto- 
$\underline{\text { Introdução }}$

limite" no mecanismo de crescimento. Neste mecanismo uma das faces do cristal está ligada ao polieletrólito e cresce dirigida por uma nucleação heterogênea. Já as outras faces estão em contato com a solução/dispersão homogênea. Uma série de poliamidas contendo grupos carboxilato foi sintetizada e utilizada como aditivos na cristalização de $\mathrm{CaCO}_{3}{ }^{83,84,85}$. Estruturas de calcita tipo hélice também foram formadas, com a volta da hélice correspondendo ao enantiômero do polímero.

Poli(L-isocianoalanil-D-alanina) com distribuição regular de cadeias laterais terminadas em ácido carboxílico, foi utilizado como aditivo na solução de cristalização de $\mathrm{CaCO}_{3}$ com objetivo de estudar a relação entre a estrutura do polímero e o crescimento de calcita em solução $^{86}$. A densidade de cargas negativas do polímero, $600 \mathrm{~mm}^{-2}$, está na faixa observada para monocamadas de Langmuir de ácidos carboxílicos, utilizados também como templates; são, porém, muito mais altas que as densidades encontradas para templates no interior de soluções. Os cristais formados são alongados no eixo-c com três faces finais $\{10.4\}$ expressadas em cada face do cristal. A estrutura formada se assemelha a de uma maçã depois de mordida ao redor do centro. $\mathrm{O}$ desenvolvimento de face $\{$ hk.0 $\}$ é atribuída à adsorção não específica do polímero nestas faces, diferenciando as estruturas formadas daquelas encontradas em $\mathrm{CaCO}_{3}$ crescidos utilizando-se monocamadas de Langmuir como template ${ }^{26}$. Nestes casos, apesar das densidades de cargas serem semelhantes, é a adsorção seletiva do polímero o fator chave no direcionamento do crescimento dos cristais. Outros tipos de moléculas, além de polímeros, têm sido utilizadas como aditivos, ou templates, em solução para estudos de processos de cristalização. Destas podem ser citadas: dendrímeros ${ }^{87,88}$, proteínas solúveis ${ }^{12,89}$, vírus ${ }^{90,91}$, etc. Não será aprofundada uma discussão a respeito do efeito das mesmas uma vez que estamos focados na influência de polieletrólitos. Ainda o efeito sinergístico da adição de tensoativos às soluções poliméricas tem sido investigado, como no caso do trabalho de Deng et.al. ${ }^{92}$ no qual SDS foi adicionado a 
$\underline{\text { Introdução }}$

soluções de PEG e PMMA mostrando que transformações morfológicas em cristais esféricos estão relacionadas com transformações na estrutura da micela do tensoativo.

Apesar do fato de o crescimento de cristais em sistemas biológicos indubitavelmente ocorrer em volumes confinados, a maioria dos experimentos que utilizam como modelo processos de biomineralização são feitos no interior da solução e aí reside a importância de estudo em meios-confinados, que ainda são escassos. Monocamadas de Langmuir proporcionam uma matriz bi-dimensional para mimetização de processos de biomineralização para o crescimento de filmes finos inorgânicos ou cristais ${ }^{26,93,94}$. Desta forma a cristalização ocorre em um meio-confinado, ou seja, na interface monocamada-solução. Nestes casos, a interação entre uma face cristalina e a cabeça polar do tensoativo leva à formação de cristais de morfologia bem definida, exibindo crescimento preferencial de faces específicas, demonstrando a importância do micro-ambiente no crescimento dos cristais. Falini et. al. ${ }^{95,96}$ estudaram a precipitação de $\mathrm{CaCO}_{3}$ em matriz de colágeno não-orientada e uniaxial, demonstrando a importância do micro-ambiente onde ocorre a nucleação e crescimento dos cristais. Ainda sob o ponto de vista biomimético, muitas matrizes bio-poliméricas podem ser usadas como templates. Entretanto, tratamentos térmicos são necessários para a remoção da parte orgânica, podendo causar variações na morfologia da parte inorgânica devido à alta temperatura. Então, cada vez mais requerem-se métodos de obtenção de compostos híbridos orgânicos-inorgânicos que não necessitem de tratamento térmico, dentre estes métodos podemos citar o método layer-by-layer ${ }^{97}$ de deposição e a matrizes já prontas, como as membranas de policarbonato de poros cilíndricos, ou membranas “track-etch"14,98 , que são solúveis em solventes orgânicos como clorofórmio e diclorometano.

Desta forma, neste trabalho de tese também se estudou a importância da precipitação de $\mathrm{CaCO}_{3}$ em meios-confinados obtidos por meio da deposição de filmes finos contendo fosfolipídeos e polieletrólitos sobre meios confinados planares, tais como aço inox, alumínio e 
$\underline{\text { Introdução }}$

silício, e sobre meios confinados tridimensionais, usando membranas de policarbonato com tamanhos de poros variados, ambos modificados com filmes finos de polieletrólitos.

\subsection{Filmes Finos}

O interesse pela fabricação de filmes finos nano e micrométricos vem crescendo a cada dia. A formação destes filmes é tema de estudo em áreas de intersecção entre as ciências básicas química, física e biologia, até a ciência de materiais. Atenção especial está voltada para filmes obtidos a partir de moléculas orgânicas em função de sua variedade de propriedades elétricas, ópticas e magnéticas. A versatilidade de aplicações para esse tipo de filme também fez com que o número de estudos sobre a obtenção dos mesmos tenha aumentado consideravelmente nos últimos anos. Estes estudos levaram a aplicações que são desenvolvidas há alguns anos e dentre elas, podem ser citadas: óptica integrada ${ }^{99,100}$, sensores e biosensores ${ }^{101,102}$, recobrimento de superfícies $^{103}$, agentes de superfície para orientação de camadas, catálise ${ }^{104}$, etc.

Os métodos de Langmuir-Blodgett ${ }^{105,106}$ (LB) e de automontagem layer-by-layer ${ }^{107}$ (LbL) são os mais utilizados para a obtenção de filmes finos nos quais se deseja alta organização molecular ${ }^{108}$. Estes dois tipos de técnicas foram utilizados neste trabalho de tese na formação das matrizes orgânicas para deposição de $\mathrm{CaCO}_{3}$.

\subsubsection{Monocamadas de Langmuir e Filmes Langmuir-Blodgett}

As monocamadas de Langmuir ${ }^{105}$ são formadas por moléculas anfifílicas insolúveis como por exemplo os ácidos graxos e os fosfolipídeos. Essas moléculas, denominadas tensoativos (do inglês surfactant, ou seja, ativo na superfície) possuem uma orientação preferencial na interface 
$\underline{\text { Introdução }}$

ar-água: enquanto que suas cadeias hidrocarbônicas ficam expostas ao ar, as cabeças polares que são hidrofílicas permanecem em contato com a água, formando uma camada de espessura monomolecular na interface. A força motriz que leva a este tipo de organização é o chamado efeito hidrofóbico, que leva as moléculas a se orientarem de forma a reduzir a energia livre do sistema.

As monocamadas formadas por estas moléculas na interface ar-líquido podem ser estudadas utilizando-se a técnica desenvolvida por Irving Langmuir, que consiste em um compartimento revestido internamente de um material hidrofóbico, a Cuba de Langmuir (Figura 2) que é preenchido com água ou solução aquosa, sobre a qual se espalha uma pequena quantidade (da ordem de $\mu \mathrm{L}$ ) da substância tensoativa insolúvel em pequenas concentrações $\left(1 \times 10^{-4}\right.$ a $\left.1 \times 10^{-3} \mathrm{~mol} \mathrm{~L}^{-1}\right)$ dissolvida em solvente orgânico volátil, na maioria das vezes clorofórmio. A cuba de Langmuir possui uma ou duas barreiras móveis, que se movimentam reduzindo a área disponível por molécula, organizando-as na interface. Esta organização pode ser estudada por meio de isotermas de pressão de superfície, como veremos a seguir.

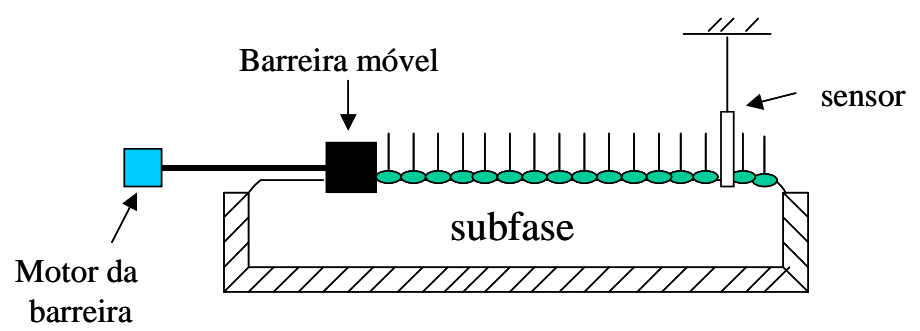

Figura 2: Esquema de uma cuba de Langmuir 
$\underline{\text { Introdução }}$

\section{Isotermas de pressão de superfície}

Quando espalhamos uma substância tensoativa sobre uma solução aquosa, com tensão superficial $\gamma_{0}$, esta poderá ser reduzida a $\gamma$. A diferença entre a tensão superficial sem a monocamada e a tensão superficial com a cobertura da monocamada define a pressão de superfície, $\pi$.

$$
\pi=\gamma_{0}-\gamma
$$

Sabendo a concentração e o volume da solução de tensoativo espalhada sobre uma área conhecida da superfície da solução aquosa, é possível determinar a área disponível por molécula. Assim, com o deslocamento da barreira móvel comprimindo a monocamada formada, é possível determinar a variação da pressão de superfície com a diminuição da área média disponível por molécula. Desta forma, a uma temperatura constante, o gráfico de pressão de superfície contra a área disponível por molécula representa uma isoterma de pressão superficial ou, simplesmente, isoterma superficial. Dependendo do estágio de compressão, podemos observar diversos comportamentos relacionados com os diferentes estados físicos bidimensionais (de forma análoga aos estados tridimensionais em uma isoterma pressão-volume). Dessa forma, associa-se cada estágio a um estado físico. Quando a pressão de superfície está em torno de zero, a interação entre as moléculas é pequena e o número de graus de liberdade elevado, devido à grande área disponível por molécula, tendo-se então o estado gasoso (G). Conforme a área por molécula é diminuída, ocorre um aumento na pressão e atinge-se o estado líquido expandido (LE) e, quando esse aumento começa a ficar mais brusco, têm-se seqüencialmente os estados líquido-condensado (LC) e sólido. Também é possível observar regiões onde a pressão de superfície permanece constante com a compressão, esta região corresponde à transição de fases, líquido-expandido para líquido condensado (LE-LC), por exemplo, onde as duas fases coexistem. Após o estado sólido, 
$\underline{\text { Introdução }}$

chega-se a um ponto que a compressão da monocamada não consegue mais provocar a elevação da pressão superficial, sendo que essa permanece constante ou cai abruptamente quando sujeita à compressão adicional, esse ponto denomina-se colapso, que seria o "desmanche" da monocamada e o começo da formação de bicamadas ou multicamadas desordenadas. A Figura 3 representa esquematicamente a formação das monocamadas por meio da compressão da barreira móvel e mostra uma isoterma $\pi$-A típica formada durante esta compressão.

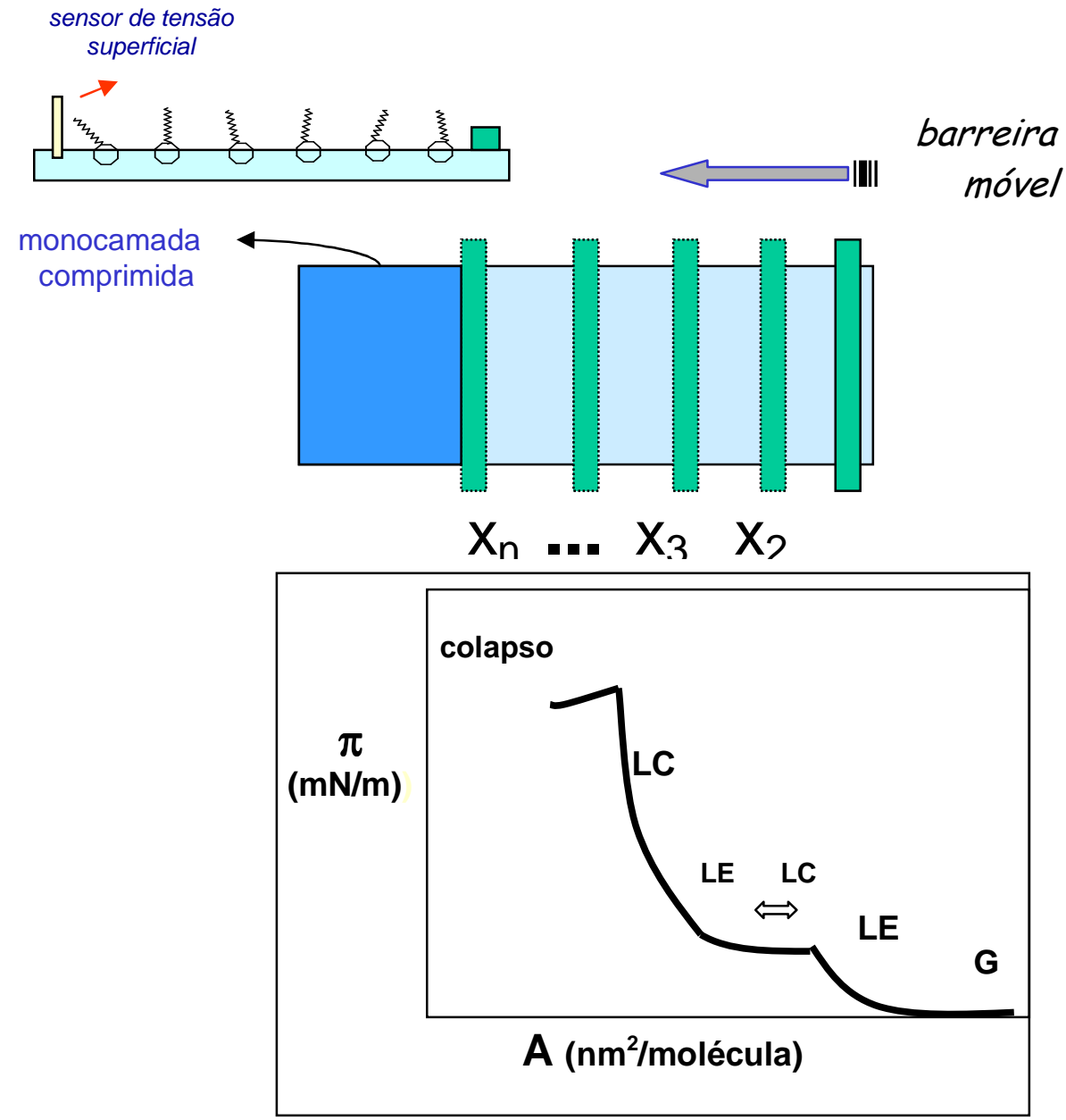

Figura 3: Esquema de um experimento na cuba de Langmuir, topo: vista lateral da cuba, mostrando as moléculas do tensoativo formando a monocamada; meio: vista de cima da cuba, evidenciando a compressão da monocamada com a barreira móvel e, por último um exemplo de isoterma $\pi \times \mathrm{A}$, mostrando os estados superficiais nos diferentes estágios de compressão da monocamada: $\mathrm{G}=$ gasoso, $\mathrm{LE}=$ líquido expandido e $\mathrm{LC}=$ líquido-condensado 
$\underline{\text { Introdução }}$

\subsubsection{Filmes de Langmuir -Blodgett e microbalança a cristal de quartzo}

A imersão ou emersão vertical de suportes sólidos através da monocamada no estado condensado dá origem aos filmes de Langmuir-Blodgett ou filmes $\mathrm{LB}^{105}$ de tal forma que, cada imersão ou emersão proporciona a deposição de uma camada em cada lado do suporte (Figura 4). Imersões e subseqüentes emersões do suporte através da interface permitem a formação de filmes com qualquer que seja o número de camadas desejado e a formação de multicamadas.

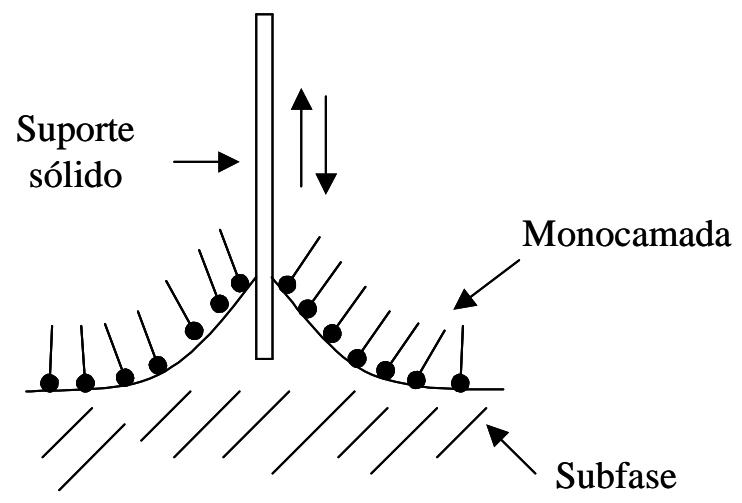

Figura 4: Transferência de moléculas anfifílicas para um suporte sólido formando um filme fino.

Assim pode-se ter um controle na espessura do filme através do número de camadas transferidas. Dependendo do tipo de transferência obtêm-se três tipos de deposição: $\mathrm{X}, \mathrm{Y}$ e $\mathrm{Z}$ (Figura 5). A emersão do substrato provoca a transferência preferencial pela parte polar (cabeça hidrofílica) e a imersão pela parte apolar (cauda hidrofóbica). 
$\underline{\text { Introdução }}$
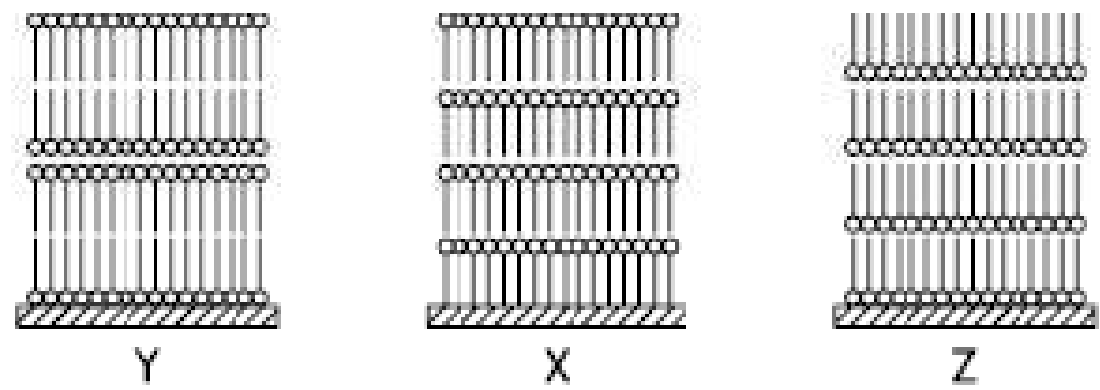

Figura 5: Filmes tipos X,Y e Z obtidos pelo método de Langmuir-Blodgett.

Uma desvantagem da técnica é o custo elevado devido aos equipamentos necessários. Também, a técnica não permite a formação de camadas de moléculas orgânicas que sejam hidrossolúveis como é o caso dos polímeros carregados, ou, polieletrólitos, a menos que os mesmos estejam ligados à outra molécula formadora da monocamada insolúvel.

\subsubsection{Comportamento de polieletrólitos em solução: adsorção em superfícies sólidas e formação de multicamadas ${ }^{109}$}

A formação de multicamadas de polieletrólitos sobre suportes sólidos consiste basicamente na adsorção alternada e consecutiva de polieletrólitos com cargas opostas, sendo que a primeira camada deve estar fortemente ancorada à superfície do sólido, seja este, planar ou tridimensional (como no caso da adsorção sobre partículas sólidas). Este fato, muitas vezes justifica o uso de um polieletrólito diferente, que tenha grande afinidade pela superfície de interesse, para a adsorção da primeira camada. O primeiro requisito para que ocorram as deposições sucessivas é que entre cada camada depositada ocorra inversão de sua carga, ou seja, uma superfície inicialmente com carga negativa deve vir a possuir carga positiva após a 
$\underline{\text { Introdução }}$

deposição de um policátion sobre a mesma. Este fenômeno é denominado sobre-compensação de cargas.

As propriedades das multicamadas dependem do processo de lavagem, ou enxágüe, entre cada deposição, para que o excesso de polieletrólito, fracamente ou não adsorvido, seja removido. Ainda, estas propriedades são dependentes de $\mathrm{pH}$, força iônica, cargas e rigidez dos polieletrólitos. Então, para se entender a formação e propriedades de filmes finos LbL de polieletrólitos, deve-se inicialmente entender como estas moléculas se comportam em solução.

O comportamento de um polieletrólito em solução depende de sua concentração, do número de unidades repetitivas $(N)$ que ele possui, bem como da dimensão $(a)$ e da fração $(f)$ destas unidades que possuem carga. Considerando uma solução diluída, se esta fração for baixa, as interações eletrostáticas não afetam a conformação do polieletrólito, permitindo ao mesmo um comportamento Gaussiano (Figura 6). Nesta situação, a distância ponta-a-ponta (R) da cadeia é dada por :

$$
R=N^{1 / 2} a
$$

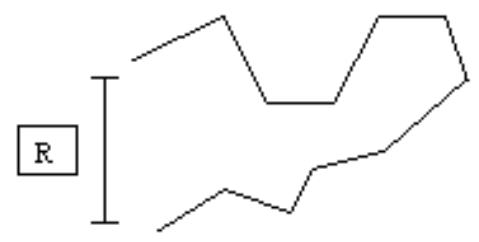

Figura 6: Distância ponta-a-ponta de uma cadeia polimérica Gaussiana.

Já se a fração de monômeros carregados for alta, as cadeias do polieletrólito se encontrarão esticadas, devido às forças eletrostáticas repulsivas entre as unidades repetitivas (Figura 7). Estas interações entre as cargas podem ser influenciadas pela adição de um eletrólito à solução de polieletrólito. Com a adição de eletrólito de concentração $n$, a interação coulômbica, 
$\underline{\text { Introdução }}$

blindada pela presença dos contra-íons, entre dois segmentos carregados a uma distância $\mathbf{r}$ um do outro é dada pelo potencial de Debye - Huckel:

$$
V(r)=\left(k T l_{B} / r\right)^{e^{-K r}}
$$

em que $\mathbf{l}_{\mathbf{B}}$ é o chamado comprimento de Bjerrum, que é a distância na qual a interação eletrostática entre duas cargas unitárias, desconsiderando-se os contra-1́ons, é igual à energia térmica $(k T)$, dado por :

$$
l_{B}=q^{2} / 4 \pi \varepsilon k T
$$

Sendo $\mathbf{q}$ a carga elementar, e $\boldsymbol{\varepsilon}$ a constante dielétrica da água. $\mathrm{K}^{-1}$, que aparece como expoente na equação para V(r), é o comprimento de blindagem de Debye, dado por:

$$
K^{-1}=\left(8 \pi n l_{B}\right)^{-1 / 2}
$$

Esse tipo de resultado pode ser obtido por meio da equação de Poisson Boltzmann e também pela teoria de Manning ${ }^{110}$, que considera a cadeia do polieletrólito como uma linha carregada com densidade elétrica uniforme. O valor típico de $l_{B}$ a $25{ }^{\circ} \mathrm{C}$ é $7,1 \AA$ e de $K^{-1}$ adicionando-se uma concentração de eletrólito de $0,01 \mathrm{~mol} \mathrm{~L}^{-1}$ é $419 \mathrm{~nm}$. Na ausência de sal, a interação entre as cargas dos monômeros é dada pela interação padrão de Coulomb $(V(r)=$ $\left.q_{1} q_{2} / 4 \pi \varepsilon r\right)$, as interações entre essas cargas passam a ser de longo alcance, a cadeia polimérica fica completamente esticada, e o seu comprimento é :

$$
R \sim N a\left(f_{B}^{2} / a\right)^{1 / 3}
$$




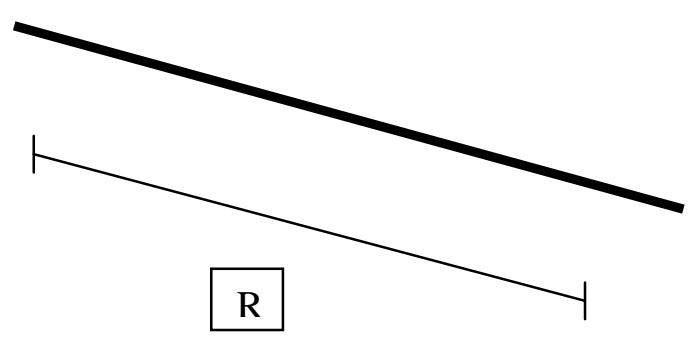

Figura 7: Polieletrólito estendido devido à repulsão entre as cargas de mesmo sinal.

Uma cadeia de polieletrólito fracamente carregada não se encontra totalmente esticada, mas pode ser vista como um a cadeia alongada de glóbulos eletrostáticos gaussianos. Esses glóbulos possuem tamanho dado por:

$$
\zeta_{e l}=a\left(f^{2} l_{B} / a\right)^{-1 / 3}
$$

e a quantidade de unidades repetitivas em cada glóbulo é :

$$
g_{e l}=\left(f^{2} l_{B} / a\right)^{-2 / 3}
$$

Neste caso, as interações dentro dos glóbulos, devido ao tamanho de cada um, depende apenas de kT, como mostrado na Figura 8. 


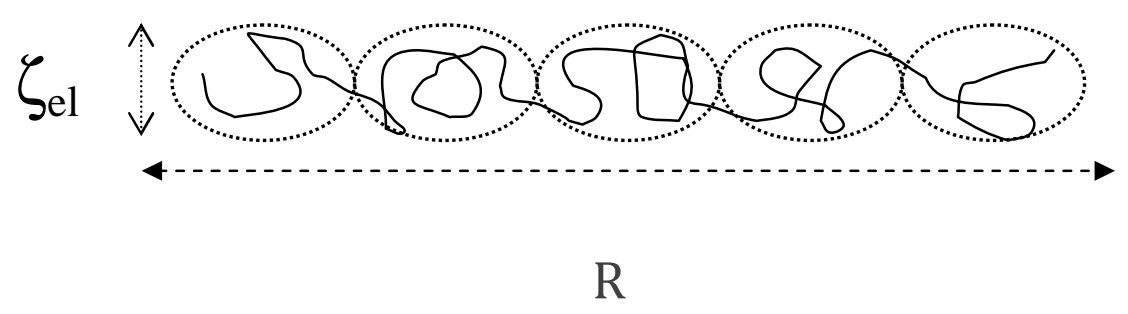

Figura 8: Cadeia de polieletrólito fracamente carregada.

A adição de sal nessa solução não irá afetar as estruturas dos glóbulos, mas se o comprimento de blindagem for menor que o comprimento da cadeia, esta não estará mais completamente alongada, e se dobrará. Este dobramento de cadeia é caracterizado pelo comprimento de persistência $\left(\mathbf{l}_{\mathbf{P}}\right)$, que corresponde ao maior comprimento que a cadeia permanece sem se dobrar. O comprimento de persistência deve diminuir com a concentração de eletrólito. Quando se trata de uma solução de polieletrólito de alta força iônica, as interações eletrostáticas passam a ser de curto alcance e é equivalente a uma interação de volume excluído, que corresponde a:

$$
V_{e l}=4 \pi l_{B}\left(f^{2} / K^{2}\right)
$$

À medida que a concentração da solução aumenta, as cadeias de polieletrólitos interagem fortemente e sobrepõe-se. Essa interação eletrostática entre as cadeias é bem maior que a excitação térmica quando a concentração é próxima à concentração na qual as cadeias começam a se sobrepor, podendo levar a algum tipo de organização. Assume-se, então, que soluções de polieletrólitos semi-diluídas constituem um líquido desordenado e isotrópico, e podem ser vistas como cadeias interpenetradas de glóbulos que têm estrutura local idêntica à de uma cadeia de polieletrólito isolada como na Figura 8. 
$\underline{\text { Introdução }}$

Conforme as cadeias de polieletrólitos se aproximam de interfaces carregadas $(q \sigma)$, podemos verificar algumas características especiais no seu comportamento, análogas àquelas devidas à estrutura de dupla camada elétrica nas vizinhanças da interface. Toda superfície carregada gera um campo elétrico que próximo à superfície é descrito por $E=(k T / q)\left(4 \pi \sigma l_{B}\right)$. Este valor diminui em função da distância à superfície devido a efeitos de blindagem. Na ausência de eletrólito adicionado, a blindagem é devida aos contra-íons confinados na vizinhança da superfície a uma distância $(\lambda)$ denominada comprimento de GouyChapman:

$$
\lambda=\frac{1}{2 \pi \sigma l_{B}}
$$

E o campo elétrico decai em função da distância à superfície $(\mathbf{z})$ como:

$$
E \simeq \frac{2}{z+1}
$$

Agora, se uma quantidade de sal for adicionada, suficiente para que $\boldsymbol{K}^{-1}<\boldsymbol{\lambda}$, o efeito de blindagem é dominado pelo sal e o campo elétrico próximo a superfície decai como:

$$
E \simeq(2 / \lambda)^{e^{-K z}}
$$

A Figura 9 representa esquematicamente o comportamento do campo elétrico em função da distância (z) na presença e na ausência de eletrólito. 


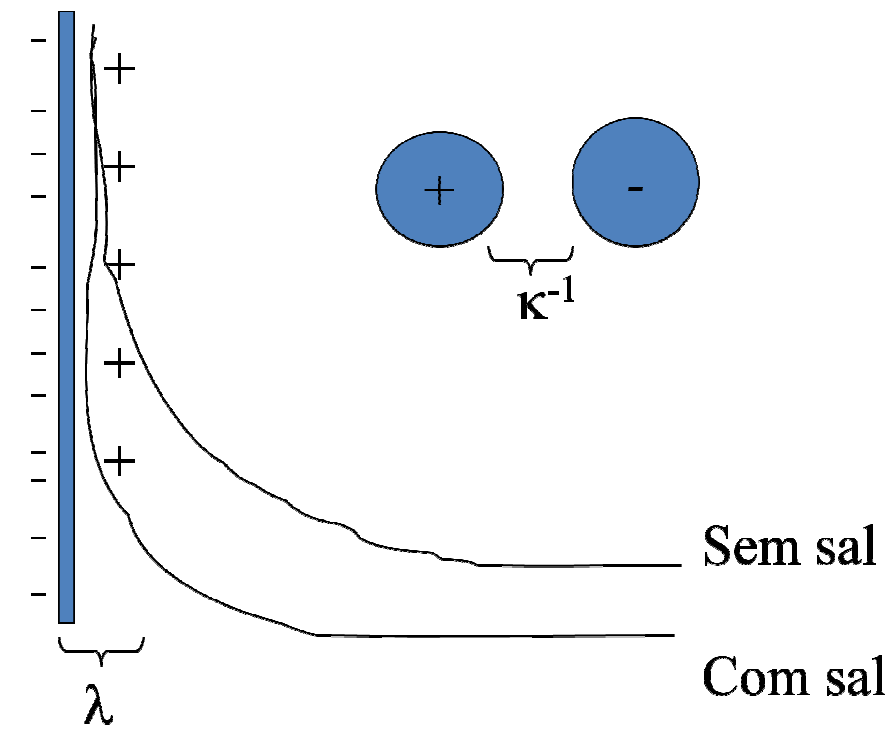

Figura 9: Decaimento do campo elétrico em função da distância à superfície, com e sem eletrólito adicionado. $\lambda$ representa a distância dos contra-íons à superfície e $K^{-1}$ o comprimento de blindagem de Debye.

Em uma solução de baixa força iônica, uma cadeia de polieletrólitos é atraída para a superfície pelo campo elétrico superficial $(E)$, ficando confinado a uma distância $\boldsymbol{\delta}$ da superfície. Se a carga superficial é suficientemente alta, $\delta<\boldsymbol{\lambda}$. O balanço entre a força eletrostática e a força de confinamento para uma cadeia Gaussiana leva a:

$$
\delta \sim\left(a^{2} / f \sigma l_{B}\right)^{1 / 3}
$$

Esta distância representa, em termos práticos, a espessura da camada de polieletrólito adsorvida. Esta espessura é independente da massa molar do polímero, e diminui suavemente com a carga superficial. Na maioria dos casos o valor está na faixa de nanômetros. Devemos notar que neste caso estamos considerando a adsorção de cadeias flexíveis de polieletrólitos, no caso de cadeias rígidas a espessura é bem menor ${ }^{111}$. Deve-se ainda observar que a estrutura da 
$\underline{\text { Introdução }}$

camada adsorvida não é alterada pela adição de sal, desde que a força iônica seja baixa o suficiente e $K^{-1}<\delta$. Porém, em altas forças iônicas, se não existirem forças de curto alcance como: ligações de hidrogênio, forças dispersivas ou dipolo-dipolo, o polieletrólito dessorve, devido à ausência de atração.

Quando uma solução diluída de polieletrólito é colocada em contato com uma superfície de carga oposta, mesmo que a concentração da solução seja baixa, as cadeias adsorvidas sobre a superfície se sobrepõem. Em baixa força iônica os polieletrólitos em equilíbrio térmico adsorvidos sobre uma camada, devido à alta repulsão entre suas cargas, não são capazes de formar grandes dobras em suas cadeias a ponto de formarem voltas e a espessura da camada corresponde à espessura da cadeia do polieletrólito esticado. Em forças iônicas muito elevadas os polieletrólitos comportam-se e são adsorvidos como polímeros neutros, desde que existam forças de curto alcance. Porém em força iônica moderada os polieletrólitos são capazes de formar voltas em suas estruturas (Figura 10). A presença de cargas nestas voltas, ou alças, leva ao que chamamos de sobrecompensação de cargas, resultando na inversão da carga global da camada. Ou seja, a carga elétrica superficial por unidade de área resultante da adsorção do polímero é maior que a carga elétrica da superfície "descoberta". Desta forma a espessura da camada corresponderá ao tamanho da maior volta do polímero.

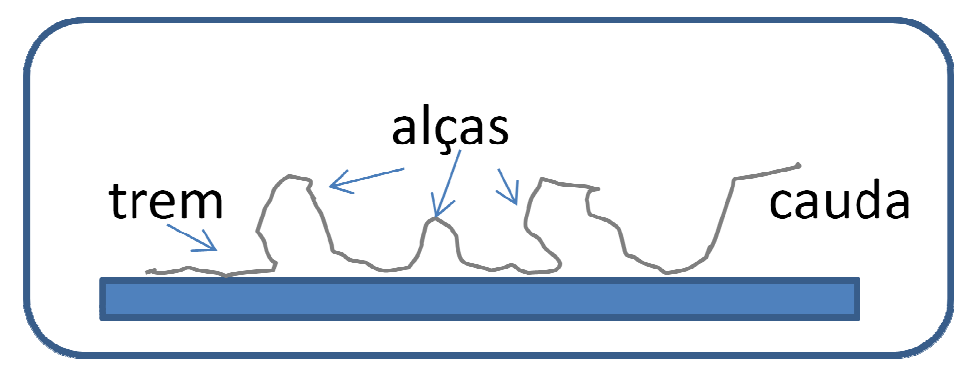

Figura 10: Conformações de um polieletrólito depositado sobre um suporte sólido 


\section{$\underline{\text { Introdução }}$}

O perfil de concentração do polieletrólito decai exponencialmente em função da distância da superfície (z) de acordo com a equação:

$$
c(z)=k^{2} a^{2} / 12 \pi l_{B} f^{2}\left(z+d_{e f f}\right)^{2}
$$

na qual $\mathbf{d}_{\text {eff }}$ mede a interação do polímero com a superfície (eletrostática e não-eletrostática).

Para a formação das multicamadas vamos considerar, inicialmente, uma superfície positivamente carregada sobre a qual um poliânion será adsorvido. Se as atrações de curto alcance entre o polieletrólito e a superfície forem altas, a quantidade de polieletrólito adsorvido na primeira camada é elevada, assim como a adsorbância, $\Gamma_{\mathbf{1}}$, tal que: $\Gamma_{1}>2 \sigma / f$. A camada então pode ser enxaguada em solução de mesma força iônica, assumindo-se que não ocorra dessorção durante o enxágüe e $\Gamma_{1}$ permaneça constante após esta etapa. Após o enxágüe, a superfície com a primeira camada de poliânion adsorvida é colocada em contato com a solução de policátion. O policátion é expulso da vizinhança da superfície sólida positivamente carregada e é complexado ao poliânion da primeira camada formando uma nova camada de espessura $L_{1}=$ $2 \Gamma_{1} / \mathrm{C}_{\mathrm{c}}$. Onde $\mathrm{C}_{\mathrm{c}}$ é a concentração do complexo dada por: $C_{c}=f^{2} / n w^{4 / 3} a^{2}$, considerando que os dois polieletrólitos possuam a mesma fração de cargas $(f)$. Onde $(w)$ é o volume correspondente ao volume da unidade repetitiva. A concentração do poliânion decai rapidamente a zero a partir do valor $C_{c} / 2$ na borda da camada. Esta espessura até a borda da camada corresponde à espessura da camada na qual o policátion é repelido da aproximação ao suporte sólido positivamente carregado e é dada por $\zeta_{c}=k a /\left(4 \pi l_{B} f^{2} C\right)^{1 / 2}$. 
O policátion está em equilíbrio com o interior da solução e pode formar voltas, ancorado ao complexo, porém, com mobilidade de suas pontas em direção à solução eletrolítica como mostrado na Figura 10. Desta forma, a concentração o poliânion decai até um valor constante igual a Cc/2 e a zero a partir da distância $\zeta_{c .}$

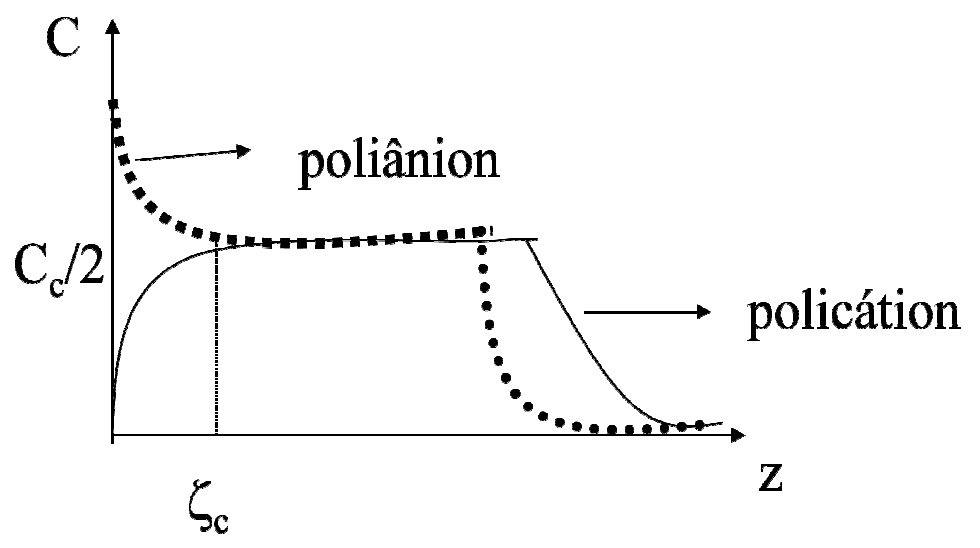

Figura 11: Perfil de decaimento da concentração de poliânion e policátion em função da distância z da superfície.

Desta forma, através de imersões e enxágües alternados e sucessivos teremos a formação das multicamadas e a obtenção do chamado, filme Layer-by-Layer (camada-a-camada) ou apenas LbL de polieletrólitos. Na seção seguinte será mostrada as bases da técnica LbL, e uma pequena revisão de trabalhos que descreve como o comportamento de polieletrólitos em solução pode influenciar na propriedade dos filmes LbL. 
$\underline{\text { Introdução }}$

\subsubsection{Formação de Filmes Finos Poliméricos: Filmes automontados ou layer-by- layer}

A técnica layer-by-layer (LbL) para a formação de filmes finos de polieletrólitos, foi desenvolvida por Decher ${ }^{107}$ na década de 90 . A atração iônica entre as cargas opostas é a força motriz para a construção das multicamadas ${ }^{112}$. Como visto na seção anterior, a metodologia consiste basicamente na formação de multicamadas por meio da adsorção alternada consecutiva de polieletrólitos aniônicos e catiônicos sobre um suporte sólido imerso na solução de interesse por um tempo em média de 20 minutos. Entre cada deposição o suporte é enxaguado em solução de mesma força iônica e pH daquela contendo o polieletrólito para remoção de moléculas não adsorvidas.

Figura 12 ilustra o procedimento para a formação de filmes LbL. Esse procedimento pode ser repetido quantas vezes se fizer necessário, resultando em filmes multicamadas. Lenahan, et. al. relataram a formação de filmes LbL com até mil camadas alternadas ${ }^{113}$. Entre cada imersão o filme deve ser seco, utilizando-se um jato de nitrogênio, para que se garanta uniformidade na deposição ao longo do suporte. 


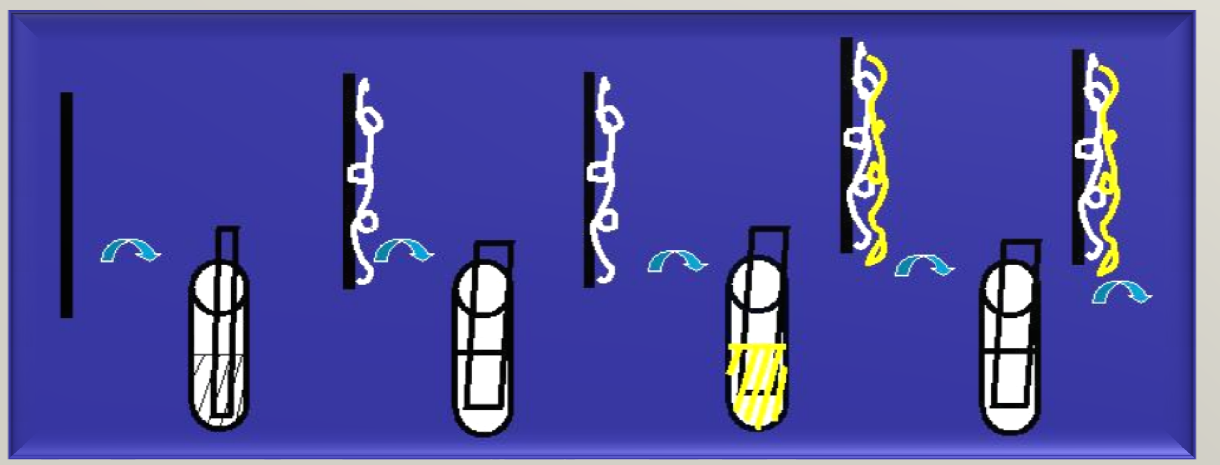

Figura 12: Ilustração da deposição alternada de dois polieletrólitos de cargas opostas e o enxágüe entre a deposição de cada camada.

Inicialmente, Decher ${ }^{107,114}$ fazia uso apenas de suportes carregados, entretanto, estudos ${ }^{115}$ mostram que as interações para formação desses filmes podem ser também de outra natureza como ligações de hidrogênio, ou forças mais fracas como forças dispersivas e interações íondipolo. Este fato permite uma versatilidade ainda maior com relação aos tipos de suportes e polímeros que podem ser utilizados. Esta técnica também tem sido empregada com suportes nãoplanares, como partículas coloidais ${ }^{116,117}$.

Como mostrado na seção anterior, para que se possa ter controle das propriedades dos filmes formados, como espessura e estabilidade, é necessário que se conheçam as propriedades e os mecanismos de adsorção de polieletrólitos. Os complexos de polieletrólitos formados sobre suportes sólidos possuem estrutura mais bem definida que os mesmos complexos formados em solução, sendo que a estrutura de cada bicamada pode se constituir por si só em um gel ${ }^{118}$, no sentido que solvente pode ficar aprisionado entre as cadeias dos polieletrólitos que interagem ou formam o complexo. O processo de crescimento das camadas só é possível devido a um fator importante: a sobrecompensação de cargas ${ }^{119,120}$. A formação de bicamadas só ocorre se, para 
$\underline{\text { Introdução }}$

cada deposição, há inversão da carga superficial, não apenas neutralização, o que permite que uma nova camada seja depositada. Hoogeveen ${ }^{121}$ pôde confirmar esta teoria por meio de medidas de potencial zeta de filmes $\mathrm{LbL}$ de poli(vinil imidazol) e poli(ácido acrílico). A sobrecompensação também faz com que o processo de formação das multicamadas seja autoregulado, uma vez que a quantidade de material adsorvida nas camadas mais internas e a carga superficial controlam a quantidade de material que será adsorvida nas camadas posteriores.

Com a deposição sucessiva das camadas, Schmitt $^{122}$ observou que existe possibilidade de interpenetração entre as cadeias poliméricas. A interpenetração pode ser explicada devido à hidratação da camada ligada ao substrato, que confere certa mobilidade a determinadas porções da cadeia polimérica, formando "alças" (Figura 10) e permitindo que ocorra interpenetração destas cadeias nas camadas posteriores. A interpenetração entre as camadas foi a explicação dada por Lowack e Helm ${ }^{123}$ quando observaram a possibilidade de crescimento de duas camadas de policátion sobre um filme LbL. Eles afirmam que a interpenetração de cadeias anteriores de poliânions e, portanto, cargas negativas remanescentes, permitiram a ligação da segunda camada do policátion.

Como anteriormente mencionado, a quantidade de eletrólito adicionada nas soluções dos polieletrólitos também pode ser um fator de influência na espessura e propriedades dos filmes LbL devido a alterações na conformação dos polieletrólitos em solução. Na ausência de eletrólito adicionado, o polieletrólito, dependendo de sua densidade de carga, normalmente assume a conformação de bastão rígido devido à repulsão coulômbica entre as cargas presentes na cadeia. A adição de eletrólito causa um efeito de blindagem das cargas do polímero, permitindo que este adquira uma conformação mais flexível, denominada novelo-ao-acaso (random coil). Esta diferença na conformação leva à formação de filmes mais espessos na presença de eletrólitos. 
$\underline{\text { Introdução }}$

Decher ${ }^{124}$ observou por meio de medidas de espalhamento de raios-X a baixo ângulo (SAXS), que a espessura de um filme LBL de hidrocloreto de poli(alilamina) (PAH) e poli(estireno sulfonato) de sódio (NaPSS) contendo diferentes concentrações de $\mathrm{NaCl}$ pode variar de 1,77 nm por bicamada $\left(\mathrm{NaCl} 1,0 \mathrm{~mol} \mathrm{~L}^{-1}\right)$ até 2,26 $\mathrm{nm}\left(\mathrm{NaCl} 2,0 \mathrm{~mol} \mathrm{~L}^{-1}\right)$. A variação de espessura também pode ocorrer se o enxágüe entre as camadas depositadas for realizado com água pura ou com solução de eletrólito, uma vez que estes procedimentos implicam em diferentes forças iônicas. Decher ${ }^{124}$ mostrou que para um filme PAH/NaPSS com 12 camadas a variação de espessura do filme pode chegar a $10 \%$ durante ciclos de enxágüe com água pura e solução de $\mathrm{NaCl} 0,1 \mathrm{~mol} \mathrm{~L}^{-1}$.

O crescimento dos filmes, geralmente, pode ser acompanhado por medidas de absorção, reflexão e espalhamento de luz dependendo do tipo de molécula e suporte que o formam. As medidas de SAXS apresentam a vantagem de além de acompanhamento do crescimento, permitir o cálculo do valor da espessura das camadas. Uma técnica que permite a quantificação do material depositado é a da microbalança a cristal de quartzo (QCM).

Além das aplicações industriais já citadas, os filmes LbL também têm sido utilizados ${ }^{64}$ como matriz polimérica em processos que mimetizam a biomineralização, como relatado no item 1.1 desta introdução. 


\section{Parte Experimental}

\subsection{Condicionamento dos Suportes Metálicos}

A literatura relata ${ }^{125}$ a importância do pré-tratamento das superfícies metálicas antes do início do processo de deposição de filmes. Estes pré-tratamentos têm como objetivo melhorar a adesão e homogeneidade dos filmes depositados e consistem em abrasão para aumentar a rugosidade superficial e/ou de tratamentos com ácido e/ou base que aumentam a energia superficial do sólido pela introdução de grupos eletricamente carregados e hidroxilas. Em nosso caso o tratamento visou também ter uma homogeneidade nos diferentes suportes utilizados para que o fator rugosidade não interferisse nas análises posteriores. Todos os suportes metálicos foram lixados realizando-se movimentos seqüenciais que descrevem o número " 8 ", com lixas de granulações 600, 1500 e 2000, respectivamente. Os tratamentos realizados estão descritos na seção de resultados 3.1 .

\subsection{Formação dos filmes $L b L$ e filmes mistos $L B / L b L$ sobre suportes metálicos}

Os filmes LB e LbL foram formados sobre superfícies metálicas de alumínio ou aço inox 316L posteriormente aos pré-tratamentos indicados na seção anterior. Fundamentalmente foram estudados dois diferentes tipos de matrizes orgânicas: mista, contendo filme LB de fosfolipídeos e LbL de polieletrólitos e simples $\boldsymbol{L} \boldsymbol{b} \boldsymbol{L}$, contendo apenas o filme LbL de polieletrólitos. Sobre os dois tipos de matrizes depositou-se $\mathrm{CaCO}_{3}$. Os lipídeos utilizados na formação dos filmes $\mathrm{LB}$ 
foram: sal de sódio do ácido dimiristoilfosfatídico (DMPA) e dimiristoilfosfatidiletanolamina (DMPE) (Sigma). Os polieletrólitos utilizados na formação dos filmes LbL foram: os poliânions iota-carragenana (l-car) (Gelymar-Chile, MW=2,69 x $\left.10^{6} \mathrm{~g} \mathrm{~mol}^{-1}\right)$, lambda-carragenana $(\lambda$-car) (Gelymar-Chile, MW=5,2 x $\left.10^{5} \mathrm{~g} \mathrm{~mol}^{-1}\right)$, kappa-I carragenana ( $\left.\mathrm{KI}-\mathrm{car}\right)($ Gelymar-Chile, $\mathrm{MW}=7,2$ x $10^{5} \mathrm{~g} \mathrm{~mol}^{-1}$ ), poli(ácido acrílico) (PAA) (Aldrich, MW=2,5 x 10 $\mathrm{g} \mathrm{mol}^{-1}$ ), o correspondente sal de sódio, poli(acrilato de sódio) (NaPA), poli(estireno sulfonato) de sódio (Sigma-Aldrich, MW= $7 \times 10^{4} \mathrm{~g} \mathrm{~mol}^{-1}$ ) e o policátion, quitosana (Qt) (polysciences, MW= $3 \times 10^{3} \mathrm{~g} \mathrm{~mol}^{-1}$ e grau de acetilação, determinado por $\mathrm{RMN}^{126}$, igual a $15 \%$.

A Figura 13 mostra a estrutura química dos fosfolipídeos e dos polieletrólitos utilizados. A diferença entre as estruturas das carragenanas utilizadas está relacionada à presença nas frações kappa e iota, ou ausência na fração lambda, da ponte 3,6 anidro galactose em suas unidades repetitivas. A presença da ponte induz a formação de estruturas helicoidas em solução. Ainda a fração lambda possui 2 a 3 grupos sulfato por unidade repetitiva, a fração iota possui dois, enquanto que a fração kappa-I apresenta apenas um.

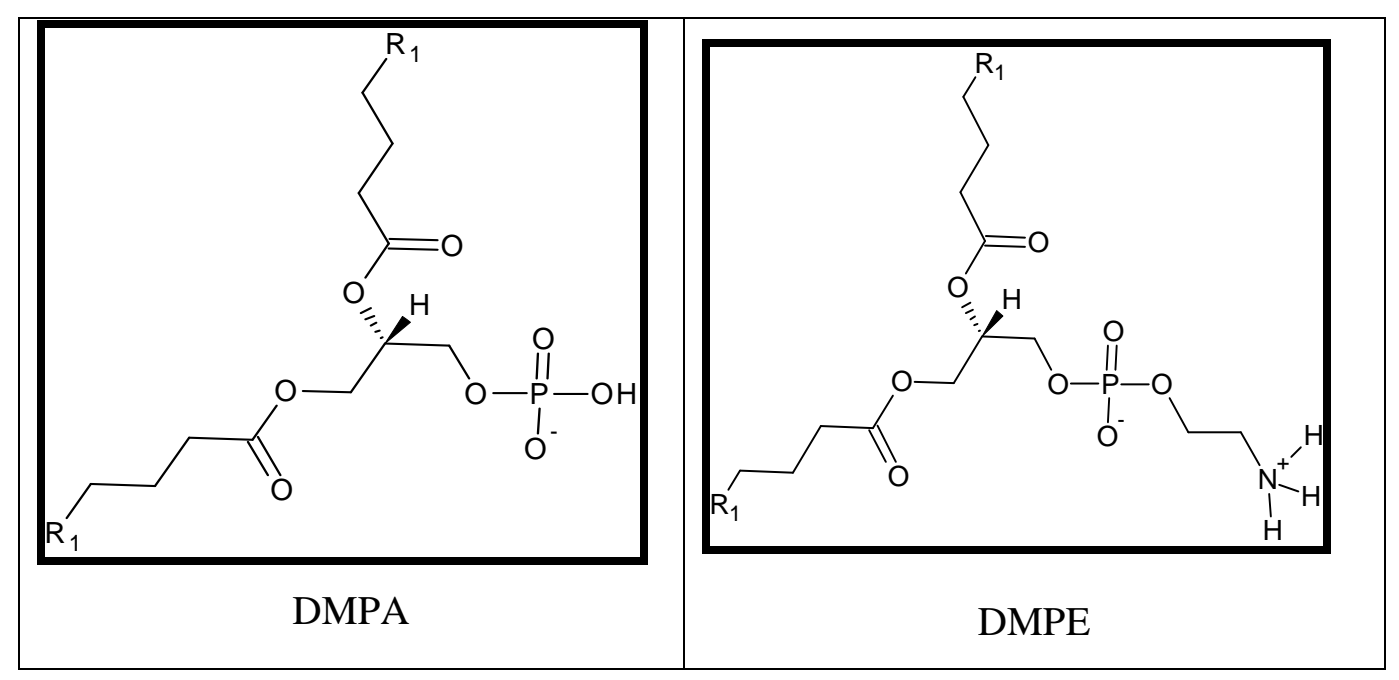




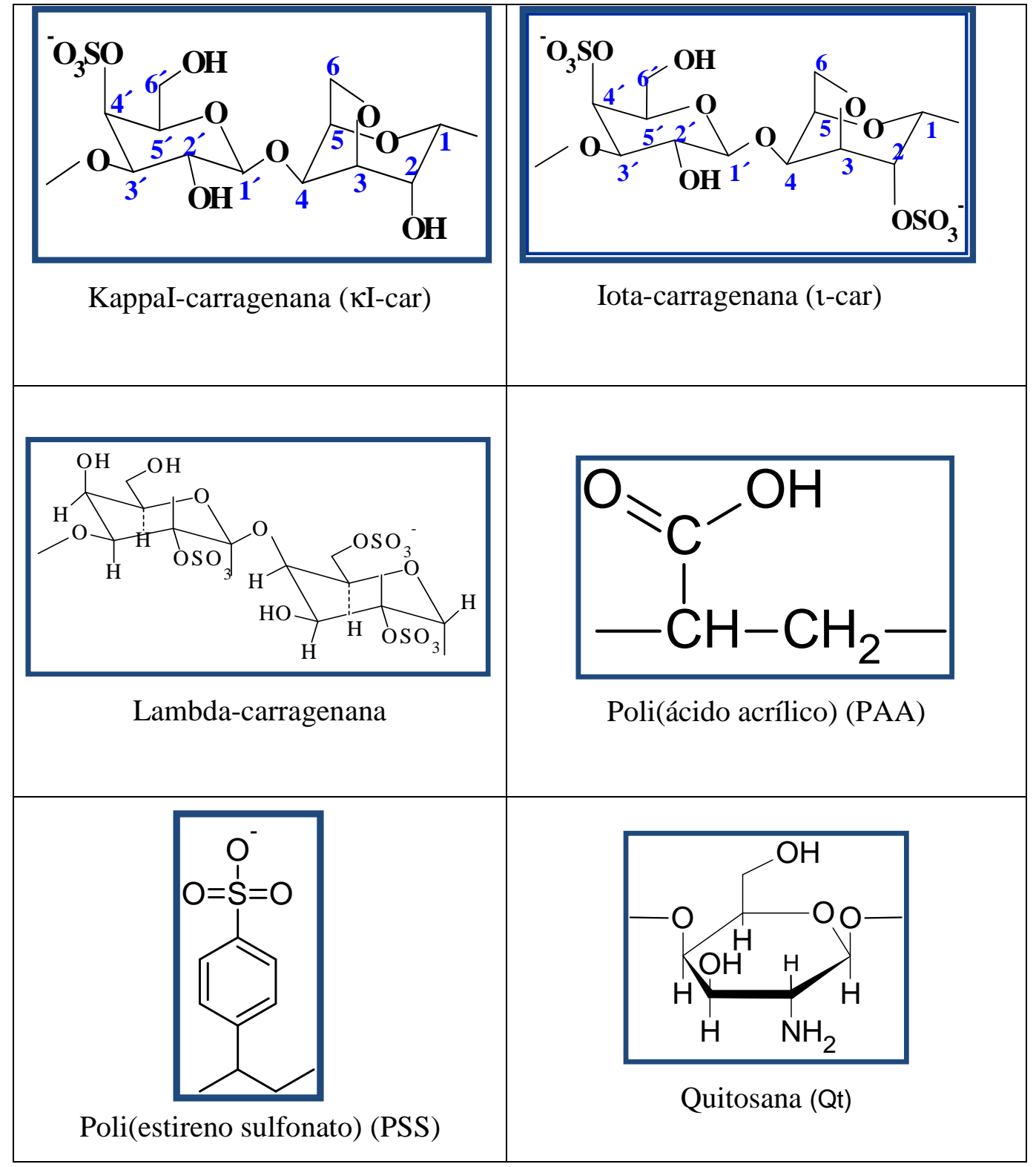

Figura 13: Estrutura dos fosfolipídeos DMPA e DMPE e dos polieletrólitos kappaI-carragenana, iota-carragenana, poli(ácido acrílico), poli(estireno sulfonato) e quitosana, utilizados nesta tese.

Antes da formação dos filmes LB, isotermas de pressão superficial $v s$ área molecular $(\pi-$ A) foram obtidas a $25^{\circ} \mathrm{C} \mathrm{em} \mathrm{uma} \mathrm{cuba} \mathrm{de} \mathrm{Langmuir} \mathrm{(Insight,} \mathrm{Brazil)} \mathrm{de} 216 \mathrm{~cm}^{2}$ de área, após o espalhamento de soluções de lipídeos $1,0 \quad \mathrm{mmol}^{-1} \quad \mathrm{~L}^{-1}$ solubilizados em mistura 
clorofórmio:metanol (3:1, v/v). Utilizaram-se os lipídeos puros e misturas com diferentes frações molares: 2.3:1, 1:1, 1:2.3. Soluções $0,1 \mathrm{mmol} \mathrm{L}^{-1} \mathrm{ZnCl}_{2}$ ou solução aquosa de quitosana $0,05 \%$ (p/p), foram preparadas para serem usadas como subfase suporte das monocamadas. Íons zinco foram adicionados na subfase para promover a adesão entre as sucessivas camadas de DMPA no filme LB.

\section{Filmes LB}

As monocamadas foram depositadas sobre suportes de alumínio ou aço-inox 316-L. Filmes LB tipo "Y", com interação cauda-cauda e cabeça-cabeça, foram formados por meio da imersão e suspensão dos suportes através da interface. Três camadas de DMPA foram depositadas a partir de subfases contendo íons zinco. Este procedimento resultou em um filme LB hidrofóbico. Uma quarta camada contendo DMPA, DMPE ou uma mistura dos mesmos $(7: 3 ; 1: 1$; 3:7) foi depositada a partir de subfase quitosana.

Figura 14(1) ilustra esquematicamente a constituição básica destes filmes. Para todas as deposições, a velocidade de imersão e submersão foi $0,038 \mathrm{~mm} \mathrm{~s}^{-1}$ mantendo-se a pressão superficial para as três primeiras camadas em $30 \mathrm{mN} \mathrm{m}^{-1}$ e $40 \mathrm{mN} \mathrm{m}^{-1}$ para a quarta camada contendo quitosana. Como esta última camada possui final hidrofílico, ela deve estar sendo estabilizada pela presença do polieletrólito, que impede que as moléculas do fosfolipídeo se reorientem expondo a cauda hidrofóbica. 

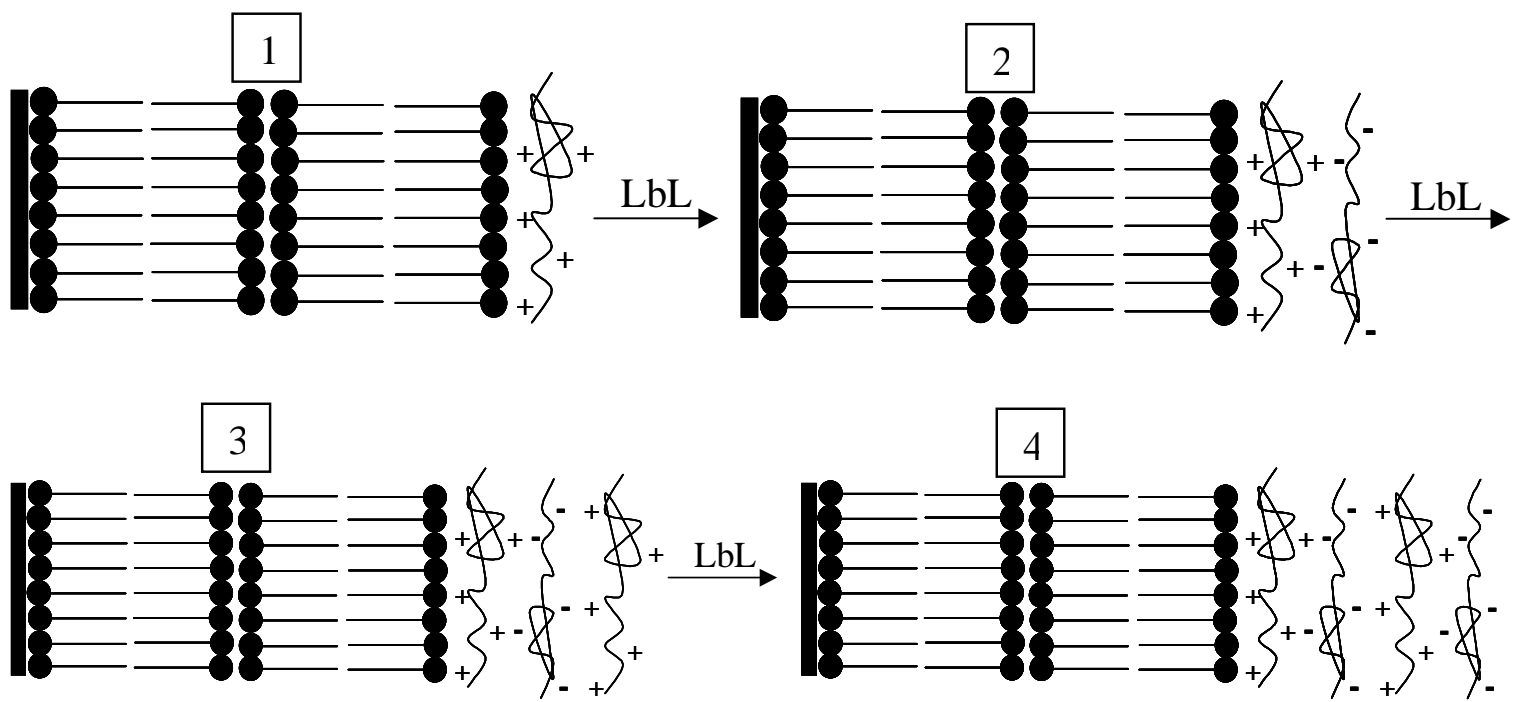

Figura 14: Representação esquemática da estrutura dos filmes mistos LB/LbL.

\section{Filmes LbL}

Os filmes LbL (Figura $14(2,3,4))$ foram depositados sobre os filmes LB previamente formados ou diretamente sobre o suporte metálico pré-tratado Para preparar esses filmes, os poliânions $(0,1 \% \mathrm{p} / \mathrm{v})$ foram solubilizados sob agitação magnética em solução $0,01 \mathrm{~mol} \mathrm{~L}^{-1}$ de $\mathrm{CaCl}_{2}$, durante 24 horas. Nestas condições o PAA (pH 3,5) apresenta fração de cargas $(f)$ igual a 0,01; já as carragenanas estão completamente ionizadas. A quitosana (pKa 6,5) foi solubilizada em solução de ácido acético $1,0 \%$ (v/v) $(\mathrm{pH} \sim 3,5)$ por 24 horas. Após a solubilização o $\mathrm{pH}$ foi ajustado para 5,4 com solução de $\mathrm{NaOH}$. Neste pH a quitosana apresenta cerca de $80 \%$ dos grupos amino carregados $\left(\mathrm{pKa}=\mathrm{pH}+\log (1-\alpha / \alpha) ; \alpha=\right.$ fração de $\left.\mathrm{NH}_{2}\right)$. A solução foi então filtrada em membrana de éster de celulose com tamanho de poro igual $0,45 \mu \mathrm{m}$ (HAWP, Millipore $^{\circledR}$ ) antes de ser utilizada. Um mínimo de três ou um máximo de treze camadas de polieletrólitos foram depositadas, alternando-se poliânion e policátion. Inicialmente, o suporte, 
modificado ou não com o filme LB, foi imerso em solução do poliânion por 20 minutos. Então, o suporte foi imerso em solução de $\mathrm{CaCl}_{2} 0,01 \mathrm{~mol} \mathrm{~L}^{-1}$ por 5 minutos, com o intuito de remover cadeias do poliânion fracamente ligadas e manter a força iônica constante. Após o enxágüe o suporte foi seco sob fluxo de $\mathrm{N}_{2}(\mathrm{~g})$. Na seqüência, o suporte foi imerso em solução de Qt e enxaguado com $\mathrm{H}_{2} \mathrm{O}$ deionizada $(\mathrm{pH}$ 5,5) e seco. A repetição dessa seqüência permite a obtenção de filmes com qualquer que seja o número de camadas desejadas.

No decorrer dessa tese os filmes multicamadas serão representados da seguinte forma: $(\mathbf{P A A} / \mathbf{Q t})_{6} \mathbf{P A A} \rightarrow$ filme contendo 13 camadas alternadas de PAA e Qt, iniciando-se e terminando-se com PAA;

$(\mathbf{P A A} / \mathbf{Q t})_{6} \mathbf{P A A} / \mathrm{CaCO}_{3} \rightarrow$ filme polimérico correspondente contendo carbonato de cálcio na superfície.

\subsection{Formação do Filme Inorgânico de $\mathrm{CaCO}_{3}$ sobre suportes planares}

A deposição do $\mathrm{CaCO}_{3}$ sobre os suportes metálicos contendo a matriz polimérica foi feita deixando-se os suportes em um recipiente fechado (15 cm de diâmetro), à temperatura ambiente, contendo 1,5 g de carbonato de amônio acondicionado em um pequeno recipiente contendo um furo de $\phi=1 \mathrm{~mm}$. A reação entre $\mathrm{CO}_{2}$, gerado pela decomposição de $(\mathrm{NH} 4)_{2} \mathrm{CO}_{3}$, água e os íons $\mathrm{Ca}^{2+}$ presentes na matriz polimérica formam $\mathrm{CaCO}_{3}$. O tempo de exposição foi de 13 horas. Vale a pensa ressaltar que neste método de deposição o suporte não está imerso em solução como em outros trabalhos publicados ${ }^{27}$. Esta mudança na metodologia corrente resulta em uma nova metodologia, que será denominada no decorrer desta tese como método "a seco". Este apresenta como vantagem a definição do local onde ocorre a reação, excluindo a possibilidade de termos 
carbonato de cálcio formado no interior da solução e sendo depositado na superfície da matriz polimérica.

$\mathrm{O}$ crescimento de $\mathrm{CaCO}_{3}$ sobre as matrizes orgânicas foi estudado de diferentes maneiras, de forma a se verificar fatores que influenciam na nucleação e crescimento do mineral. Dentre os fatores considerados no estudo, podemos citar:

a) Efeito da quantidade de solvente na vizinhança

Para este estudo dois diferentes métodos foram utilizados: o método "a seco" que foi reportado por nosso grupo pela primeira vez em Ramos et al. ${ }^{97}$ e o método no qual o suporte contendo a matriz orgânica é imerso em solução $0,01 \mathrm{~mol} \mathrm{~L}^{-1}$ de $\mathrm{CaCl}_{2}$. No primeiro caso, a fonte de íons cálcio provém dos íons ligados como contra-íons à matriz orgânica e dos íons aprisionados nos interstícios da rede tridimensional formada pela matriz orgânica, enquanto que no segundo os íons cálcio também estão distribuídos em toda a solução que circunda o filme.

b) Tipo de grupo carregado negativamente e conformação do poliânion formador da matriz orgânica

Foram utilizados os poliânions: poli(ácido acrílico) (PAA) e poli(acrilato de sódio) (NaPA) que contêm grupos carboxilatos como grupo negativamente carregado, lambda-carragenana $(\lambda$-car), kappaI-carragenana ( $\kappa \mathrm{I}$-car) e iota-carragenana (l-car) que possuem grupos ésteres sulfato, como grupo negativamente carregado, e, finalmente poli(estireno sulfonato) de sódio (PSS) que possui grupos sulfonato como grupo negativamente carregado. Como policátion utilizou-se em todos os casos a quitosana (Qt) em pH 5,4. 
As estruturas químicas dos compostos utilizados são mostradas na Figura 13.

c) Rugosidade do suporte

Foram utilizados suportes de alumínio, aço inox e silício para estudo da influência da rugosidade do suporte na formação dos filmes. Os suportes metálicos foram previamente lixados e polidos. Todos os suportes foram lavados com solução tampão fosfato $\mathrm{pH}$ 7,5 como melhor descrito na seção de resultados (3.1).

d) Tipo de fosfolipídeo que compõem o filme $L B$

Foi estudada a influência de pré-recobrimento dos suportes sólidos com filmes LB sobre a formação dos filmes $\mathrm{LbL}$ e sobre o crescimento de $\mathrm{CaCO}_{3}$. Para este fim utilizou-se fosfolipídeos contendo 14 carbonos em sua calda apolar, porém com diferentes cargas elétricas em sua cabeça polar: negativo ou zwitterionico.

\subsection{Crescimento de $\mathrm{CaCO}_{3}$ em meio confinado tridimensional: membranas de policarbonato}

Membranas de policarbonato com poros cilíndricos têm sido utilizadas como moldes (templates) em estudos de nucleação e crescimento de $\mathrm{CaCO}_{3}$ em meio confinado ${ }^{98,14}$. Este tipo de molde pode também ser modificado por meio da introdução de filmes finos nos poros da membrana como mostra o estudo de Liang et. al. ${ }^{127}$, no qual filmes LbL de PAA, PSS e PAH foram crescidos no interior dos poros com intuito de formar nanotubos poliméricos.

Inicialmente as membranas de policarbonato Milli-Pore $^{\mathrm{R}}$ foram limpas durante 30 segundos no interior de um limpador de plasma (Harrick Plasma PDC-32G). Em seguida, as membranas foram mergulhadas em solução de quitosana $0,1 \%(\mathrm{p} / \mathrm{v})$ e mantidas em recipiente 
fechado sob vácuo durante 40 minutos, para retirar o ar dos poros, auxiliando na entrada do polímero. O vácuo foi então retirado e as membranas permaneceram por mais 20 minutos na mesma solução.

A superfície das membranas foi limpa com papel de filtro para remoção de excesso de polímero que poderia estar adsorvido sobre as superfícies da membrana, obstruindo os poros. Em seguida as membranas foram mergulhadas em água durante 5 minutos para enxágüe. Para a deposição da próxima camada do filme LbL, as membranas adsorvidas com quitosana foram imersas em solução de $0,1 \% \mathrm{p} / \mathrm{v}$ de PAA contendo $0,01 \mathrm{~mol} \mathrm{~L}^{-1}$ de $\mathrm{CaCl}_{2}$ seguindo-se a mesma seqüência anteriormente descrita: 40 minutos sob vácuo e mais 20 minutos sem vácuo. Retirou-se então o excesso de PAA com papel de filtro e o enxágüe nesta etapa foi feito com solução 0,01 mol $\mathrm{L}^{-1}$ de $\mathrm{CaCl}_{2}$. As sequiências foram repetidas até a obtenção do número de camadas desejadas, que foram 4 camadas (filme terminado em PAA) ou 5 camadas (filmes terminados em quitosana).

Após o crescimento do filme LbL, as membranas foram imersas em solução $0,01 \mathrm{~mol} \mathrm{~L}^{-1}$ de $\mathrm{CaCl}_{2}$ contendo $10 \mathrm{ppm}$ de PAA ( $\mathrm{Mw} 8000 \mathrm{~g} \mathrm{~mol}^{-1}$ ) e deixadas um pernoite em repouso antes do início da cristalização. Estudou-se o efeito da adição ou não de PAA nesta solução de $\mathrm{CaCl}_{2}$.

Para a cristalização as membranas foram colocadas entre duas lâminas de vidro de microscópio e algumas gotas da solução de $\mathrm{CaCl}_{2}$, contendo ou não PAA, foram adicionadas entre as placas e a membrana, conforme esquematizado na Figura 15. Na seqüência, para a deposição de $\mathrm{CaCO}_{3}$, o conjunto, de lâminas e membranas, foi colocado em recipiente fechado e exposto a $\mathrm{CO}_{2}$ provindo da decomposição de $\left(\mathrm{NH}_{4}\right)_{2} \mathrm{CO}_{3}$, por um pernoite. 


\section{Vista de cima}

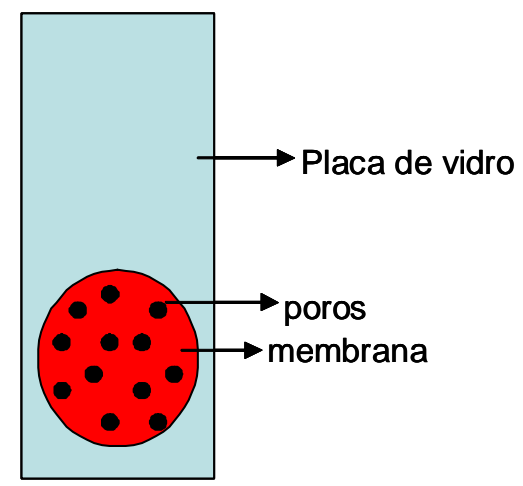

Vista lateral

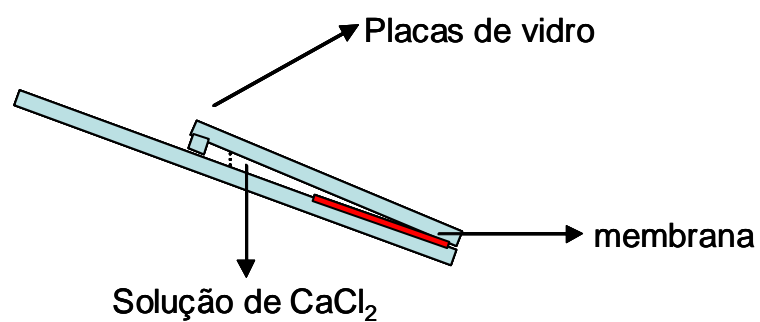

Figura 15: Esquema da montagem experimental para deposição de $\mathrm{CaCO}_{3}$ em membranas de policarbonato.

\subsection{Caracterização dos Filmes Orgânicos e Híbridos}

Os filmes formados sobre os suportes metálicos foram caracterizados por diferentes técnicas que tinham por objetivo: análise do crescimento das camadas, análise da cristalinidade do carbonato de cálcio formado e morfologia dos filmes.

\subsubsection{Teste de adesão dos filmes sobre os suportes}

Os testes de adesão foram realizados em equipamento gentilmente disponibilizado pela empresa 3M (Ribeirão Preto-SP) segundo as normas IRAM 2454, NM 60454-2:2006 e SABS 122. O teste consiste na adesão de uma fita adesiva de $10 \mathrm{~mm}$ de largura, que possui grande afinidade por substâncias polares, fabricada pela empresa 3M, sobre os suportes $(20 \mathrm{~mm}$ x 20 
mm) previamente recobertos pelos filmes orgânicos e híbridos. A adesão da fita sobre o suporte é realizada passando-se um rolete de $6 \mathrm{Kg}$ sobre a mesma. Antes da realização das medidas esperou-se 20 min. Em seguida a remoção da fita é realizada com a amostra colocada a $180^{\circ} \mathrm{em}$ uma máquina de ensaio de tração Instron, Emic, Thwing Albert 37-4, com taxa constante de extensão, velocidade de separação das garras de $300 \mathrm{~mm} /$ minutos, usando célula de carga de 50 $\mathrm{kg}$ e fundo de escala de $10 \mathrm{~kg}$, que é capaz de medir a força necessária para remoção da fita colada aos filmes dos suportes a velocidade constante de $300 \mathrm{~mm} / \mathrm{min}$. Os resultados são expressos na unidade gf (grama força) que equivale a $0,01 \mathrm{~N}$.

\subsubsection{Reflectância Difusa}

Espectroscopia de absorção eletrônica na região do U.V.-visível por reflectância difusa, utilizando-se esfera integradora (espectrofotômetro UV -VIS -NIR Varian Cary 500Laboratório de Materiais Fotônicos- DQ-UNESP- Araraquara), foi utilizada para monitoramento do crescimento das camadas e subseqüente formação da matriz polimérica. Os dados de reflexão foram obtidos no comprimento de onda máximo de absorção do PAA 212 nm correspondente à transição $\pi-\pi^{*}$ dos elétrons da ligação $\mathrm{C}=\mathrm{O}$.

A diferença entre a intensidade de luz inicial $\left(\mathrm{I}_{0}\right)$ e a intensidade de luz que chega no detector (I) é igual à quantidade de luz absorvida pela amostra que por sua vez é proporcional, segundo a lei de Beer, à quantidade de material depositado. Portanto, a quantidade de luz refletida é inversamente proporcional à quantidade do polieletrólito depositada, ou seja, quanto maior for a quantidade de PAA adsorvido maior será a quantidade de luz absorvida e menor a quantidade de luz refletida. 


\subsubsection{Espalhamento de Raios-x a baixo ângulo (SAXS)}

A organização dos filmes orgânicos e híbridos foi estudada por meio da técnica de espalhamento de raios-X a baixo ângulo (linha D11A-SAXS no Laboratório Nacional de Luz Síncroton em Campinas-SP). O feixe de luz apresenta comprimento de onda monocromático de 1.608 Å. A distância entre a amostra e o detector foi $627,98 \mathrm{~mm}$ e as imagens de SAXS foram obtidas com detector bidimensional (Fuji Bas III), com vetor de espalhamento $(\mathrm{Q}=4 \pi$ sen $\theta / 2) / \lambda$ ] no intervalo de 2,6 a $4,4 \mathrm{~nm}^{-1}$. As imagens obtidas foram analisadas e curvas de intensidade versus vetor de espalhamento $(\mathrm{Q})$ foram obtidas utilizando-se o software Fit2D (V.12.077) (A.P.Hammersley/ESRF 1987-2004).

\subsubsection{Microbalança a Cristal de Quartzo (QCM)}

A quantidade de material adsorvido por bicamada foi quantificada por meio da técnica de microbalança a cristal de quartzo, QCM. Esta técnica consiste na formação das multicamadas sobre um substrato de cristal de quartzo recoberto por eletrodos metálicos em ambas as faces (Figura 16). A microbalança é um detector de massa sensível, baseado no efeito piezelétrico. Sua vantagem está na alta sensibilidade $\left(\mathrm{ng} \mathrm{cm}^{-2}\right)$. A montagem de uma QCM compreende: um cristal de quartzo recoberto de filmes metálicos (ouro), que funcionam como eletrodos através dos quais é aplicada uma diferença de potencial. Esta diferença de potencial provoca uma vibração do cristal de quartzo e a frequiência pode ser medida através de um freqüencímetro. 


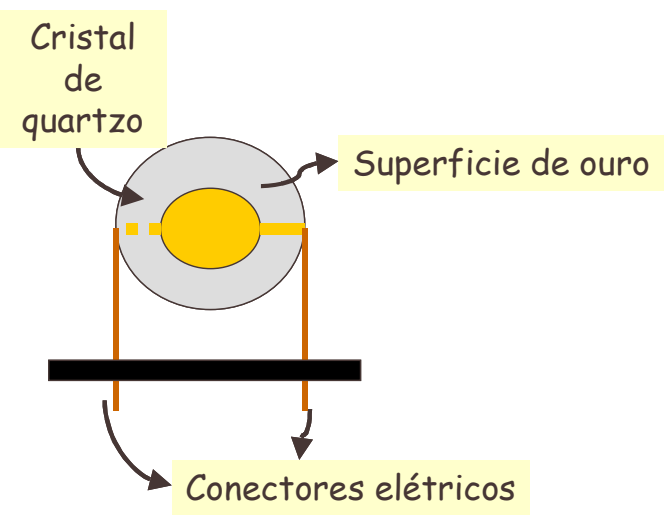

Figura 16: Esquema da montagem típica de uma QCM evidenciando o cristal piezoelétrico de quartzo, recoberto pelos eletrodos de ouro.

O princípio desta técnica está relacionado com a proporcionalidade entre a variação de freqüência de ressonância do cristal e a massa depositada sobre ele. A freqüência de vibração diminui com uma pequena quantidade de material aderido sobre ele.

A relação entre a variação de freqüência $\Delta \mathrm{F}(\mathrm{Hz})$ resultante de uma mudança na massa é dada pela equação de Sauerbrey ${ }^{128}$ :

$$
\Delta F=\left[2\left(F_{0}\right)^{2} \Delta m\right]\left(\mu_{q} \rho_{q}\right)^{-1 / 2}
$$

Onde $\mathbf{F}_{\mathbf{0}}$ é a freqüência inicial, $\boldsymbol{\mu}_{\mathbf{q}}$ é o módulo de cisalhamento do quartzo, $\boldsymbol{\rho}_{\mathbf{q}}$ a densidade do quartzo, $\Delta \mathbf{F}$ a variação de freqüência e $\Delta \boldsymbol{m}$ é a massa total depositada em ambas as faces do cristal.

Os filmes Lb-LbL foram depositados sobre cristal de quartzo recoberto por ouro e utilizando-se a técnica de QCM pôde-se medir a quantidade, em massa, de polieletrólito depositado por camada, bem como a quantidade de $\mathrm{CaCO}_{3}$ formado na ultima camada. Para a formação de $\mathrm{CaCO}_{3}$ sobre os cristais de quartzo utilizou-se fluxo de $\mathrm{CO}_{2}$ gerado a partir de 
cilindro (White Martins) com vazão de $0,3 \mathrm{~L} \mathrm{~min}^{-1}$. Esta metodologia foi adotada em substituição à exposição a $\left(\mathrm{NH}_{4}\right)_{2} \mathrm{CO}_{3}$, pois o contato metálico do cristal da $\mathrm{QCM}$ é composto por um fio de cobre que reage facilmente com $\mathrm{NH}_{3}$ também produto da decomposição do carbonato de amônio, formando complexos que interferem no valor de massa medido além de destruir o contato elétrico.

\subsubsection{Espectroscopia na Região do Infravermelho com reflexão total atenuada (ATR- FTIR)}

Para análise dos grupos presentes na superfície foi utilizada a técnica de espectroscopia de reflexão total atenuada na superfície na região do infravermelho por transformada de Fourier, ATR-FTIR. Os espectros foram obtidos em espectrofotômetro Bomem-mb102 (Prof. Elia TfouniFFCLRP- Departamento de Química).

\subsubsection{Difração de Raios-X}

Por meio de Difração de raios-X (DRX), (difratômetro Bruker-AXS D5005 FFCLRPDepartamento de Química), tendo como fonte tubo selado de $\mathrm{Cu}(2,2 \mathrm{~kW})$ com um filtro monocromador de níquel cuja radiação gerada possui $\lambda=1,54 \AA$, analisou-se a cristalinidade do carbonato de cálcio formado nas superfícies. Utilizando-se esta técnica também se determinou o tamanho dos cristalitos seguindo-se a equação de Scherrer $^{129}$ na qual se faz a comparação entre a largura do pico de difração de um material referência, neste caso $\mathrm{KCl}$, e a largura do pico de difração na amostra de interesse. 


$$
\mathrm{D}=0,9 \lambda / \mathrm{B} \cos \theta
$$

Sendo que: $\boldsymbol{\lambda}$ é o comprimento de onda da radiação (1,54 $\mathrm{A}), \boldsymbol{\theta} \square$ é o ângulo de Bragg determinado pelo pico da amostra e $\mathbf{B}$ é a diferença dos quadrados das larguras à meia altura dos picos da amostra e do padrão.

$$
\mathrm{B}=\mathrm{B}^{2}{ }_{\mathrm{am}}-\mathrm{B}^{2}{ }_{\mathrm{pd}}
$$

\subsubsection{Hidrofilicidade dos filmes}

A hidrofilicidade dos filmes foi avaliada por meio de medidas de ângulo de contato estático e dinâmico, utilizando-se equipamento OCA-20 Dataphysics- Alemanha. Este equipamento consiste de uma câmera CCD que coleta imagens da gota depositada sobre a superfície de interesse. Essas imagens são tratadas por um software que automaticamente extrai a tangente e o ângulo formado entre a gota e a superfície, em intervalos de tempo prédeterminados.

\subsubsection{Proteção contra corrosão}

Os suportes metálicos de alumínio e aço inox $(20 \mathrm{~mm}$ x $20 \mathrm{~mm}$ x $1 \mathrm{~mm})$ foram submetidos a medidas de corrente $(j)$ vs potencial (V) para verificação de mudanças nas propriedades eletroquímicas dos mesmos devido à presença do filme híbrido $(\mathrm{DMPA})_{4} /(\mathrm{Qt} / \mathrm{PAA})_{2} / \mathrm{CaCO}_{3}$ sobre a superfície. As medidas foram realizadas utilizando uma fonte/medidor de corrente/voltagem Keithley 2410-C acoplado com um eletrodo de calomelano 
Parte Experimental

saturado, utilizado como referência com os suportes imersos em solução de $\mathrm{NaCl} 3 \%$ (p/v). A varredura foi realizada de 0 a $3 \mathrm{~V}$ com taxa de varredura de $0,1 \mathrm{~V} \mathrm{~s}^{-1}$ (laboratório BIOMAGDepartamento de Física- FFCLRP).

\subsubsection{Análises Morfológicas}

A morfologia dos filmes foi avaliada por microscopia ótica (MO) [Olympus B-max] e microscopia eletrônica de varredura (MEV) [Zeiss-digital scanning probe microscpe- EVO 50DQ /FFCLRP / USP, Zeiss-digital scanning probe microscope- DSM 960- Instituto de Física de São Carlos-USP e JEOL 6300 FEG-SEM- School of Chemistry-Bristol-UK]. Antes das análises as amostras foram recobertas com um filme de $25 \mathrm{~nm}$ de ouro utilizando-se evaporadora Bal-Tec SCD-050 Sputter Coater.

Também utilizou-se microscopia de força atômica (Shimadzu, Japão, modelo SPM 9600, DQ/ FFCLRP / USP) para verificação da rugosidade dos suportes antes e após o processo de polimento dos mesmo.

Para os cilindros de $\mathrm{CaCO}_{3}$ preparados em meio confinado tridimensional foram realizadas análises por microscopia eletrônica de transmissão tal como obtenção dos padrões de difração de elétrons utilizando-se equipamento JEOL 3010 operando a 100 KV- School of Chemistry, Bristol, UK. Para indexação dos padrões de difração foi utilizado o programa JEMS (electron microscopy software versão 3.8806- LNLS). 


\subsubsection{Espalhamento Raman}

Os diferentes polimorfos de $\mathrm{CaCO}_{3}$, calcita e vaterita, apresentam modos vibracionais diferenciados e podem ser identificados por meio de espectros Raman, com o uso de padrões apropriados. Os espectros Raman dos suportes contendo a matriz orgânica e $\mathrm{CaCO}_{3}$ foram obtidos em espectrômetro Raman Renishaw- EPSRC JREI (School of Chemistry, University of Bristol-UK). Este equipamento possui lasers com comprimentos de onda em três diferentes regiões do espectro eletromagnético: visível (verde: $514 \mathrm{~nm}$ ), ultravioleta $(325 \mathrm{~nm}$ ) e infravermelho (785 nm), mostrado na Figura 17. Na obtenção de todos os espectros utilizou-se o laser de $514 \mathrm{~nm}$ como radiação incidente.

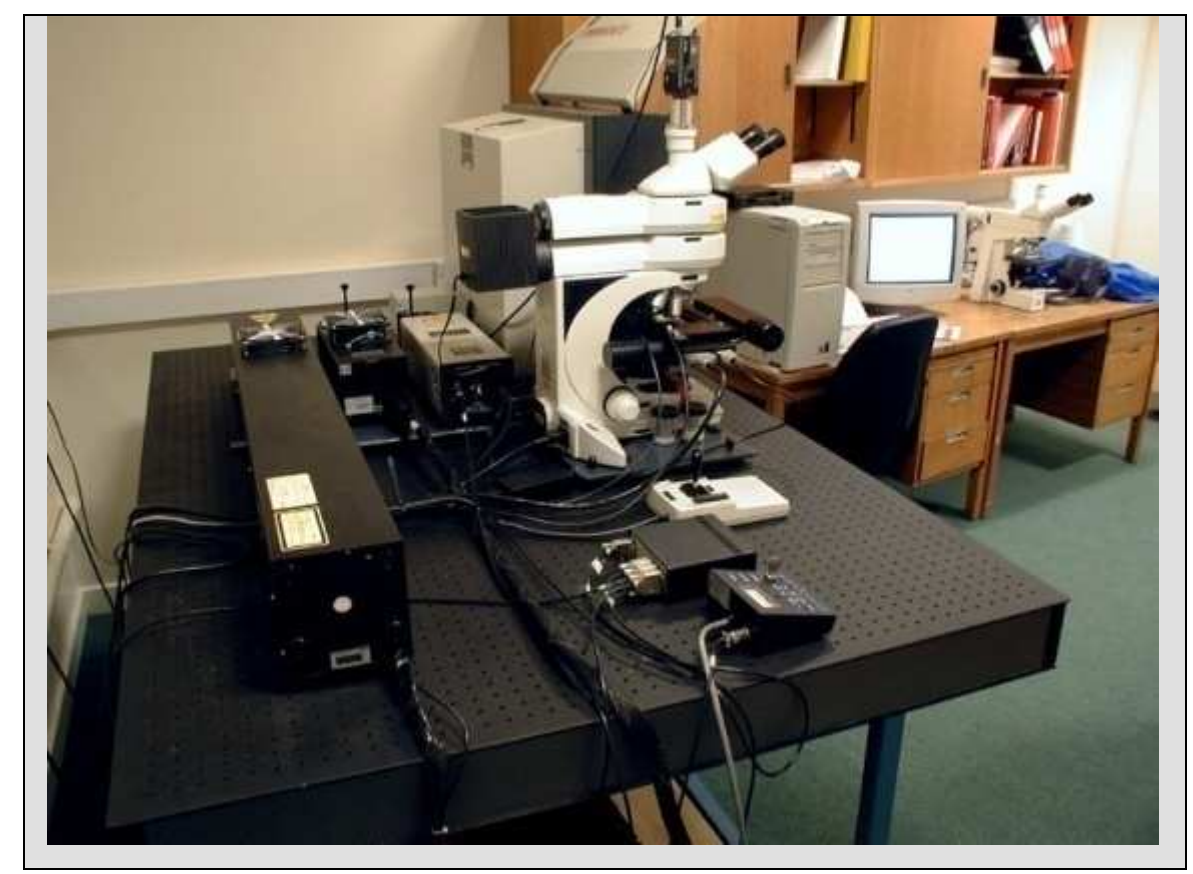




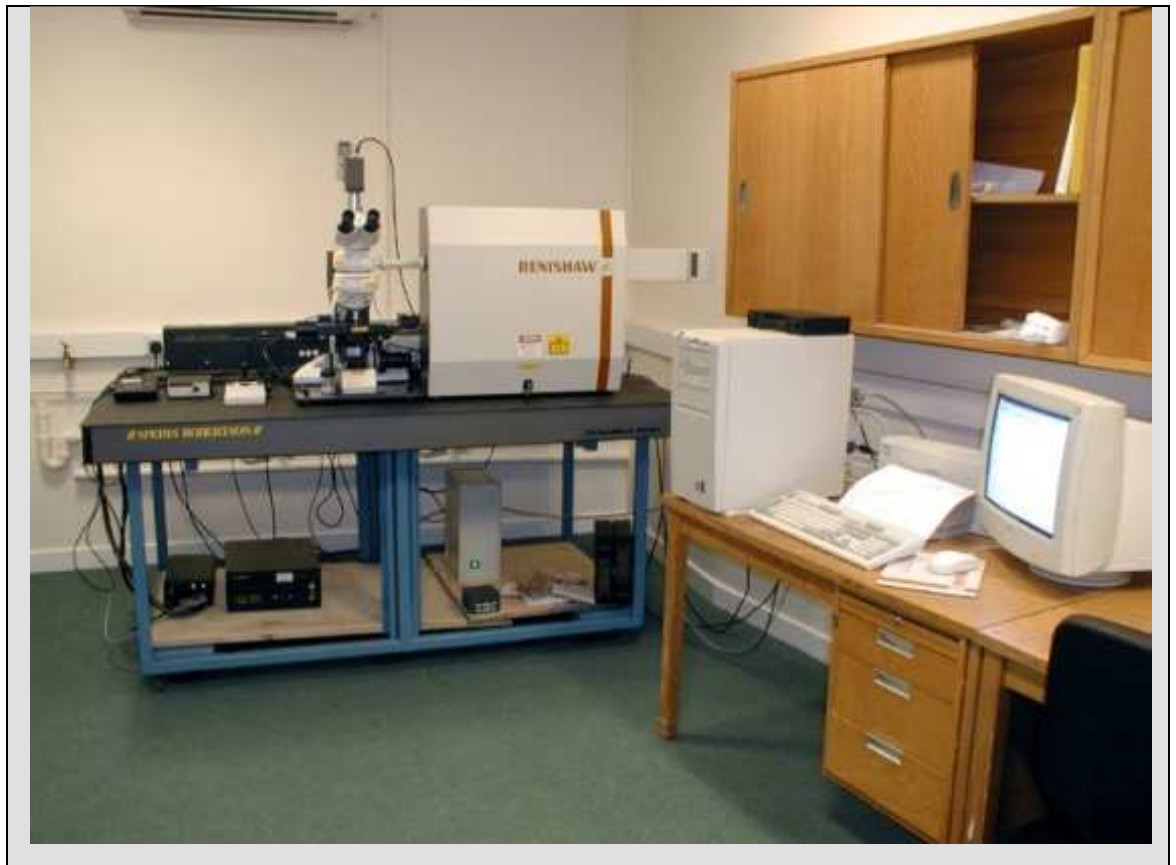

Figura 17: Equipamento Raman instalado na Universidade de Bristol- School of Chemist 


\section{Resultados e Discussão}

\subsection{Condicionamento das superfícies metálicas}

Foram realizados diferentes testes para o condicionamento das superfícies. Estes testes estão resumidos na Tabela 1. Todas as soluções foram preparadas e todos os enxágües foram realizados com água ultra-pura Milli- $\mathrm{Q}^{\mathrm{R}}$. Antes de todos os pré-tratamentos, as placas metálicas de dimensões variadas foram lixadas e polidas com lixas 600, 1500 e 2000, respectivamente.

Tabela 1: Pré-tratamentos realizados em superfícies metálicas

\begin{tabular}{|c|c|c|c|}
\hline Pré-Tratamento & Solução & $\mathrm{T}\left({ }^{\circ} \mathrm{C}\right)$ & Tempo* (s) \\
\hline \multirow{4}{*}{1.} & $\begin{array}{c}\text { 1.a) } \mathrm{NaOH}+ \\
\mathrm{Na}_{3} \mathrm{PO}_{4} \cdot 10 \mathrm{H}_{2} \mathrm{O}+\mathrm{Na}_{2} \mathrm{CO}_{3} \\
(10 \mathrm{~g} / \mathrm{L})\end{array}$ & 50 & 180 \\
\hline & 1.b) $\mathrm{NaOH}(5 \% \mathrm{p} / \mathrm{v})$ & 50 & 180 \\
\hline & 1.c) $\mathrm{HNO}_{3}(12 \% \mathrm{p} / \mathrm{v})$ & 25 & 30 \\
\hline & 1.d) Enxágüe com $\mathrm{H}_{2} \mathrm{O}$ & 25 & 300 \\
\hline \multirow{3}{*}{2.} & 2.a) $\mathrm{NaOH}(2,5 \% \mathrm{p} / \mathrm{v})$ & 50 & 120 \\
\hline & 2.b) $\mathrm{HNO}_{3}(12 \% \mathrm{p} / \mathrm{v})$ & 25 & 30 \\
\hline & 2.c) Enxágüe com $\mathrm{H}_{2} \mathrm{O}$ & 25 & 300 \\
\hline \multirow{4}{*}{3.} & 3.a) acetona & 25 & 300 \\
\hline & 3.b) $\mathrm{H}_{2} \mathrm{O}$ & 25 & 300 \\
\hline & 3.c)hexano & 25 & 300 \\
\hline & 3.d) $\mathrm{H}_{2} \mathrm{O}$ & 50 & 900 \\
\hline 4. & $\begin{array}{c}\text { Solução tampão pH 7,5 } \\
\mathrm{KH}_{2} \mathrm{PO}_{4}+\mathrm{NaOH}(0,1 \\
\left.\text { mol.L }{ }^{-1}\right)+\operatorname{Span} 20^{* *}\left(4 \times 10^{-}\right. \\
{ }^{5}{\left.\mathrm{~mol} . \mathrm{L}^{-1}\right)}^{-}\end{array}$ & 65 & 300 \\
\hline
\end{tabular}

*tempo de permanência em ultra-som na temperatura indicada

** $\operatorname{span} 20=$ laurato de sorbitano 


\section{$\underline{\text { Resultados e Discussão }}$}

Utilizando-se os pré-tratamentos 1 e 2, não foram obtidos resultados satisfatórios, uma vez que com o passar do tempo os suportes de alumínio ficaram escuros devido à oxidação da superfície. Já, o pré-tratamento 3 aumentou consideravelmente a hidrofobicidade da superfície $\left(\theta=110^{\circ}\right)$ o que seria desvantajoso para a adsorção dos polieletrólitos a partir de soluções aquosas. O pré-tratamento 4 foi utilizado baseado no procedimento descrito em um manual de limpeza alcalina da empresa OSMINICS ${ }^{\circledR}$ (MN-USA- www.osmonics.com). Estas soluções são formadas por hidróxidos, tensoativos e podem, ou não, conter aditivos como EDTA. O papel do hidróxido seria a "limpeza química" reagindo com compostos oleosos e formando sabões solúveis em água que são facilmente removidos. Por sua vez, ao tensoativo cabe a "limpeza física", pois age como agente emulsificante envolvendo gotículas de gordura para que possam ser removidas da superfície, podendo também atuar como agentes de passivação da superfície. Aos aditivos cabe a remoção de íons através da formação de complexos.

A solução por nós formulada (item 4, tabela 1) envolveu o uso de um tampão (pH 7,5) de $\mathrm{KH}_{2} \mathrm{PO}_{4}$ e NaOH e um tensoativo não-iônico Span 20 (c.m.c.= $1 \times 10^{-5} \mathrm{~mol} \mathrm{~L}^{-1}$ ) em concentração $4 \times 10^{-5} \mathrm{~mol} \mathrm{~L}{ }^{-1}$. A superfície de alumínio tratada com esta solução por 5 minutos a $65^{\circ} \mathrm{C}$ em ultrasom apresentou ângulo de contato $\theta=80^{\circ}$. Portanto, para padronização de condicionamento dos suportes sólidos, foi utilizada, antes da deposição dos filmes orgânicos, a solução 4 como prétratamento. As superfícies de silício utilizadas neste trabalho foram também limpas com esta solução, apesar de não terem sido lixadas. A Figura 18 mostra como a rugosidade das superfícies muda após o tratamento de polimento e limpeza. Também podemos comparar as diferenças nas rugosidades superficiais dos suportes de Alumínio, Aço e Silício. Comparativamente, a amostra de alumínio se mostrou a mais rugosa, com rugosidade média de aproximadamente $1 \mu \mathrm{m}$. Já o aço inox 316L apresentou rugosidade média de aproximadamente 0,75 $\mu \mathrm{m}$. A amostra de silício, 
por ser muito lisa, dificultou a aquisição das imagens de AFM, porém ainda conseguiu-se obter o valor de rugosidade média como sendo menor que $0,4 \mu \mathrm{m}$.

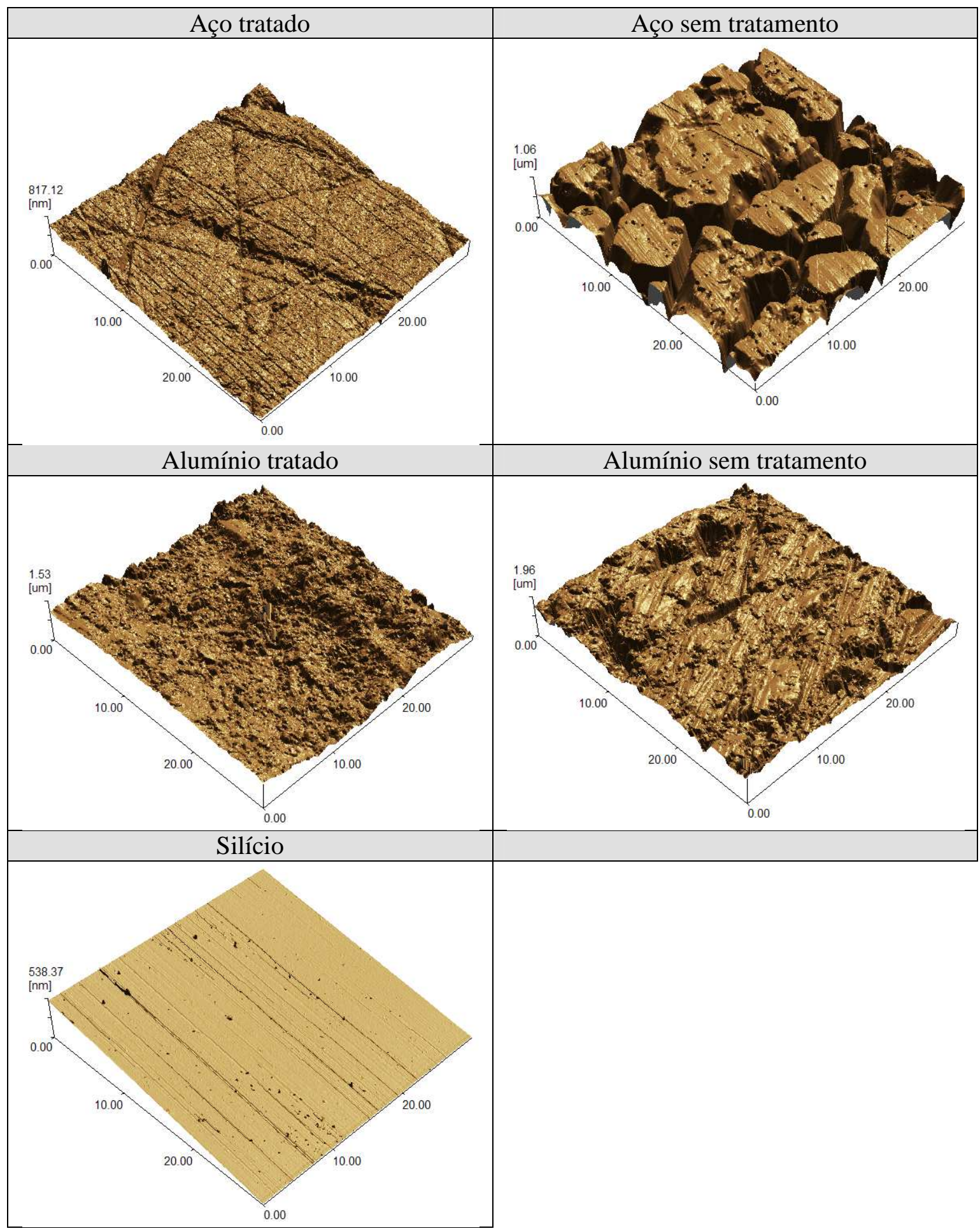

Figura 18: Imagens de AFM das superfícies dos metais e silício antes e após o tratamento de polimento e limpeza. 
Resultados e Discussão

\subsection{Formação das matrizes orgânicas de PAA e crescimento de $\mathrm{CaCO}_{3}$ sobre filmes de LbL de PAA, NaPA e $\lambda$-car}

\subsubsection{Espectroscopia eletrônica na região UV-vis: análise da deposição dos filmes} $L b L$

As medidas de reflectância difusa dos filmes de PAA/Qt mostram uma relação linear com o número de camadas depositadas sobre suportes de alumínio (Figura 19). Este resultado demonstra que para o filme LbL, a quantidade do poliânion mantém-se constante por camada desde 13 até pelo menos 19 camadas depositadas.

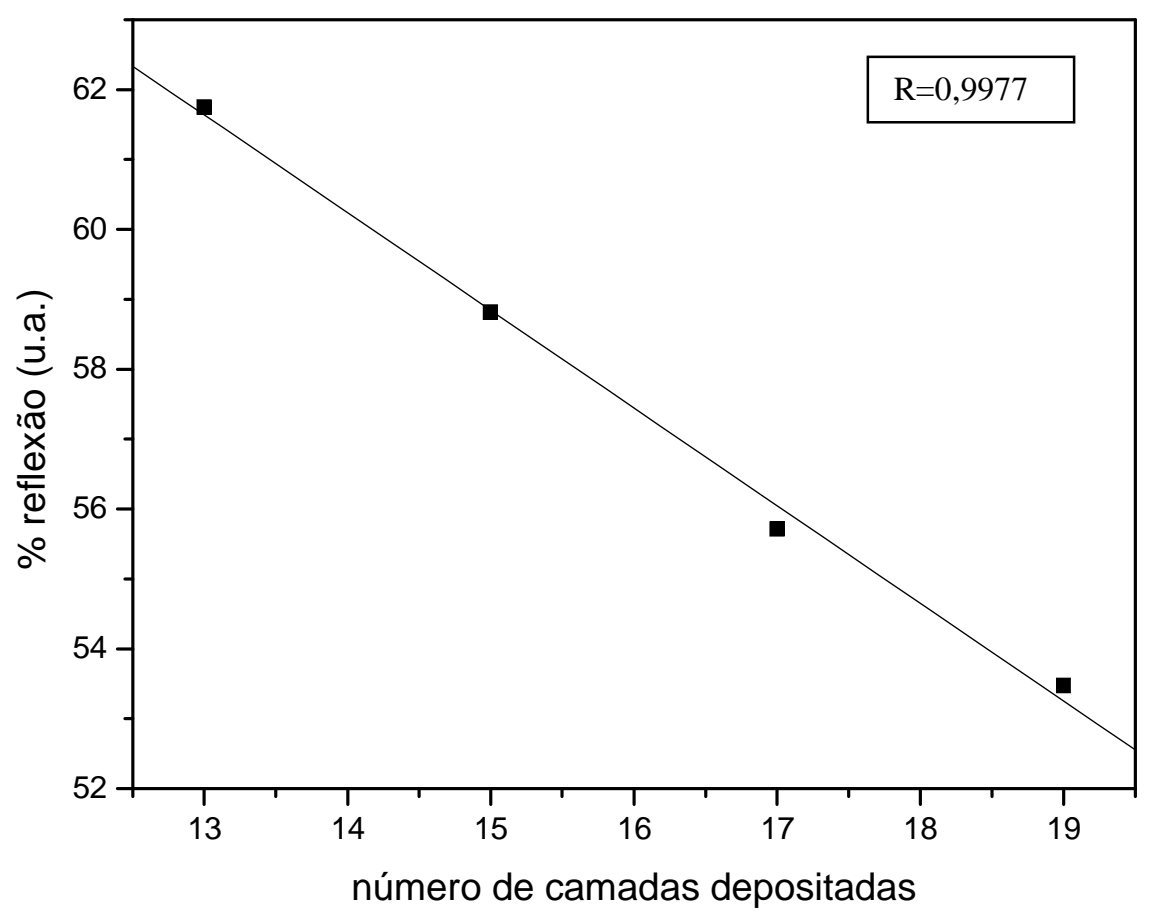

Figura 19: Variação da quantidade de luz refletida em função do número de camadas de PAA e Qt depositadas. 
Resultados e Discussão

\subsubsection{Espalhamento de raio-X a baixo ângulo (SAXS): Efeito do ordenamento da matriz orgânica de filmes $L b L$ e $L B / L b L$ depositados sobre alumínio}

A técnica de espalhamento de raios-X a baixos ângulos foi usada para verificar o ordenamento da matriz orgânica que forma o meio confinado planar preparado a partir de filmes finos $\mathrm{LbL}$ ou $\mathrm{LB} / \mathrm{LbL}$. Os resultados obtidos foram transformados em curvas de espalhamento e são apresentados na Figura 20. As franjas de Kiessig ${ }^{130}$, geralmente observadas para filmes multicamadas de polieletrólitos, não puderam ser observadas nas curvas de SAXS mostrados na Figura 20, pois, a faixa de ângulos onde estas franjas são observadas estaria abaixo de $2^{\circ}$, portanto fora da faixa de ângulos usadas neste estudo. Por outro lado, as curvas de SAXS (Figura 20) mostram três picos de Bragg distintos para todos os sistemas estudados: filmes LbL de $\lambda$ carragenana e quitosana na presença ou ausência do pré-recobrimento LB de DMPE e com ou sem deposição de $\mathrm{CaCO}_{3}$. Estes picos de Bragg só podem ser observados em sistemas que apresentam periodicidade precisa, no caso dos filmes esta periodicidade está relacionada com a espessura constante entre cada bicamada depositada. O valor da distância intercamada (d) calculada a partir dos máximos dos picos através da equação de Bragg é aproximadamente 56 A. A partir das intensidades relativas entre os picos também é possível inferir que os filmes LbL depositados sobre filmes LB de (DMPA) $)_{3}$ DMPE são muito mais organizados do que os filmes depositados diretamente sobre os suportes metálicos pois, a intensidade dos picos nos filmes contendo o filme LB, diminui gradativamente em função do vetor de espalhamento (Q) como é de se esperar para perfis de SAXS de sistemas organizados. Esse resultado comprova que a presença do filme LB como "pré-recobrimento" direciona a deposição das multicamadas de polieletrólitos subseqüentes. Além disso, quando $\mathrm{CaCO}_{3}$ é depositado sobre os suportes metálicos modificados com filmes mistos LB/LbL, são observadas mudanças na refletividade das amostras, alargamento dos picos e mudança na intensidade relativa dos mesmos. Entretanto, as amostras 
$\underline{\text { Resultados e Discussão }}$

obtidas pela deposição de $\mathrm{CaCO}_{3}$ sobre os suportes modificados apenas com o filme LbL (sem o pré-recobrimento com o filme $\mathrm{LB}$ ) e aquelas obtidas sobre filmes $\mathrm{LB} / \mathrm{LbL}$ em tempos mais curtos (2 min), forneceram curvas de espalhamento que se assemelham às curvas obtidas para os suportes modificados apenas com a matriz orgânica. Esses resultados foram interpretados da seguinte forma: carbonato de cálcio depositado em tempos curtos não interage suficientemente com a matriz orgânica a ponto de modificá-la, ou seja, a ordem das camadas internas do filme LbL não é perturbada. $\mathrm{O}$ mesmo parece ocorrer com o crescimento de $\mathrm{CaCO}_{3}$ sobre filmes $\mathrm{LbL}$, aparentemente menos organizados. No caso de meio confinado mais organizado, resultante da deposição de filmes $\mathrm{Lb} / \mathrm{LbL}$, a deposição de $\mathrm{CaCO}_{3}$ causa uma maior alteração, podendo propiciar uma maior interação entre as partes orgânica e inorgânica do filme.

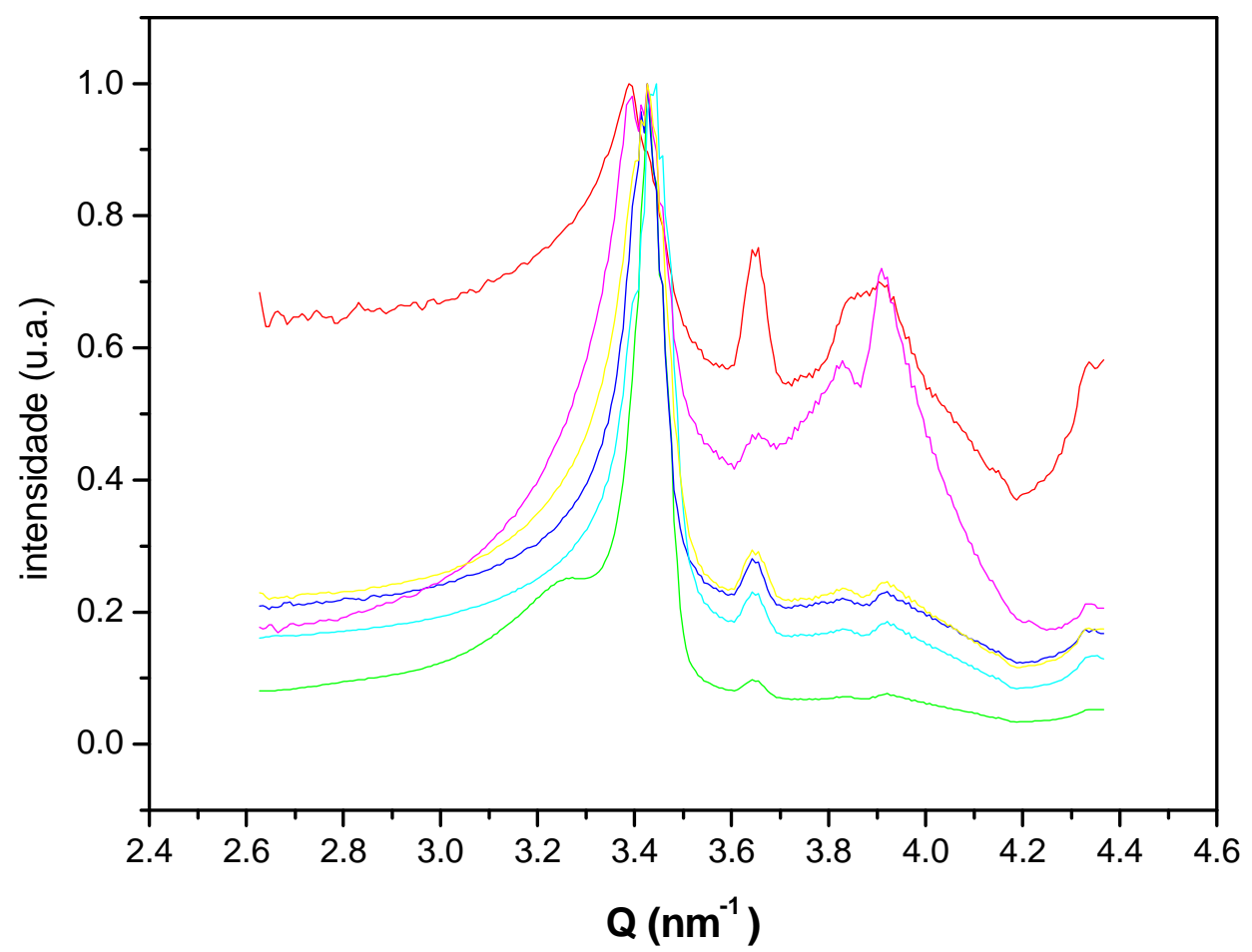

Figura 20: Curvas de intensidade de luz espalhada vs vetor de espalhamento (Q): Filme misto LB-(DMPA) $)_{3} \mathrm{DMPE} / \mathrm{LbL}-(\mathrm{Qt} / \lambda \text {-car })_{6}(\lambda$-car $)+\mathrm{CaCO}_{3}$ (linha vermelha), Filme $\mathrm{LbL}-(\mathrm{Qt} / \lambda$ - 
Resultados e Discussão

car $)_{6}(\lambda$-car $)+\mathrm{CaCO}_{3}$ (linha verde), Filme $\mathrm{LbL}-(\mathrm{Qt} / \lambda \text {-car })_{6}(\lambda$-car) (linha azul escuro), Filme misto LB-(DMPA) $)_{3} \mathrm{DMPE} / \mathrm{LbL}-(\mathrm{Q} t / \lambda \text {-car })_{6}(\lambda$-car) (linha azul claro), Filme misto LB$(\mathrm{DMPA})_{3} \mathrm{DMPE} / \mathrm{LbL}-(\mathrm{Qt} / \mathrm{PAA})_{6}(\mathrm{PAA})+\mathrm{CaCO}_{3}$ (linha rosa), Filme misto LB$(\mathrm{DMPA})_{3} \mathrm{DMPE} / \mathrm{LbL}-(\mathrm{Qt} / \lambda \text {-car })_{6}(\lambda$-car $)+\mathrm{CaCO}_{3}$ depositado em tempo curto (linha amarela).

Para o PAA, os cálculos a partir da teoria de Debye e das equações propostas por Gouy (ver item 1.4.3 da introdução), a espessura da camada de contra-íons ( $\lambda$, equação 9) e o comprimento de blindagem de Debye ( $K$, equação 4) apresentam valores da ordem de 400 nm. Já, a distância do polieletrólito à superfície carregada é aproximadamente $6 \mathrm{~nm}$, indicando que os contra-íons que blindariam a carga de cada camada devem ser facilmente deslocados favorecendo a ligação do polieletrólito. Para $\lambda$-car, devido à sua alta densidade de carga, a distância do polieletrólito à superfície do metal é aproximadamente $0,2 \mathrm{~nm}$. Ainda, segundo estas teorias, a espessura ( $\delta$, equação 12$)$ de cada camada é aproximadamente 18 e 9 nm para PAA e $\lambda$-car, respectivamente. Este resultado está de acordo com o comportamento dos dois polieletrólitos em solução. A $\lambda$-car por ser um polieletrólito forte e possuir todos os grupos éster sulfato ionizados, apresenta suas cadeias mais esticadas devido à repulsão entre os mesmos, e portanto uma espessura de camadas menor comparada ao PAA, que no pH 3,7 de estudo, possui fração de cargas $(f)$ 0,01, ou seja, 1 carga negativa a cada 100 unidades repetitivas. Apesar dos valores obtidos a partir da teoria discordarem dos valores absolutos obtidos pelas medidas de espalhamento de raios-X, as tendências podem ser satisfatoriamente explicadas. Há que se levar em consideração as simplificações da teoria, que assume por exemplo que não haja interações intramoleculares para as moléculas do polieletrólito, o que de fato não é obedecido para as moléculas no filme. 


\subsubsection{Massa depositada por camada}

A quantidade de polieletrólito adsorvida por bi-camada (poliânion/quitosana) foi quantificada por meio da técnica de QCM. Esta técnica permite a determinação da massa de uma única bicamada. A Figura 21 mostra a variação da massa adsorvida em função do número de bicamadas depositadas para o filme LbL de PAA/Qt. Podemos observar que a massa passa a variar linearmente aproximadamente a partir da sexta camada depositada ( $3^{\mathrm{a}}$ bicamada). Este resultado já era esperado uma vez que as primeiras camadas são normalmente mais finas, contendo menos material adsorvido devido a um menor número de cargas no substrato em relação às cadeias do polieletrólito. Após algumas camadas um regime estacionário é alcançado e as propriedades dos filmes são independentes do suporte utilizado ${ }^{115}$. 


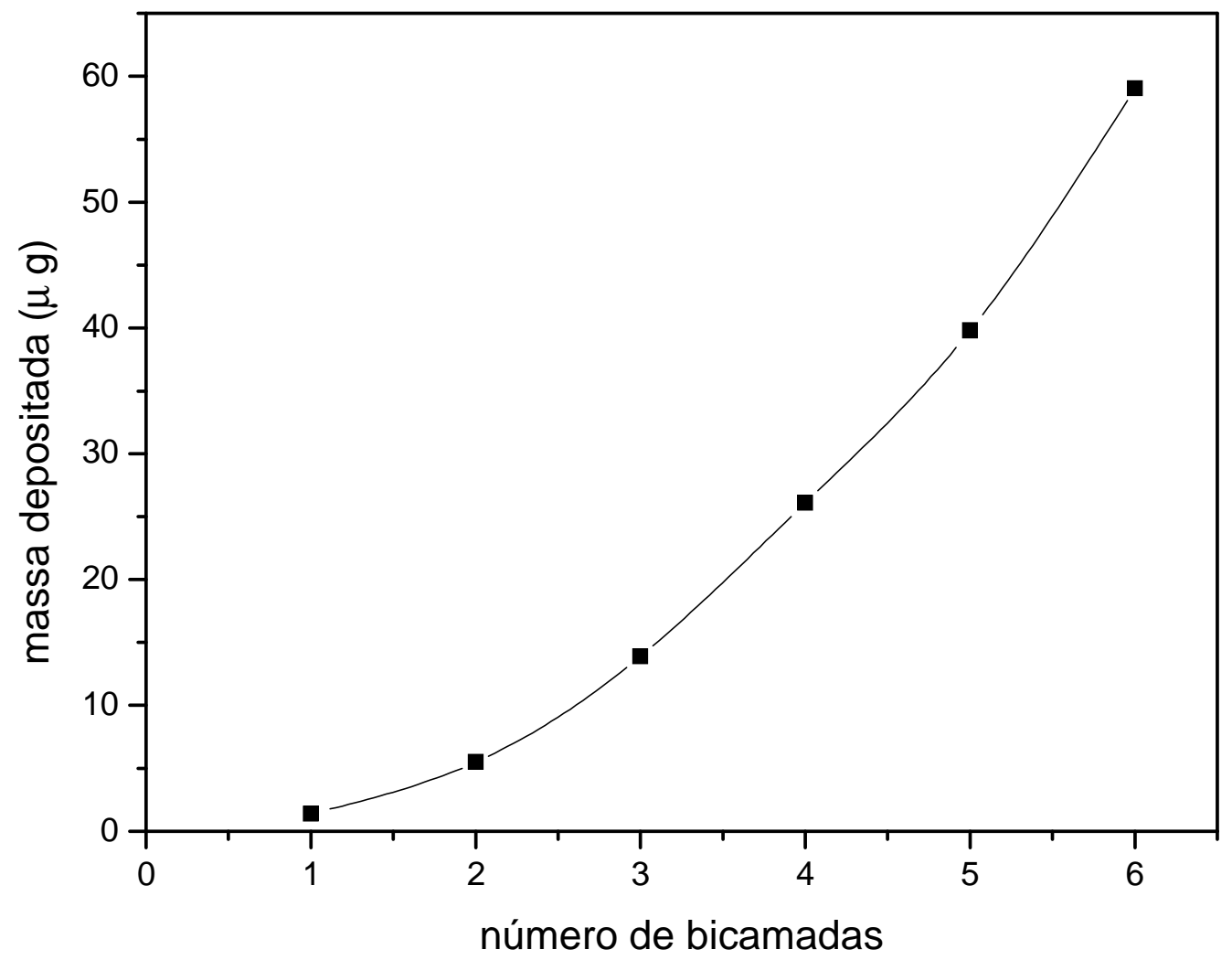

Figura 21: Variação da massa adsorvida em função do número de bicamadas de (PAA/Qt) depositadas.

Já para os filmes NaPA/ Qt podemos notar (Tabela 2) que grande quantidade do poliânion adsorve sobre a quitosana, porém, grande parte das cadeias ligadas são dessorvidas quando o filme é imerso novamente na solução de quitosana. A dessorção do poliânion chegou até, aproximadamente, $1,16 \mu \mathrm{g}$ da terceira para a quarta camada, ou seja, em torno de $70 \%$. Este resultado pode estar relacionado com a conformação do NaPA, que deve estar com suas cadeias completamente esticadas não permitindo a sobre-compensação de cargas, impedindo a deposição da camada seguinte de policátion ou até mesmo soltando-se do suporte sólido e dissolvendo-se novamente na solução de quitosana. Outra explicação para a dessorção de NaPA pode contemplar o tipo de interação entre os dois polieletrólitos. Há que se considerar que a densidade de cargas 
$\underline{\text { Resultados e Discussão }}$

da quitosana é baixa e uma outra forma que esse polieletrólito poderia interagir seria por meio de ligações de hidrogênio. Essas são possíveis com PAA, que está parcialmente ionizado, mas inexistentes com o sal correspondente, NaPA.

Tabela 2: Freqüências e massas de polieletrólitos (NaPA, Qt) adsorvidos

\begin{tabular}{|c|c|c|c|c|}
\hline Camada & Polieletrólito & $\begin{array}{c}\text { Freqüência (f) } \\
(\mathrm{MHz})\end{array}$ & $\mathrm{f}_{0} *-\mathrm{f}(\mathrm{Hz})$ & $\Delta \mathrm{m}(\mu \mathrm{g})$ \\
\hline 1 & $\mathrm{NaPA}$ & 9,994935 & 246 & 0,359 \\
\hline 2 & $\mathrm{Qt}$ & 9,995005 & 176 & $-0,257$ \\
\hline 3 & $\mathrm{NaPA}$ & 9,994023 & 1135 & 1,66 \\
\hline 4 & $\mathrm{Qt}$ & 9,994819 & 339 & $-0,495$ \\
\hline 5 & $\mathrm{NaPA}$ & 9,993890 & 1268 & 1,85 \\
\hline 6 & $\mathrm{Qt}$ & 9,994162 & 996 & $-1,46$ \\
\hline 7 & $\mathrm{NaPA}$ & 9,993674 & 1484 & 2,17 \\
\hline
\end{tabular}

$* \mathrm{f}_{0}=9995181$

Seguindo esta caracterização da matriz polimérica, tentou-se quantificar o $\mathrm{CaCO}_{3}$ depositado sobre os filmes LbL PAA/Qt. Para essa quantificação fez-se o enxágüe da última camada de PAA depositado com $\mathrm{CaCl}_{2} 0,1 \mathrm{~mol} \mathrm{~L}^{-1}$ na tentativa de aumentar-se a quantidade de $\mathrm{Ca}^{2+}$ ligado ao poliânion através da troca dos íons $\mathrm{H}^{+}$ligados a ele. A troca dos íons $\mathrm{H}^{+}$foi eficiente como mostram os resultados da análise por infravermelho que serão mostrados na próxima seção.

A formação de $\mathrm{CaCO}_{3}$ foi obtida nesse caso por meio da exposição do filme $\mathrm{LbL}$ a um fluxo de $\mathrm{CO}_{2}$ ao invés da exposição à $\left(\mathrm{NH}_{4}\right)_{2} \mathrm{CO}_{3}$ pois o contato metálico da QCM é composto por fios de cobre que reagem facilmente com $\mathrm{NH}_{3}$ interferindo na medida da massa. A Figura 22 mostra a variação de freqüência do cristal após 4 horas de exposição. A massa total depositada após 15 horas de exposição foi $18,5 \mu \mathrm{g}$. Teoricamente, a massa total de $\mathrm{CaCO}_{3}$ que poderia ter 
sido formada na superfície, levando-se em conta a massa de PAA depositada na última camada $(13,3 \mu \mathrm{g})$, que todos os grupos $\mathrm{COO}^{-}$do poli(ácido) tivessem como contra-íon $\mathrm{Ca}^{2+}$ e que cada $\mathrm{Ca}^{2+}$ formasse uma unidade de $\mathrm{CaCO}_{3}$, seria de aproximadamente $7,2 \mu \mathrm{g}$.

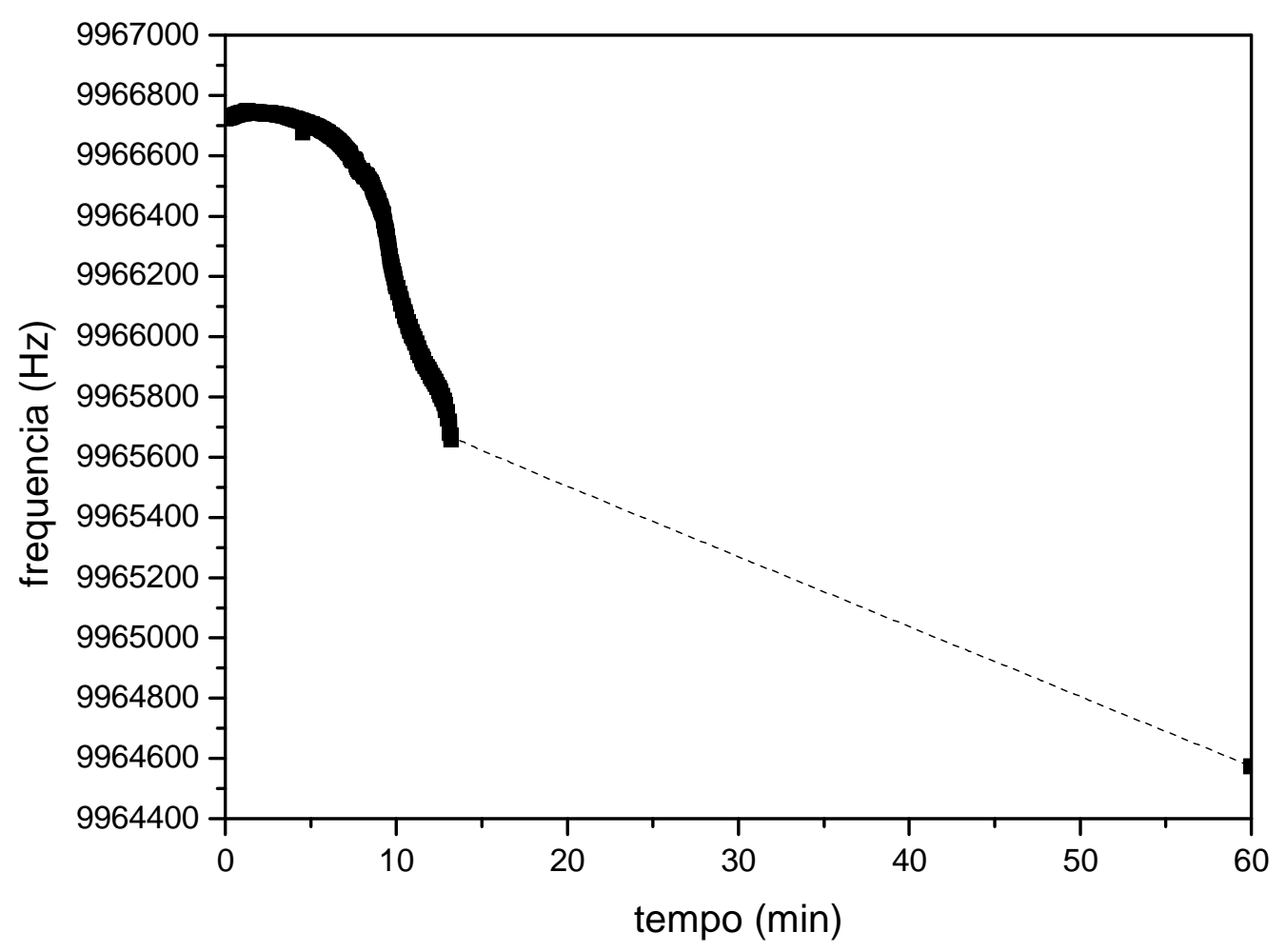

Figura 22: Variação de freqüência do cristal de quartzo contendo filme LbL PAA/Qt exposto à $\mathrm{CO}_{2}$.

Esta diferença entre o valor teórico e o valor obtido experimentalmente indica que o $\mathrm{CaCO}_{3}$ não deve estar sendo formado apenas a partir dos íons cálcio ligados ao poli(ácido), mas também a partir dos íons cálcio sem solução aprisionados na matriz polimérica do filme LbL uma vez que a estrutura de cada bicamada pode constituir-se por si só um gel ${ }^{118}$. Esta diferença de ambientes químicos dos íons cálcio poderia inclusive levar à formação de $\mathrm{CaCO}_{3}$ com distintas 


\section{$\underline{\text { Resultados e Discussão }}$}

estruturas cristalinas, fato que possivelmente ocorre, como mostram os resultados de difração de raios-X apresentados na seção 3.2.5.

\subsubsection{Análise dos grupos químicos presentes na superfície}

A formação de $\mathrm{CaCO}_{3}$ sobre a matriz polimérica, tal como a formação da própria matriz sobre os suportes metálicos foi confirmada por espectroscopia na região do infravermelho utilizando-se um acessório para reflexão total atenuada na superfície.

O aumento na intensidade relativa das bandas em 1420 e $1530 \mathrm{~cm}^{-1}$ (Figura 23) após a exposição do suporte metálico contendo o filme LbL PAA/Qt a $\left(\mathrm{NH}_{4}\right)_{2} \mathrm{CO}_{3}$, pode ser atribuída à formação de $\mathrm{CaCO}_{3}$. Deve-se analisar o aumento na intensidade relativa e não absoluta entre essas bandas, pois o PAA e a Qt apresentam bandas no mesmo número de onda atribuído ao carbonato usado como referência (Figura 24). A intensidade relativa entre essas bandas aumenta após a exposição do suporte metálico contendo o filme orgânico ao $\left(\mathrm{NH}_{4}\right)_{2} \mathrm{CO}_{3}$ e, pode-se observar além disso, que a intensidade relativa aumenta ainda mais quando o enxágüe na ultima camada é realizado com solução $0,1 \mathrm{~mol} \mathrm{~L}^{-1}$ de $\mathrm{CaCl}_{2}$ revelando ser maior a quantidade de carbonato de cálcio formado. Pode-se também constatar que a banda em $1700 \mathrm{~cm}^{-1}$ é sensível à concentração de íons cálcio na solução de enxágüe, sendo a mesma extinta quando a concentração é de $0,1 \mathrm{~mol} \mathrm{~L}^{-1}$. Esta banda pode ser atribuída a grupos -COOH e somente pode ser observada com o grupo protonado, portanto, podemos mostrar que em concentração de $\mathrm{Ca}^{2+}$ 0,1 mol. $\mathrm{L}^{-1}$ todos os grupos carboxilas estão desprotonados. 


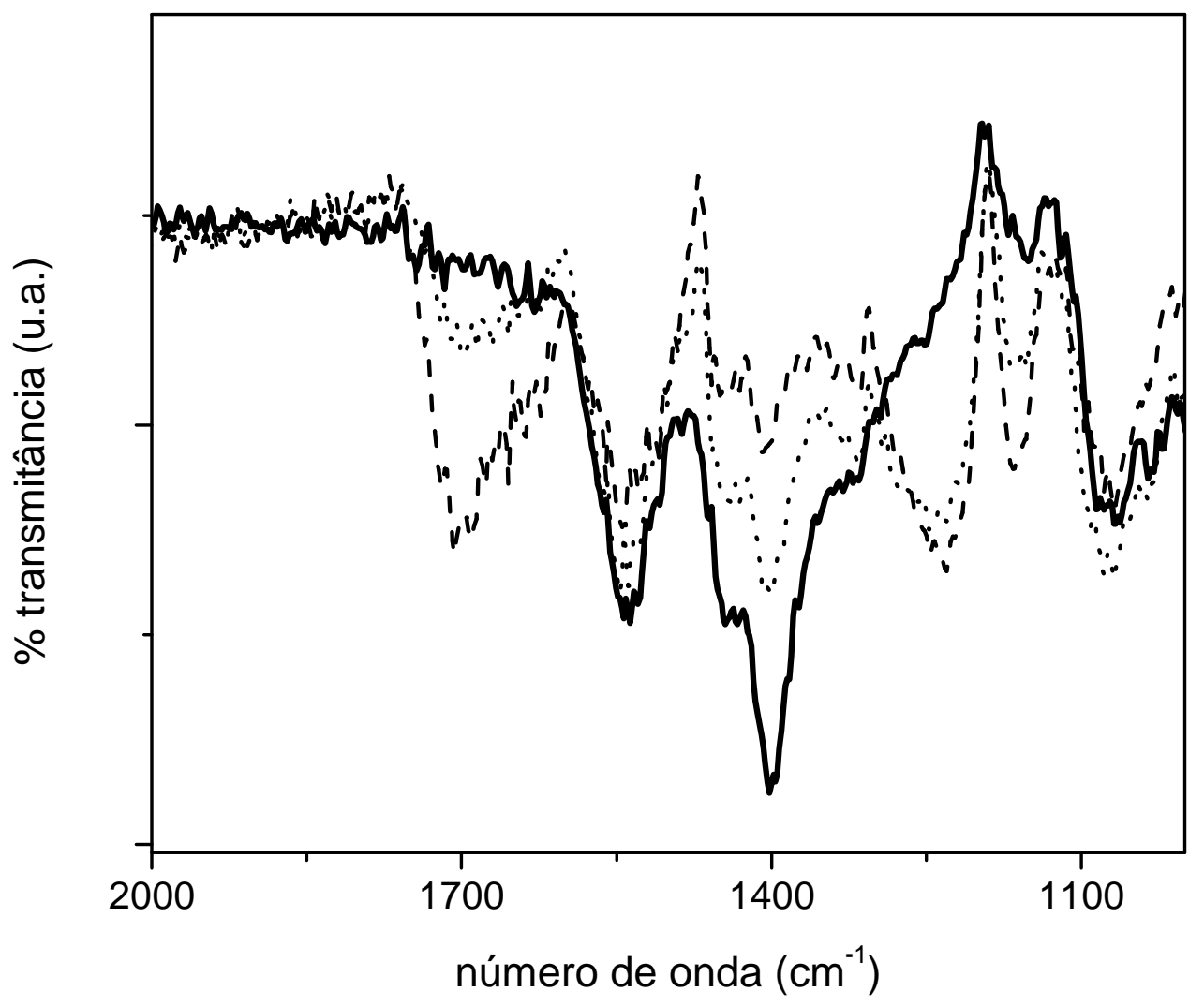

Figura 23: Espectro ATR-IR para suportes de alumínio contendo matriz polimérica $(\mathrm{PAA} / \mathrm{Qt})_{6} \mathrm{PAA}$ mudando-se a concentração de $\mathrm{Ca}^{2+}$ no enxágüe da ultima camada de PAA. Matriz polimérica sem enxágüe e sem exposição a $\left(\mathrm{NH}_{4}\right)_{2} \mathrm{CO}_{3}$ (linha tracejada); enxágüe com: $\mathrm{Ca}^{2+} 0,01 \mathrm{~mol} \mathrm{~L}{ }^{-1}$ com exposição à $\left(\mathrm{NH}_{4}\right)_{2} \mathrm{CO}_{3}$ por 13 horas (linha pontilhada), $\mathrm{Ca}^{2+} 0,1 \mathrm{~mol} \mathrm{~L}^{-1}$ com exposição à $\left(\mathrm{NH}_{4}\right)_{2} \mathrm{CO}_{3}$ por 13 horas (linha sólida). 


\section{Resultados e Discussão}

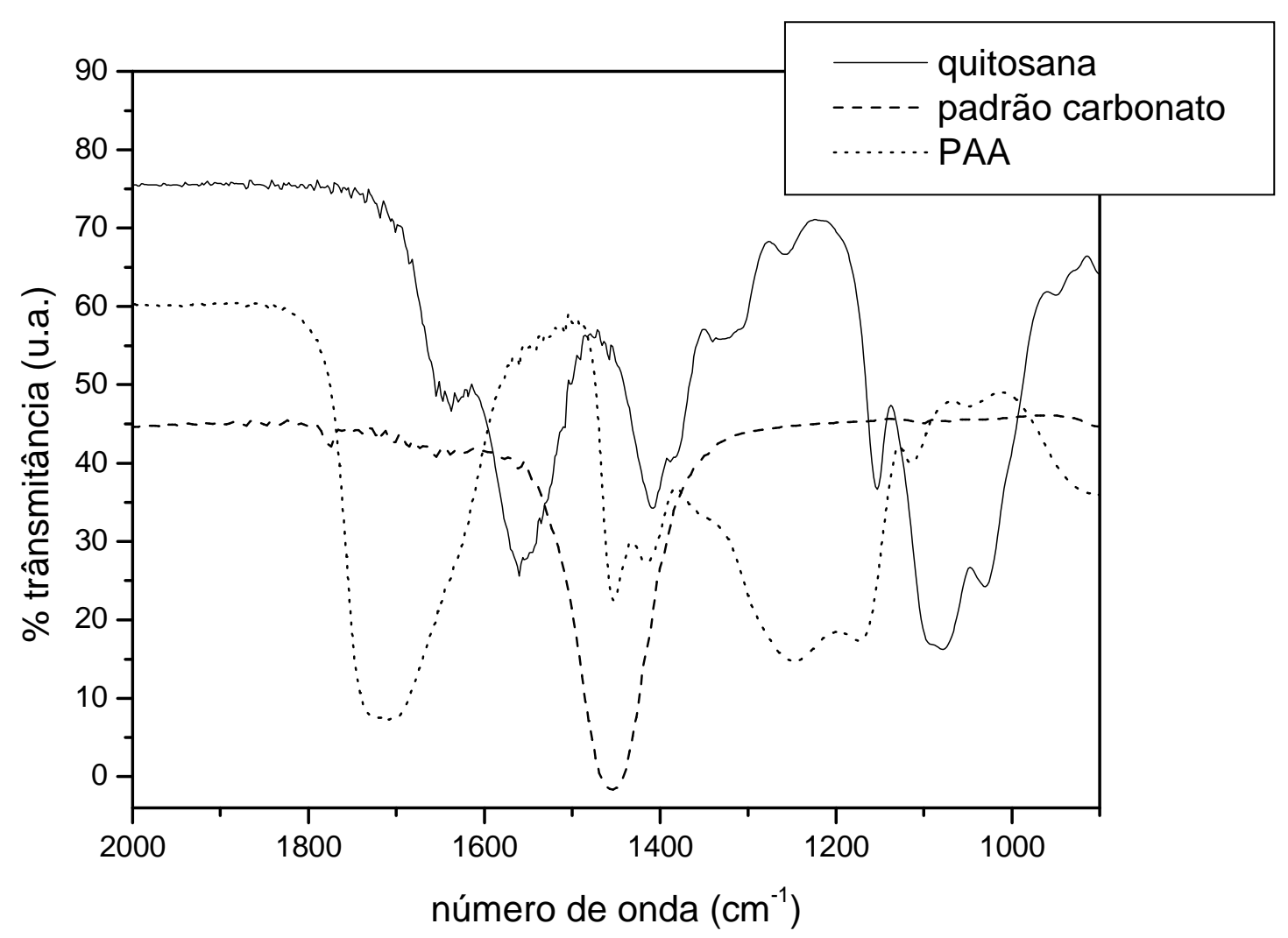

Figura 24: Espectros ATR-IR de padrões quitosana (linha sólida), carbonato (linha tracejada), poli(ácido acrílico) (linha pontilhada).

Foram obtidos espectros ATR-IR de filmes LbL formados por iota-carragenana (1-car) antes e após exposição a carbonato de amônio em recipiente fechado. A Figura 25 mostra os resultados obtidos. O aparecimento da banda em $1425 \mathrm{~cm}^{-1}$ pode ser atribuído à formação de $\mathrm{CaCO}_{3}$. Neste filmes não foi possível identificar bandas referentes à quitosana, pois o policátion estava presente no filme em pequena quantidade uma vez que foi depositada em apenas uma camada. Pequenos deslocamentos entre o padrão carbonato e a amostra contendo o filme híbrido 
podem ser atribuídos aos diferentes métodos utilizados na obtenção dos espectros, uma vez que para o padrão utilizou-se o método da pastilha de $\mathrm{KBr}$.

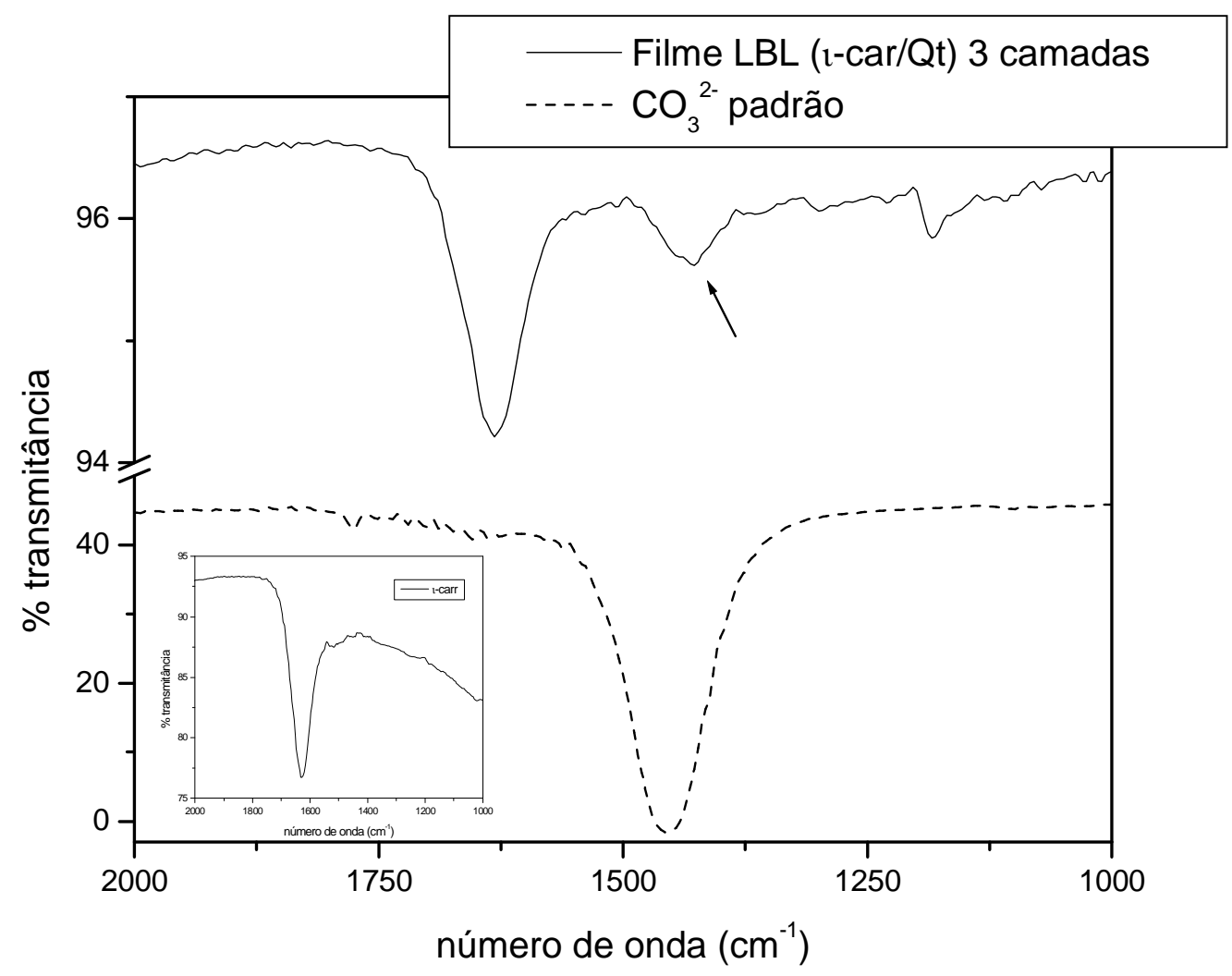

Figura 25: Espectros ATR-IR filme LbL l-carr/Qt em suporte de alumínio após exposição a $\left(\mathrm{NH}_{4}\right)_{2} \mathrm{CO}_{3}$ por 15 horas (linha sólida), padrão carbonato (linha tracejada). O encarte mostra espectro do filme $\mathrm{LbL}$ 1-carr/Qt sem exposição a $\left(\mathrm{NH}_{4}\right)_{2} \mathrm{CO}_{3}$. 
Resultados e Discussão

\subsubsection{Cristalinidade do $\mathrm{CaCO}_{3}$}

Os dados de difração de raios-X dos filmes híbridos (PAA/Qt) ${ }_{6} \mathrm{PAA} / \mathrm{CaCO}_{3}$ (Figura 26) depositados sobre suportes de alumínio exibem um grande número de picos de difração os quais podem ser atribuídos ao $\mathrm{CaCO}_{3}$ nas formas cristalinas calcita e vaterita e também ao suporte de alumínio. Os cristais de calcita exibem morfologia romboédrica, típica para esta forma cristalina, orientadas predominantemente na direção cristalográfica <104> como mostra o pico intenso em $2 \theta=29,4^{\circ}$. Os dados de difração também exibem picos que, muito provavelmente, podem ser atribuídos ao $\mathrm{CaCO}_{3}$ na forma cristalina vaterita. Os picos referentes a esta forma cristalina estão deslocados alguns décimos de graus com relação ao padrão. Por exemplo, enquanto o padrão exibe o pico referente ao conjunto de planos (114) da vaterita em $2 \theta=32,8^{\circ}$ os dados experimentais de difração exibem o pico referente a estes planos em $2 \theta=32,6^{\circ}$. Os outros picos referentes à forma vaterita (marcados com um asterisco nos dados de difração) e seus respectivos deslocamentos com relação ao padrão estão resumidos na Tabela 3 . Os picos intensos em $2 \theta=$ $38,4^{\circ} ; 44,8^{\circ}$ e $65,2^{\circ}$ são atribuídos ao suporte de alumínio. A formação desses dois tipos de formas cristalina corrobora com a possibilidade de formação de $\mathrm{CaCO}_{3}$ a partir de íons cálcio em dois ambientes químicos distintos: ligados ao poliânion como contra-íon e presentes na solução de $\mathrm{CaCl}_{2}$ aprisionada na matriz polimérica. 


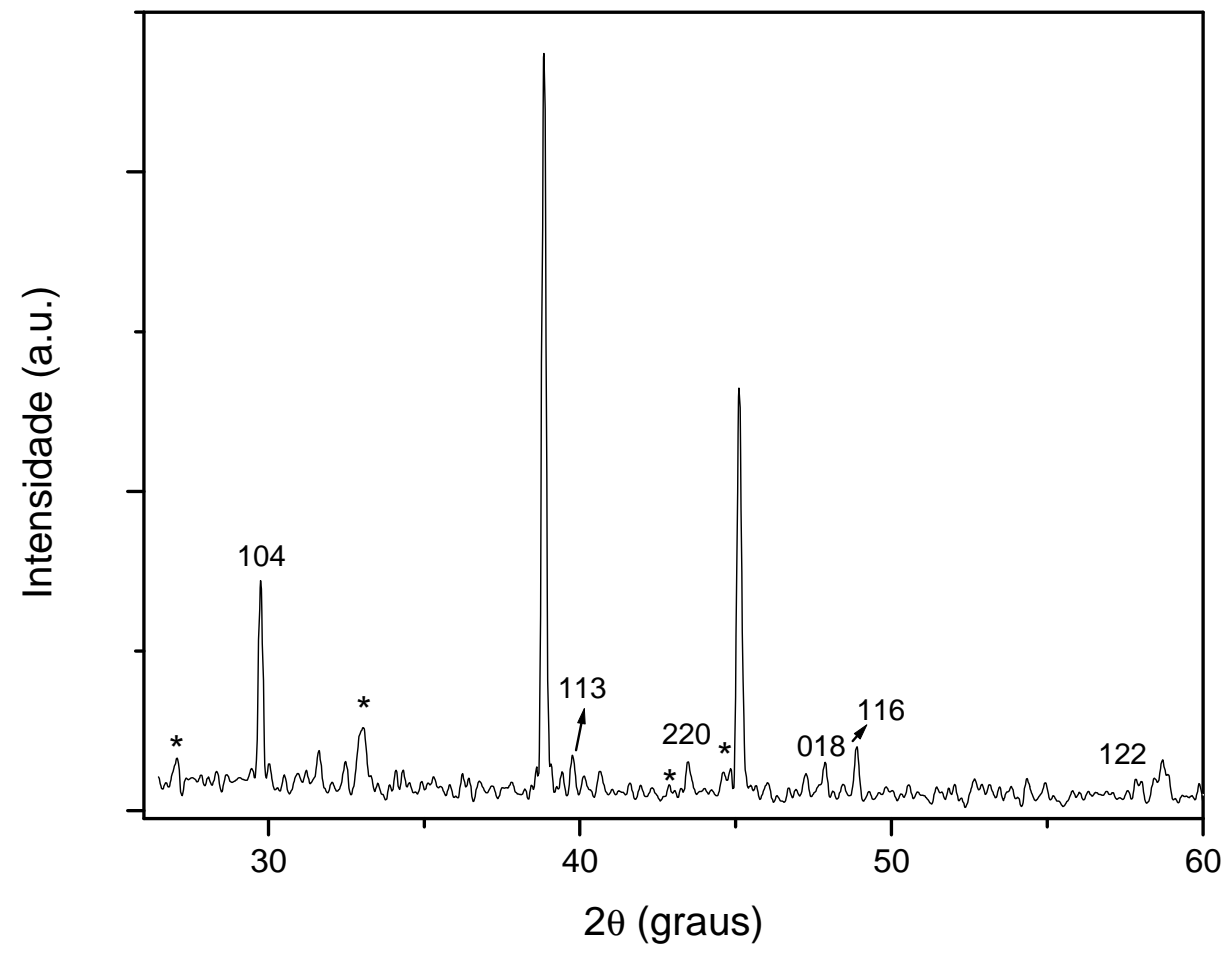

Figura 26: Picos de difração do filme híbrido (PAA/Qt) ${ }_{6} \mathrm{PAA} / \mathrm{CaCO}_{3}$. Os picos marcados com asterisco correspondem a $\mathrm{CaCO}_{3}$ na forma cristalina vaterita.

Tabela 3: Picos padrão e experimentais e seus deslocamentos correspondentes

\begin{tabular}{ccc}
\hline $\begin{array}{c}\text { Padrão } \\
\text { (graus) }\end{array}$ & $\begin{array}{c}\text { Experimental } \\
\text { (graus) }\end{array}$ & $\begin{array}{c}\Delta(\mathbf{2 \theta}) \\
\text { (graus) }\end{array}$ \\
\hline 27.1 & 27.1 & 0 \\
\hline 32.8 & 32.6 & 0.2 \\
\hline 42.6 & 42.4 & 0.2 \\
\hline 43.8 & 44.2 & 0.4 \\
\hline
\end{tabular}

O tamanho médio dos cristalitos foi estimado pela equação de Scherrer e o valor encontrado foi de aproximadamente $30 \mathrm{~nm}$. 


\subsection{Molhabilidade dos Filmes}

Por meio de medidas de ângulo de contato $(\theta)$ entre o substrato e água pode-se avaliar a hidrofilicidade da superfície antes e após a deposição dos filmes. A Figura 27 ilustra uma gota formada sobre o substrato submetido apenas ao pré-tratamento superficial com solução alcalina de limpeza (4) (a) e o substrato recoberto com a matriz polimérica (PAA/Qt) ${ }_{3}$ PAA seguido por exposição a carbonato de amônio por 13 horas (b). Na Figura 28 podemos observar a variação de $\theta$ em função do tempo de contato gota/suporte para o suporte metálico contendo recoberto com o filme $\mathrm{LbL}(\mathrm{PAA} / \mathrm{Qt})_{5} \mathrm{PAA}$, contendo carbonato de cálcio na ultima camada. Logo após o desprendimento da gota, o ângulo de contato é maior e diminui em função do tempo devido às interações entre a água e os grupos hidrofílicos, presentes na superfície do filme. $\mathrm{O}$ valor de equilíbrio é atingido após 30 segundos aproximadamente.
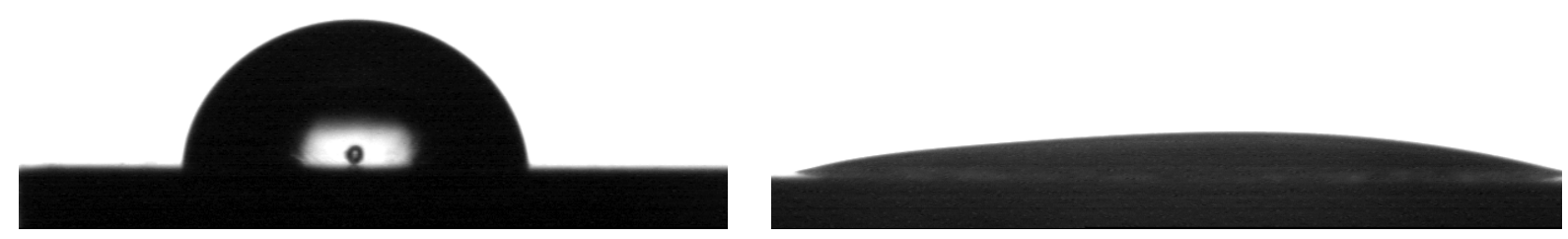

Figura 27: Espalhamento de uma gota de água sobre: a) suporte de alumínio; b) suporte de alumínio contendo matriz polimérica $(\mathrm{PAA} / \mathrm{Qt})_{3} \mathrm{PAA}$ seguido por exposição a carbonato de amônio por 13 horas 


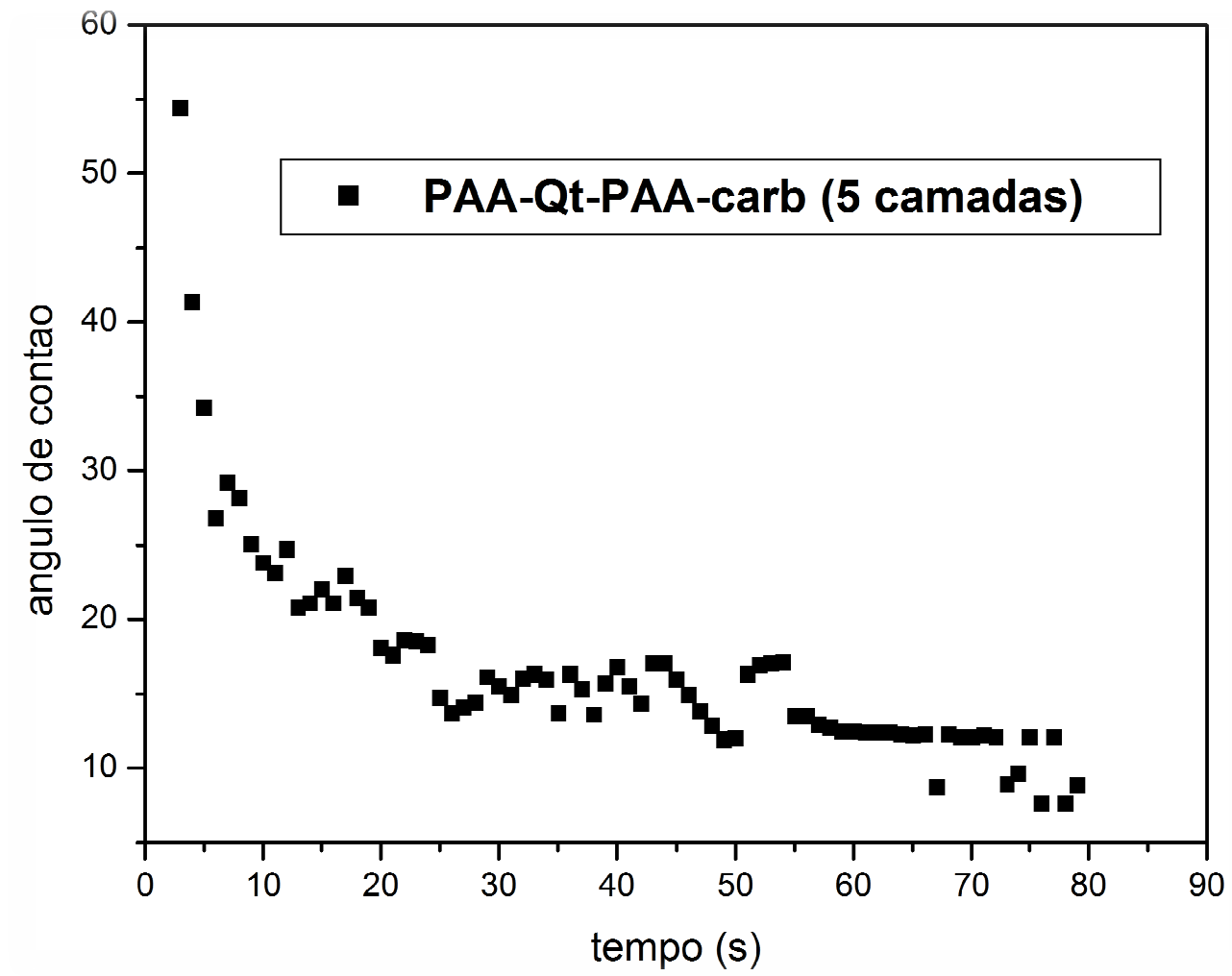

Figura 28: Evolução de $\theta$ com o tempo para suporte de alumínio recoberto por filme LbL (PAA/Qt) ${ }_{5}$ PAA com $\mathrm{CaCO}_{3}$ depositado na última camada.

A Tabela 4 mostra os resultados de $\theta$ equilíbrio e tempo para alcance do equilíbrio para diferentes tipos de matriz polimérica. Podemos observar que $\theta$ decresce com o aumento do número de camadas de polieletrólito depositadas e com a presença da parte inorgânica. 
Resultados e Discussão

Tabela 4: Tempo e valores de $\theta$ equilíbrio para diferentes tipos de filmes depositados sobre suporte de alumínio

\begin{tabular}{|c|c|c|c|}
\hline & Amostra & Tempo equilíbrio & $\theta$ (graus) \\
\hline 1 & Sem recobrimento & $>120$ & 85 \\
\hline 2 & $(\mathrm{PAA} / \mathrm{Qt})_{4} \mathrm{PAA}$ & 60 & 45 \\
\hline 3 & $(\mathrm{PAA} / \mathrm{Qt})_{4} \mathrm{PAA} / \mathrm{CaCO}_{3}$ & $>120$ & 29 \\
\hline 4 & $(\mathrm{PAA} / \mathrm{Qt})_{5} \mathrm{PAA} / \mathrm{CaCO}_{3}$ & 30 & 7 \\
\hline 5 & $(\mathrm{PAA} / \mathrm{Qt})_{6} \mathrm{PAA} / \mathrm{CaCO}_{3}$ & 30 & 10 \\
\hline 6 & $(\mathrm{PAA} / \mathrm{Qt})_{4} \mathrm{l}-\mathrm{car} \mathrm{Ca} 2+/ \mathrm{CaCO}_{3}$ & $>120$ & 39 \\
\hline 7 & 1 -car-Zn2+/ Qt $/ \mathrm{l}-\mathrm{car}-\mathrm{Ca}^{2+} / \mathrm{CaCO}_{3}$ & 80 & 39 \\
\hline 8 & 1-car-Ca $2+/ \mathrm{Qt} / \mathrm{l}-\mathrm{car}-\mathrm{Ca}^{2}+/ \mathrm{CaCO}_{3}$ & $>120$ & 66 \\
\hline
\end{tabular}

O decréscimo de $\theta$ com o aumento do número de camadas depositadas pode ser atribuído à eliminação da influência do efeito do substrato com aumento na espessura dos filmes. A presença de $\mathrm{CaCO}_{3}$ também aumenta a hidrofilicidade do filme.

O tipo de contra-íon ligando a primeira camada de poliânion também é importante para aumento da hidrofilicidade dos filmes. Para os filmes híbridos l-car/Qt/ $\mathrm{CaCO}_{3}$ a presença de íons $\mathrm{Zn}^{2+}$ na primeira camada resulta em filmes $\operatorname{com} \theta=39^{\circ}$ enquanto que na presença de íons $\mathrm{Ca}^{2+} \mathrm{o}$ ângulo de contato de equilíbrio é $66^{\circ}$ (amostras 7 e 8 ). Já o tipo de polieletrólito na primeira camada não altera o ângulo de contato do filme (amostras 6 e 7). Ainda, ângulo de contato de equilíbrio para os filmes contendo l-car são maiores comparados aos valores obtidos para o PAA. Como será evidenciado na seção 3.7 na presença de filme LbL contendo l-car ocorre a formação de partículas isoladas de $\mathrm{CaCO}_{3}$ ao invés da formação de um filme contínuo. Desta forma, a diminuição no ângulo de contato para estas amostras relaciona-se principalmente à exposição do 
$\underline{\text { Resultados e Discussão }}$

recobrimento orgânico, e as partículas isoladas de $\mathrm{CaCO}_{3}$ têm pouca influência no valor final apresentado.

Por outro lado, deve-se ter cautela ao analisar o ângulo de contato para estes tipos de filmes uma vez que a própria penetração da gota na matriz polimérica pode resultar em uma alteração no ângulo de contato e então não estaríamos analisando o espalhamento da gota e sim a sua penetração. Para uma análise mais completa necessitaríamos de imagens não só da lateral, mas também do topo do filme, para inferir sobre a ocorrência ou não de penetração. Porém, comparativamente, podemos inferir sobre a diferença na hidrofilicidade dos filmes formados.

\subsection{Adesão dos filmes aos suportes sólidos}

A adesão dos filmes aos suportes de alumínio e aço inox foi testada por meio de testes de tração utilizando-se fita adesiva. A adesão não foi testada sobre as superfícies de silício, pois visualmente a adesão de todos os filmes sobre esse tipo de suporte é muito baixa. As diferenças na adesão dos filmes podem estar relacionadas com fatores intrínsecos ao suporte, como sua rugosidade, tal como com as diferenças de interação entre os grupos químicos presentes na superfície dos suportes e os grupos presentes nos polieletrólitos. Suportes mais rugosos têm áreas superficiais maiores do que os suportes mais lisos, gerando maior área de contato filme/suporte. A modificação das superfícies metálicas com o pré-recobrimento LB deve aumentar o número de pontos de ligação do polieletrólito à superfície, aumentando, assim, a adesão dos filmes LbL. A Tabela 5 resume os resultados obtidos nos testes de adesão. 
$\underline{\text { Resultados e Discussão }}$

Tabela 5: Força de adesão dos filmes orgânicos e híbridos aos suportes metálicos estudados. A área de teste em todos os casos foi de $40 \mathrm{~mm}^{2}$

\begin{tabular}{|c|c|c|c|c|}
\hline Suporte & Filme LB & Filme LbL & $\mathrm{CaCO}_{3}$ & $\begin{array}{l}\text { Força de adesão } \\
\qquad( \pm 2 \text { gf })\end{array}$ \\
\hline Alumínio & -------------------- & $(\mathrm{PAA} / \mathrm{Qt})_{6} \mathrm{PAA}$ & Não & 23 \\
\hline Alumínio & |------------------ & $(\mathrm{PAA} / \mathrm{Qt})_{6} \mathrm{PAA}$ & Sim & 23 \\
\hline Alumínio & $(\mathrm{DMPA})_{4}$ & $(\mathrm{PAA} / \mathrm{Qt})_{2} \mathrm{PAA}$ & Não & 23 \\
\hline Alumínio & $(\mathrm{DMPA})_{4}$ & $(\mathrm{PAA} / \mathrm{Qt})_{6} \mathrm{PAA}$ & Não & 24 \\
\hline Alumínio & $(\mathrm{DMPA})_{4}$ & $(\mathrm{PAA} / \mathrm{Qt})_{6} \mathrm{PAA}$ & Sim & 23 \\
\hline Alumínio & $(\mathrm{DMPA})_{3} \mathrm{DMPE}$ & $(\mathrm{PAA} / \mathrm{Qt})_{6} \mathrm{PAA}$ & Sim & 24 \\
\hline Alumínio & $(\mathrm{DMPA})_{4}$ & $(\mathrm{Qt} / \mathrm{l}-\mathrm{car})_{2}$ & Não & 24 \\
\hline Alumínio & $(\mathrm{DMPA})_{3} \mathrm{DMPE}$ & $(\mathrm{Qt} / \mathrm{l}-\mathrm{car})_{2}$ & Não & 23 \\
\hline Alumínio & ----------------------- & $(\lambda \text {-car/Qt })_{6} \lambda$-car & Não & 22 \\
\hline Alumínio & $(\mathrm{DMPA})_{4}$ & $(\lambda \text {-car/Qt })_{6} \lambda$-car & Não & 23 \\
\hline Alumínio & $(\mathrm{DMPA})_{3} \mathrm{DMPE}$ & $(\lambda \text {-car/Qt })_{6} \lambda$-car & Não & 24 \\
\hline Alumínio & $(\mathrm{DMPA})_{4}$ & $(\mathrm{Qt} / \lambda \text {-car })_{2}$ & Não & 21 \\
\hline Aço inox & --------------------- & $(\mathrm{PAA} / \mathrm{Qt})_{12} \mathrm{PAA}$ & Não & 23 \\
\hline Aço inox & |----------------------- & $(\mathrm{PAA} / \mathrm{Qt})_{6} \mathrm{PAA}$ & Sim & 24 \\
\hline Aço inox & DMPA & $(\mathrm{Qt} / \mathrm{PAA})_{2}$ & Não & 8 \\
\hline Aço inox & DMPE & $(\mathrm{Qt} / \mathrm{PAA})_{2}$ & Não & 11 \\
\hline
\end{tabular}

Analisando os valores mostrados na Tabela 5 pode-se notar que para os suportes de alumínio não são observadas variações significativas no valor de adesão encontrado variando-se os seguintes parâmetros: presença de $\mathrm{CaCO}_{3}$ na última camada, tipo de fosfolipídeo formador do 
Resultados e Discussão

filme LB tipo de poliânion e número de camadas do filme LbL. Porém, para os suportes de aço inox, que possui rugosidade média menor do que o alumínio (ver seção 3.1), observou-se diminuição na adesão dos filmes devido à presença do filme do pré-recobrimento LB. Esta observação aparentemente controversa, pois a presença de cargas do lipídeo deveria resultar em forças de adesão mais elevadas, pode ser explicada pela diminuição na rugosidade do suporte de aço pela presença do filme LB que preenche os "poços" na superfície do metal. Este efeito é pronunciado para o suporte de baixa rugosidade, porém, para o suporte de alumínio, com maior rugosidade, a presença do filme LB pouco afeta suas características superficiais. Recentemente, diversos autores estudaram a adesão de filmes bioativos sobre superfícies metálicas utilizando-se o método de remoção da fita ${ }^{131,132}$. Porém, nestes trabalhos apenas uma análise qualitativa de remoção total, parcial, ou não remoção do filme pela fita é realizada. No trabalho de Kim, et.al. ${ }^{132}$ a remoção de filmes de hidroxiapatita com e sem tratamento térmico é realizada com fita e avaliada utilizando-se microscopia eletrônica de varredura. A análise desses resultados deve ser cautelosa uma vez que a interpretação dos resultados é altamente questionada, pois independente das condições experimentais, parte da camada, e não o filme como um todo, é sempre removida $^{133}$. Ainda, o método é extremamente dependente do tipo de fita e das condições de operação, dificultando análises comparativas. 
Resultados e Discussão

\subsection{Proteção do metal contra corrosão}

A presença de recobrimentos sobre superfícies metálicas pode modificar as propriedades eletroquímicas dessas superfícies, melhorando sua resistência frente a processos oxidativos. $\mathrm{O}$ recobrimento forma uma nova interface que atua como uma barreira física que impede ou diminui a difusão de moléculas impedindo ou dificultando seu acesso à superfície metálica. Essas moléculas não serão, portanto, capazes de reagir com a superfície, melhorando sua estabilidade à corrosão $^{134}$. Por exemplo, em estudo apresentado por Balamurugan, et.al. ${ }^{135}$ foi constatada melhora nas propriedades relacionadas a processos corrosivos de uma liga de titânio na presença de um compósito vítreo contendo apatita. Também, no estudo realizado por Lazarevic et.al. ${ }^{134}$ utilizando-se superfícies de alumínio recobertas por filmes epóxi notou-se que diferenças na estabilidade química do metal puderam ser observadas com filmes de diferentes porosidades, sendo que naturalmente os menos porosos protegem mais o metal frente à corrosão.

Pode-se notar na Figura 29 que, como esperado, a condutividade do alumínio puro é maior do que a condutividade do aço puro e as duas são diminuídas na presença do filme híbrido. As curvas obtidas a partir dos suportes metálicos contendo apenas a matriz orgânica (não mostrado) não apresenta variação com relação às curvas obtidas com a presença de $\mathrm{CaCO}_{3}$. Podemos notar também que para um mesmo valor de voltagem aplicada ( $2 \mathrm{~V} v s$ ECS) a diminuição na corrente observada para o aço inox é maior do que para o alumínio. Enquanto que para o alumínio a densidade de corrente diminui apenas $10 \%$, a diminuição para o aço inox corresponde à aproximadamente $68 \%$. Estas diferenças podem estar relacionadas com a diferença na homogeneidade obtida para os filmes em suportes de diferente rugosidade. Para o suporte mais liso, neste caso o aço inox, o recobrimento deve conter menos imperfeições, sendo mais efetivo no bloqueio do acesso de moléculas à superfície metálica. 


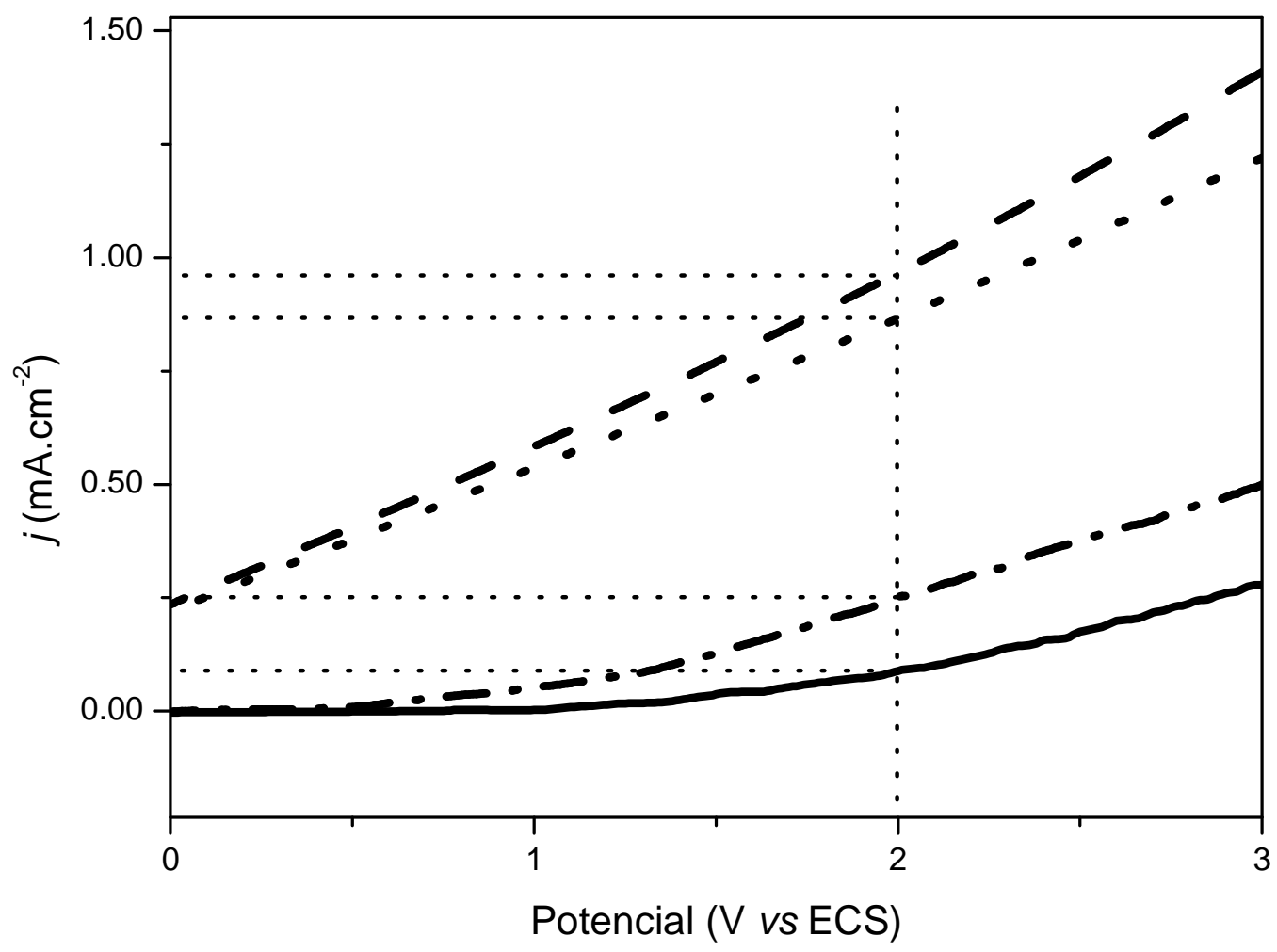

Figura 29: Curvas de densidade de corrente $(j)$ vs potencial para: suporte de aço (linha traço e ponto), suporte de aço contendo filme híbrido (DMPA) $)_{4} /(\mathrm{Qt} / \mathrm{PAA})_{2} / \mathrm{CaCO}_{3}$ (linha sólida), suporte de alumínio (linha tracejada), suporte de alumínio contendo filme híbrido $(\mathrm{DMPA})_{4} /(\mathrm{Qt} / \mathrm{PAA})_{2} / \mathrm{CaCO}_{3}$ (linha pontilhada).

Demonstra-se desta forma, que os filmes descritos nesta tese podem causar passivação dos suportes metálicos utilizados, protegendo-os contra corrosão. 
Resultados e Discussão

\subsection{Formação de $\mathrm{CaCO}_{3}$ sobre filmes de PAA e NaPA pelo método "a seco": comparação da fração de grupos carregados contidos nos poliânions}

\subsubsection{Microscopia Óptica}

Os filmes, poliméricos formados por PAA e NaPA e híbridos, foram analisados e comparados quanto à sua morfologia utilizando-se microscopia ótica e microscopia eletrônica de varredura (MEV). Para o crescimento de $\mathrm{CaCO}_{3}$ sobre estes filmes utilizou-se o método "a seco" descrito no item 2.3 (pág. 38) da parte experimental.

As imagens de microscopia ótica dos filmes LbL e híbridos (Figura 30 e 31) mostram que a porosidade do filme polimérico diminui com aumento do número de camadas depositadas (Figura 30). Pode-se notar também que após exposição a carbonato de amônio a refletividade do filme é aumentada, provavelmente devido à presença da fase cristalina. Na Figura 31 podemos verificar diferenças notórias na morfologia dos filmes depositados sobre alumínio e sobre aço inox. Em aço é possível observar melhor a estrutura de camadas do filme LbL. Este resultado mostra que a morfologia do suporte é um fator importante na determinação da morfologia dos recobrimentos e pode influenciar, com isso, a formação do $\mathrm{CaCO}_{3}$. A influência da rugosidade superficial na formação de $\mathrm{CaCO}_{3}$ foi estudada detalhadamente, os resultados serão mostrados no item 3.6.2 para formação de $\mathrm{CaCO}_{3}$ pelo método "a seco" e no item 3.9.1 para a formação de $\mathrm{CaCO}_{3}$ sobre os suportes mergulhados em solução. 
$\underline{\text { Resultados e Discussão }}$

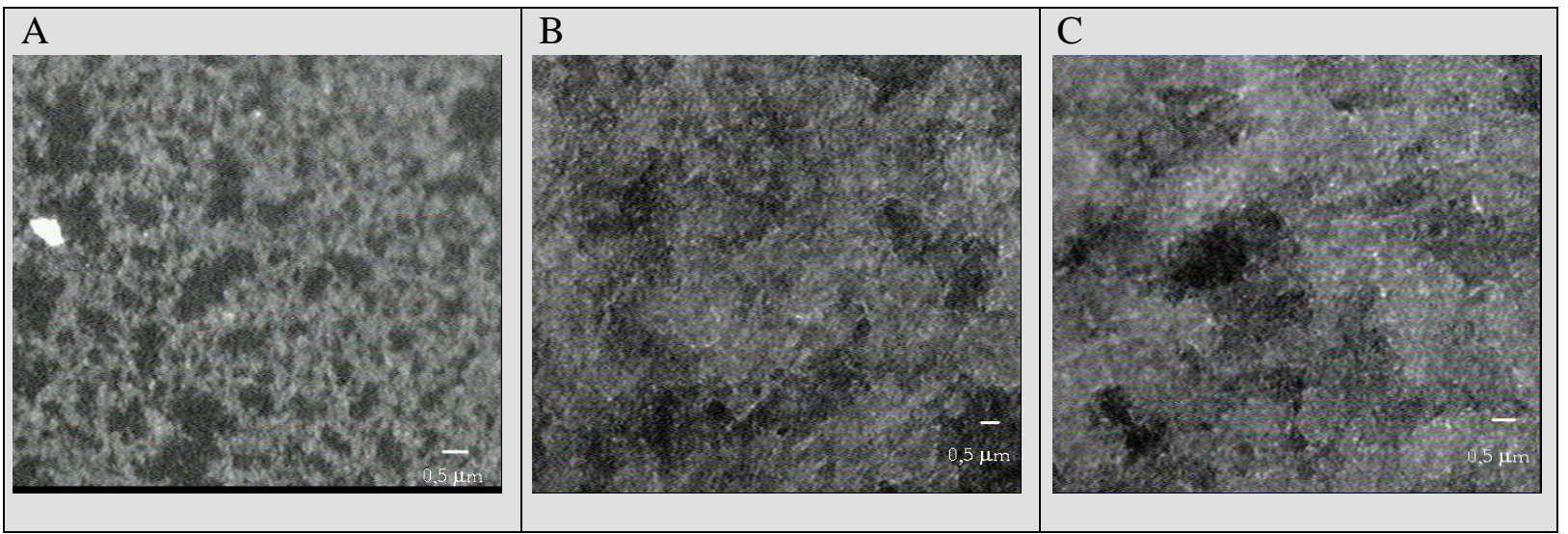

Figura 30: Microscopia ótica com luz polarizada dos filmes PAA/Qt depositados sobre suportes de alumínio: A) (PAA/Qt) $\left.{ }_{3} \mathrm{PAA} ; \mathrm{B}\right)(\mathrm{PAA} / \mathrm{Qt})_{6} \mathrm{PAA}$ e C) (PAA/Qt) ${ }_{6} \mathrm{PAA}$ após exposição por 15 horas a $\left(\mathrm{NH}_{4}\right)_{2} \mathrm{CO}_{3}$ em recipiente fechado.

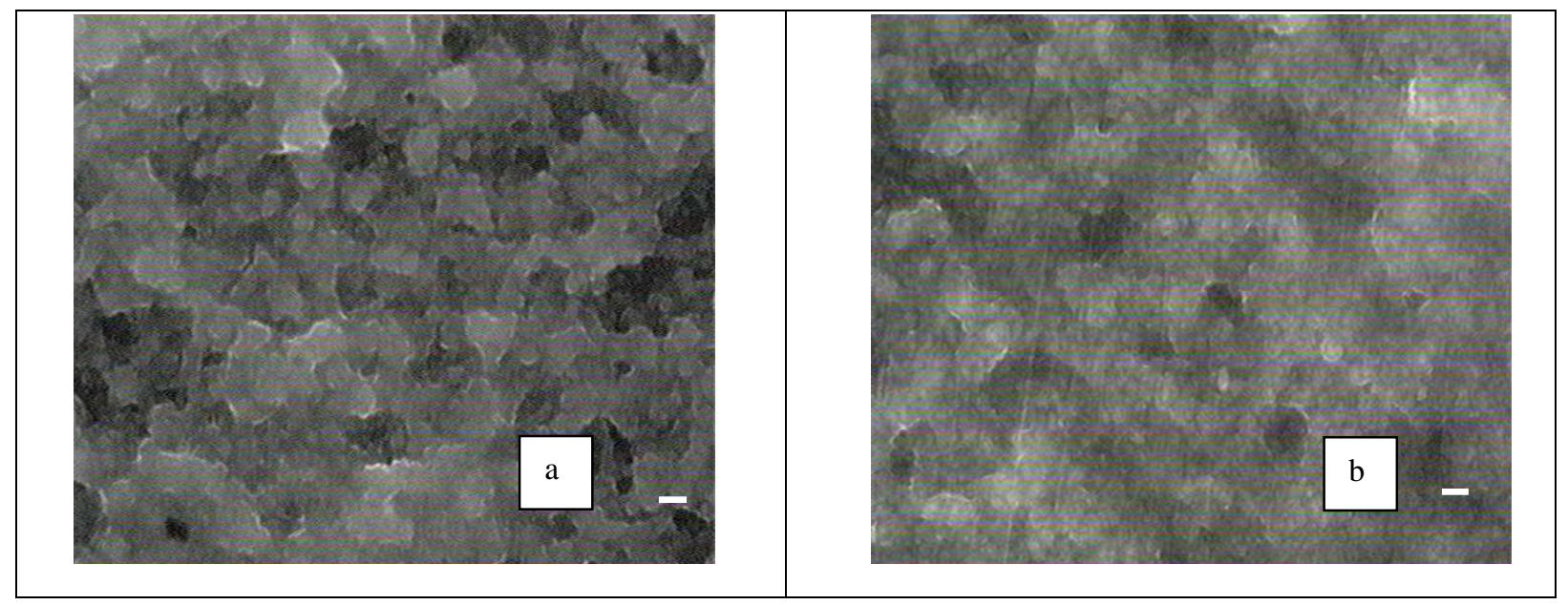

Figura 31: Microscopia ótica com luz polarizada dos filmes PAA/Qt depositados sobre suportes de aço inox 316L a) (PAA/Qt) ${ }_{6} \mathrm{PAA}$ e b) (PAA/Qt) ${ }_{6} \mathrm{PAA}$ após exposição por 15 horas a $\left(\mathrm{NH}_{4}\right)_{2} \mathrm{CO}_{3}$ em recipiente fechado. 
Resultados e Discussão

Ainda se tratando do crescimento de partículas de $\mathrm{CaCO}_{3}$ pelo método "a seco", por meio de microscopia eletrônica, que possui maior amplificação e resolução comparada à microscopia óptica, podemos notar que o recobrimento polimérico é contínuo e relativamente homogêneo e pode resistir por alguns minutos à alta fluência do feixe de elétrons. Depois de aproximadamente dois minutos, para o filme PAA/Qt depositado sobre suporte de alumínio, (Figura 32A) é foi possível observar a crescimento de uma bolha e uma rachadura no centro. Aparentemente, a formação de carbonato de cálcio ocorreu sobre toda a matriz polimérica (Figura 32 B e D), formando um filme denso, homogêneo e contínuo constituído por partículas regulares esféricas com tamanho médio entre 300 e $550 \mathrm{~nm}$. A presença do constituinte inorgânico aumenta a estabilidade do recobrimento, como observado pela alta tolerância ao feixe de elétrons, constatada pela ausência de rachaduras nesses filmes.

Suportes de silício foram utilizados com intuído de se verificar o efeito da rugosidade do suporte no crescimento dos cristais de $\mathrm{CaCO}_{3}$. Filmes $\mathrm{LbL}$ de (PAA/Qt) ${ }_{6} \mathrm{PAA}$ foram utilizados como matriz orgânica para o posterior crescimento do $\mathrm{CaCO}_{3}$. Os filmes de $\mathrm{CaCO}_{3}$ depositados sobre matriz orgânica de PAA e quitosana depositados sobre silício (Figura 33) se assemelham àqueles depositados sobre alumínio e aço inox (Figura 32). Isto mostra que utilizando-se 13 camadas do filme LbL pelo método de deposição "a seco", a matriz polimérica parece ser espessa o suficiente para homogeneizar a superfície do suporte sólido e a morfologia do suporte não afetar a forma e o crescimento dos cristalitos. 

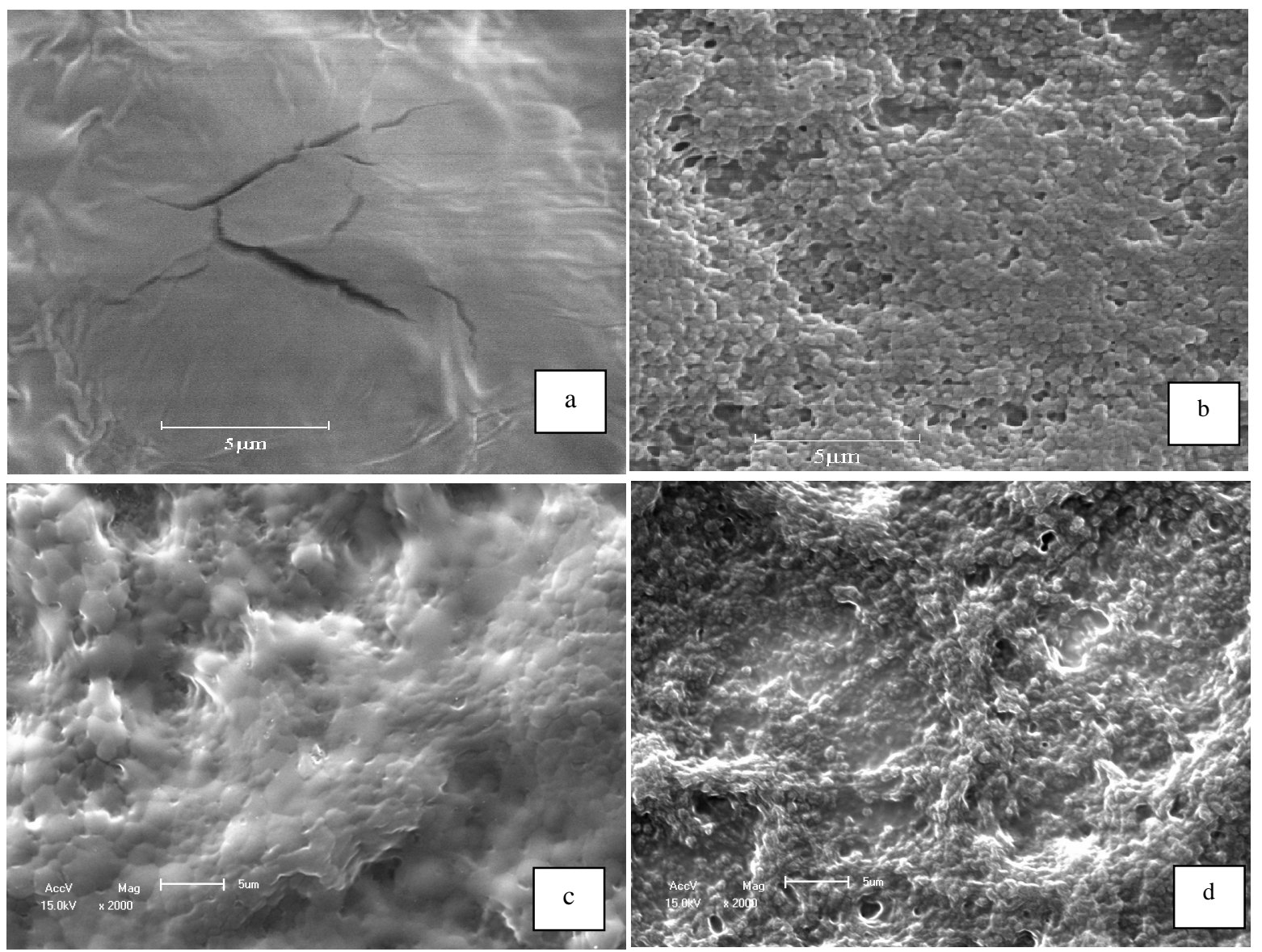

Figura 32: Micrografias de filmes LbL (PAA/Qt) ${ }_{6} \mathrm{PAA}$ depositados sobre a,b)suportes de alumínio c,d) suportes de aço inox 316L. As imagens (b) e (d) foram obtidas após exposição dos à $\left(\mathrm{NH}_{4}\right)_{2} \mathrm{CO}_{3}$ em recipiente fechado por 13 horas. 


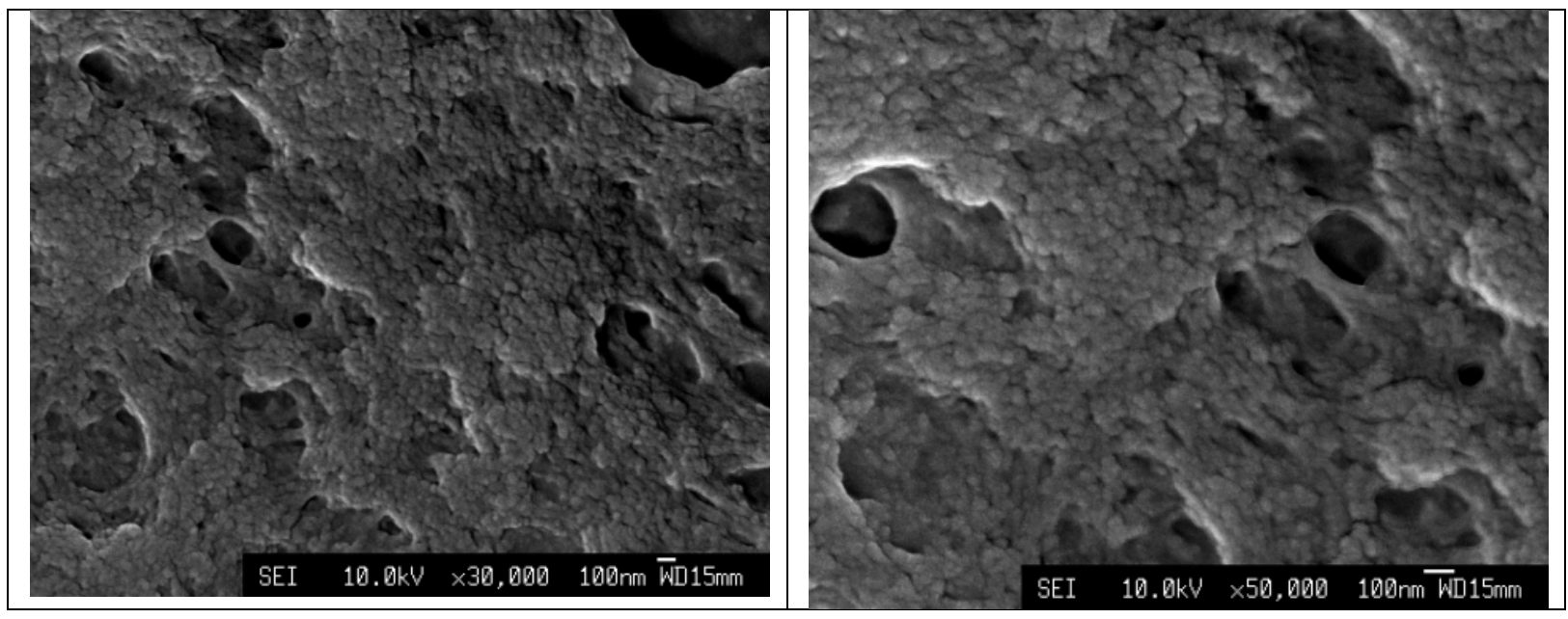

Figura 33: Filme $\mathrm{LbL}$ de $(\mathrm{PAA} / \mathrm{Qt})_{6} \mathrm{PAA}+\mathrm{CaCO}_{3}$ depositados sobre suporte de silício.

As micrografias eletrônicas também foram obtidas mudando-se ângulo de inclinação dos suportes para observação lateral da morfologia do filme. A Figura 34 obtida com inclinação de $60^{\circ}$ mostra o crescimento do filme polimérico em uma região limite substrato metálico/ recobrimento. O defeito em forma de "U" foi feito propositalmente para que fosse possível a observação do crescimento axial dos filmes.

\section{Variando-se o ângulo de inclinação das amostras (}

Figura 35) pode-se observar que os filmes, polimérico e híbrido, são rugosos e que a micro-rugosidade dos mesmos aumenta com o recobrimento inorgânico sobre a última camada de polieletrólito. Comparando-se as

\section{figuras}

Figura 35E e 35F podemos observar a formação de partículas esféricas sobre a matriz polimérica após a exposição a $\left(\mathrm{NH}_{4}\right)_{2} \mathrm{CO}_{3}$. 


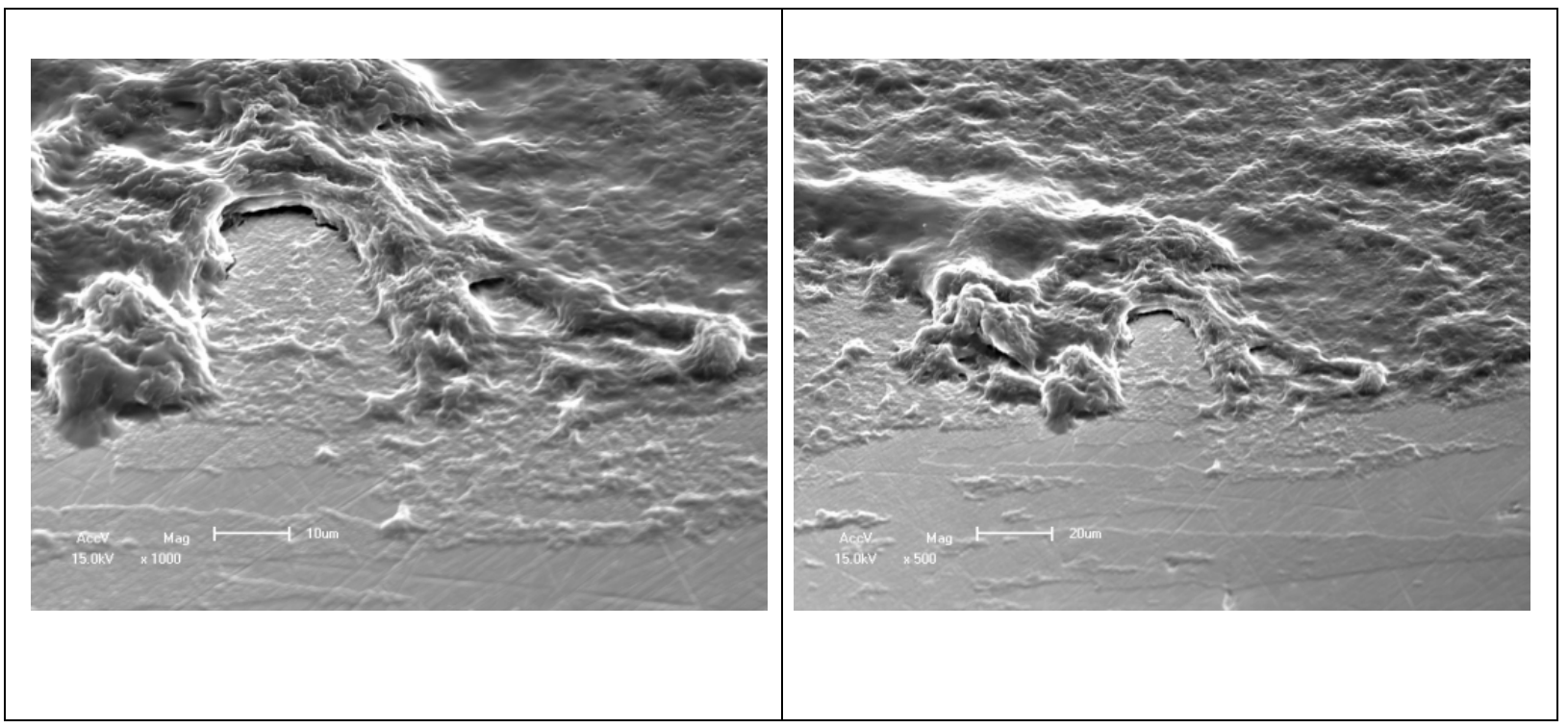

Figura 34: Micrografias de filmes LbL (PAA/Qt) ${ }_{6}$ PAA depositados sobre suportes de aço inox $316 \mathrm{~L}$ (inclinação de $60^{\circ}$ ).

Também foram obtidas imagens para filmes LbL NaPA/Qt e filmes híbridos. Aparentemente, os filmes formados utilizando-se como poliânion o NaPA não são tão homogêneos quanto os que utilizam o PAA. Ainda, a espessura parece ser menor (como é de se esperar para polieletrólitos totalmente ionizados ( $\mathrm{f}=1$ ), pois nas imagens (Figura 36 e 37) mesmo após a deposição do filme LbL pode-se notar riscos pertencentes ao suporte metálico. Mais uma vez utilizando-se a teoria de Debye, a espessura de uma camada de NaPA deve ser próxima a 4 nm enquanto que para o PAA a espessura deve ser aproximadamente $18 \mathrm{~nm}$. Estas observações podem ainda ser devido à pouca quantidade de NaPA ligado nas camadas, pois como mostram os dados obtidos na QCM (seção 3.2.3) há dessorção significativa do poliânion durante a deposição da quitosana. 
$\underline{\text { Resultados e Discussão }}$
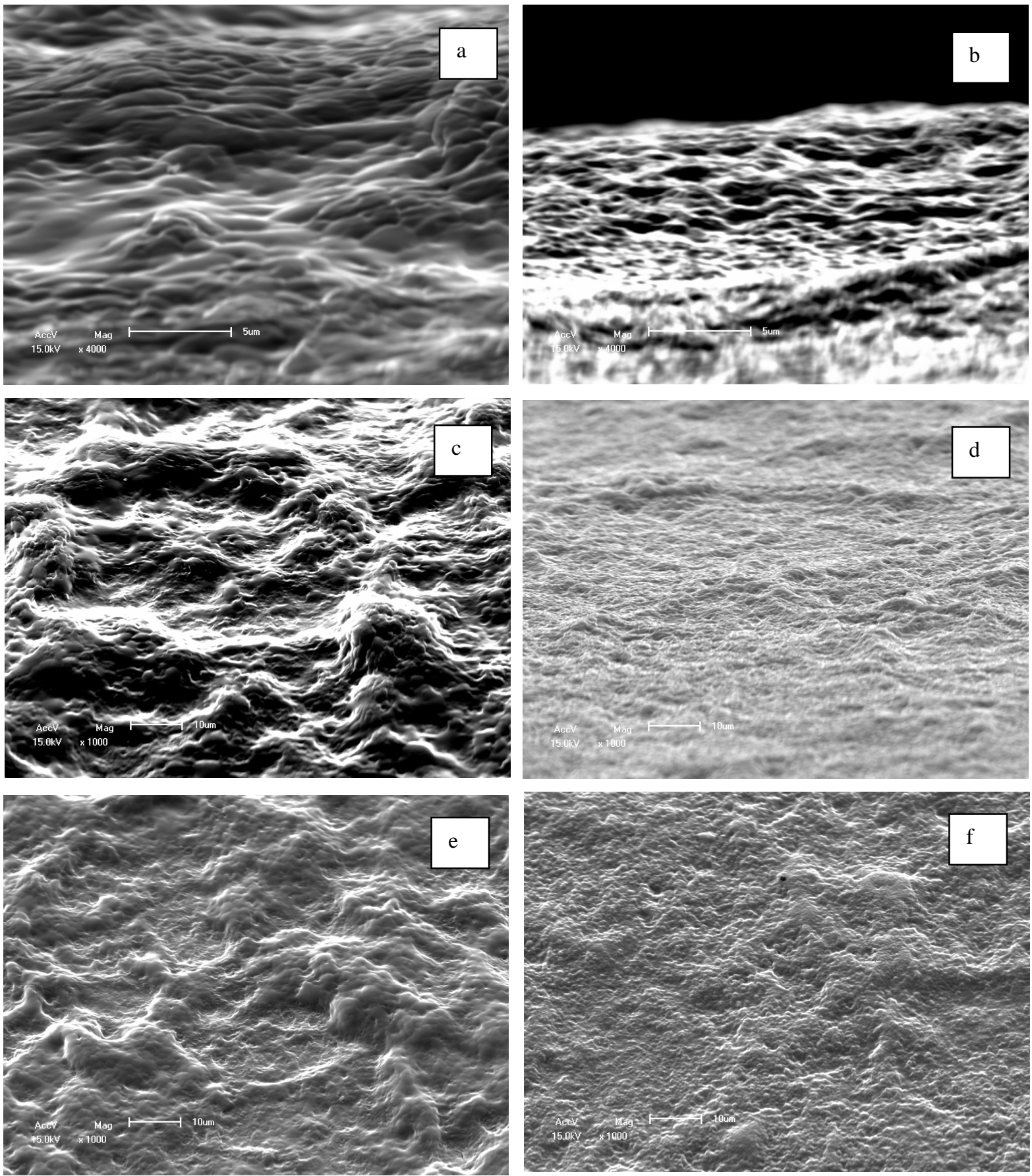

Figura 35: Micrografias dos filmes $(\mathrm{PAA} / \mathrm{Qt})_{6} \mathrm{PAA}$ depositados sobre suportes de aço inox

316L. As imagens foram obtidas variando-se a inclinação das amostras a,b) $60^{\circ}$; c,d) $42,5^{\circ}$; e,f)

$10^{\circ}$. As imagens $b, d$ e $\mathrm{f}$ foram obtidas depois da exposição dos suportes contendo a matriz polimérica a $\left(\mathrm{NH}_{4}\right)_{2} \mathrm{CO}_{3}$ por 15 horas. 

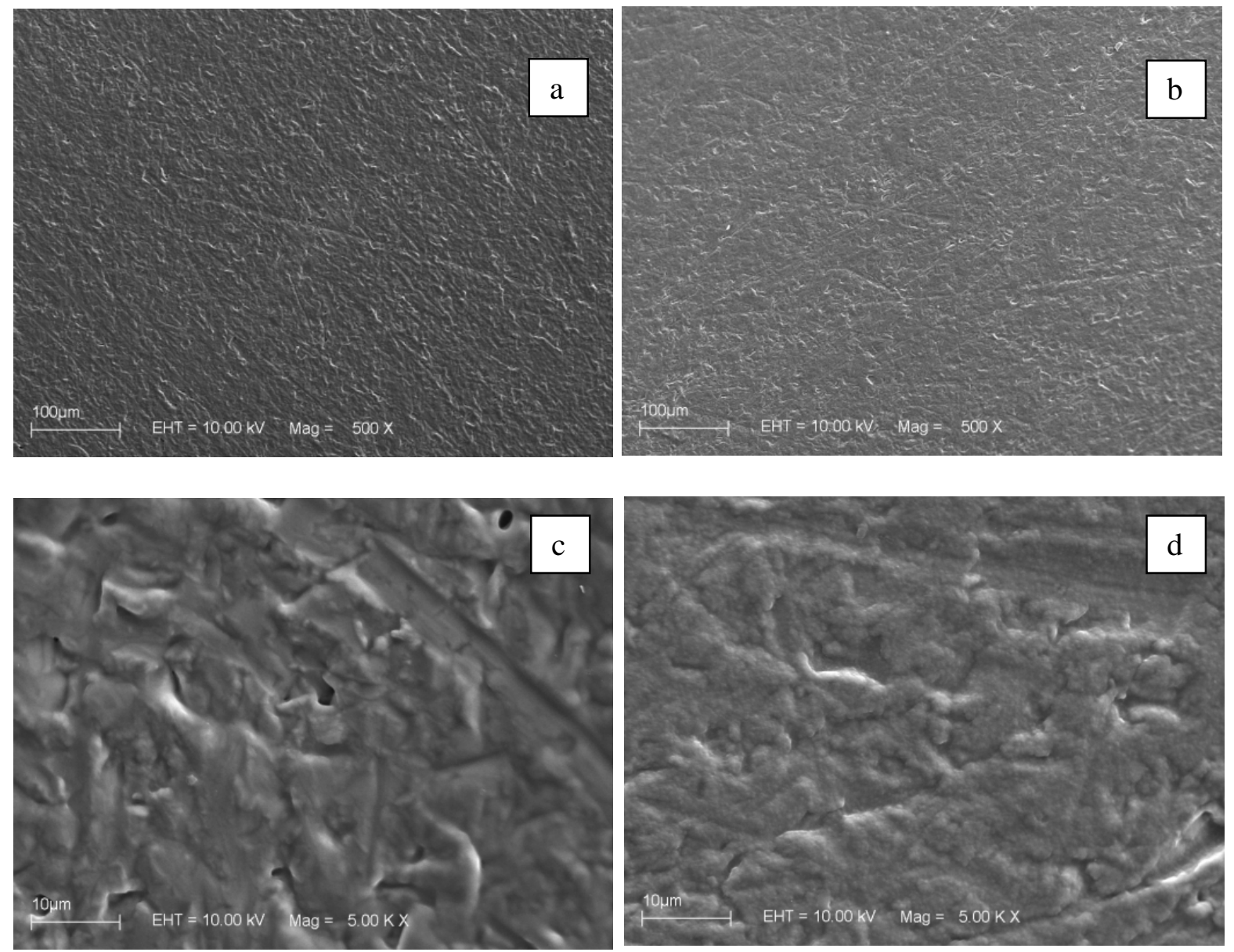

Figura 36: Filmes LbL (NAPA/Qt) ${ }_{6} \mathrm{NaPA}$ depositados sobre suporte de alumínio a, c) sem exposição a $\left.\left(\mathrm{NH}_{4}\right)_{2} \mathrm{CO}_{3} ; \mathrm{b}, \mathrm{d}\right)$ após exposição a $\left(\mathrm{NH}_{4}\right)_{2} \mathrm{CO}_{3}$ por 13 horas.

Comparando-se as Figura 36A e 37A observamos que, notavelmente, a deposição da matriz polimérica sobre alumínio se dá em maior quantidade, uma vez que na Figura 36A mal conseguimos observar a estrutura da matriz e provavelmente devido à baixa quantidade de polieletrólitos contidos no filme LbL nota-se que a formação de carbonato de cálcio é mais densa e homogênea em filmes LbL NaPA/Qt depositados sobre alumínio do que quando depositados sobre aço inox (Figura 36D e 37D). 
$\underline{\text { Resultados e Discussão }}$

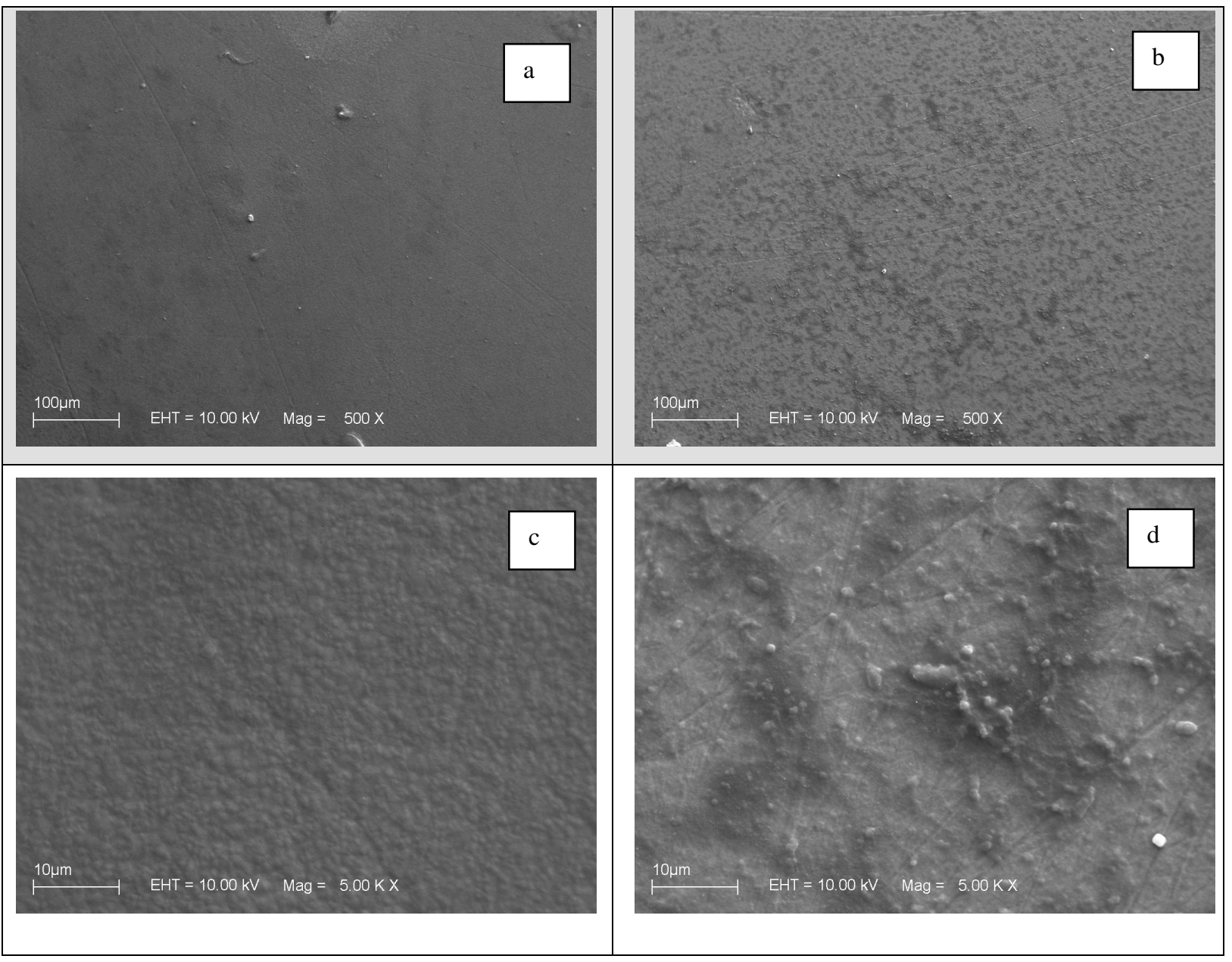

Figura 37: Filmes LbL (NaPA/Qt) ${ }_{6} \mathrm{NaPA}$ depositados sobre suporte de aço inox $\left.316 \mathrm{~L} \mathrm{a}, \mathrm{c}\right)$ sem exposição a $\left.\left(\mathrm{NH}_{4}\right)_{2} \mathrm{CO}_{3} ; \mathrm{b}, \mathrm{d}\right)$ após exposição a $\left(\mathrm{NH}_{4}\right)_{2} \mathrm{CO}_{3}$ por 13 horas. 
$\underline{\text { Resultados e Discussão }}$

\subsection{Crescimento de partículas de $\mathrm{CaCO}_{3}$ sobre filmes $L B / L b L$ usando um poliânion capaz de formar hélice e gelificar: l-car}

Nesta seção serão mostrados resultados da formação de matrizes orgânicas mistas $\mathrm{LB} / \mathrm{LbL}$ sobre suportes de alumínio e posterior crescimento de partículas de $\mathrm{CaCO}_{3}$ pelo método "a seco".

\subsubsection{Monocamadas mistas DMPA/DMPE}

DMPA é um fosfolipídeo negativamente carregado em toda a faixa de pH. DMPE é um fosfolipídeo zwiteriônico, ou seja, possui um grupo negativamente e outro positivamente carregado. Os dois possuem quatorze carbonos em cada uma de suas duas cadeias hidrofóbicas e a isoterma de pressão de superfície $(\pi)$ em função da área por molécula (A) apresenta uma região de coexistência de fases correspondente à transição de um estado líquido-expandido (LE) a um estado líquido-condensado (LC) entre (3-4) e $9 \mathrm{mN} \mathrm{m}^{-1}$, respectivamente, quando as monocamadas são formadas sobre água pura (Figura 38). As isotermas obtidas estão em concordância com as publicadas na literatura ${ }^{136,137}$.

Apesar das suas similaridades, estes fosfolipídeos não se misturam idealmente, como pode ser observado nas isotermas das monocamadas mistas (Figura 38). De fato, o valor da energia livre de excesso calculada para a mistura equimolar é de $-0.83 \mathrm{~kJ} \mathrm{~mol}^{-1}$ indicando a existência de um sistema formado por uma única fase. 


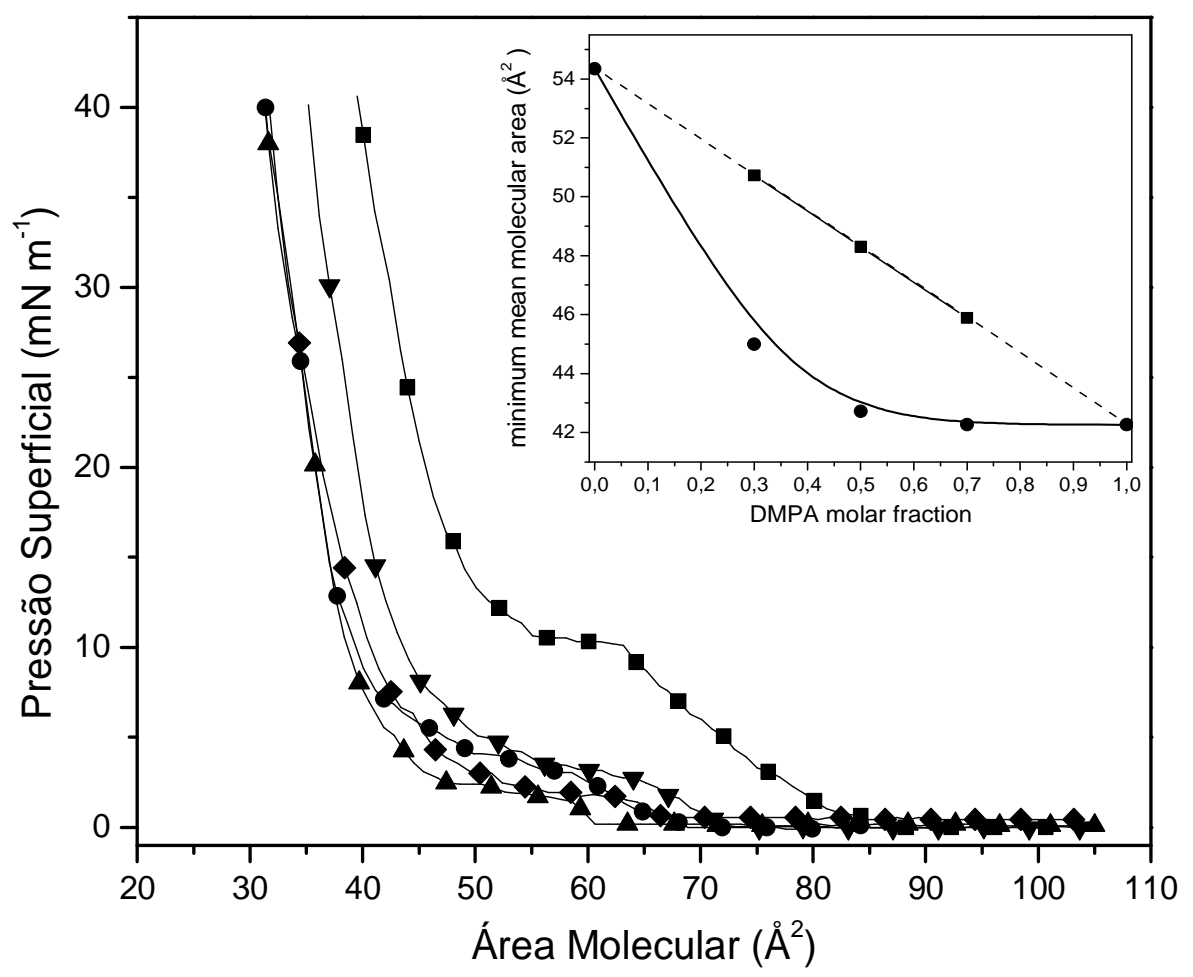

Figura 38: Isotermas de pressão superficial obtidas sobre água pura para monocamadas mistas DMPA/DMPE com diferentes frações molares de DMPA: $0.5(\boldsymbol{\Delta}), 0.3(\boldsymbol{\nabla})$ e $0.7(\diamond)$. DMPA puro (•) e DMPE puro (ロ) são também mostrados na figura. O encarte apresenta valores esperados para área molecular média mínima calculada para uma mistura ideal (ロ) e dados experimentais $(\bullet)$.

Quando Qt é adicionada à subfase, a transição de fases LE-LC é extinta em todas as isotermas, como observado na Figura 39. As monocamadas tornam-se mais compressíveis e por isso um valor maior de $\pi\left(40 \mathrm{mN} \cdot \mathrm{m}^{-1}\right)$ foi utilizado para a transferência dos fosfolipídeos a partir da solução de Qt. 


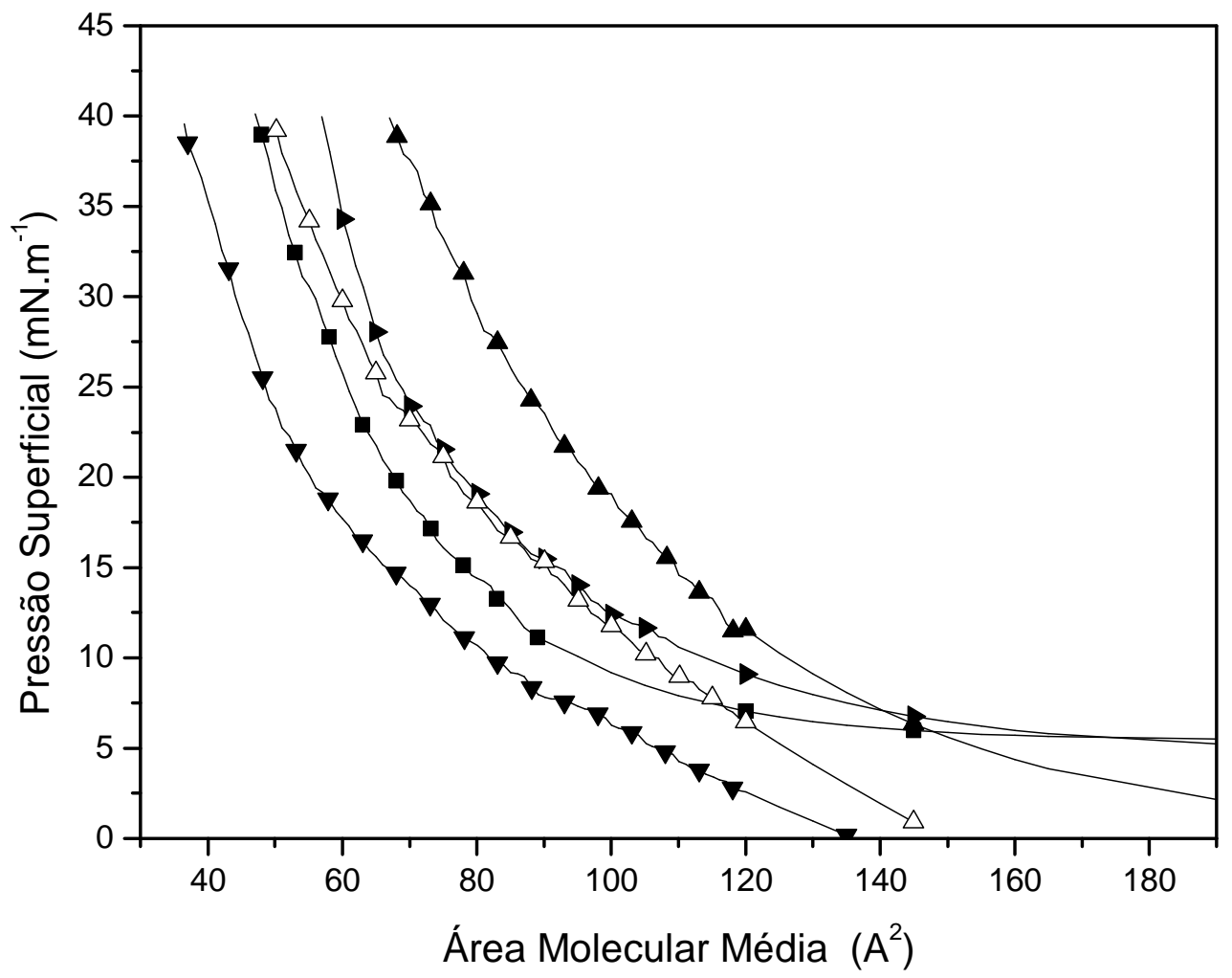

Figura 39: Efeito da adição de quitosana $0,05 \%(\mathrm{p} / \mathrm{p})$ sobre as isotermas $\pi$-A do DMPA (घ) DMPE $(\bullet)$ e monocamadas mistas com diferentes frações molares de DMPA 0,5 ( $\mathbf{\Delta}), 0,3(\boldsymbol{\nabla})$ e $0,7(*)$.

\subsubsection{Formação dos filmes mistos $L B / L b L$}

Todos os filmes LB preparados neste trabalho seguiram o mesmo procedimento até a deposição da terceira camada, como descrito na parte experimental. A diferenciação ocorreu na quarta camada, que foi depositada a partir de subfase quitosana, $\mathrm{pH}$ 5,4, com a composição da monocamada variada, entre DMPA e DMPE puros e mistura dos mesmos.

A massa de fosfolipídeo depositada nas camadas iniciais e também a massa total (lipídeo + Qt) depositada na quarta camada, foi determinada pela técnica QCM, como mostrado na Tabela 
Resultados e Discussão

1. A partir da curva $\pi$-A correspondente e da fração molar, pudemos estimar a quantidade de fosfolipídeo que estaria presente no filme e, então, por subtração, a quantidade de Qt transferida juntamente com a quarta camada. Os resultados da QCM (Tabela 6) mostram que Qt foi mais efetivamente transferida quando a monocamada era constituída apenas por DMPE. As isotermas de DMPA e DMPE sobre Qt (Figura 39) mostram que a $40 \mathrm{mN} \mathrm{m}^{-1}$ as densidades superficiais são $2,0 \times 10^{14}$ e $1,7 \times 10^{14}$ moléculas $\mathrm{cm}^{-2}$, respectivamente. Assim, não podemos atribuir a maior massa de Qt ao número de moléculas do fosfolipídeo presentes na interface. A massa de Qt (536 ng) depositada juntamente com a monocamada de DMPE corresponde $1,3 \times 10^{15}$ unidades de dissacarídeo $\mathrm{cm}^{-2}$, enquanto que com DMPA a massa de Qt transferida (385 ng) corresponde a $9,5 \times 10^{14}$ unidades de dissacarídeo $\mathrm{cm}^{-2}$. Considerando o número médio de moléculas dos fosfolipídeos na superfície do filme em cada caso, podemos estimar que as frações lipídeo:Qt são 1:6,5 e 1:1,5 para DMPE e DMPA, respectivamente. Este número pode nos dar uma idéia sobre a possibilidade da formação de alças na cadeia do polieletrólito adsorvido, que, neste caso, deve ser maior quando Qt adsorve sobre DMPE. Também foi observado por meio de medidas de QCM que a diferença de massa de Qt depositada juntamente com cada monocamada de fosfolipídeo deve influenciar a deposição das camadas de filme LbL subseqüentes. A massa do poliânion (1car) depositada na primeira camada do filme LbL foi maior quando a camada anterior era constituída por DMPA/Qt relativamente a quando o filme era depositado sobre DMPE/Qt. Este resultado indica que 1 -car liga-se melhor ao filme contendo menor massa do policátion (Qt). Esta aparente controvérsia pode ser explicada se pensarmos que em $\mathrm{pH}$ 5,4 a quitosana está apenas parcialmente carregada e esta carga pode ter sido utilizada na ligação entre a mesma e o DMPA. Neste caso, os grupos $-\mathrm{OH}$ e $-\mathrm{NH}_{2}$ da quitosana estão disponíveis para ligar 1-car por meio de ligações de hidrogênio. No caso de DMPE, eletricamente neutro, a interação com Qt deve ocorrer por meio de ligações de hidrogênio e apenas os poucos grupos carregados $-\mathrm{NH}_{3}{ }^{+}$da quitosana 
$\underline{\text { Resultados e Discussão }}$

estariam disponíveis para ligar 1-car, resultando em uma menor massa do poliânion no filme. Ainda, a presença de alças na cadeia do policátion deixa alguns grupos indisponíveis para ligação. Portanto, quando Qt está ligada a DMPE, ela pode apresentar menor número de pontos de ligação quando comparada à situação na qual ela está ligada a DMPA. Uma representação esquemática da diferença de ligações dos polieletrólitos em presença de DMPA e DMPE é mostrada na Figura 40.

Tabela 6: Massas depositadas de fosfolipídeo, quitosana, iota-carragenana e $\mathrm{CaCO}_{3}$

\begin{tabular}{|c|c|c|c|}
\hline & $\begin{array}{r}\text { Massa total } \\
\text { depositada (ng) }\end{array}$ & $\begin{array}{l}\text { Massa de } \\
\text { lipídeo* }{ }^{*}(n g)\end{array}$ & $\begin{array}{r}\text { Massa de } \\
\text { quitosana (ng) }\end{array}$ \\
\hline DMPA/Qt & $520 \pm 51$ & 135 & 385 \\
\hline 1-car & $980 \pm 91$ & ----- & ----- \\
\hline $\mathrm{CaCO}_{3}$ & $6300 \pm 600$ & ----- & ----- \\
\hline DMPE/Qt & $653 \pm 63$ & 116 & 536 \\
\hline l-car & $236 \pm 22$ & & \\
\hline $\mathrm{CaCO}_{3}$ & $4500 \pm 430$ & ----- & ----- \\
\hline $\begin{array}{l}\text { DMPA:DMP } \\
(1: 1) / Q t\end{array}$ & $435 \pm 42$ & 98,2 & 336 \\
\hline l-car & $721 \pm 70$ & ----- & ----- \\
\hline $\mathrm{CaCO}_{3}$ & $2460 \pm 240$ & ----- & ----- \\
\hline
\end{tabular}

${ }^{*}$ valores estimados a partir das curvas $\pi-A$. 


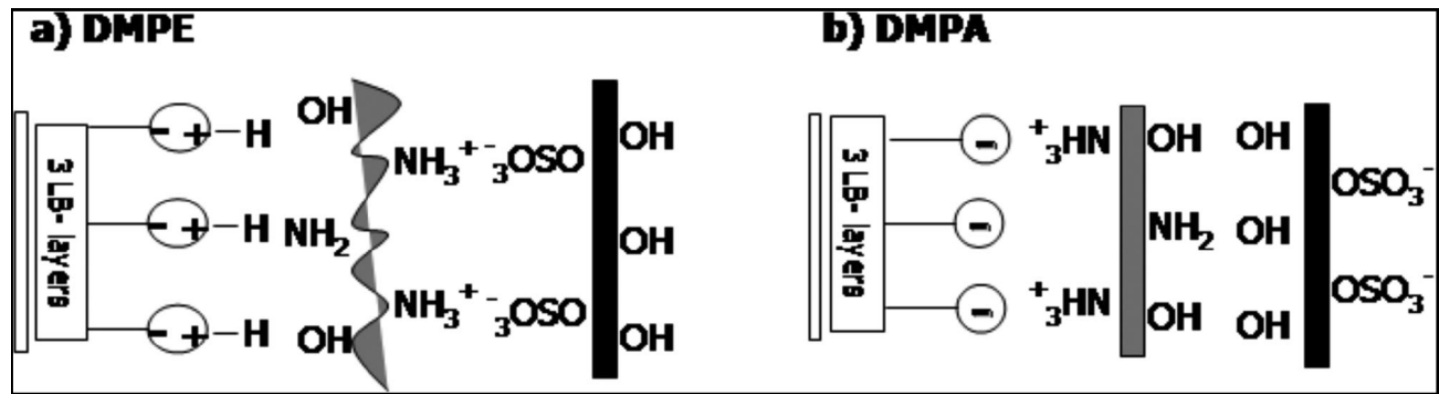

Figura 40: Representação esquemática da influência da carga do fosfolipídeo na conformação dos polieletrólitos depositados.

Como já discutido anteriormente, para o crescimento dos cristais de $\mathrm{CaCO}_{3}$, os íons cálcio são provenientes de, principalmente, duas fontes: íons cálcio ligados ao poliânion como contraíon e íons cálcio aprisionados ou adsorvidos na matriz orgânica. Os ânions são gerados a partir da decomposição de carbonato de amônio que produz $\mathrm{CO}_{2}$, que por sua vez forma carbonato na presença de água. Assim, a supersaturação é dependente da capacidade do filme orgânico aprisionar água, ou $\mathrm{CaCl}_{2}$ especialmente, na última camada. Se esta capacidade varia sistematicamente, pode-se esperar diferenças no crescimento dos cristais.

\subsubsection{Formação de $\mathrm{CaCO}_{3}$ sobre filmes híbridos contendo l-carr}

Inicialmente preparou-se carbonato de cálcio sobre filmes LbL depositados diretamente sobre o suporte metálico e comparou-se com aquele obtido usando-se uma pré-cobertura feita com filme LB de DMPA. Observou-se que a distribuição de tamanhos dos cristais formados sobre filmes LB/LbL é mais monodispersa que a distribuição de tamanhos dos cristais crescidos somente sobre matriz LbL de l-car e Qt (Figura 41). Este resultado mostra que o filme LB usado como pré-cobertura dirige a formação do filme e afeta a formação dos cristais resultando, nesse caso em tamanhos mais definidos. 
Resultados e Discussão

A Figura 42 mostra a evolução no crescimento e mudanças na morfologia dos cristais formados sobre matrizes orgânicas preparadas variando-se a densidade de carga superficial através da variação na fração DMPA/DMPE nos filmes LB usados como cobertura inicial do metal (pré-coating).

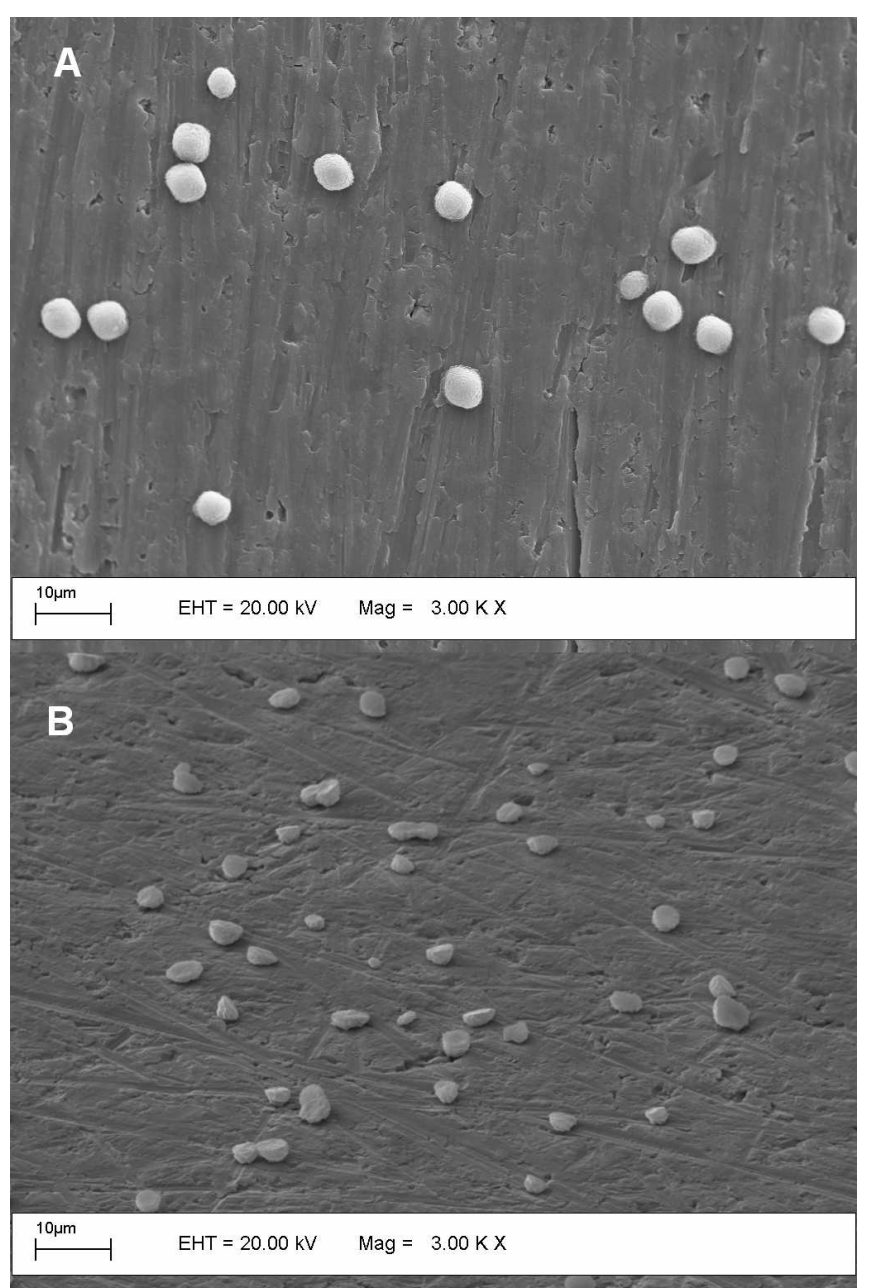

Figura 41: Imagens de MEV de cristais de $\mathrm{CaCO}_{3}$ crescidos sobre: a) 2-bicamadas de filme LbL (Qt/l-car) depositado sobre filme LB de DMPA e b) 2-bicamadas de filme LbL (Qt/ l-car) depositados sobre suporte de alumínio. 

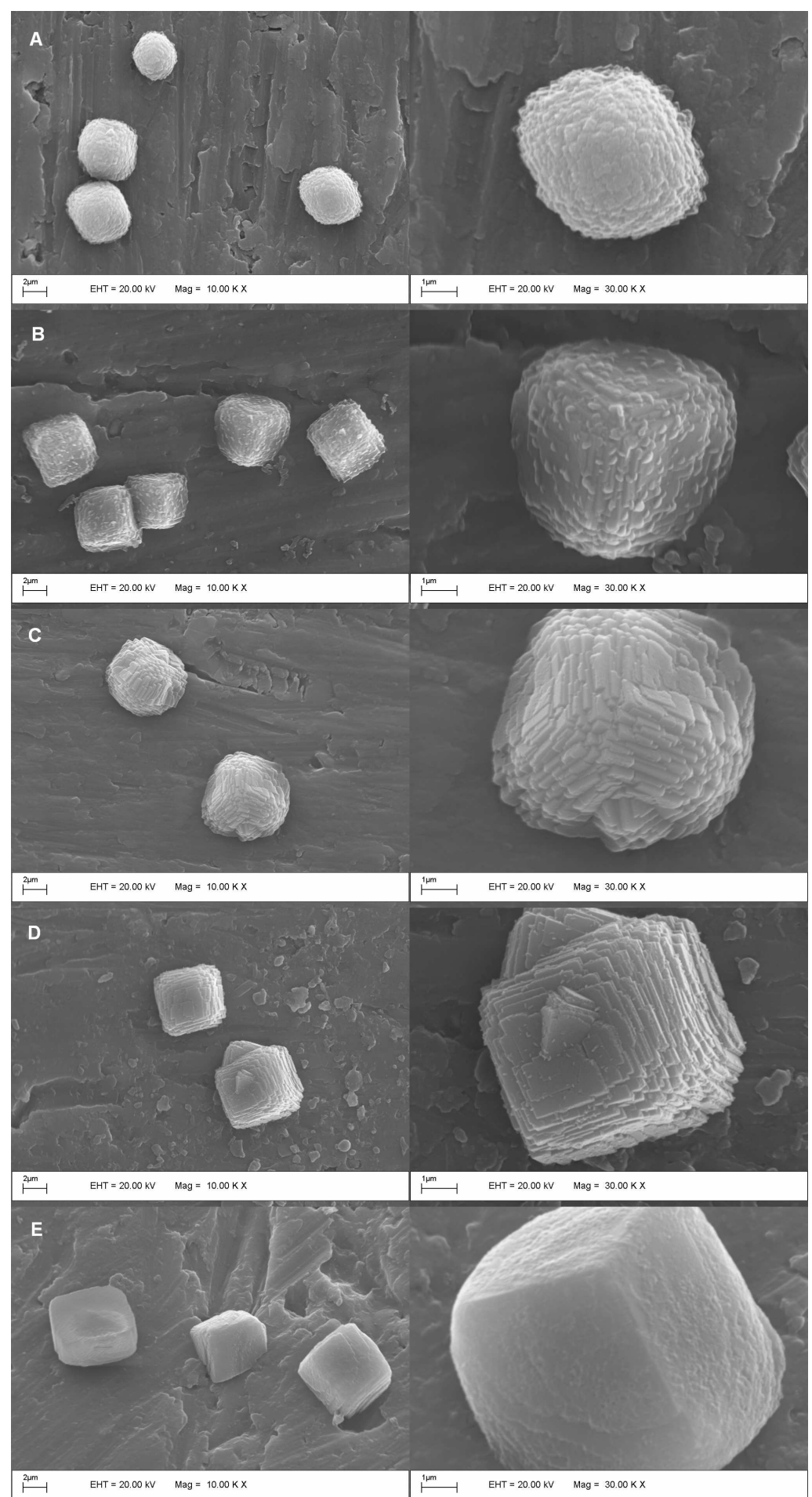

Figura 42: Imagens de MEV dos cristais de $\mathrm{CaCO}_{3}$ crescidos sobre filmes $\mathrm{LB} / \mathrm{LbL}$ formados sobre suportes de alumínio recobertos com filmes LB DMPA/DMPE e filmes LbL Qt/l-car utilizando-se diferentes frações molares de DMPA (a) 1, (b) 0,7, (c) 0,5, (d) 0,3 and (e) 0 (DMPE puro). 


\section{$\underline{\text { Resultados e Discussão }}$}

Os cristais formados sobre superfícies contendo apenas DMPA no filme LB mostram uma estrutura tipo "cogumelo", enquanto o filme LB contendo apenas DMPE na última camada leva à formação de cristais com morfologia cúbica com superfícies mais lisas. Assim, por meio do aumento da quantidade de DMPE na última camada dos filmes LB, obtem-se cristais mais regulares e com superfícies mais lisas. Deve-se notar que nestas condições a quantidade do poliânion l-car no filme é menor do que naqueles compostos de filmes LB de DMPA. Além disso, de acordo com a Tabela 6, a massa total de $\mathrm{CaCO}_{3}$ formada sobre o filme $\mathrm{LB} / \mathrm{LbL}$ contendo apenas DMPA é maior que a massa formada sobre o filme LB/LbL contendo apenas DMPE na pré-cobertura: $6,3 \mu \mathrm{g}$ de $\mathrm{CaCO}_{3}$ foi formado com DMPA e somente 4,5 $\mu \mathrm{g}$ com DMPE. Em contrapartida, o tamanho médio dos cristais formados sobre os filmes LB/LbL contendo DMPE na última camada $(10 \mu \mathrm{m})$ é reduzido quase à metade nos filmes contendo apenas DMPA na pré-cobertura $(5,5 \mu \mathrm{m})$.

Alguns autores ${ }^{44,138}$, investigaram a formação de $\mathrm{CaCO}_{3}$ sobre membranas de quitosana modificadas pela adsorção de poli(ácido acrílico). Nestes estudos, mostrou-se que diferenças na concentração local de $\mathrm{Ca}^{2+}$, ou seja, diferenças na supersaturação local, tal como, diferenças na conformação e orientação das cadeias do polieletrólito, têm influência na orientação e na formação de diferentes polimorfos de $\mathrm{CaCO}_{3}$. Naturalmente, apenas quando o produto iônico $\left[\mathrm{Ca}^{2+}\right]\left[\mathrm{CO}_{3}{ }^{2-}\right]$ supera o produto de solubilidade $\left(\mathrm{K}_{\mathrm{ps}}\right)$ de $2,4 \times 10^{-6} \mathrm{~mol}^{2} \mathrm{~L}^{-2}$, ocorre precipitação de $\mathrm{CaCO}_{3}$. Por meio de mudanças no valor do produto iônico, diferentes polimorfos de $\mathrm{CaCO}_{3}$ foram obtidos. No presente estudo, o produto iônico foi modificado por meio de diferenças na quantidade de 1 -car adsorvida sobre o filme LB contendo Qt, modificando-se desta forma a concentração local de $\mathrm{Ca}^{2+}$.

A estrutura do $\mathrm{CaCO}_{3}$ crescido sobre o filme LB/LbL de DMPE (Figura 6E) aparentemente é derivada do mesmo "bloco" de nucleação que originou as estruturas 
$\underline{\text { Resultados e Discussão }}$

intermediárias observadas na Figura 42B-D. Entretanto, as estruturas mais lisas, observadas sobre o filme LB precursor contendo DMPE na última camada da pré-cobertura, devem ser conseqüência de um maior preenchimento dos espaços entre os "blocos". Além disso, uma menor densidade de cristais e uma menor quantidade média de $\mathrm{CaCO}_{3}$ são encontradas neste tipo de filme. Espera-se, portanto, que a quantidade de pontos de nucleação deva ser menor, mas com um reservatório de íons cálcio nas vizinhanças dos núcleos suficiente para propiciar um eficiente mecanismo de preenchimento. Essa situação deve ser satisfeita pelas particularidades do arranjo da matriz orgânica, que deve resultar em condições de supersaturação locais próprias de meios confinados, como é o caso de géis. Esta hipótese explicaria a menor rugosidade dos cristais sobre a matriz LB/LbL quando o filme LB termina com DMPE. Nessas condições, conforme discutido anteriormente, as moléculas de DMPE propiciam a ligação do polieletrólito l-car por meio de ligações de hidrogênio, deixando indisponível um certo número de grupos hidroxila do hidrocolóide, responsável pela distribuição da solução aquosa, usada no enxágüe, na superfície da matriz. A exposição dos grupos ésteres sulfato, juntamente com enovelamento das cadeias de 1car e distribuição não homogênea de íons hidroxila deve gerar lócus de solução aquosa restrito às vizinhanças dos contra-íons expostos para os quais haja também uma certa concentração de íons hidroxila. Esta condição do meio confinado seria equivalente a um gel bidimensional com poros espaçados e explicaria os tipos de cristais obtidos nesse caso. 
Resultados e Discussão

\subsubsection{Variação no tempo de exposição da matriz orgânica a $\left(\mathrm{NH}_{4}\right)_{2} \mathrm{CO}_{3}$ : acompanhamento do crescimento dos cristais}

Para acompanhamento do crescimento dos cristais realizaram-se experimentos variandose o tempo de exposição da matriz orgânica a $\left(\mathrm{NH}_{4}\right)_{2} \mathrm{CO}_{3}$. A matriz orgânica utilizada era constituída por filme misto LB/LbL onde a última camada do filme LB continha DMPA:DMPE 7:3 e filme LbL (Qt/l-carr $)_{2}$ depositados diretamente sobre o suporte metálico de alumínio prétratado. As Figura 43 e 44 mostram a evolução no crescimento dos cristais em função do tempo de exposição. $\mathrm{O}$ método de exposição à $\left(\mathrm{NH}_{4}\right)_{2} \mathrm{CO}_{3}$ utilizado não nos permitiu a obtenção de dados em tempos inferiores a um minuto. Dados sobre nucleação e crescimento de cristais de carbonato de cálcio observados por microscopia no ângulo de Brewster mostram que o crescimento de $\mathrm{CaCO}_{3}$ é acelerado pela presença de monocamadas de Langmuir de ácidos $\operatorname{graxo}^{26}$. Os tempos de indução variam de 25 a 60 minutos em monocamadas de ácidos graxos contendo 16 a 30 carbonos, respectivamente, na ausência da monocamada o tempo de indução é próximo à 1 hora e 45 minutos. A ligação dos íons às monocamadas aumenta a concentração local, catalizando a cristalização. Os dados obtidos mostram que para as condições estudadas nesta tese a nucleação dos cristais inicia-se em tempos inferiores a um minuto de exposição a $\left(\mathrm{NH}_{4}\right)_{2} \mathrm{CO}_{3}$ (Figura 43). Este resultado indica que a presença da matriz orgânica modifica a supersaturação local, acelerando a nucleação e crescimento dos cristais. Após 1 minuto já é possível observar a formação de cristais com tamanhos apreciáveis, próximos a 1,0 $\mu \mathrm{m}$. Contudo, pode-se observar que com o aumento do tempo de exposição os cristais mudam em tamanho, porém mantêm a mesma morfologia inicial (Figura 44). 


\section{$\underline{\text { Resultados e Discussão }}$}

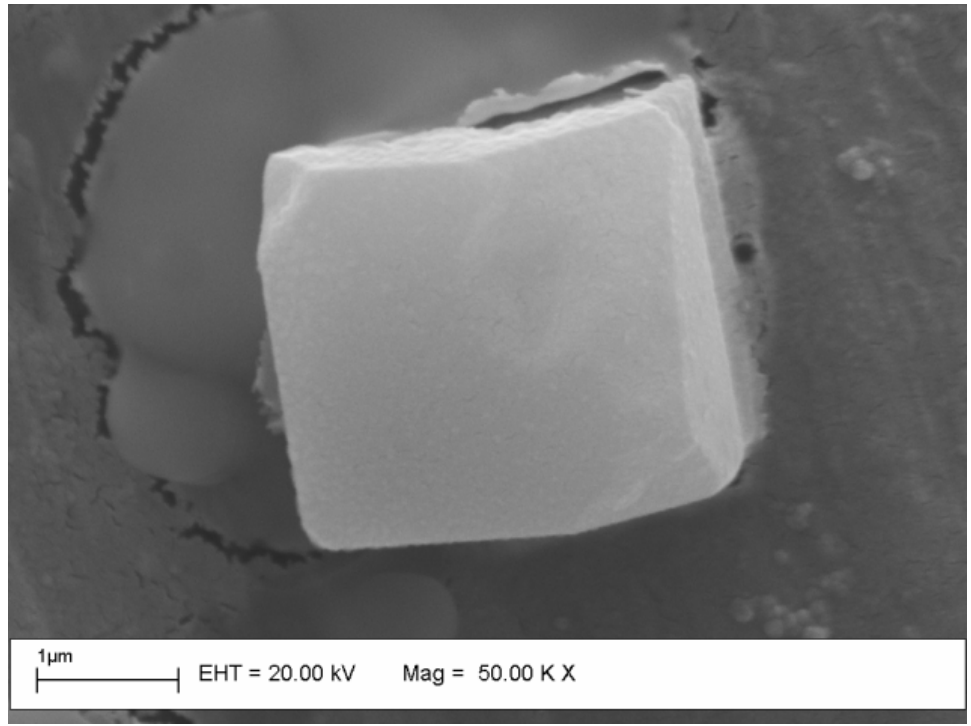

Figura 43: Formação de $\mathrm{CaCO}_{3}$ sobre matriz orgânica depositada sobre alumínio exposta a $\left(\mathrm{NH}_{4}\right)_{2} \mathrm{CO}_{3}$ por um minuto.

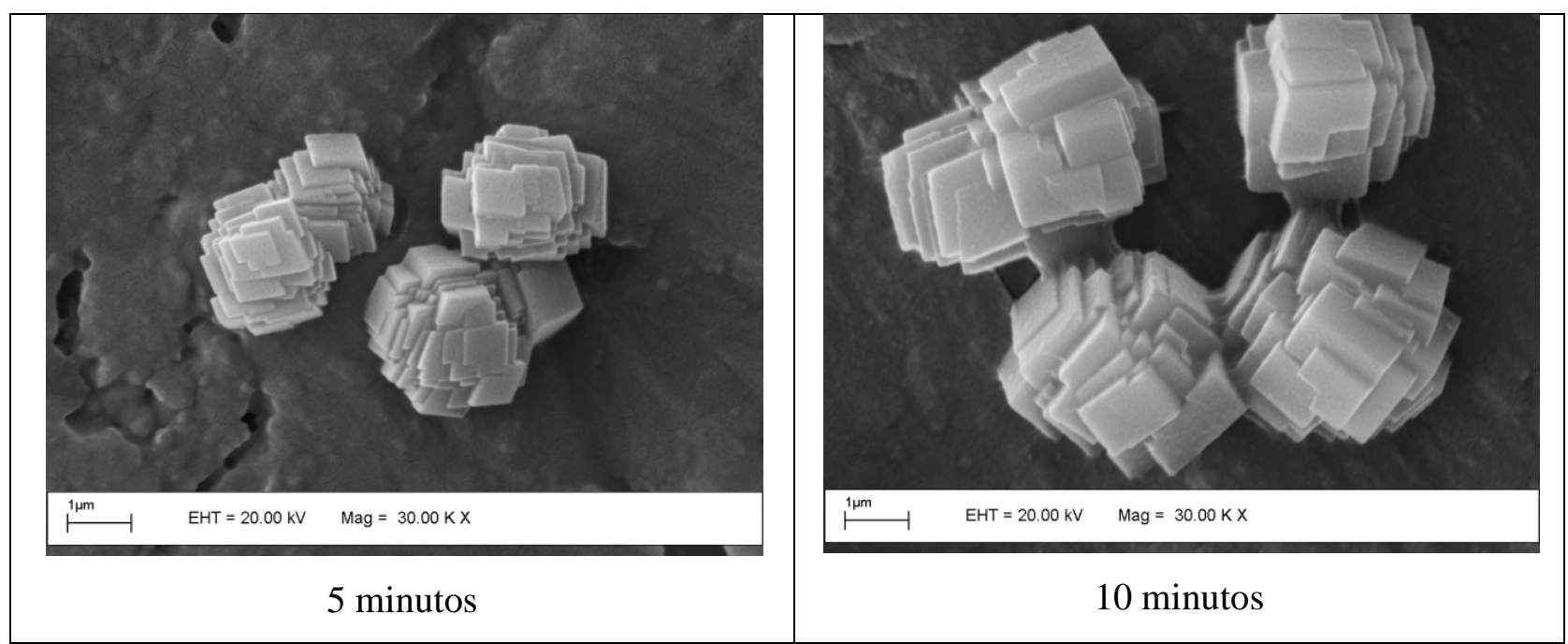




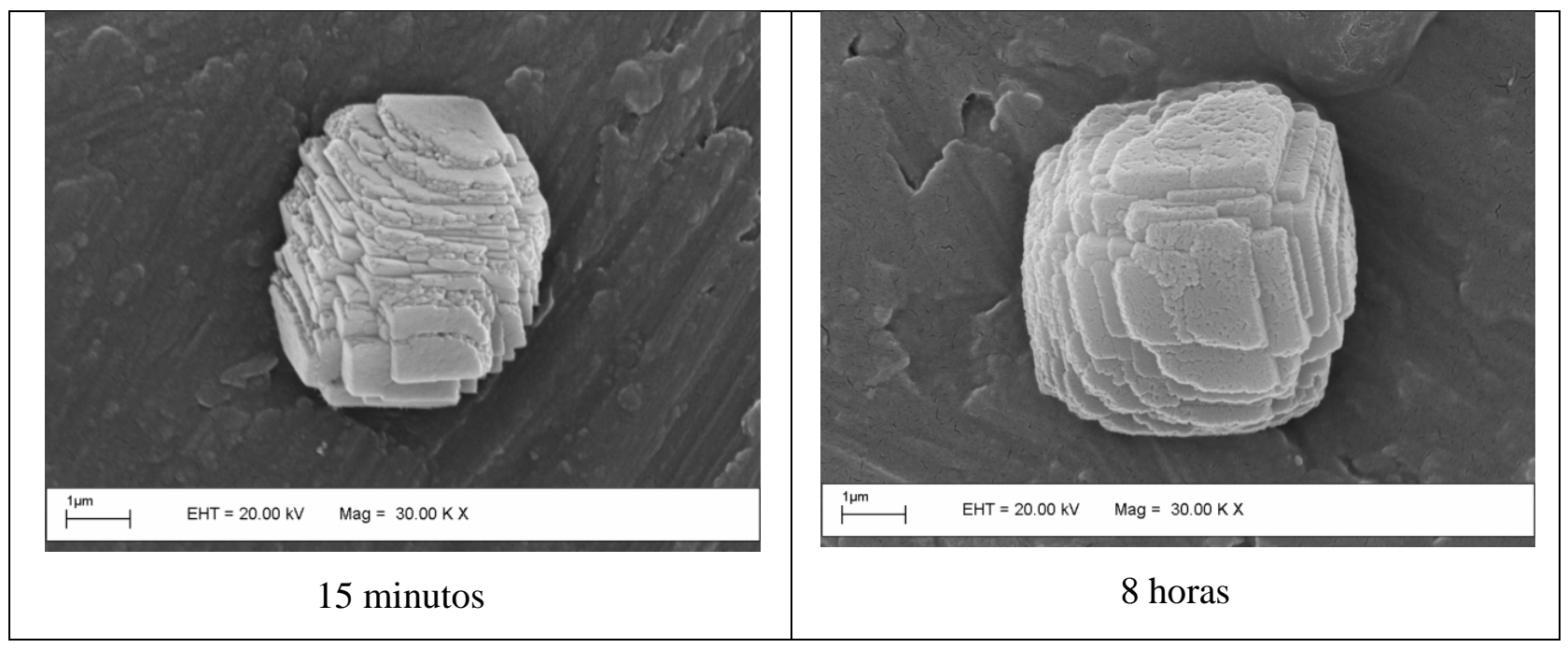

Figura 44: Evolução no crescimento de cristais de $\mathrm{CaCO}_{3}$ em função do tempo de exposição à $\left(\mathrm{NH}_{4}\right)_{2} \mathrm{CO}_{3}$.

\subsection{Crescimento de filmes de $\mathrm{CaCO}_{3}$ sobre matrizes orgânicas} mistas LB/LbL usando poliânions que apresentam conformação de novelo-ao-acaso: poli(ácido acrílico), PAA, e lambdacarragenana ( $\lambda$-car)- Efeito do tipo de fosfolipídeo no filme $L B$.

Nesta seção serão mostrados resultados da formação de matrizes orgânicas mistas LB/LbL compostas por DMPA ou DMPE e PAA ou $\lambda$-car sobre suportes de alumínio e posterior crescimento de partículas de $\mathrm{CaCO}_{3}$.

Variando-se o tipo de poliânion utilizado para o crescimento de filmes LbL pudemos obter filmes contínuos de $\mathrm{CaCO}_{3}$ ao invés de partículas isoladas. Para o crescimento dos filmes da $\mathrm{CaCO}_{3}$ utilizou-se dois tipos de poliânions: $\lambda$-car e PAA. Constatou-se que a morfologia dos cristais de $\mathrm{CaCO}_{3}$ sofrem influência tanto do tipo de polieletrólito quanto do tipo de fosfolipídeo, utilizados na formação das matrizes orgânicas LB/LbL. 
Resultados e Discussão

As principais diferenças entre PAA e 1 -car devem-se à natureza dos grupos carregados e suas conformações em solução. PAA é um poli(ácido carboxílico) que apresenta conformação “novelo-ao-acaso", enquanto l-car é um polissacarídeo sulfatado com conformação helicoidal ${ }^{139}$ em solução aquosa. Para estudar também a influência do tipo de grupo carregado da influência da conformação, foi utilizada na formação do filme LbL a $\lambda$-car que também é um polissacarídeo sulfato, porém possui conformação "novelo-ao-acaso"140,141 como o PAA. Uma explicação possível para a formação ou não formação dos filmes contínuos pode ser atribuída a diferenças nos mecanismos de nucleação e crescimento dos cristais de $\mathrm{CaCO}_{3}$ que poderiam ocorrer nos diferentes tipos de filme LbL utilizados como matriz. Por exemplo, poderíamos esperar que as estruturas helicoidais formadas em solução pela l-car, quando transferidas ao suporte sólido pudessem confinar solução de $\mathrm{CaCl}_{2}$, acumulando íons cálcio em espaços maiores, porém mais isolados o que levaria ao crescimento de cristais de $\mathrm{CaCO}_{3}$ separados. Entretanto, uma distribuição de cargas mais homogênea do PAA e da $\lambda$-car promoveria uma distribuição contínua de íons $\mathrm{Ca}^{2+}$ sobre toda a matriz, possibilitando a formação de filmes de $\mathrm{CaCO}_{3}$ contínuos e homogêneos. Por outro lado, a distância entre cargas na interface do filme LbL ou a diferente afinidade dos grupos negativamente carregados por íons cálcio poderiam ser também causas para a formação, ou não, dos filmes contínuos.

A densidade superficial do PAA depende do grau de ionização ${ }^{142}$. Para o $\mathrm{pH}$ de trabalho $(3,7)$ a fração de cargas das cadeias (f) é aproximadamente 0,01 . No caso da 1 -car e $\lambda$-car f é aproximadamente o mesmo $^{143}, 2$ grupos sulfato carregados por unidade repetitiva dissacarídica. Entretanto, a densidade superficial depende da separação entre os grupos eletricamente carregados, que por sua vez depende da conformação da macromolécula. Para PAA com f=0,01, a distância entre os grupos carregados, $r$, na configuração estendida é aproximadamente $25 \mathrm{~nm}$. 
Para $\lambda$-car, na conformação "novelo-ao-acaso", r= 0,5 nm e para 1 -car, na configuração helicoidal $\mathrm{r}=0,4 \mathrm{~nm}$.

Primeiramente, comparamos o efeito do tipo de polieletrólito (PAA and $\lambda$-car) no crescimento de cristais de $\mathrm{CaCO}_{3}$ em filmes $\mathrm{LbL}$ sem a presença do filme LB. Podemos observar na Figura 45 imagens de MEV dos filmes de $\mathrm{CaCO}_{3}$ formados sobre filmes $\mathrm{LbL}$ de treze camadas alternadas do poliânion e quitosana. Aparentemente, ocorre a formação de $\mathrm{CaCO}_{3} \mathrm{em}$ toda a matriz polimérica, e tanto PAA quanto $\lambda$-car promovem a formação de um filme inorgânico fino e particulado (Figura 45). Entretanto,o tamanho dos grãos formados são diferentes nos dois filmes: com $\lambda$-carr os grãos são maiores que $~ 200 \mathrm{~nm}$ (Figura 45a), enquanto nos filmes com PAA os grãos apresentam dimensões de aproximadamente $50 \mathrm{~nm}$ (Figura 45b). Todavia, para $\lambda$-car cada grão é formado por um conjunto de partículas ainda menores, estimados em 20 nm (encarte (a)). No caso do PAA a sinterização das partículas é mais pronunciada e não é possível distinguir partículas menores nos grãos formados (encarte (b)). Este resultado pode refletir a influência das diferentes densidades de carga dos dois polieletrólitos. 

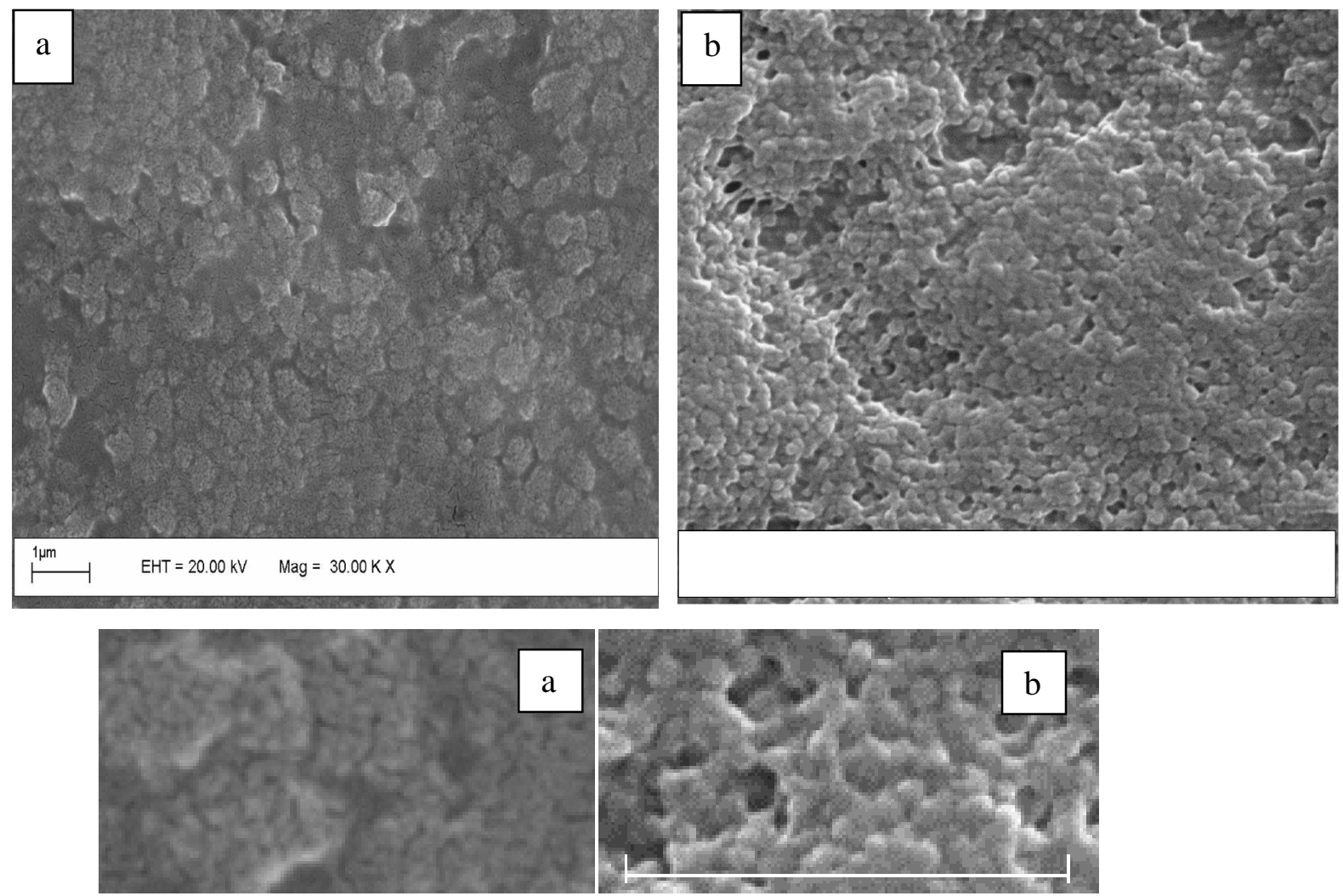

Figura 45: imagens de $\mathrm{MEV}$ de filmes de $\mathrm{CaCO}_{3}$ crescidos sobre matriz ( $\left.\mathrm{LbL}\right)_{13}$ formadas com a) $(\lambda \text {-car/Qt })_{6} \lambda$-car; b) (PAA/Qt $)_{6} \mathrm{PAA}$. Abaixo, aumento da imagem correspondente.

Também foi estudada a formação de filmes de $\mathrm{CaCO}_{3}$ sobre matrizes orgânicas mistas LB/LbL. Mudanças no tipo de fosfolipídeo utilizado influenciam a morfologia dos cristais que formam os filmes. Imagens de MEV dos filmes de $\mathrm{CaCO}_{3}$ formados utilizando-se DMPA como fosfolipídeo (Figuras 46 e 47) mostram que a matriz mista $\mathrm{LB} / \mathrm{LbL}$ formada com $\lambda$-carr e Qt, com 3 ou 13 camadas depositadas, levam à formação, principalmente, de partículas alongadas, sendo a maior parte orientada com o maior eixo paralelo à superfície. No entanto, filmes DMPA/(Qt/PAA $)_{n}$ levam à formação de partículas menores, achatadas aparentemente com orientação randômica. Deve-se considerar que, quando DMPA é utilizado como pré-cobertura para a formação do filme LbL, o policátion, Qt, utilizado na primeira camada, deve ligar-se eletrostaticamente, deixando grupos $-\mathrm{NH}_{2} \mathrm{e}-\mathrm{OH}$ disponíveis para ligação de hidrogênio com o 
poliânion da camada seguinte. No pH utilizado o PAA deve estar apenas parcialmente ionizado, com um baixo comprimento de persistência. Por outro lado $\lambda$-car, está completamente ionizada e deve apresentar conformação mais estendida, como um elevado comprimento de persistência.

Quando DMPE é utilizado na última camada do filme LB (Figura 48), é evidente a formação de partículas elipsoidais orientadas com diferentes ângulos, mas, principalmente, com seus eixos maiores orientados perpendicularmente à superfície, formando estruturas tipo "flor" no caso do filme LbL contendo $\lambda$-car. Para PAA a orientação é principalmente paralela à superfície.
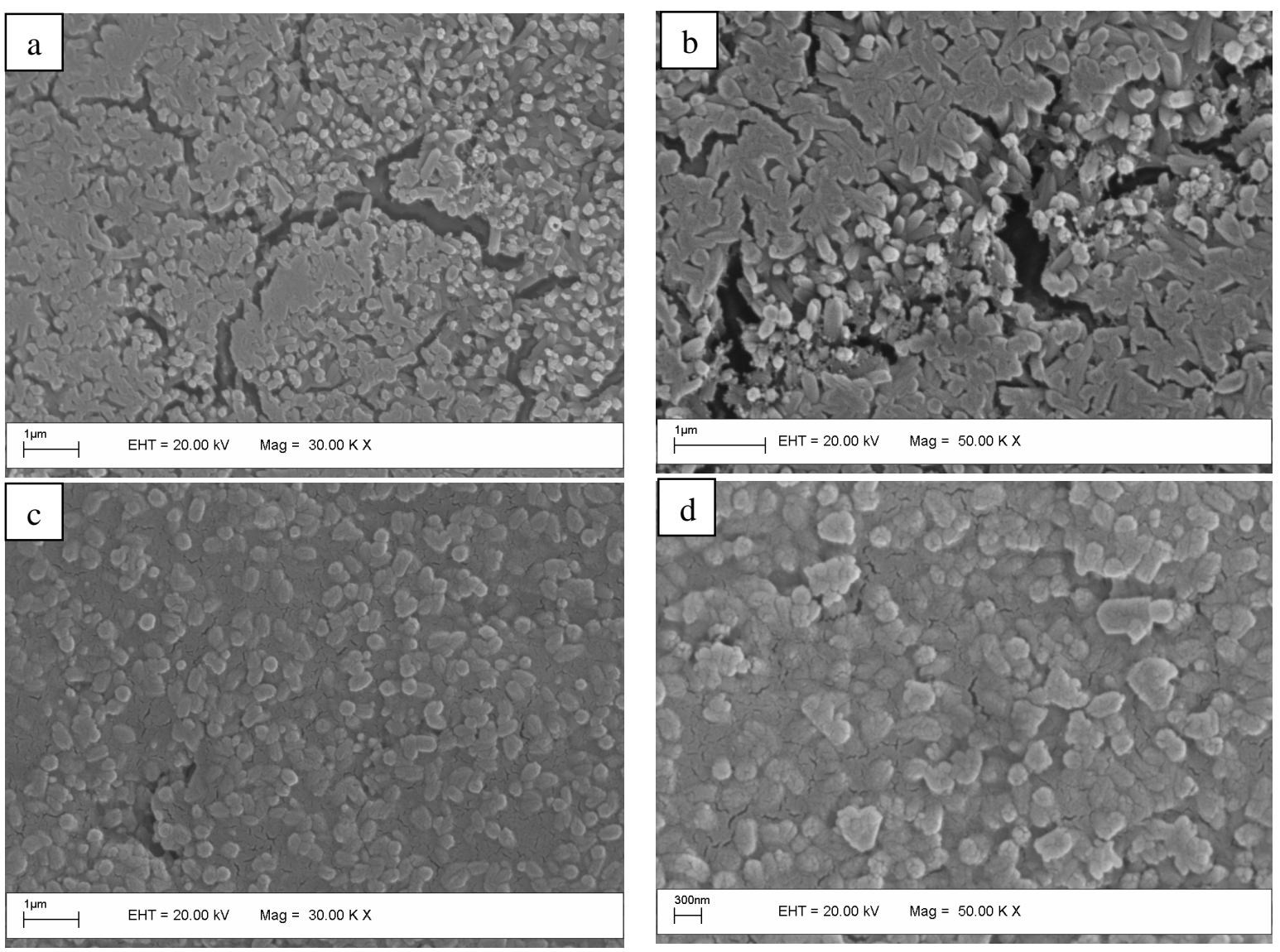

Figura 46: imagens de MEV de filmes de $\mathrm{CaCO}_{3}$ crescidos sobre matriz orgânica mista DMPA/ LB-(LbL) ${ }_{3}$ formadas com a,b) $\lambda$-car; c,d) PAA. 
Resultados e Discussão
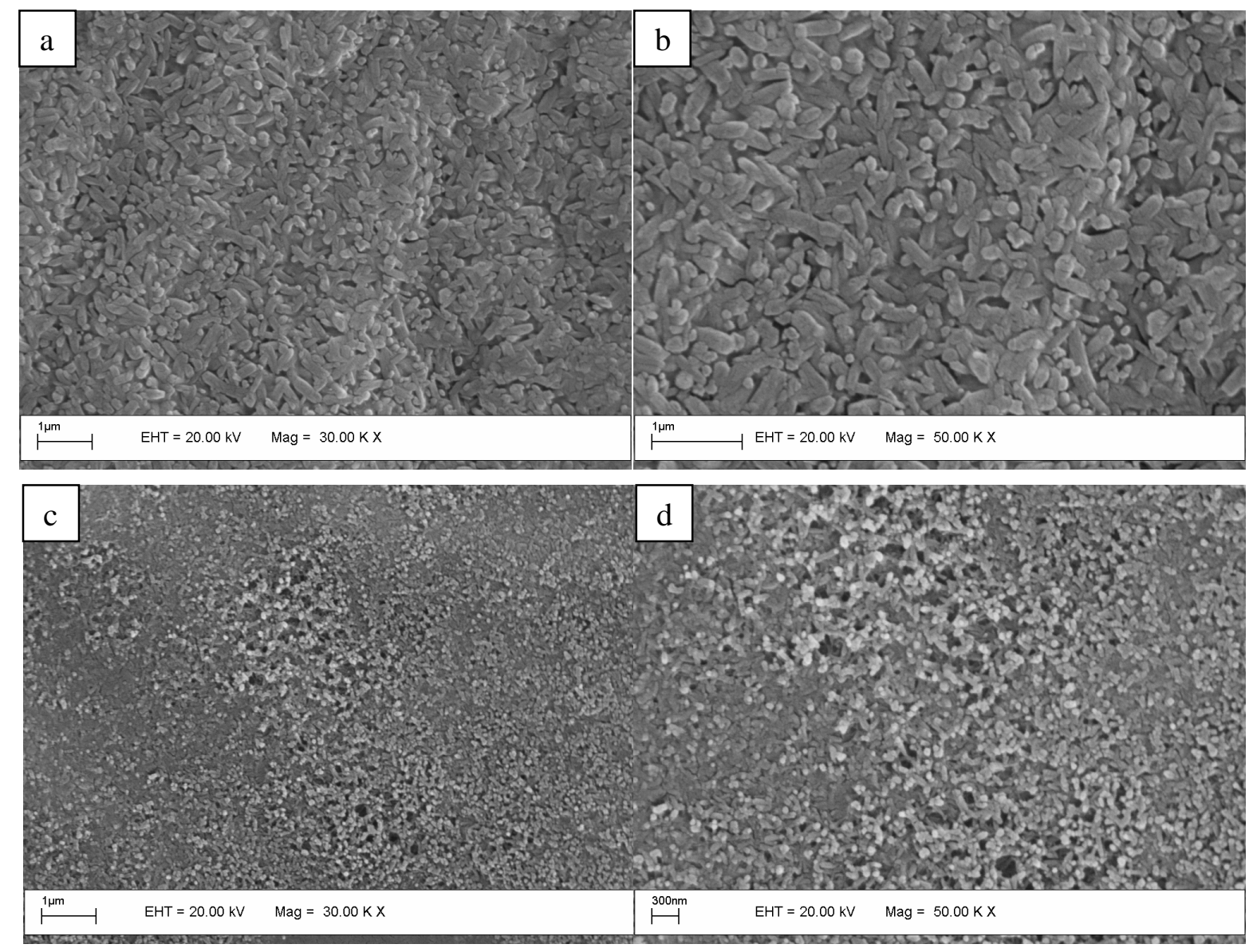

Figura 47: imagens de MEV de filmes de $\mathrm{CaCO}_{3}$ crescidos sobre matriz orgânica mista DMPA/ LB-(LbL) ${ }_{13}$ formadas com a,b) $\lambda$-carr; c,d) PAA. 

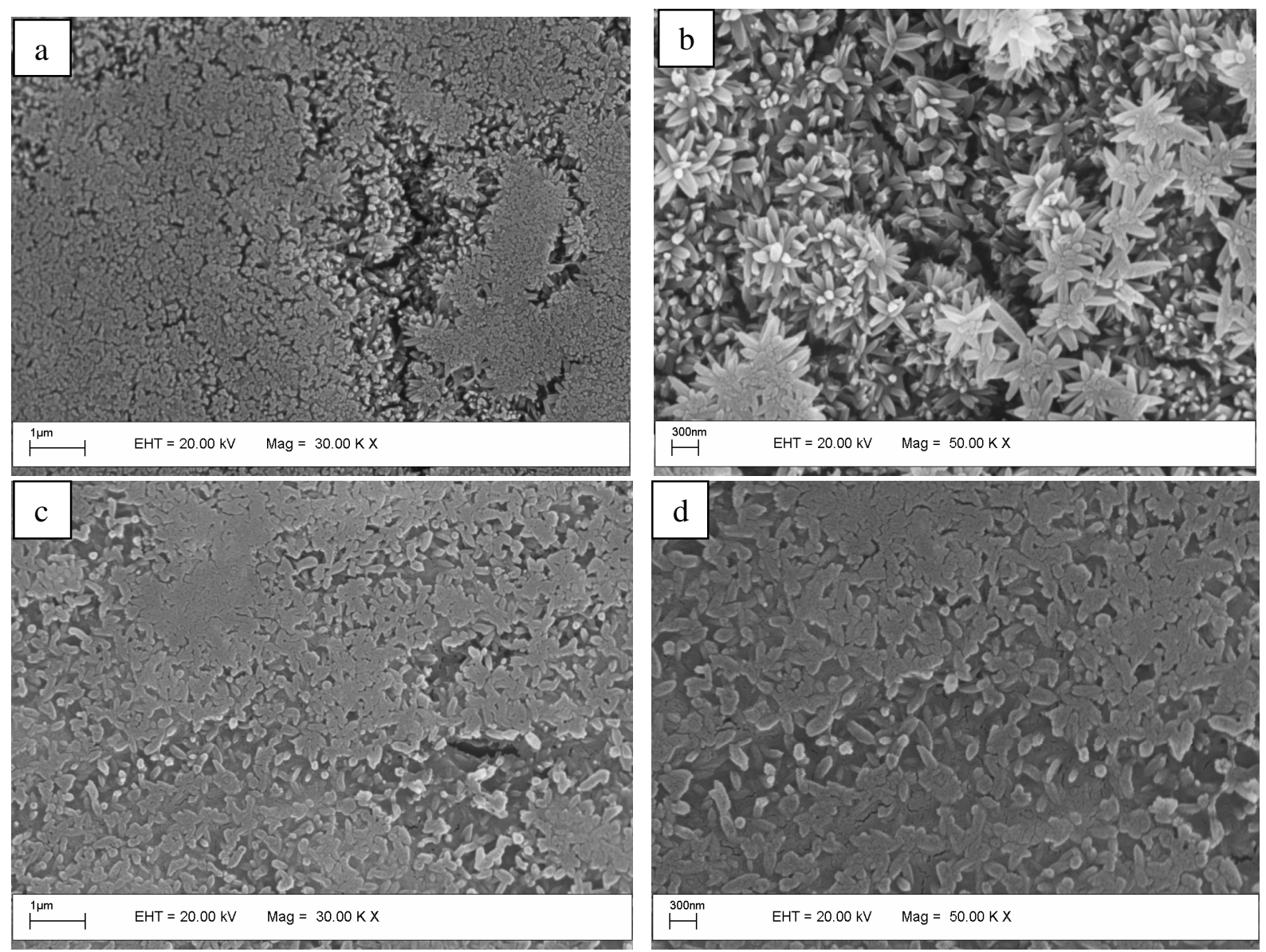

Figura 48: Imagens de MEV de filmes de $\mathrm{CaCO}_{3}$ crescidos sobre matriz orgânica mista DMPE/ LB-(LbL) $)_{3}$ formadas com quitosana e $\lambda$-car $(a, b)$; PAA $(c, d)$.

Desta forma, mostramos que a carga da cabeça polar dos fosfolipídeos que compõe o filme LB podem direcionar a nucleação e crescimento das partículas de $\mathrm{CaCO} 3$ por meio de mudanças na estrutura da matriz polimérica sobre a qual ocorreu a cristalização. A presença de DMPE leva à formação de partículas alongadas que se orientam perpendicularmente ou paralelamente ao suporte dependendo do tipo de poliânion que compões o filme LbL. Já, na presença de DMPA partículas alongadas são formadas apenas na presença de $\lambda$-car e partículas achatadas que parecem não exibir orientação preferencial são formadas na presença de PAA. O formato e a orientação das partículas são dependentes do conjunto fosfolipídeo/poliânion. 
Resultados e Discussão

Imagens de AFM (Figura 49) dos filmes com e sem carbonato de cálcio exibem diferenças significativas. Podemos observar que o filme contendo somente a matriz polimérica possui elevações máximas com aproximadamente $181 \mathrm{~nm}$, enquanto os filmes contendo $\mathrm{CaCO}_{3}$ mostram elevações máximas com aproximadamente $61 \mathrm{~nm}$ para o filme contendo DMPA e $(\mathrm{LbL})_{13}$ com $\lambda$-car e $43 \mathrm{~nm}$ para o filme de $\mathrm{CaCO}_{3}$ formado diretamente sobre o filme (LbL) 13 com $\lambda$-car. Como o filme híbrido não pode ser menos espesso que a matriz polimérica apenas, esta diferença entre as alturas dos filmes orgânico e híbrido pode ser atribuída ao recobrimento total da matriz orgânica pelo filme inorgânico.

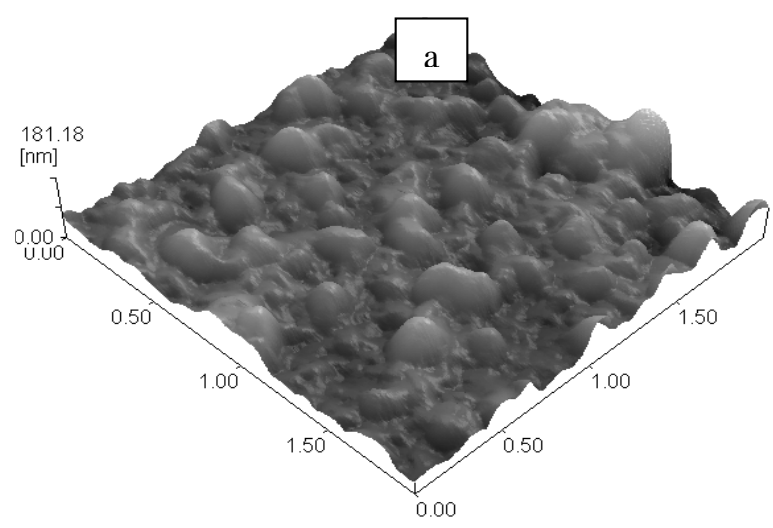

$2.00 \times 2.00[\mathrm{um}] \quad Z 0.00-181.18[\mathrm{~nm}]$

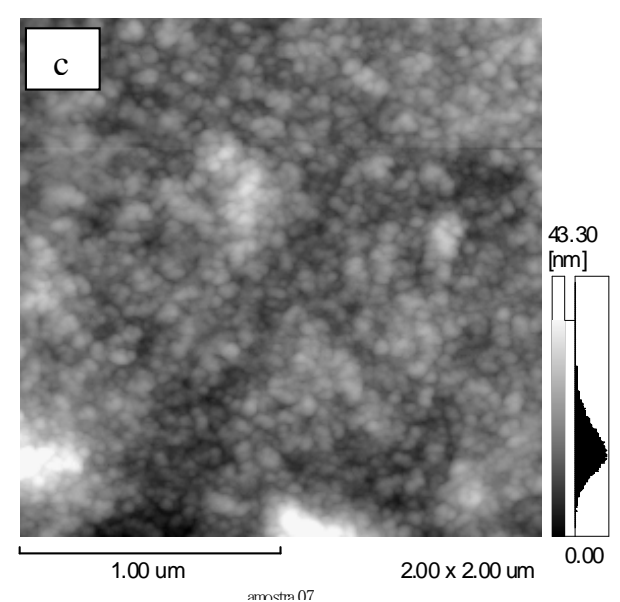

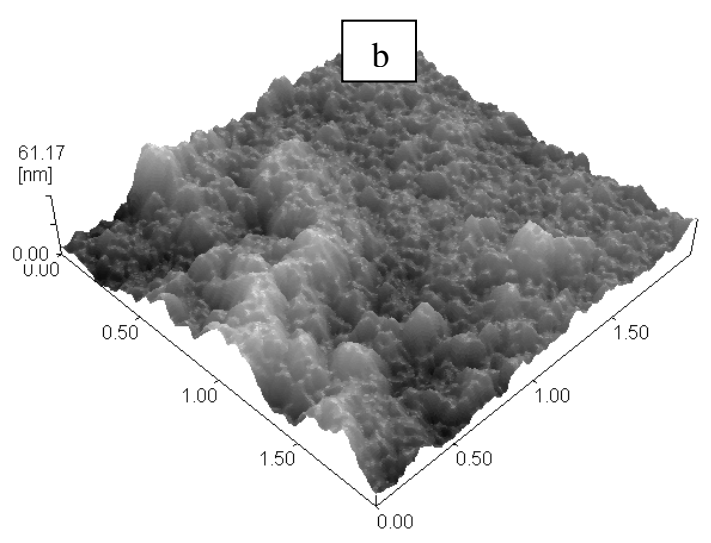

$2.00 \times 2.00[\mathrm{um}] \quad$ Z $0.00-61.17[\mathrm{~nm}]$

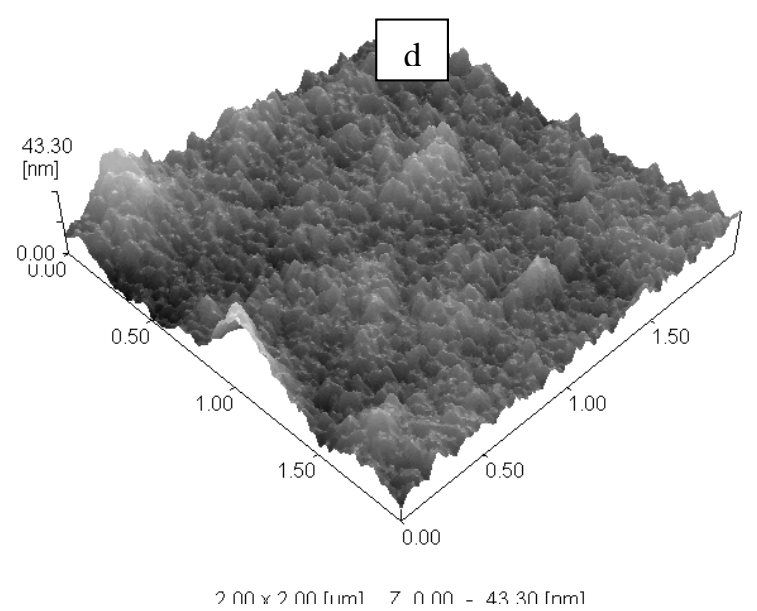

Figura 49: Imagens de AFM dos filmes (a) DMPA LB/(LbL) 13 sem $\mathrm{CaCO}_{3}$, (b) DMPA $\mathrm{LB} /(\mathrm{LbL})_{13}$ com $\mathrm{CaCO}_{3}$, (c) vista de cima, (LbL) ${ }_{13} \operatorname{com~} \mathrm{CaCO}_{3}$, (d) (LbL) $)_{13} \operatorname{com~} \mathrm{CaCO}_{3}$. 


\subsection{Efeito do microambiente na deposição de $\mathrm{CaCO}_{3}$ : suportes planares em solução de $\mathrm{CaCl}_{2} 10 \mathrm{mmol} \mathrm{L}^{-1}$.}

O microambiente no qual ocorre a formação de $\mathrm{CaCO} 3$ foi modificado por meio de mudanças nas seguintes condições: rugosidade do suporte, tipo de poliânion e disponibilidade de íons cálcio. Com intuito de se verificar a influência da disponibilidade iônica, e conseqüentemente do microambiente onde os cristais são crescidos, a deposição de $\mathrm{CaCO}_{3}$ sobre os suportes contendo a matriz orgânica foi realizada por meio da imersão dos mesmos em solução de $\mathrm{CaCl}_{2}$ 0,01 mol L-1 e seqüente exposição ao $\left(\mathrm{NH}_{4}\right)_{2} \mathrm{CO}_{3}$ em recipiente fechado por 13 horas. Foram utilizados dois diferentes tipos de poliânion (PAA e PSS) formadores do filme LbL. A escolha do PSS justifica-se por apresentar uma estrutura de cadeia mais simples e conter grupos sulfonato, em contraponto aos grupos sulfato das carragenanas, que exibem estrutura mais complexa. Também foram utilizadas duas diferentes maneiras de imersão do suporte contendo a matriz orgânica: face contendo a matriz orgânica virada para cima e face contendo a matriz orgânica virada para baixo. Esses experimentos tiveram por objetivo oferecer uma prova definitiva sobre a existência ou não de diferenças para o carbonato de cálcio depositado a partir do interior da solução ou crescido apenas sobre a matriz polimérica. Deposições realizadas no interior de soluções podem anular o efeito da matriz orgânica, uma vez que, partículas maiores podem precipitar na solução e apenas aderir sobre o suporte, mascarando as partículas menores que teriam crescido diretamente ligadas ao mesmo. Este foi o motivo para introduzirmos o método da deposição a seco. Nesse caso, estamos interessados no microambiente e gostaríamos que as condições fossem as mais próximas possíveis, porém queríamos descartar a possibilidade de deposição a partir da solução. Por isso, optou-se também pelo método de deposição onde o suporte é imerso em solução com a face contendo a matriz orgânica voltada para baixo, assim, o 


\section{$\underline{\text { Resultados e Discussão }}$}

carbonato de cálcio pode crescer ligado diretamente a partir dos íons cálcio ligados à matriz orgânica, e ainda, crescer axialmente devido aos íons cálcio em solução, presentes na vizinhança da matriz, eliminando a possibilidade de precipitação a partir do interior da solução sobre o suporte.

\subsubsection{Efeito da Rugosidade do suporte}

Os resultados apresentados nas Figuras 49 e 50 referem-se a filmes filmes de PAA e quitosana formados sobre suporte de alumínio, silício e aço-inox imersos em solução com a face voltada para cima. Observa-se a formação de cristais de $\mathrm{CaCO}_{3}$ que se agregam como ilhas isoladas. O tamanho desses agregados é muito variado e difere, consideravelmente, do tamanho dos agregados formados pelo método "a seco" (Figura 32). Nota-se ainda, que os agregados são formados por partículas de tamanho e morfologia variados, permitindo assim identificar morfologicamente partículas de calcita, na forma de pequenos romboedros que se agregam, e vaterita (círculo vermelho na Figura 50b), apesar da nítida predominância de calcita. Além da formação de agregados de partículas, também foi possível a observação da formação de filme contínuo, como mostrado na Figura 50d. 


\section{$\underline{\text { Resultados e Discussão }}$}
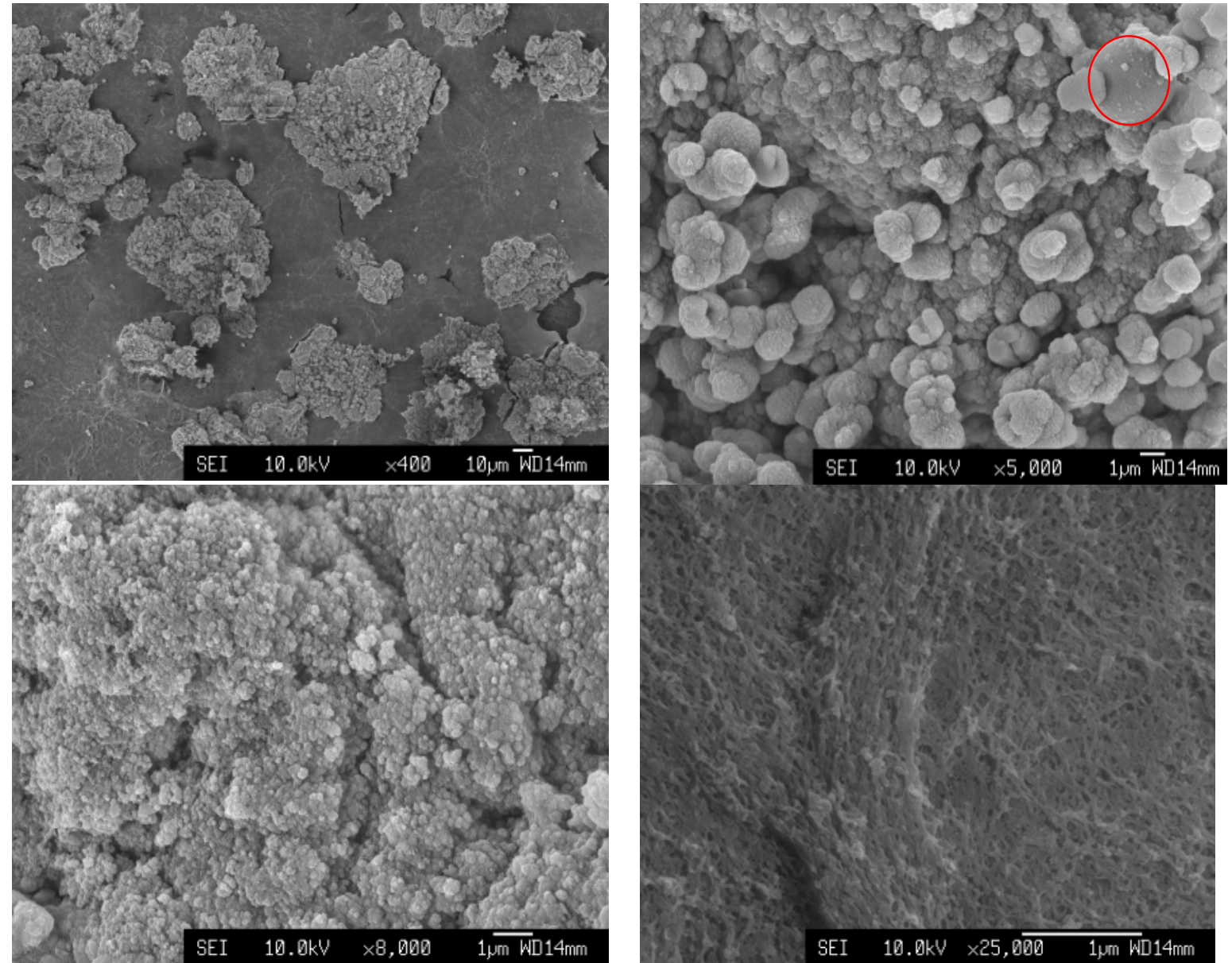

Figura 50: Filme híbrido (PAA/Qt) ${ }_{6} \mathrm{PAA} / \mathrm{CaCO}_{3}$ depositado sobre suporte de alumínio. O filme polimérico foi imerso em solução de $\mathrm{CaCl}_{2} 0,01 \mathrm{~mol} \mathrm{~L}^{-1}$ para a deposição do carbonato de cálcio. 

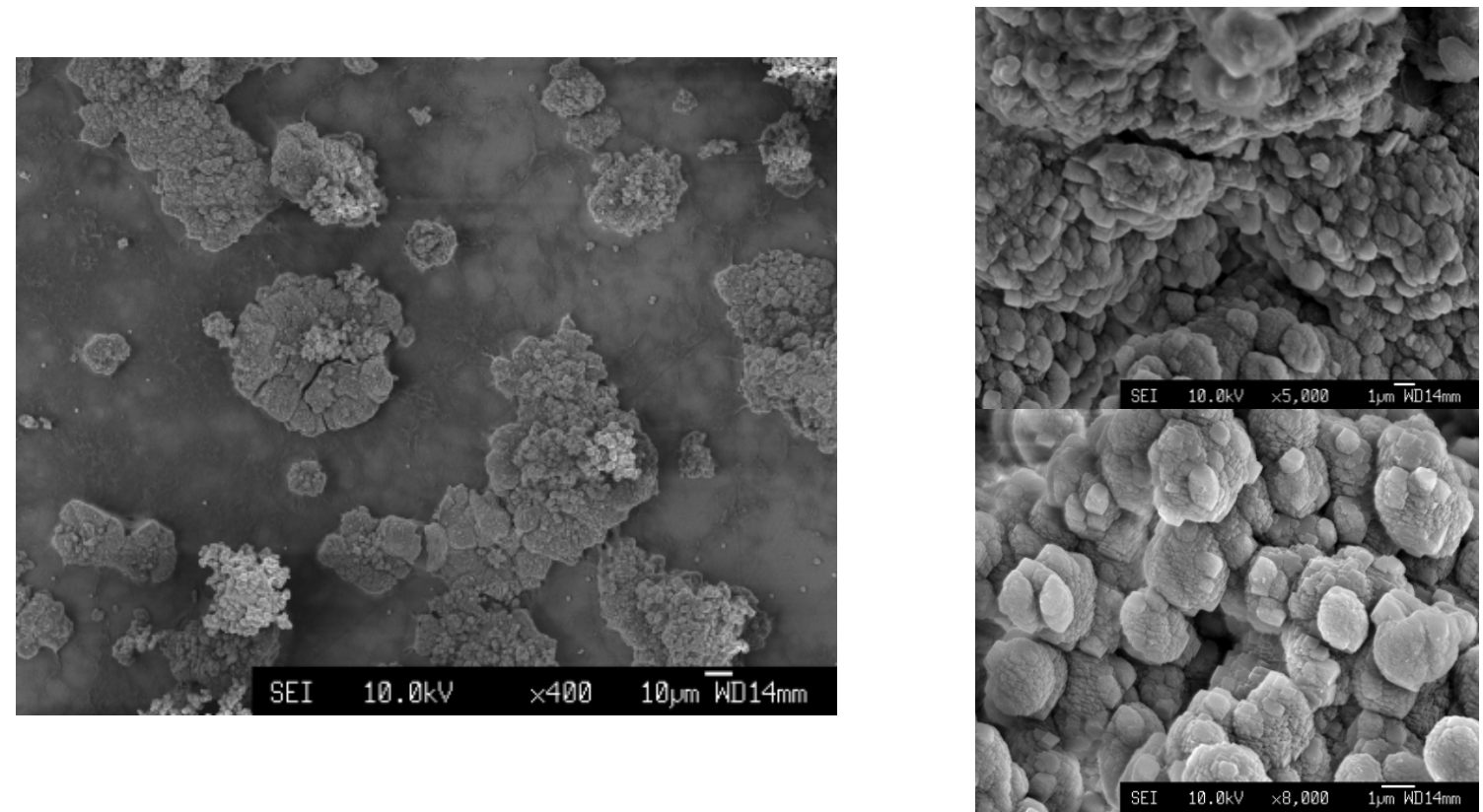

Figura 51: Filme híbrido (PAA/Qt) ${ }_{6} \mathrm{PAA} / \mathrm{CaCO}_{3}$ depositado sobre suporte de aço-inox. $\mathrm{O}$ filme polimérico foi imerso em solução de $\mathrm{CaCl}_{2} 0,01 \mathrm{~mol} \mathrm{~L}{ }^{-1}$.

Nos difratogramas apresentados na Figura 52 observamos que o tipo de suporte não influencia nos tipos de polimorfos formados. Os difratogramas são idênticos, desconsiderando-se os picos referentes aos suportes. Os picos observados correspondem aos polimorfos calcita (C) e vaterita (V). Como as diferenças de largura de pico não são significativas e como todas as condições foram mantidas constantes (concentração da solução, tipo de recobrimento do substrato, temperatura e tempo de deposição), pode-se usar a razão entre intensidades de picos observados para calcita e vaterita para estimar a proporção entre os polimorfos presentes na amostra. Devemos levar em consideração que o fator de estrutura dos planos (hkl) com diferentes índices de Miller, influencia na intensidade dos picos observados para os mesmos, portanto não temos uma análise apenas qualitativa, mas sim uma estimativa das proporções entre calcita e vaterita, comparando-se cada amostra. Calculou-se a razão entre as áreas dos picos em 29,1 , 
Resultados e Discussão

correspondente à calcita, e em $27^{\circ}$, correspondente à vaterita. Os resultados estão mostrados na Tabela 7.

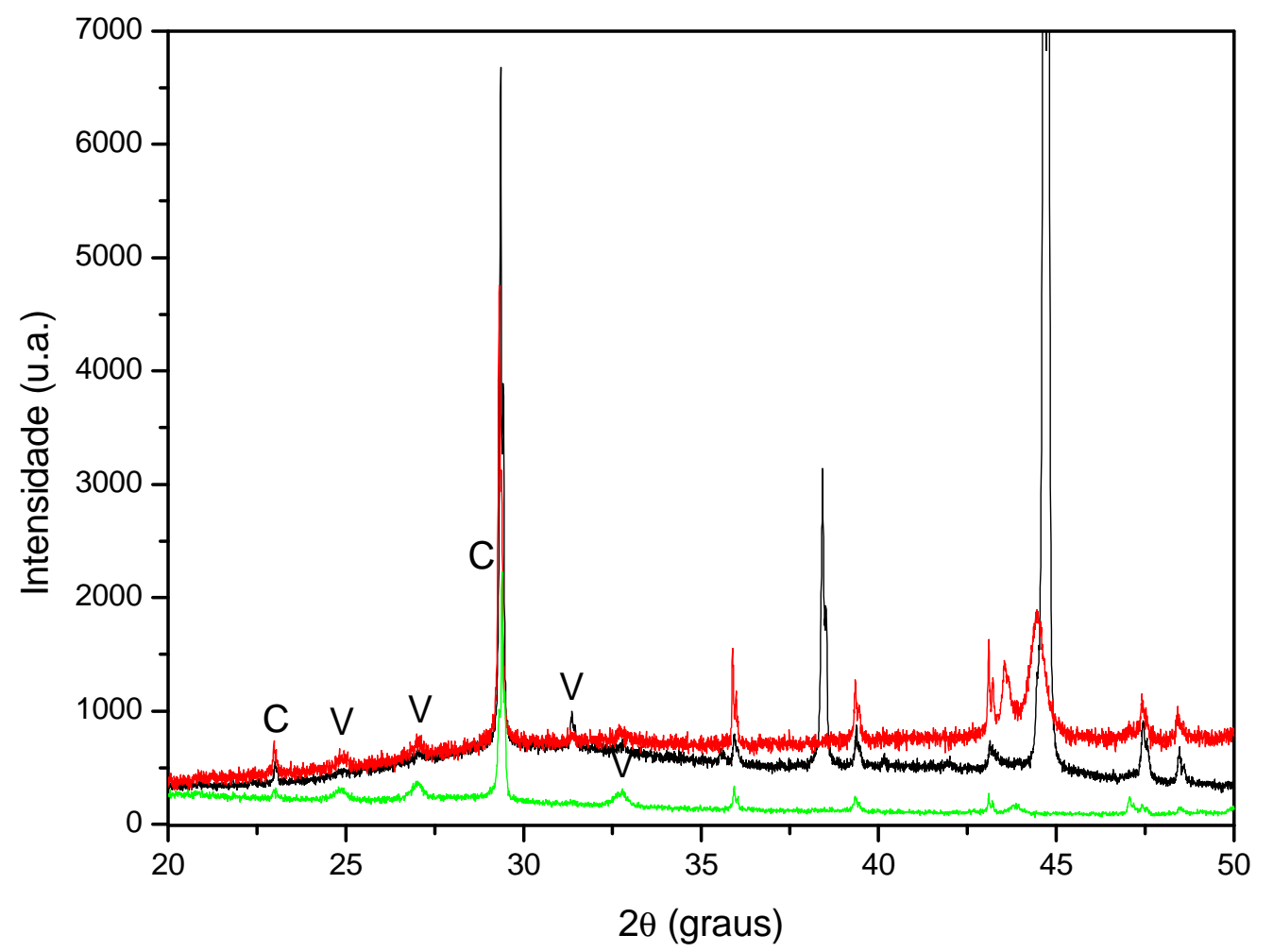

Figura 52: Difratograma de filmes $\mathrm{LbL}$ de $(\mathrm{PAA} / \mathrm{cht})_{6} \mathrm{PAA}+\mathrm{CaCO}_{3}$ depositados sobre diferentes suportes, imersos em solução de $\mathrm{CaCl}_{2}$ 0,01 mol L $\mathrm{L}^{-1}$. Alumínio (linha preta), aço-inox (linha vermelha) e silício (linha verde). 
Tabela 7: Razão entre as áreas dos picos correspondentes aos polimorfos calcita (C) e vaterita (V) para amostras de $\mathrm{CaCO} 3$ formadas sobre filmes LbL de quitosana e PAA, depositados sobre suportes de diferentes rugosidade

\begin{tabular}{|c|c|}
\hline Amostra & Razão C/V \\
\hline Alumínio & 2,9 \\
\hline Aço-inox & 2,2 \\
\hline Silício & 1,6 \\
\hline
\end{tabular}

Nas amostras de carbonato de cálcio depositadas sobre os suportes metálicos modificados com o filme polimérico formou-se mais calcita quando os suportes eram aço-inox e alumínio, mais rugosos, quando comparadas com as amostras formadas sobre silício. Desta forma pode-se afirmar que o suporte mais rugoso (alumínio) estabiliza o polimorfo termodinamicamente mais estável em detrimento ao polimorfo cinéticamente mais estável, vaterita. Estes resultados podem ser decorrentes de diferenças de processos difusivos quando suportes de diferentes rugosidades são utilizados. Sobre silício, por possuir superfície mais lisa, processos difusivos são favorecidos, establizando-se o polimorfo cinéticamente mais estável.

\subsubsection{Tipo de poliânion formador do filme $L b L$ : suportes planares em solução $0,01 \mathrm{~mol} \mathrm{~L}^{-1} \mathrm{CaCl}_{2}$.}

Continuando com a idéia de usar um polieletrólito com estrutura mais simples que a carragenana, empregou-se o poli(estireno sulfonato) de sódio (PSS), para efeito de comparação do efeito do poliânion formador do filme LbL. Os resultados apresentados nas Figuras 53-55 devem ser comparados àqueles apresentados nas Figuras 50 e 51 obtidos quando do uso de PAA na formação da matriz LbL. No caso de PSS o anion é o sulfonato ao invés de carboxila. 


\section{Resultados e Discussão}

Observa-se que, variando-se o tipo de poliânion utilizado na formação do filme LbL, a morfologia e o tamanho das partículas de $\mathrm{CaCO}_{3}$ varia consideravelmente. Mais uma vez a rugosidade do suporte no qual o filme LbL está depositado, não exerceu influência sobre a morfologia das partículas formadas. Em todos os casos o suporte foi posicionado com a face orientada para cima na solução de $\mathrm{CaCl}_{2}$.

Nas imagens de MEV mostradas nas Figura 53, 54 e 55, observam-se, especialmente, dois tipos de estruturas: romboedros e esferas, que estão isoladas uma das outras, diferentemente de quando o filme LbL é formado por PAA, que produz filmes particulados. Como ambos, PAA e PSS, devem ter conformações similares, conclui-se que nem a conformação do polieletrólito, nem a rugosidade do suporte metálico são fatores primordiais para a formação de estruturas de carbonato de cálcio contínuas. Desta forma, pode-se supor que o tipo de grupo carregado ligado à cadeia carbônica possa ser o fator chave que leva à formação de filmes. Espera-se que a nucleação varie com o tipo de micro-ambiente ao qual os íons cálcio, precursores do $\mathrm{CaCO}_{3}$, estão ligados.
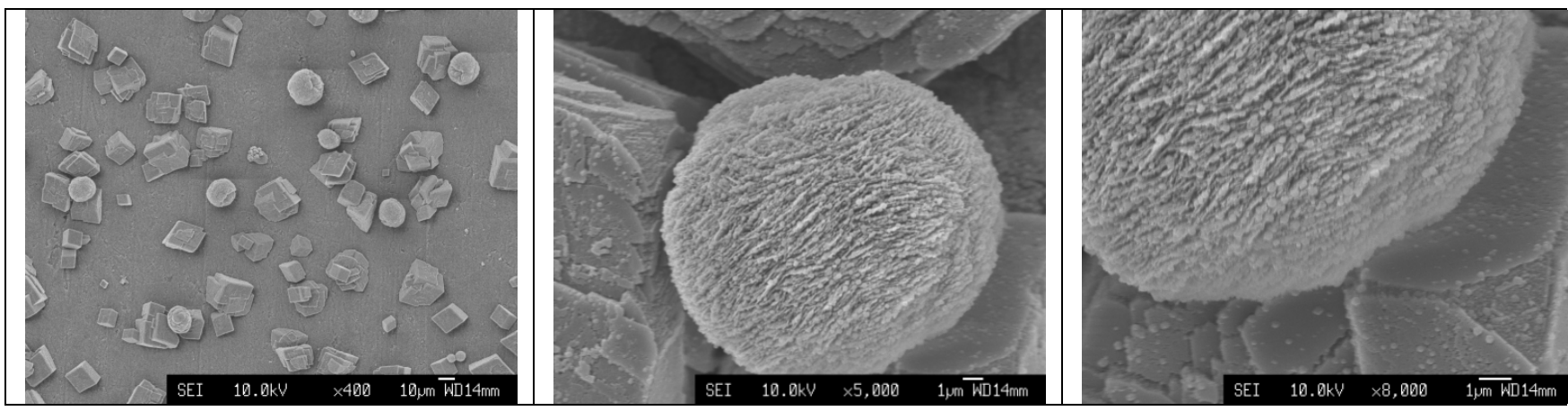

Figura 53: Filme $\mathrm{LbL}$ de (PSS/Qt) ${ }_{6} \mathrm{PSS}+\mathrm{CaCO}_{3}$ depositados sobre suporte de alumínio imerso em solução de $\mathrm{CaCl}_{2} 0,01 \mathrm{~mol} \mathrm{~L}{ }^{-1}$, orientado com a face para cima. 


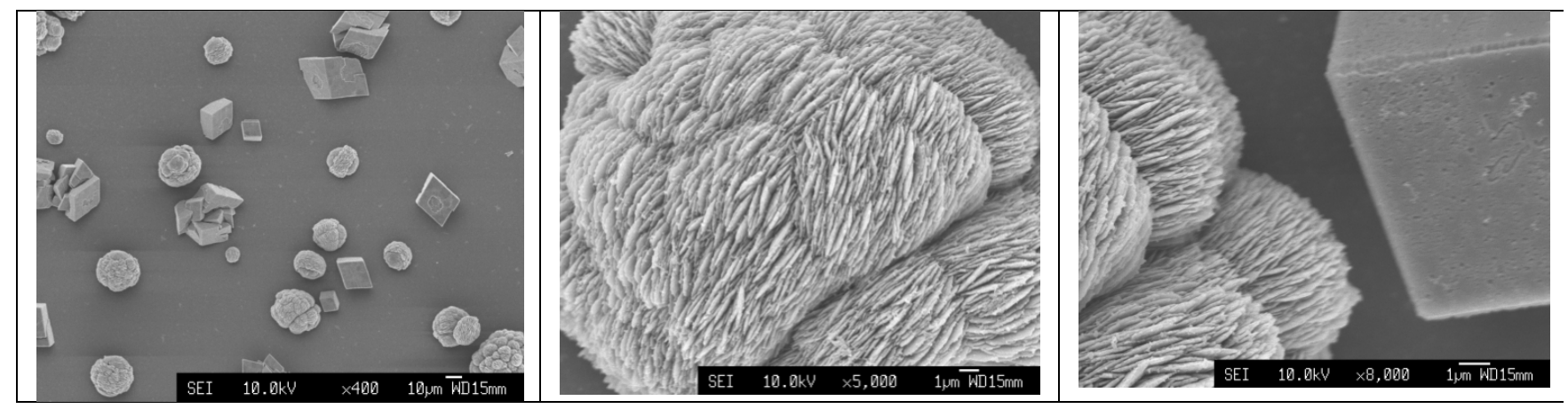

Figura 54: Filme LbL de (PSS/Qt) ${ }_{6} \mathrm{PSS}+\mathrm{CaCO}_{3}$ depositados sobre suporte de silício imerso em solução de $\mathrm{CaCl}_{2} 0,01 \mathrm{~mol} \mathrm{~L}{ }^{-1}$, orientado com a face para cima.

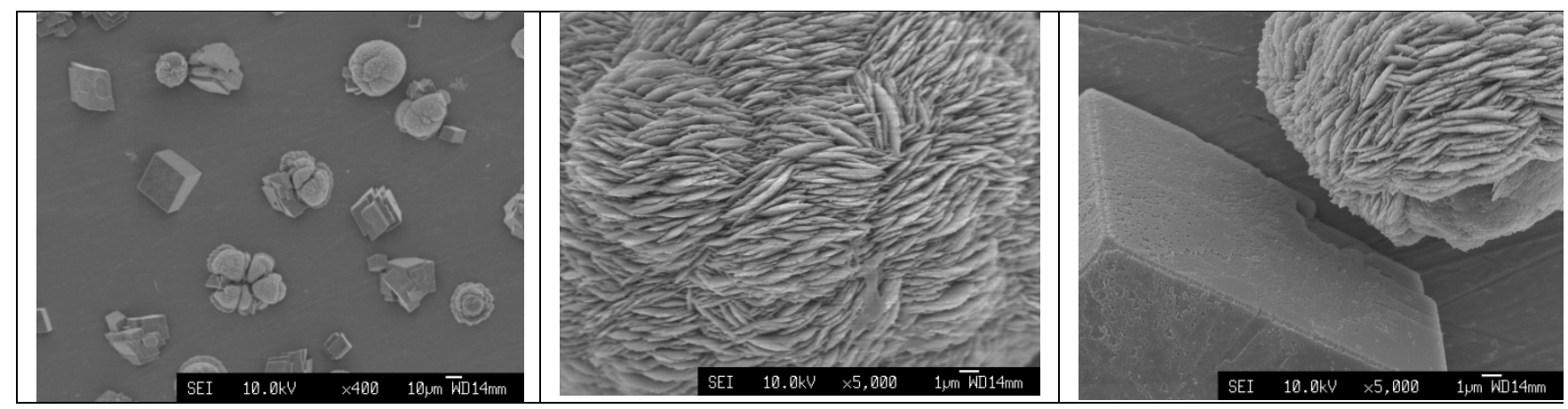

Figura 55: Filme LbL de (PSS/Qt) ${ }_{6} \mathrm{PSS}+\mathrm{CaCO}_{3}$ depositados sobre suporte de aço-inox imerso em solução de $\mathrm{CaCl}_{2} 0,01 \mathrm{~mol} \mathrm{~L}{ }^{-1}$, orientado com a face para cima.

Os difratograma das amostras de $\mathrm{CaCO}_{3}$ formadas sobre filme $\mathrm{LbL}$ de PSS e quitosana nos diferentes suportes imersos em solução (Figura 56), apresentam novamente a presença de picos correspondentes a duas formas cristalinas distintas, o que corrobora com as imagens de MEV, onde se distinguem, nitidamente, dois tipos de estruturas. Possivelmente, a estrutura romboédrica, corresponde à formação de calcita em solução, as estruturas esféricas corresponderiam ao polimorfo vaterita, formado a partir de íons cálcio ligados aos grupos sulfonato do PSS. Infelizmente, devido à presença da banda amorfa observada na amostra depositada sobre aço inox, muito provavelmente associada ao sinal do suporte de silicona 
utilizado no equipamento de DRX onde as análises foram realizadas, fica difícil a análise de picos entre valores de $2 \theta$ que vão de 22 a 35 graus. Porém, as amostras depositadas sobre silício exibem picos referente aos polimorfos vaterita (V) e calcita (C) marcados no difratograma da Figura 56. A partir destes difratogramas, tão bem quanto daqueles obtidos para os filmes de PAA, podemos estimar a proporção entre os polimorfos calcita e vaterita, como mostrado na Tabela 8.

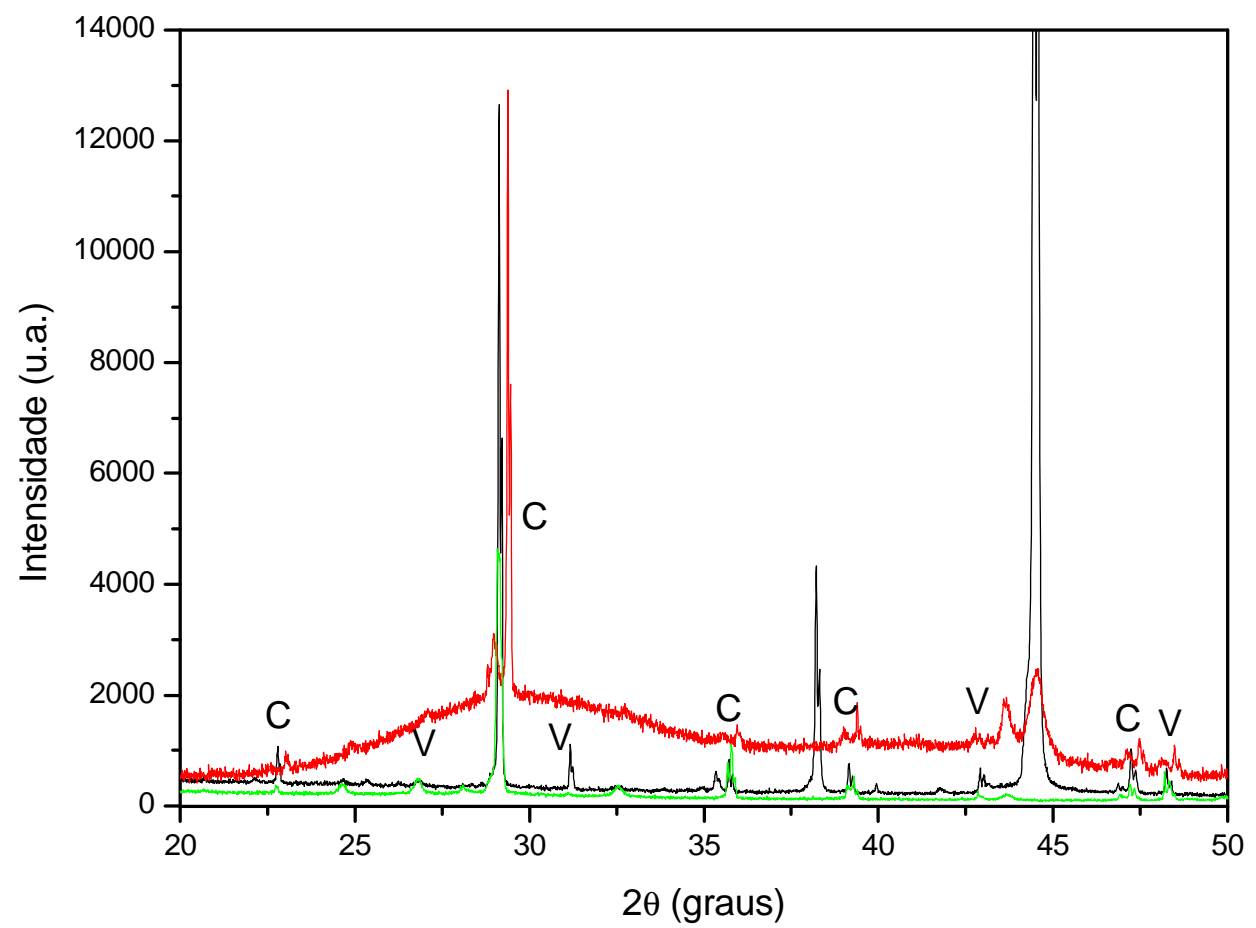

Figura 56: Difratograma de filmes $\mathrm{LbL}$ de $(\mathrm{PSS} / \mathrm{Qt})_{6} \mathrm{PSS}+\mathrm{CaCO}_{3}$ depositados sobre diferentes suportes, imersos em solução de $\mathrm{CaCl}_{2}$ 0,01 mol L ${ }^{-1}$. Alumínio (linha preta), aço-inox (linha vermelha) e silício (linha verde). 
Tabela 8: Razão entre as áreas dos picos em $29,1^{\circ}$ e $27^{\circ}$ correspondentes aos polimorfos calcita (C) e vaterita (V), respectivamente, para amostras de $\mathrm{CaCO}_{3}$ formadas sobre filmes $\mathrm{LbL}$ de quitosana e PSS, depositados sobre suportes de diferentes rugosidades. No caso do suporte de aço-inox a estimativa foi prejudicada pela banda amorfa, indicada pelo valor entre parênteses.

\begin{tabular}{|c|c|}
\hline Amostra & Razão C/V \\
\hline Alumínio & 6,2 \\
\hline Aço-inox & $(2)$ \\
\hline Silício & 4,7 \\
\hline
\end{tabular}

A análise do suporte de aço-inox foi prejudicada devido à presença da banda larga observada no difratograma. Porém, pode-se constatar que, como no caso da matriz polimérica orgânica formada por PAA, em todos os casos há maior proporção de calcita $(\mathrm{C})$ em relação à vaterita $(\mathrm{V})$ e a razão entre os polimorfos $(\mathrm{C} / \mathrm{V})$ é maior sobre o suporte mais rugoso (alumínio). Ou seja, o polimorformo menos estável, vaterita, é estabilizado sobre o suporte mais liso. Entretanto, no caso do poliânion PSS, observou-se uma diminuição da presença dessa forma, dada pelo aumento considerável da razão C/V. Conclui-se que tanto a rugosidade, quanto o poliânion que forma a matriz polimérica, podem influenciar na estabilidade do polimorfo menos estável, sendo o mesmo estabilizado sobre suportes mais lisos e sobre o poliânion PAA, que apresenta grupos carboxilato, em detrimento a PSS, que apresenta grupos sulfonato. Por simples consideração de valores de constantes de solubilidade de sais de cálcio envolvendo esses dois ânions, pode-se dizer que vaterita é mais estabilizada no caso em que íons cálcio ligam-se mais eficientemente ao poliânion. Por uma análise de requisitos geométricos as diferenças nos ângulos das ligações nos grupos $-\mathrm{COO}^{-} \mathrm{e}-\mathrm{SO}_{4}{ }^{-}$levam à formação de interfaces diferentes onde os cátions $\mathrm{Ca}^{2+}$ estão ligados, direcionando de maneiras diferentes o empacotamento dos íons e em conseqüência o desenvolvimento do núcleo inorgânico. De qualquer forma, estes resultados 
$\underline{\text { Resultados e Discussão }}$

confirmam a influência da rugosidade do suporte metálico no tipo, e quantidade, de polimorfo de $\mathrm{CaCO}_{3}$ formado.

\subsection{Efeito da orientação do suporte}

Com o intuito de comparar-se os experimentos em solução com aqueles realizado pelo método seco e, ao mesmo tempo eliminar-se o efeito da precipitação em solução, os suportes contendo a matriz orgânica foram imersos em solução de $\mathrm{CaCl}_{2} 0,01 \mathrm{~mol} \mathrm{~L} \mathrm{~L}^{-1}$, com a face contendo a matriz voltada para baixo, como explicado anteriormente. Também foram utilizados diferentes tipos de suporte metálicos: silício, alumínio e aço-inox, tal como, dois tipos diferentes de poliânion: PAA e PSS.

Para todas as amostras preparadas utilizando-se esta metodologia observou-se (Figura 57, 58, 59), a formação de um filme contínuo e também a formação de partículas maiores que cresceram axialmente. A morfologia dos filmes formados assemelha-se bastante às estruturas dos filmes obtidos pelo método a seco, indicando que o efeito do template não é perdido. Apesar de também ocorrer formação de agregados na forma de ilhas isoladas, observa-se diminuição na quantidade de partículas com crescimento axial comparando-se esses resultados com os aqueles obtidos para os mesmo tipo de filme LbL contendo PAA, porém com a deposição realizada com a face voltada para cima (Figuras 49, 50 e 51).

Pode-se ainda observar na amostra de filme LbL de PAA e quitosana, crescidos sobre aço inox (Figura 57) a presença de estruturas fibrosas que devem ser atribuídas ao polímero, misturada em meio aos cristais. Porém, não foram observadas diferenças morfológicas consideráveis nas partículas formadas, comparando-se os diferentes suportes. Foi possível 


\section{$\underline{\text { Resultados e Discussão }}$}

observar (Figuras 57 e 58) a formação de partículas romboédricas com tamanhos variáveis entre 10 e $20 \mu \mathrm{m}$ e ao redor dessas partículas observa-se a formação de agregados de partículas também romboédricas porém com tamanhos menores 500 a 1000 nm.
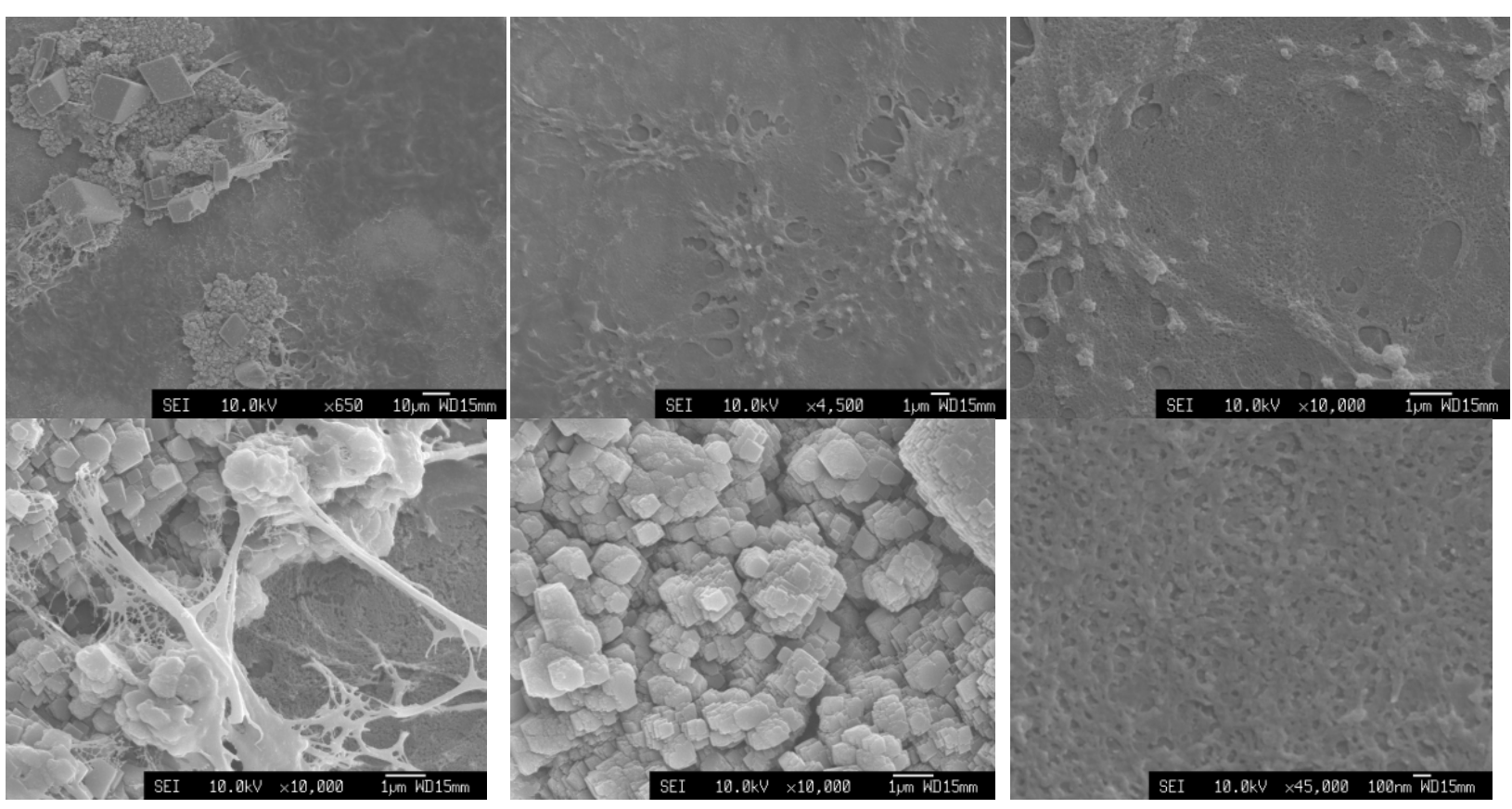

Figura 57: Filme $\mathrm{LbL}$ de $(\mathrm{PAA} / \mathrm{Qt})_{6} \mathrm{PAA}+\mathrm{CaCO}_{3}$ depositados sobre suporte de aço inox imerso em solução de $\mathrm{CaCl}_{2} 0,01 \mathrm{~mol} \mathrm{~L}{ }^{-1}$, com a face para baixo. 

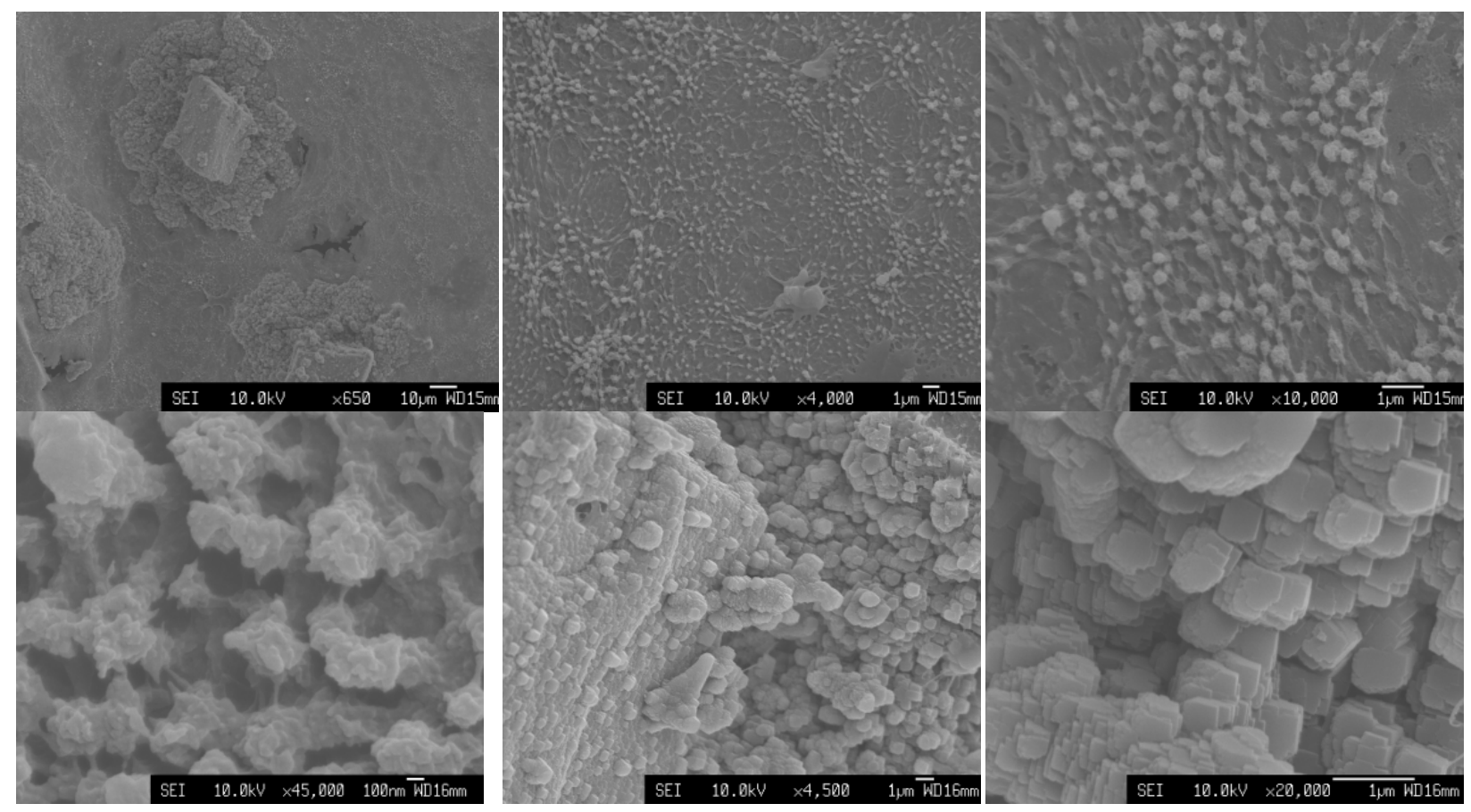

Figura 58: Filme $\mathrm{LbL}$ de $(\mathrm{PAA} / \mathrm{Qt})_{6} \mathrm{PAA}+\mathrm{CaCO}_{3}$ depositados sobre suporte de silício imerso em solução de $\mathrm{CaCl}_{2} 0,01 \mathrm{~mol} \mathrm{~L}{ }^{-1}$, com a face para baixo.

Assim como nas deposições realizadas com a face voltada para cima (Figura 54), utilizando-se o poliânion PSS (Figura 59) sobre suportes de silício, ocorreu a formação de dois tipos de estruturas: romboedros e esferas. Isto pode confirmar a suposição de que as estruturas esferulíticas cresceram ligadas diretamente ao filme por meio dos íons cálcio ligados ao grupo sulfonato do poliânion e os romboedros de calcita cresceram axialmente devido aos íons cálcio presentes em solução, neste caso, na vizinhança do filme. Ainda, o filme formado sobre toda a superfície parece ser constituído pelo mesmo tipo de nanocristais com dimensão de $\sim 10 \mathrm{~nm}$, que se agregam para compor as esferas (Figura 59 b, c e d). 


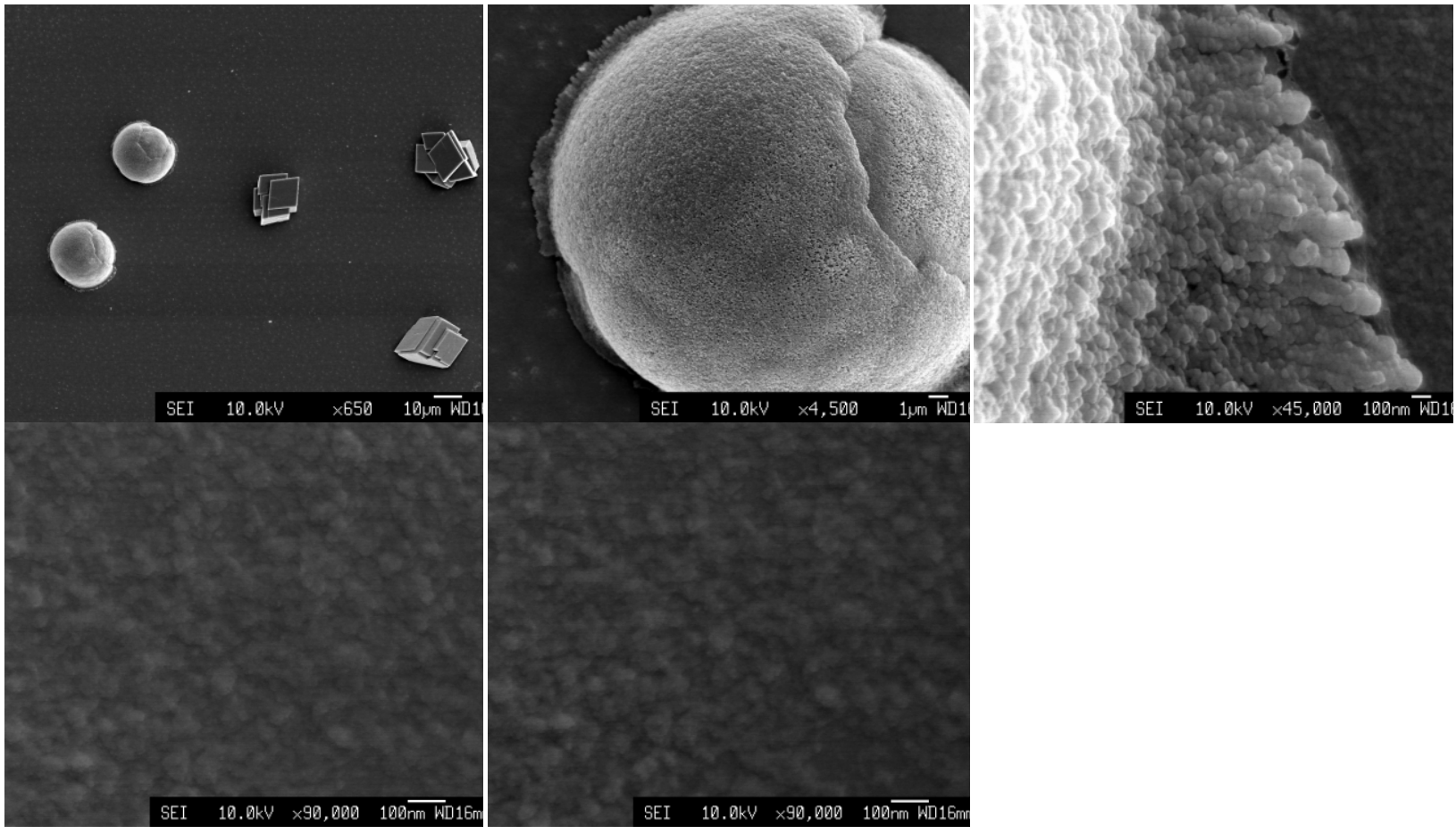

Figura 59: Filme $\mathrm{LbL}$ de $(\mathrm{PSS} / \mathrm{Qt})_{6} \mathrm{PSS}+\mathrm{CaCO}_{3}$ depositados sobre suporte de silício imerso em solução de $\mathrm{CaCl}_{2} 0,01 \mathrm{~mol} \mathrm{~L}^{-1}$, com a face para baixo.

\subsection{Identificação dos polimorfos de $\mathrm{CaCO}_{3}$ formados: Espectroscopia Raman}

\subsubsection{Cristalização no interior da solução de $\mathrm{CaCl}_{2}$}

Espectroscopia Raman é muito utilizada na identificação de estruturas, pois gera espectros característicos e bem definidos, como impressões digitais das mesmas. Além disso, diferentes polimorfos de uma mesma substância podem ser identificados, como no caso do $\mathrm{CaCO}_{3}$, onde as diferentes formas cristalinas podem ser identificadas por meio de deslocamentos nos picos que correspondem a vibrações tipo estiramentos dos átomos que formam o retículo cristalino ${ }^{144}$. Fazendo uso desta característica dos espectros Raman de $\mathrm{CaCO}_{3}$, foram realizadas tentativas de identificação dos polimorfos formados em duas diferentes formas de deposição: deposição com suporte imerso em solução e deposição utilizando-se o método a seco. Também foi estudada a 
$\underline{\text { Resultados e Discussão }}$

formação dos diferentes polimorfos em suportes de diferente rugosidade (alumínio, aço inox e silício).

Nos espectros Raman de $\mathrm{CaCO}_{3}$, três diferentes zonas podem ser utilizadas na tentativa de distinção dos três diferentes polimorfos ${ }^{144}$. Estas mesmas regiões foram por nós utilizadas como mostram os espectros apresentados na Figura 60 e Tabela 9 e comparadas com os espetros de referência ${ }^{144}$. Não são apresentados todos os espectros, porém, as atribuições das bandas observadas em todas as amostras analisadas estão resumidas na Tabela 9. A banda mais intensa, em $\sim 1100 \mathrm{~cm}^{-1}$, correspondente ao estiramento simétrico do grupo $\mathrm{CO}_{3}{ }^{2-}$ foi observado em todas as amostras. Na região no infravermelho próximo os diferentes polimorfos apresentam bandas que, além de se deslocarem, também variam seu formato, facilitando a interpretação dos espectros e identificação do polimorfo. Isso pode ser bem observado na Figura 60, na qual para o polimorfo calcita observa-se apenas uma banda em $281 \mathrm{~cm}^{-1}$, enquanto que para o polimorfo vaterita a banda nesta região pode ser deconvoluída em duas bandas uma com máximo em 265 $\mathrm{cm}^{-1}$ e outra com máximo em $303,4 \mathrm{~cm}^{-1}$. Também, se dois polimorfos diferentes estão presentes numa mesma amostra, as bandas se sobrepõe dificultando a análise quantitativa das mesmas. Porém, a focalização e obtenção dos espectros em diferentes regiões da amostra, nos permitiram a identificação qualitativa de mais de um polimorfo em certos casos, como resumido na Tabela 9.

Há uma dificuldade inerente ao método de micro-Raman que é a focalização das partículas que se deseja analisar, uma vez que as imagens de MEV nos mostram que estas estão em escala de tamanho micro ou até mesmo nanométricas. A diferença de foco no qual se obtém ou não espectro é tênue fazendo com que a técnica seja limitada para a análise de micro e nanopartículas. 


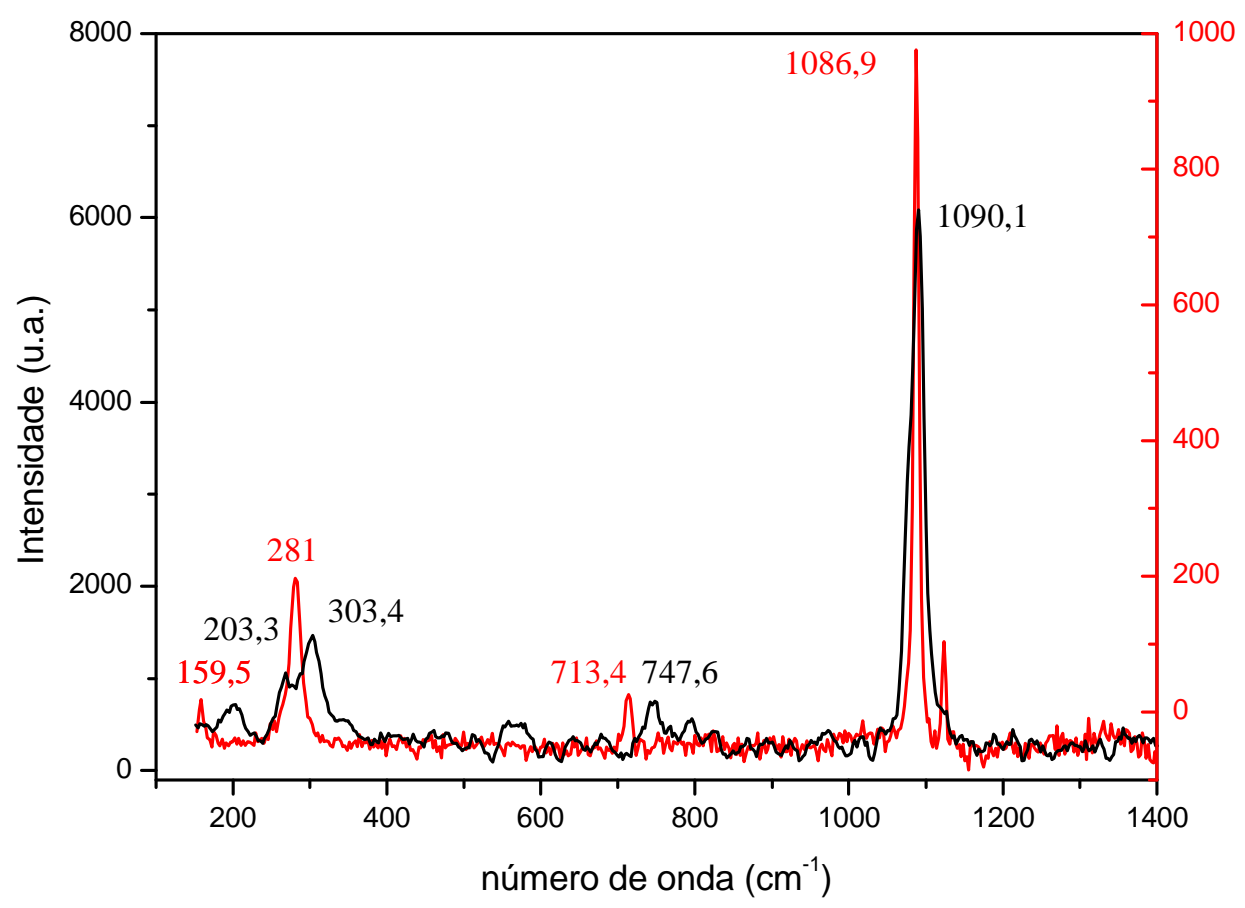

Figura 60: Espectros Raman de partículas de $\mathrm{CaCO}_{3}$ formadas sobre filme $\mathrm{LbL}$ (PAA/Qt) 6 PAA depositados sobre alumínio (linha preta) e aço-inox (linha vermelha). Observa-se a formação preferencial de diferentes polimorfos em cada caso: vaterita sobre alumínio e calcita sobre açoinox.

No espectro mostrado na Figura 60 pudemos identificar a formação de dois diferentes polimorfos formados variando-se apenas o tipo de suporte utilizado, como também observamos por meio dos difratogramas mostrados na sessão anterior. Porém, utilizando-se o Raman, identificou-se sobre alumínio partículas de $\mathrm{CaCO}_{3}$ apenas na forma cristalina vaterita, o que vai contra os resultados obtidos por difração de raios-X onde foi possível identificar os dois tipos de polimorfos, enquanto que sobre aço-inox identificou-se, apenas o polimorfo calcita. As diferenças encontradas comparando-se as duas técnicas podem estar relacionadas com as dificuldades encontradas nas análises por micro-Raman como descrito anteriormente. Vale a pena salientar que as morfologias dos filmes e partículas formadas sobre os dois tipos de suportes não 
$\underline{\text { Resultados e Discussão }}$

diferem consideravelmente, como mostrado nas imagens de MEV para os mesmos sistemas (Figura 50 e 51). Ainda, nos mesmos filmes formados sobre silício puderam ser identificadas as duas formas cristalinas, calcita e vaterita. Isto pode indicar que, mesmo nos filmes sobre aço-inox e alumínio, as duas formas também podem estar presentes, mas pelas dificuldades inerentes ao método de micro-Raman, citadas acima, as mesmas não puderam ser identificadas. Também, nos difratogramas obtidos para as mesmas amostras, as duas formas cristalinas foram identificadas em todos os casos, por meio dos picos de Bragg correspondente a cada polimorfo.

Tabela 9: Bandas presentes no espectro Raman de amostras de filmes $\mathrm{LbL}$ contendo $\mathrm{CaCO}_{3}$

\begin{tabular}{|c|c|c|c|c|c|c|}
\hline $\begin{array}{c}\text { matriz } \\
\text { orgânica }\end{array}$ & Suporte & Banda 1 & Banda 2 & Banda 3 & Banda 4 & Polimorfo \\
\hline$(\mathrm{PAA} / \mathrm{Qt})_{6} \mathrm{PAA}$ & Alumínio & 203,3 & 303,4 & 747,6 & 1090,1 & Vaterita \\
\hline$(\mathrm{PAA} / \mathrm{Qt})_{6} \mathrm{PAA}$ & Alumínio & 212,0 & 303,4 & 742,2 & 1090,1 & Vaterita \\
\hline$(\mathrm{PAA} / \mathrm{Qt})_{6} \mathrm{PAA}$ & Alumínio & 160,0 & 281,0 & 713,4 & 1086,9 & Calcita \\
\hline$(\mathrm{PAA} / \mathrm{Qt})_{6} \mathrm{PAA}$ & Silício & 157,0 & 281,0 & 713,4 & 1086,9 & Calcita \\
\hline$(\mathrm{PAA} / \mathrm{Qt})_{6} \mathrm{PAA}$ & Silício & $\operatorname{xxxxxxxx}$ & 281,0 & 713,4 & 1086,9 & Calcita \\
\hline$(\mathrm{PAA} / \mathrm{Qt})_{6} \mathrm{PAA}$ & Silício & $\operatorname{xxxxxxxx}$ & 305,3 & 754,5 & 1091,8 & Vaterita \\
\hline$(\mathrm{PAA} / \mathrm{Qt})_{6} \mathrm{PAA}$ & Aço inox & 159,5 & 281,0 & 713,4 & 1086,9 & Calcita \\
\hline$(\mathrm{PAA} / \mathrm{Qt})_{6} \mathrm{PAA}$ & Aço inox & 157,0 & 281,0 & 713,4 & 1086,9 & Calcita \\
\hline$(\mathrm{PSS} / \mathrm{Qt})_{6} \mathrm{PSS}$ & Alumínio & 157,0 & 281,9 & 711,6 & 1085,2 & Calcita \\
\hline$(\mathrm{PSS} / \mathrm{Qt})_{6} \mathrm{PSS}$ & Alumínio & 157,0 & 281,9 & 711,6 & 1085,2 & Calcita \\
\hline$(\mathrm{PSS} / \mathrm{Qt})_{6} \mathrm{PSS}$ & Silício & 211,1 & 302,5 & 751,9 & 1091,8 & Vaterita \\
\hline$(\mathrm{PSS} / \mathrm{Qt})_{6} \mathrm{PSS}$ & Aço inox & 153,0 & 281,0 & 713,4 & 1086,9 & Calcita \\
\hline
\end{tabular}




\subsubsection{Cristalização fora da solução pelo método "a seco"}

Devido ao tamanho reduzido das partículas formadas nos filmes de $\mathrm{CaCO}_{3}$ preparados pelo método a seco, a análise foi ainda mais difícil. O tamanho das partículas formadas por esse método, é muito inferior àquelas partículas obtidas em solução, formando filmes pouco espessos, possibilitando maior penetração do feixe de luz pode na amostra, gerando um espectro complexo e com muitas bandas, onde podemos observar, também, picos referentes às moléculas poliméricas que compõe o filme LbL, como mostrado nos espectros Raman das Figura 61, 62 e 63 e resumidos na Tabela 10 .

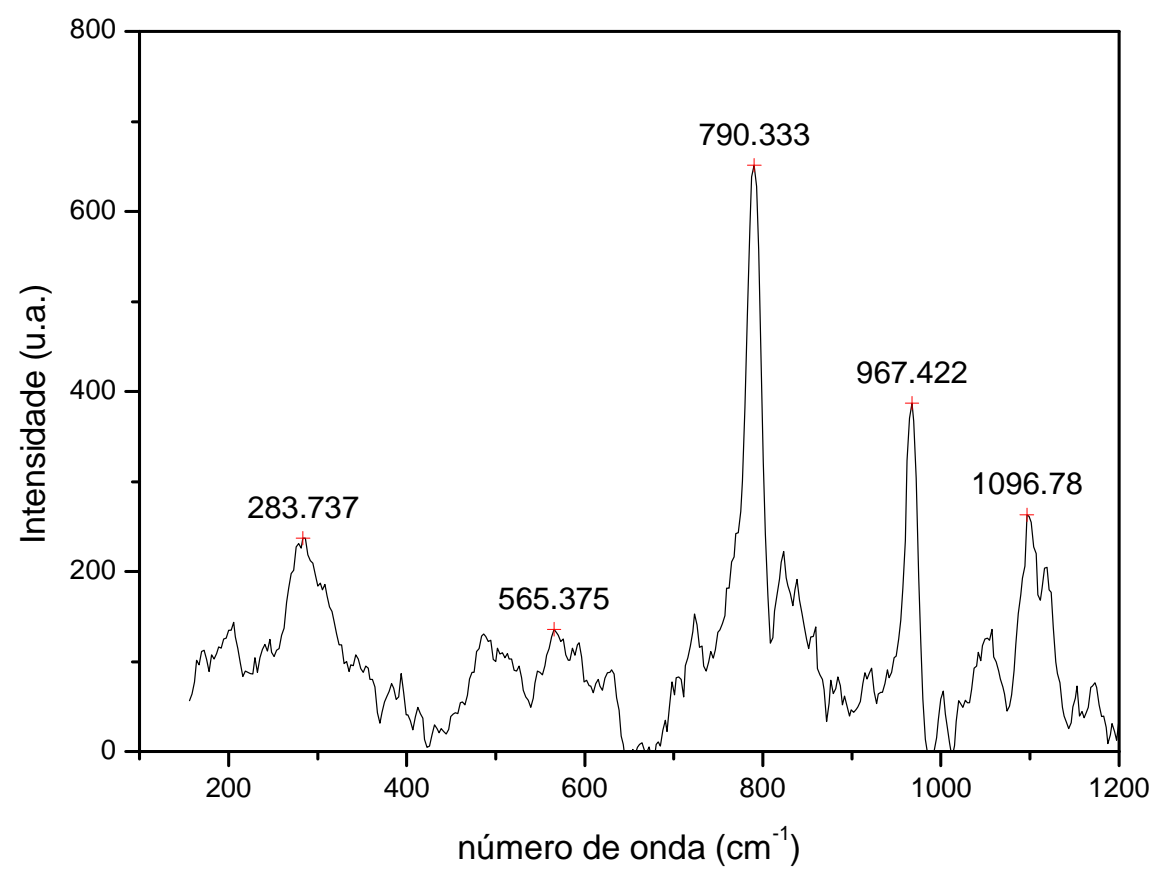


Resultados e Discussão

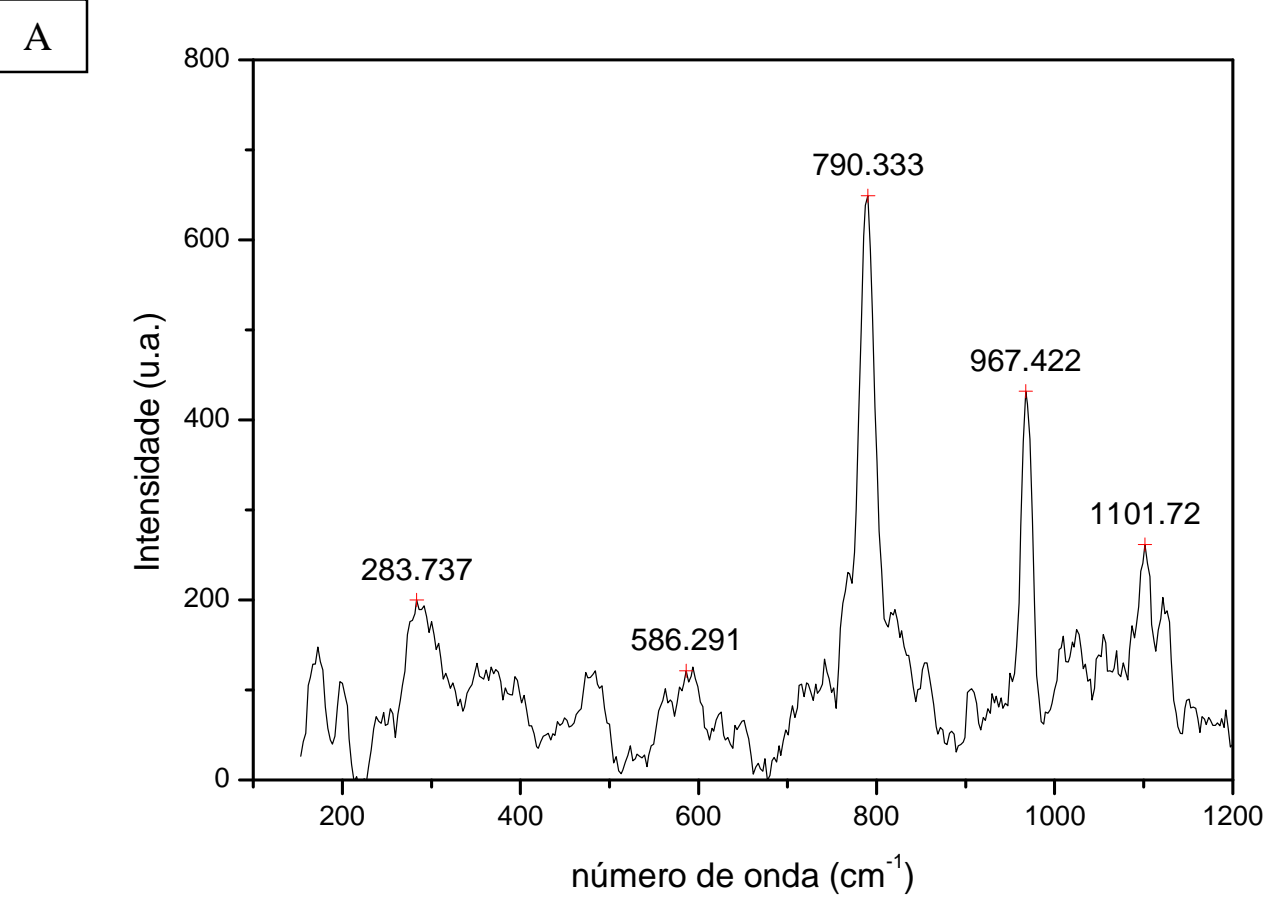

Figura 61: Espectros Raman de amostras de filmes $\mathrm{LbL}(\kappa \mathrm{I}-\mathrm{car} / \mathrm{Qt})_{6} \mathrm{KI}-\mathrm{car}+\mathrm{CaCO}_{3}$, depositados sobre alumínio. Os espectros A e B foram obtidos em regiões diferentes de uma mesma amostra.

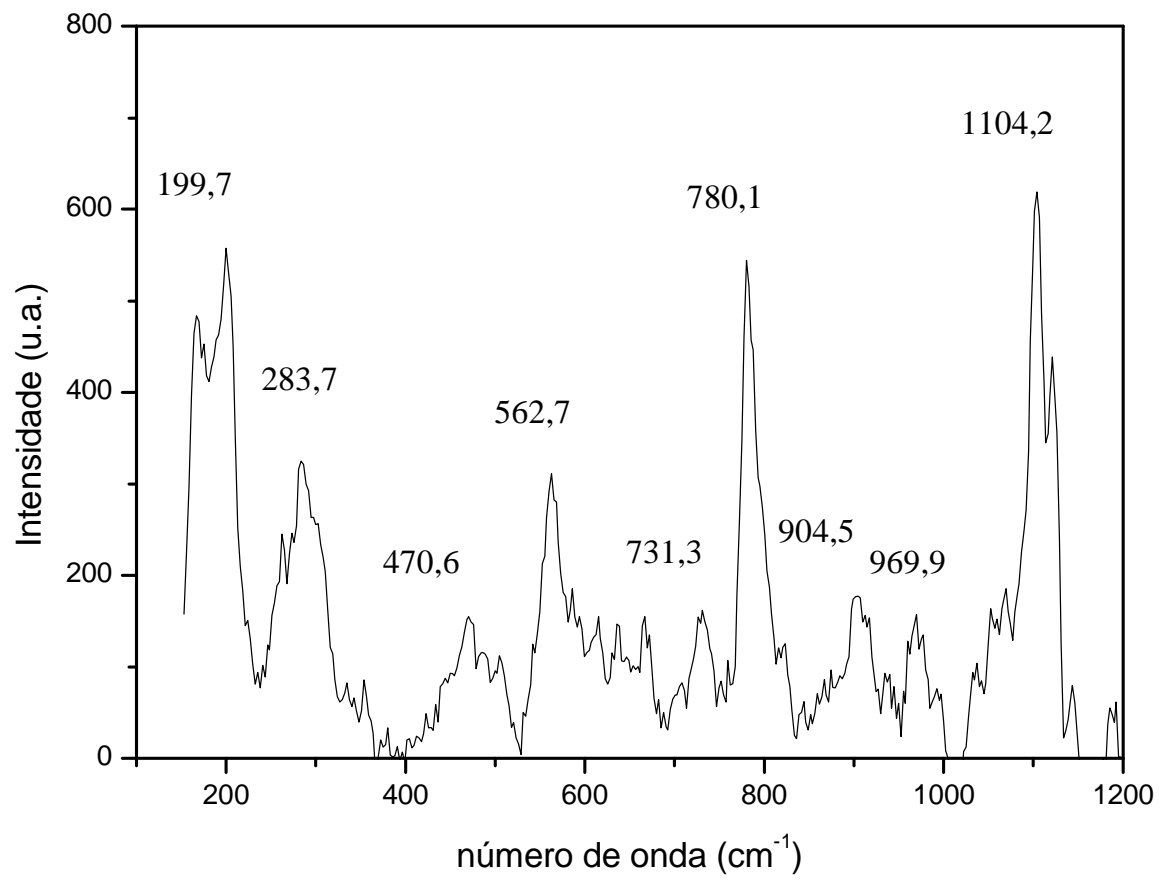

Figura 62: Espectro Raman de amostras de filmes $\mathrm{LbL}(\lambda \text {-car/Qt })_{6} \lambda$-car $+\mathrm{CaCO}_{3}$, depositados sobre alumínio. 


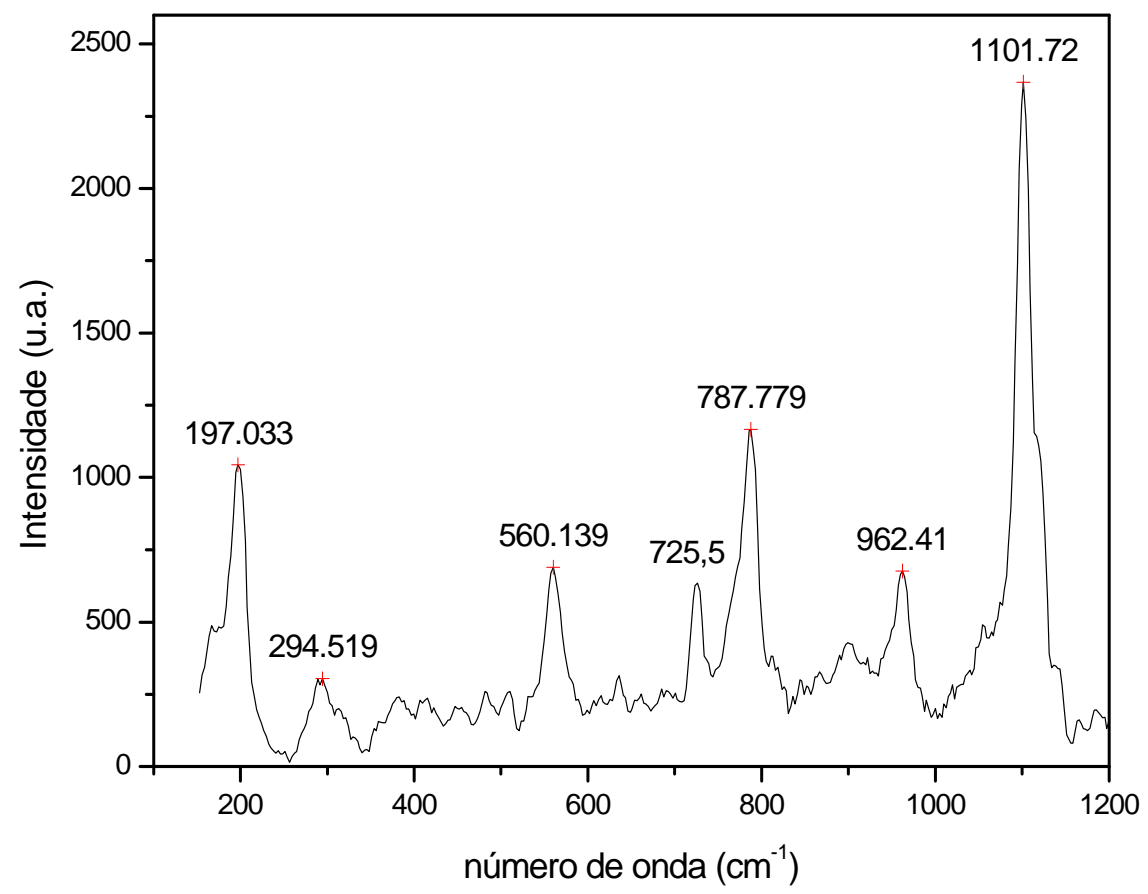

Figura 63: Espectro Raman de amostras de filmes $\mathrm{LbL}(\mathrm{PAA} / \mathrm{Qt})_{6} \mathrm{PAA}+\mathrm{CaCO}_{3}$, depositados sobre alumínio.

Em todas as amostras observa-se a presença da banda em $\sim 1100 \mathrm{~cm}^{-1}$ característica para todos os polimorfos de $\mathrm{CaCO}_{3}$. Também a banda em $\sim 283 \mathrm{~cm}^{-1}$ pode ser observada em todas as amostras formadas com filme LbL de $\kappa$-I e $\lambda$-car crescidos sobre alumínio. Já nas amostras de $\lambda$ car crescida sobre silício, observa-se o pico em $\sim 301 \mathrm{~cm}^{-1}$ que pode ser indicativo de presença de vaterita. Já nos filmes contendo PAA as bandas nesta região estão deslocadas para números de onda maior, com relação à calcita, e para números de onda menores, com relação à vaterita, apresentando valores intermediários que dificultam o processo de identificação dos polimorfos. Porém, foi mostrado nos resultados anteriores e também no artigo por nós publicado ${ }^{97}$, que os filmes LbL contendo PAA crescidos sobre alumínio, apresentam os polimorfos calcita e vaterita, que foram identificados por meio de difração de raios-X. As bandas demais bandas presentes nos espectros Raman podem ser atribuídas a grupos presentes na matriz orgânica, como a banda em 
Resultados e Discussão

$\sim 960 \mathrm{~cm}^{-1}$ correspondente à vibração da ligação $\mathrm{C}-\mathrm{H}^{145}$ pode ser observada em todos nos espectros Raman apresentados nas Figura 61, 62 e 63. Além disso, a banda em $\sim 730 \mathrm{~cm}^{-1}$ pode ser atribuída o estiramento do grupo $\mathrm{C}_{-} \mathrm{C}^{145}$ e também esta presente nos espectros. A banda em $\sim 560 \mathrm{~cm}^{-1}$ pode ser atribuída ao estiramento da ligação C-O.

Tabela 10: Bandas referentes ao $\mathrm{CaCO}_{3}$ no espectro Raman de amostras de filmes LbL contendo $\mathrm{CaCO}_{3}$ depositado sem uso de solução

\begin{tabular}{|c|c|c|c|c|c|c|}
\hline Matriz orgânica & Suporte & $\begin{array}{c}\text { banda } \\
\mathbf{1}\end{array}$ & $\begin{array}{c}\text { banda } \\
\mathbf{2}\end{array}$ & $\begin{array}{c}\text { banda } \\
\mathbf{3}\end{array}$ & $\begin{array}{c}\text { banda } \\
\mathbf{4}\end{array}$ & polimorfo \\
\hline$(\kappa \mathrm{I}-\mathrm{car} / \mathrm{Qt})_{6} \mathrm{KI}-\mathrm{car}$ & Alumínio & 201,1 & 283,7 & 790,3 & 1097 & Calcita \\
\hline$(\kappa \mathrm{I}-\mathrm{car} / \mathrm{Qt})_{6} \mathrm{KI}-\mathrm{car}$ & Alumínio & 172,5 & 283,7 & 790,3 & 1102 & Calcita \\
\hline$(\kappa \mathrm{I}-\mathrm{car} / \mathrm{Qt})_{6} \mathrm{KI}-\mathrm{car}$ & Aço inox & 190,6 & $\mathrm{xxxxxx}$ & $\mathrm{Xxxxxx}$ & 1122 & $? ? ? ? ?$ \\
\hline$(\kappa \mathrm{I} \text {-car/Qt })_{6} \mathrm{KI}-\mathrm{car}$ & Aço inox & $\mathrm{Xxxx}$ & $\mathrm{xxxxxx}$ & $\mathrm{Xxxxxx}$ & 1121 & $? ? ? ? ?$ \\
\hline$(\lambda \text {-car/Qt })_{6} \lambda$-car & Alumínio & 199,7 & 283,7 & 780,1 & 1104 & Calcita \\
\hline$(\lambda \text {-car/Qt })_{6} \lambda$-car & Silício & 174,8 & 301,2 & $\mathrm{Xxxxxx}$ & 1124 & Vaterita \\
\hline$(\lambda \text {-car/Qt })_{6} \lambda$-car & Aço inox & 197,0 & $\mathrm{xxxxxx}$ & 703,0 & 1126 & $? ? ? ? ?$ \\
\hline$(\mathrm{PAA} / \mathrm{Qt})_{6} \mathrm{PAA}$ & Alumínio & 197,0 & 294,5 & 787,8 & 1102 & Calcita \\
\hline$(\mathrm{PAA} / \mathrm{Qt})_{6} \mathrm{PAA}$ & Alumínio & 199,7 & 286,4 & 787,8 & 1102 & Calcita \\
\hline
\end{tabular}


$\underline{\text { Resultados e Discussão }}$

\subsection{Crescimento de $\mathrm{CaCO}_{3}$ em meio confinado tridimensional}

Os resultados que serão descritos na seqüência foram obtidos em trabalho realizado em colaboração com a Profa. Dra. Fiona Meldrum em estágio na Universidade de Bristol, Inglaterra.

Inicialmente, formou-se o filme $\mathrm{LbL}$ de PAA e quitosana no interior de membranas de policarbonato com tamanho de poros de $5 \mu \mathrm{m}$ (Figura 64), utilizando-se a metodologia descrita na seção 2.4. Observa-se, nitidamente, nesta figura o preenchimento dos poros pelo filme LbL que fica depositado na parede da membrana. Devido ao tamanho dos poros que levaria à formação de estruturas cristalinas muito grandes para serem analisadas por microscopia eletrônica de transmissão, então, optou-se pelo uso de membranas com tamanho de poros menores, que permitem a formação de estrutura nanométricas, viabilizando o uso de MET nas análises. As amostras para análise de difração de elétrons por MET, foram obtidas gotejando-se as dispersões de $\mathrm{CaCO}_{3}$ em etanol sobre retículos de cobre recobertos com filme de carbono, secando-os em recipiente fechado.

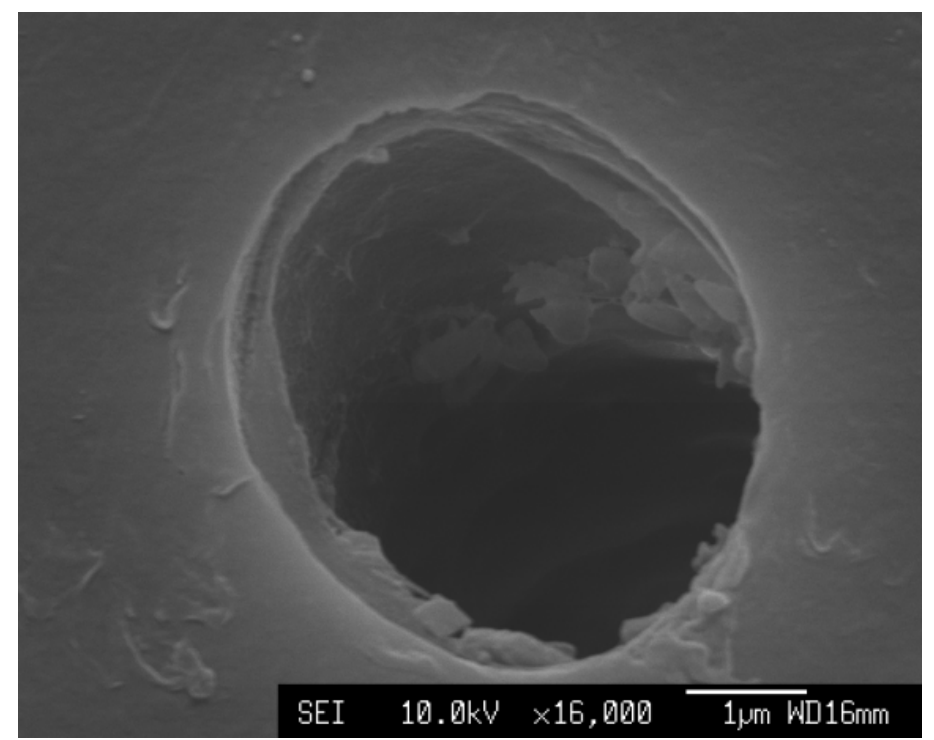

Figura 64: Filme LbL de (PAA/Qt) ${ }_{6} \mathrm{PAA}$ formado no interior de membrana de policarbonado com poros de $4 \mu \mathrm{m}$. 
Sobre membranas com poros de $200 \mathrm{~nm}$ foram depositadas 4 ou 5 camadas do filme LbL alternando-se quitosana e PAA (sempre começando por quitosana). Desta forma obtivemos filmes terminadas em poliânion (4 camadas) e filmes terminados em policátion ( 5 camadas). Sobre essas amostras depositou-se carbonato de cálcio utilizando-se o método descrito no item 2.4 da parte experimental.

O molde proporcionado pela membrana de policarbonato foi removido utilizando-se $\mathrm{CH}_{2} \mathrm{Cl}_{2}$ como solvente. A lavagem foi feita adicionando-se algumas gotas do solvente a um recipiente contendo a membrana já com os cristais depositados, seguido por sonicação durante 2 minutos e centrifugação durante 3 minutos a 9000 rpm. Após a centrifugação o sobrenadante foi removido e adicionou-se $\mathrm{CH}_{2} \mathrm{Cl}_{2}$ novamente para início de mais uma lavagem. Este procedimento foi repetido o número de vezes necessário para a completa remoção da membrana, confirmada por análise de micrografias obtidas por MEV e MET. Utilizou-se, também, altas temperaturas na tentativa de remoção do molde, porém, desta forma perde-se o efeito da matriz polimérica formando-se apenas cilindros o polimorfo mais estável, ou seja, calcita.

Nas imagens apresentadas na Figura 65, podemos observar a formação de estruturas cilíndricas de $\mathrm{CaCO}_{3}$ que foram crescidas em membranas de policarbonato, com tamanho de poros de $200 \mathrm{~nm}$, contendo 4 camadas do filme LbL de Qt/PAA. As membranas foram removidas lavando-se três vezes com $\mathrm{CH}_{2} \mathrm{Cl}_{2}$, como descrito acima. Após a remoção do molde, os cristais formados foram re-dispersos em etanol e a suspensão gotejada sobre suportes de vidro que foram recobertos com ouro para posterior caracterização por MEV. 

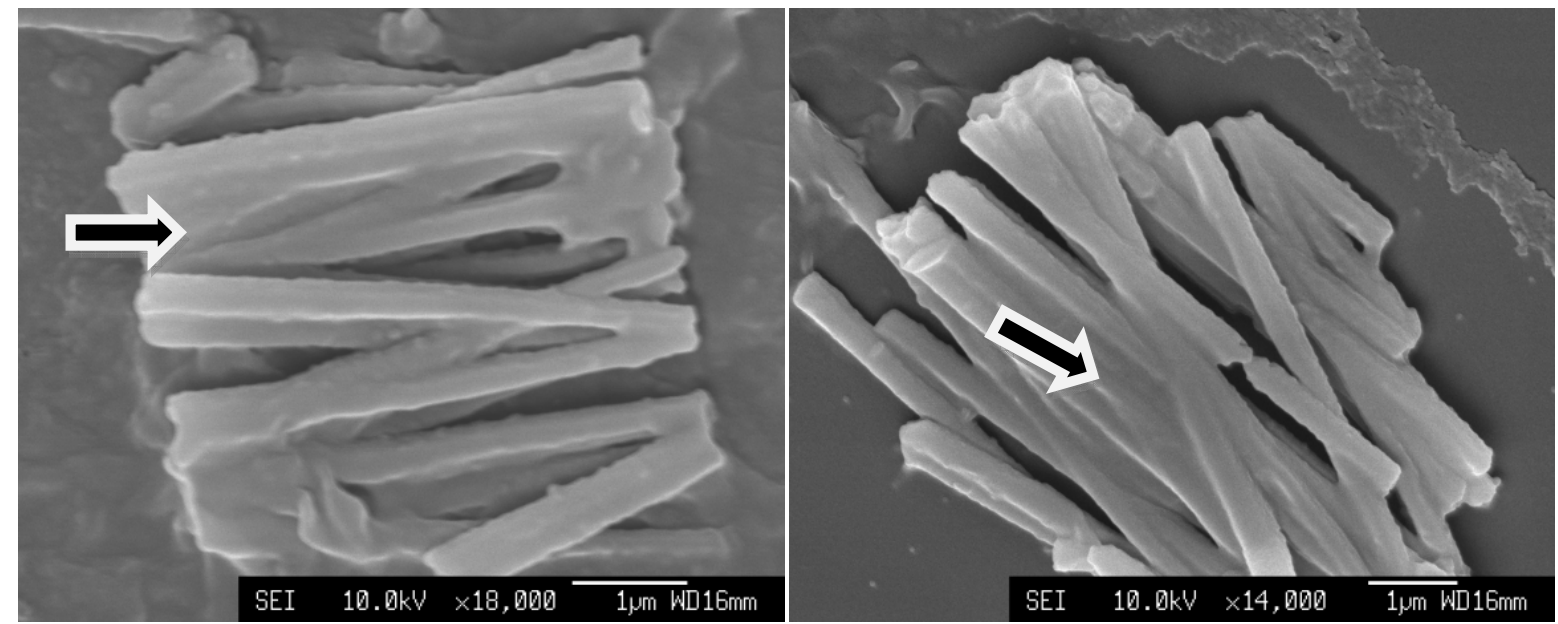

Figura 65: Estruturas de $\mathrm{CaCO}_{3}$ obtidas utilizando-se membranas de policarbonato, com tamanho de poros de $200 \mathrm{~nm}$, como template. A membrana foi modificada com 4 camadas de filme $\mathrm{LbL}$, alternando-se quitosana e PAA. Enxágüe 3 vezes com $\mathrm{CH}_{2} \mathrm{Cl}_{2}$.

Observa-se na Figura 65 que as estruturas formadas apresentam morfologia cilíndrica, seguindo a morfologia dos poros da membrana utilizada como template. Ainda, nota-se que as três lavagens não foram suficientes para remoção de toda a parte orgânica e os cilindros parecem recobertos por estes materiais como indicado pelas setas nas figuras a e b. Por isso, optou-se por um número maior de lavagens para remoção do template e do filme LbL.

As imagens apresentadas na Figura 66 correspondem às amostras enxaguadas 5 vezes com $\mathrm{CH}_{2} \mathrm{Cl}_{2}$. Nota-se grande diferença na remoção do recobrimento das estruturas quando comparadas com as amostras enxaguadas apenas três vezes. As estruturas parecem consistir em bastões ocos, com paredes formadas por pequenas partículas de $\mathrm{CaCO}_{3}$ de dimensões menores que $5 \mathrm{~nm}$, que se agregam formando uma estrutura contínua. Pode-se observar a presença de pequenos poros nas superfícies desses cilindros.

Alternativamente, utilizou-se remoção do molde a altas temperaturas. Para isso as membranas contendo o filme $\mathrm{LbL}$ e $\mathrm{CaCO}_{3}$ foram colocadas em forno $\mathrm{EDG} \mathrm{FV}-2$ à temperatura de $480^{\circ} \mathrm{C}$ durante 4 horas. Podemos observar na Figura 67 que a morfologia superficial dos 
cilindros formados após tratamento térmico varia com relação àqueles cilindros isolados por dissolução da membrana com solvente orgânico (Figura 66).

Especialmente, podemos observar nos nanotubos mostrados Figura 67 a presença de poros de dimensões consideráveis (10-25 nm). Uma explicação para o aparecimento deste tipo de estrutura pode estar relacionada com a remoção por decomposição térmica da membrana e dos polieletrólitos que, por sua vez, deixariam espaços vazios em regiões que antes do tratamento térmico estavam ocupadas por moléculas de polímeros. Esta suposição é corroborada pelo tipo de estruturas observadas na Figura 68, cujas micrografias foram obtidas a partir de amostras inicialmente enxaguadas com $\mathrm{CH}_{2} \mathrm{Cl}_{2}$, re-dispersas com etanol e gotejadas sobre placas de vidro e submetidas a posterior tratamento térmico em forno a $480^{\circ} \mathrm{C}$ durante 4 horas.

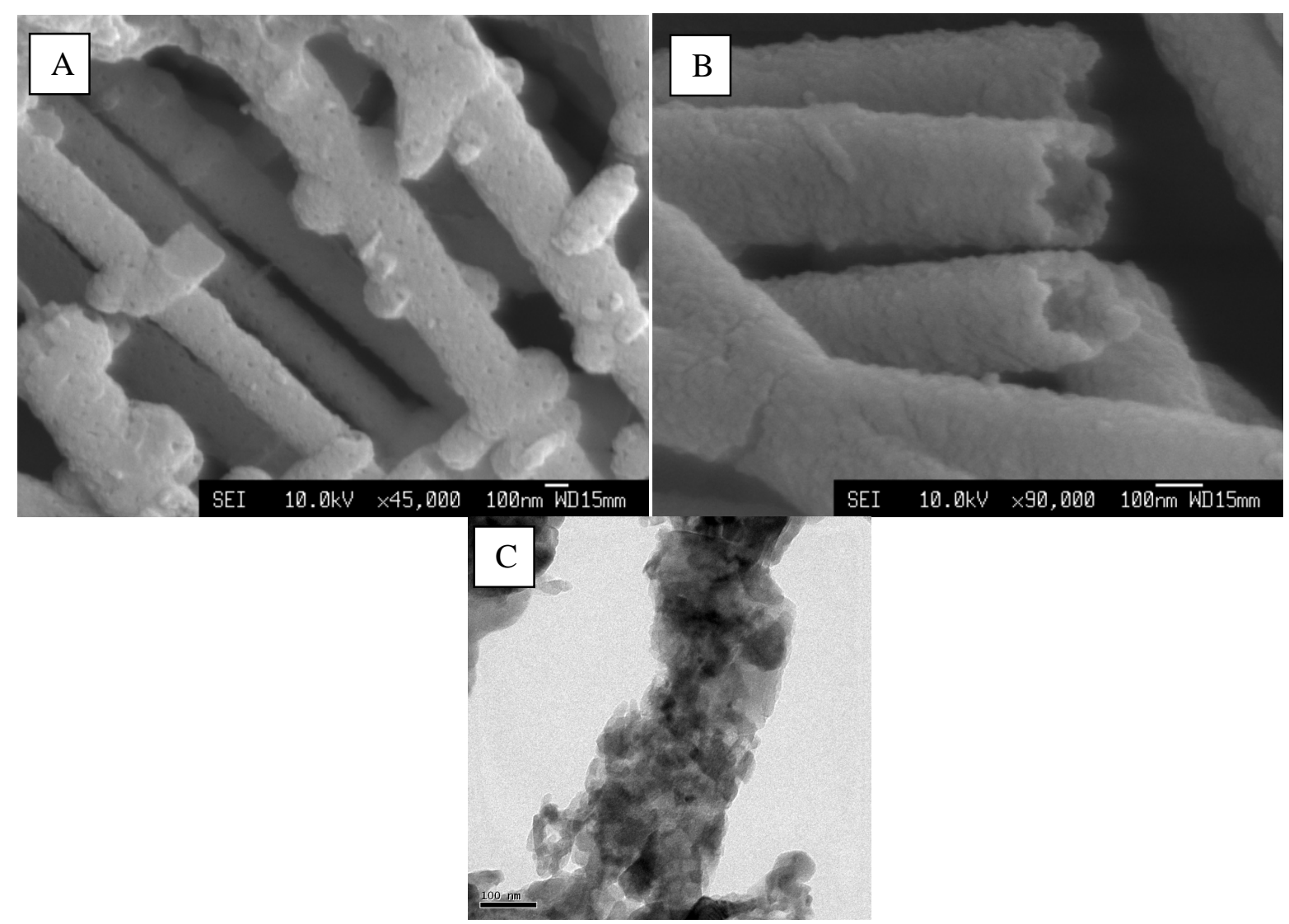


Figura 66: Estruturas de $\mathrm{CaCO}_{3}$ obtidas utilizando-se como molde membranas de policarbonato, com tamanho de poros de $200 \mathrm{~nm}$. A membrana foi modificada com (Qt/PAA) $)_{2}$ antes da deposição de carbonato de cálcio. A lavagem para a remoção da parte orgânica foi feita com 5 enxágues com $\mathrm{CH}_{2} \mathrm{Cl}_{2}$. As imagens A e B foram obtidas por MEV e a imagem $\mathrm{C}$, por MET.
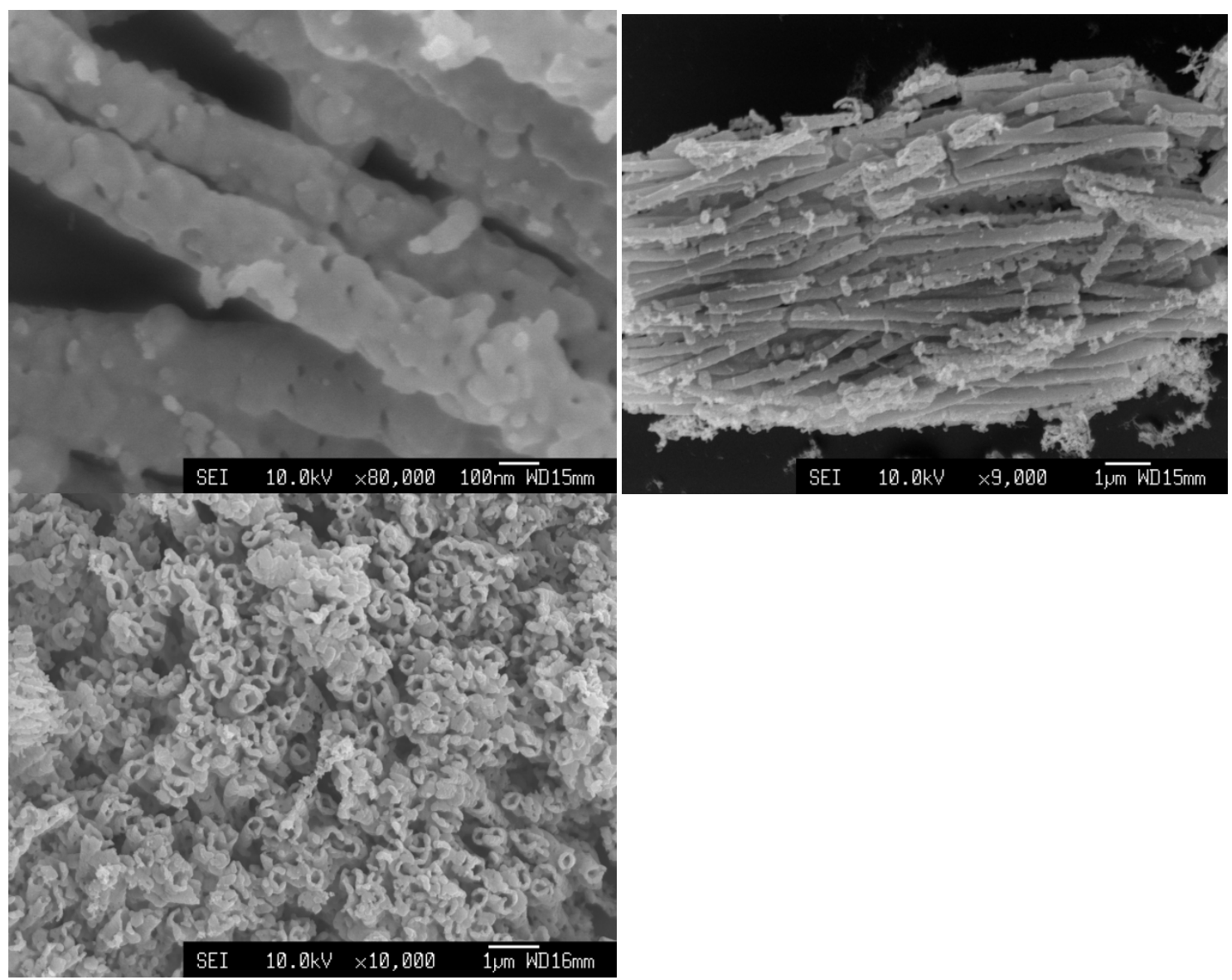

Figura 67: Estruturas de $\mathrm{CaCO}_{3}$ obtidas utilizando-se como molde membranas de policarbonato, com tamanho de poros de $200 \mathrm{~nm}$. A membrana foi modificada com (Qt/PAA) $)_{2}$ antes da deposição de carbonato de cálcio. A remoção da parte orgânica foi feita por decomposição a altas temperaturas $\left(480^{\circ} \mathrm{C}\right)$. 


\section{$\underline{\text { Resultados e Discussão }}$}

Nas estruturas apresentadas na Figura 68 não observamos a presença dos poros grandes nas superfícies dos cilindros conforme fora observado na Figura 67, evidenciando que a presença dos mesmos deve estar relacionada com o modo como os polieletrólitos são removidos, possibilitando a observação de poros que podem ser sua "impressão-digital”.
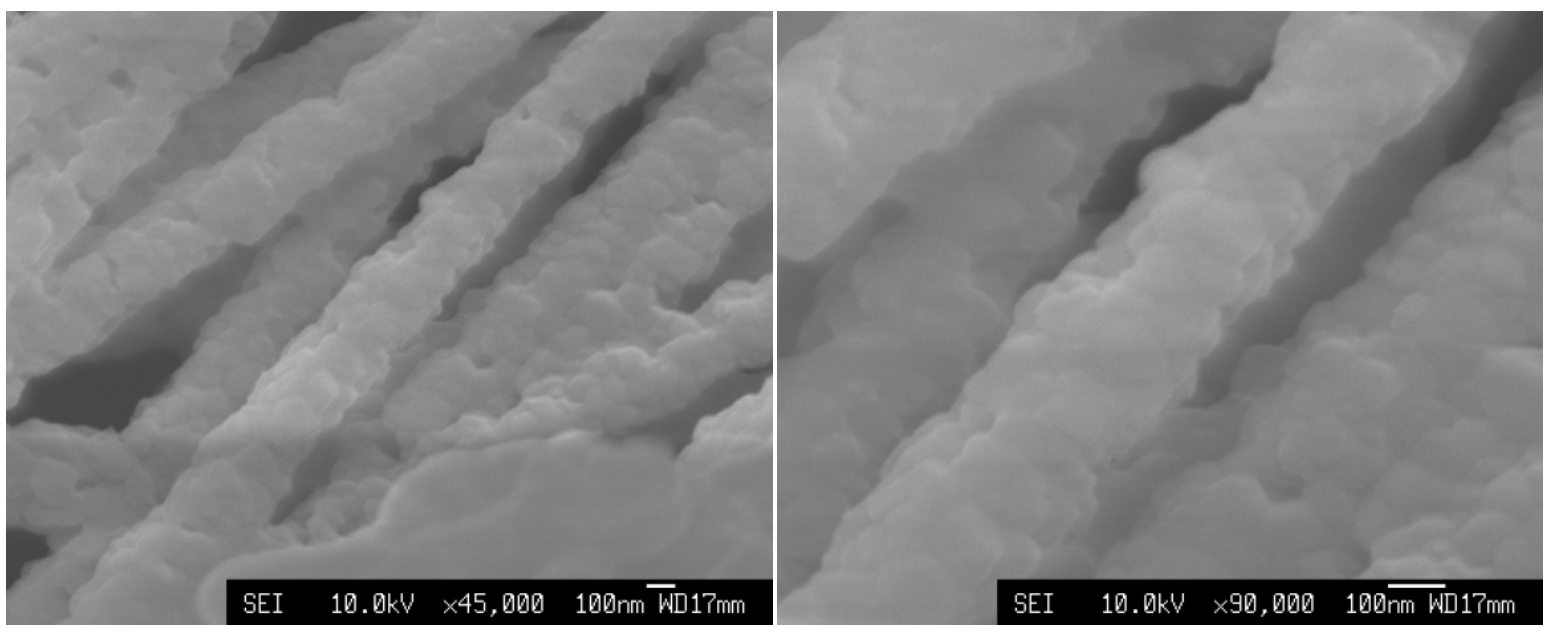

Figura 68: Estruturas de $\mathrm{CaCO}_{3}$ obtidas utilizando-se como molde membranas de policarbonato, com tamanho de poros de $200 \mathrm{~nm}$. A membrana foi modificada com (Qt/PAA) ${ }_{2}$ antes da deposição de carbonato de cálcio. A lavagem para a remoção da parte orgânica foi feita com 5 enxágues com $\mathrm{CH}_{2} \mathrm{Cl}_{2}$, seguida por decomposição a altas temperaturas $\left(480^{\circ} \mathrm{C}\right)$.

Além do efeito do tipo de procedimento para a remoção da parte orgânica, foi estudado o efeito do tipo de polieletrólito depositado na ultima camada. Para isso foram depositados filmes LbL com 5 camadas de polieletrólito (Qt/PAA) 2 Qt dentro dos poros da membrana de policarbonato, terminado-se, dessa maneira com o polieletrólito positivamente carregado, quitosana. Desta forma, o micro-ambiente onde os cristais cresceram foi modificado.

Comparando-se a micrografia apresentada na Figura 66(a) com aquela da Figura 69(b) podemos observar que os nanotubos, obtidos em moldes de membranas de policarbonato, modificadas com o filme LbL terminando com o poliânion parecem ser mais porosos. 
Resultados e Discussão

Observando o detalhe com aumento maior (barra de $100 \mathrm{~nm}$ ), nota-se que a diferença está, principalmente no tamanho dos cristalitos. Para os cilindros obtidos em membranas modificadas com filmes LbL terminados em quitosana os cristalitos apresentam tamanhos médios de $5 \mathrm{~nm}$, enquanto que com filmes terminados em PAA observam-se cristalitos que chegam a $15 \mathrm{~nm}$.

Além disso, observam-se nitidamente nas Figura 66, 67 e 70 que as estruturas formadas são ocas em seu interior. Estudou-se então, o efeito da adição do PAA de baixa massa molar $(8000 \mathrm{~g} / \mathrm{mol})$ à solução de $\mathrm{CaCl}_{2}$ utilizada na etapa do procedimento que precede a cristalização de $\mathrm{CaCO} 3$ formado em mebranas modificads com os filme de 5 camadas (Qt/PAA) 2 Qt. Este método foi nomeado PILP, do inglês "Polymer-induced liquid precursor", como citado na introdução (seção 1.3) desta tese. Enquanto que com o uso de PAA foram formados cilindros ocos, na ausência do mesmo, estruturas completamente preenchidas foram formadas (Figura 71). O PAA utilizado como aditivo pode ser ligar, especialmente, às paredes dos poros da membrana contendo o filme LbL, direcionando a nucleação e o crescimento dos cristais nesta região, formando estruturas ocas. De acordo com a hipótese "template-matriz"146,147 largamente aceita, a matriz orgânica contém macromoléculas específicas as quais promovem uma nucleação dos cristais localmente seletiva e determinam a natureza do polimorfo, tal como, a orientação espacial dos cristais em crescimento, como se dá no caso da presença de PAA.

Já, na ausência do PAA (como aditivo) a formação se dá por todo o interior dos poros (Figura 71). Esta explicação faz sentido, se levarmos em consideração que o filme de quitosana retém 28\% mais água que o filme de PAA, aprisionando, assim, maior quantidade de solução de $\mathrm{CaCl}_{2}$ que contém os íons cálcio precursores do $\mathrm{CaCO}_{3}$ formado ao final. A quantidade de água aprisionada nos poros foi determinada por pesagens das membranas contendo filmes terminados em PAA e filmes terminados em quitosana, que foram deixados em água deionizada durante 1 hora e novamente pesados. 


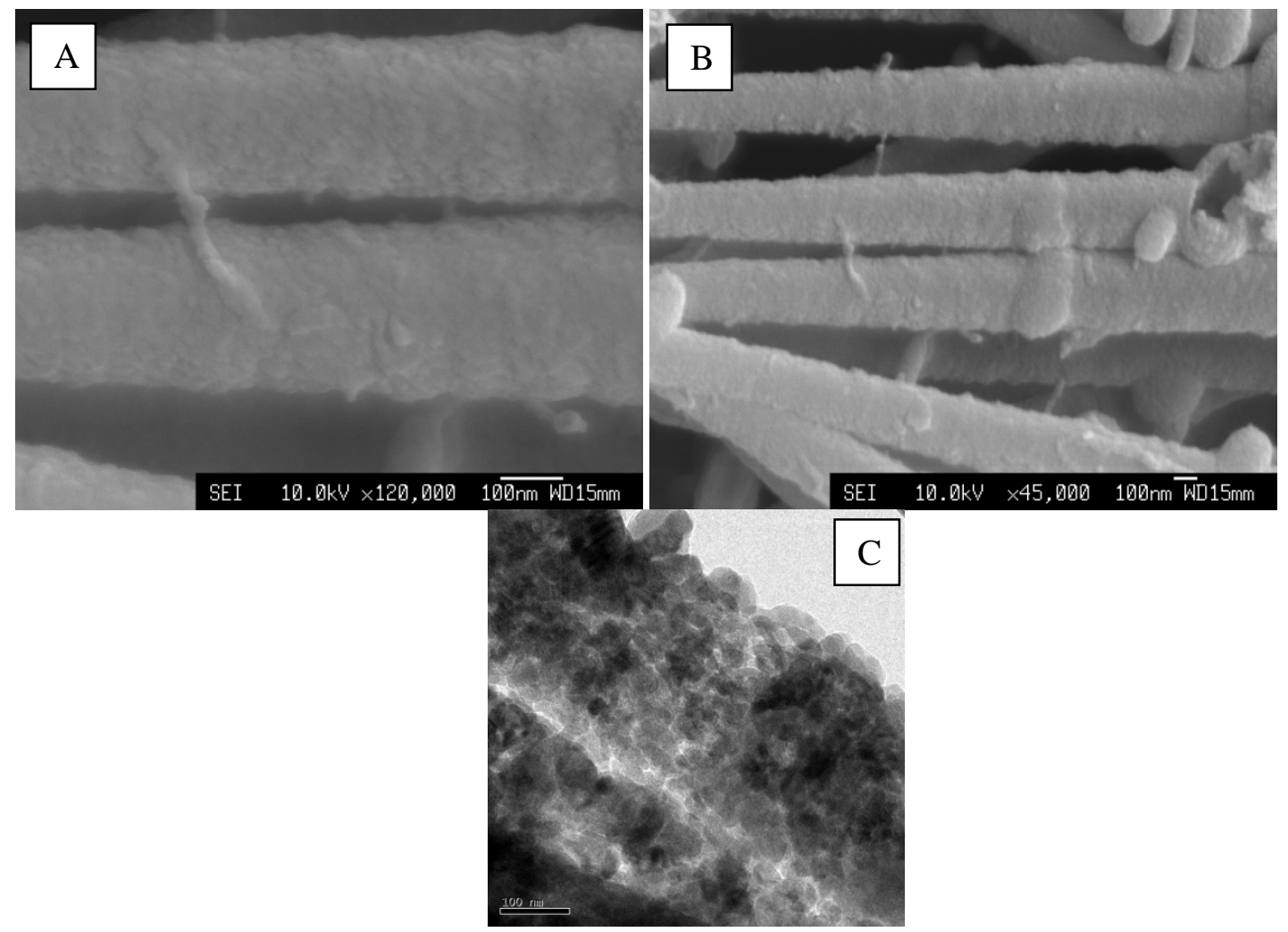

Figura 69: Estruturas de $\mathrm{CaCO}_{3}$ obtidas utilizando-se membranas de policarbonato, com tamanho de poros de $200 \mathrm{~nm}$, como template. A membrana foi modificada com 5 camadas de filme LbL, alternando-se quitosana e PAA. Lavagem para a remoção da parte orgânica 5 vezes com $\mathrm{CH}_{2} \mathrm{Cl}_{2}$. As imagens $\mathrm{A}$ e $\mathrm{B}$ foram obtidas por MEV e a imagem $\mathrm{C}$, por MET. 

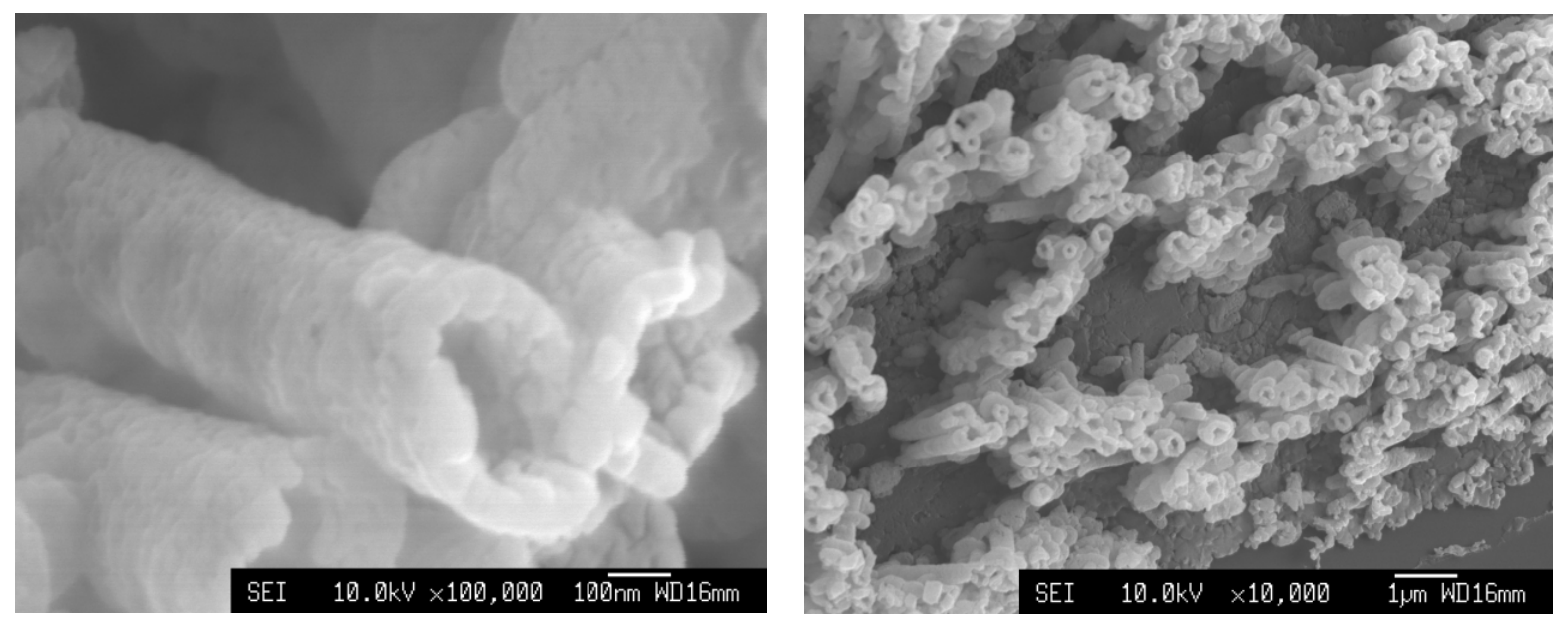

Figura 70: Estruturas de $\mathrm{CaCO}_{3}$ obtidas utilizando-se membranas de policarbonato, com tamanho de poros de $200 \mathrm{~nm}$, como template. A membrana foi modificada com 5 camadas de filme LbL, alternando-se quitosana e PAA. Remoção da parte orgânica por decomposição a altas temperaturas $\left(480^{\circ} \mathrm{C}\right)$.
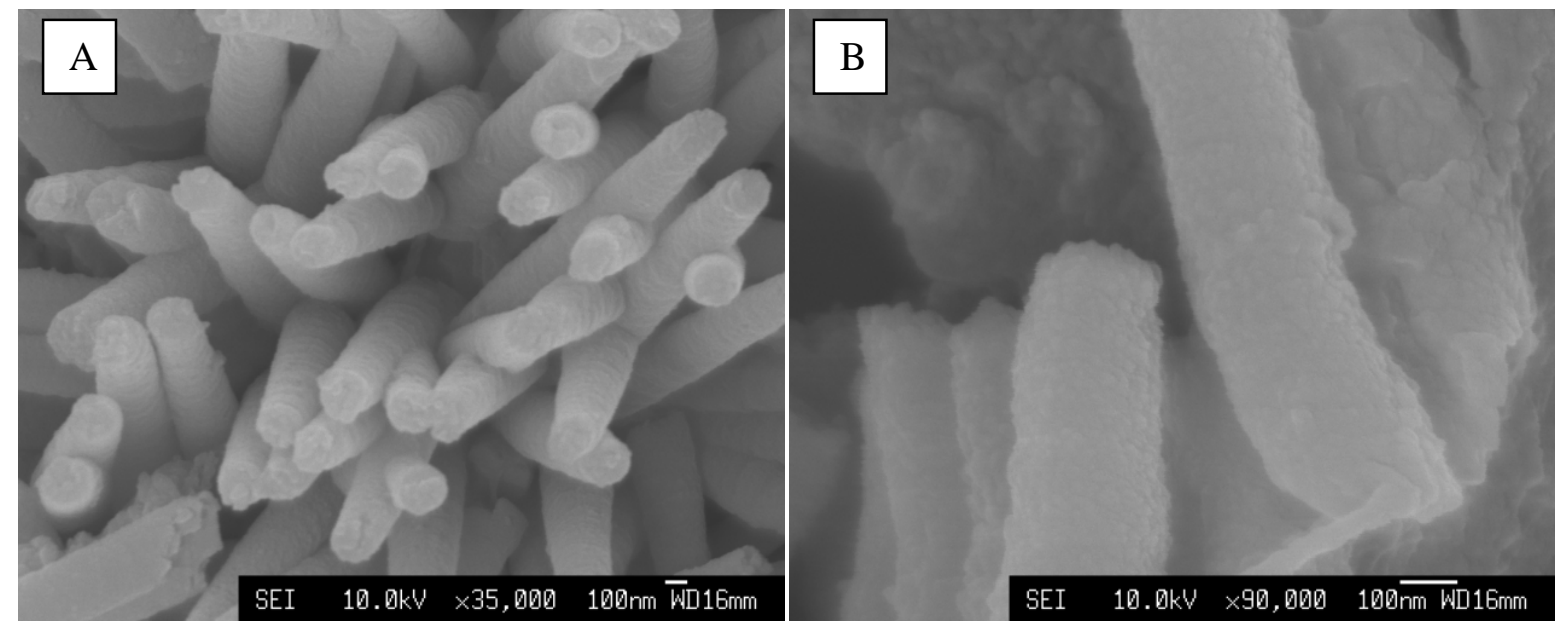


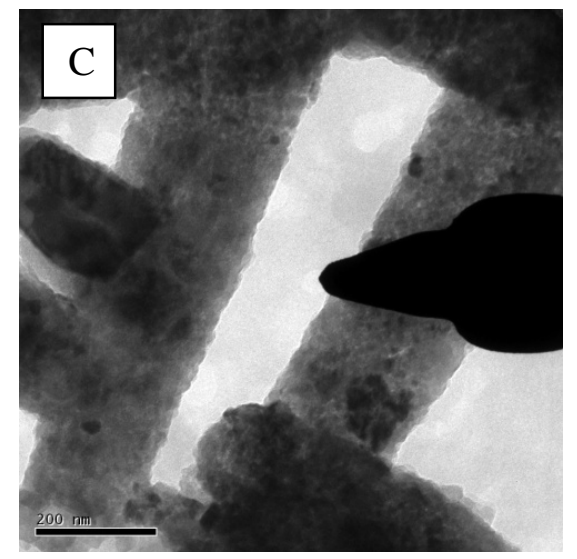

Figura 71: Estruturas de $\mathrm{CaCO}_{3}$ obtidas utilizando-se como molde membranas de policarbonato, com tamanho de poros de $200 \mathrm{~nm}$. A membrana foi modificada com filme LbL (Qt/PAA $)_{2} \mathrm{Qt}$, não utilizando-se PAA como aditivo na solução de $\mathrm{CaCl}_{2}$ do último enxágue. A remoção da parte orgânica foi feita com 5 enxágues com $\mathrm{CH}_{2} \mathrm{Cl}_{2}$. As imagens A e B foram obtidas por $\mathrm{MEV}$ e a imagem C, por MET.

Membranas de policarbonato com tamanho de poros de $50 \mathrm{~nm}$ foram utilizadas com intuito de ser verificar o efeito do tamanho dos poros no crescimento do $\mathrm{CaCO}_{3}$. A dispersidade de tamanho de poros em membranas com estas dimensões é maior do que naquelas de $200 \mathrm{~nm}$. Observa-se (Figura 72) que o tamanho das partículas que compõe o cilindro também variam em função do tamanho do poro da membrana de policarbonato. Em membranas com poros de $50 \mathrm{~nm}$, o tamanho das partículas que compõe o cilindro chegam a até $20 \mathrm{~nm}$. 


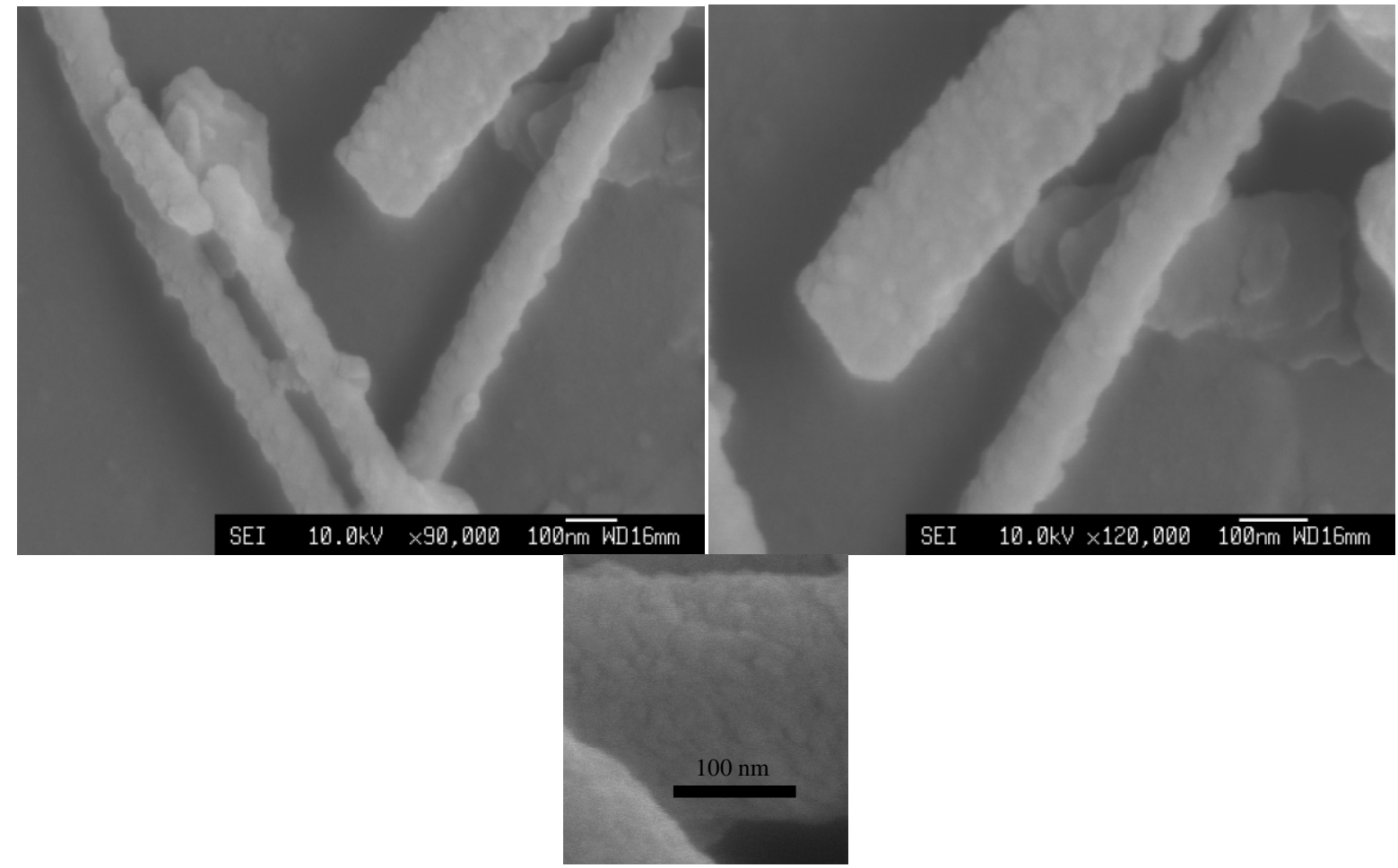

Figura 72: Estruturas de $\mathrm{CaCO}_{3}$ obtidas utilizando-se membranas de policarbonato, com tamanho de poros de $50 \mathrm{~nm}$, como template. A membrana foi modificada com 4 camadas de filme LbL, alternando-se quitosana e PAA. Lavagem para a remoção da parte orgânica 5 vezes com $\mathrm{CH}_{2} \mathrm{Cl}_{2}$. A figura $72 \mathrm{C}$ mostra uma ampliação da figura $66 \mathrm{~B}$ para comparação.

A Figura 73 apresenta micrografias de estruturas de carbonato de cálcio obtidas quando a membrana é removida a altas temperaturas. Observa-se que as estruturas cristalinas formadas são mais bem definidas. Os cilindros, neste caso, são formados por nanocristais que se agregam seguindo a geometria cilíndrica dos poros da membrana. Os nanocristais, por sua vez, apresentam morfologia nitidamente romboédrica de calcita, que é o polimorfo termodinamicamente mais estável, como era de se esperar após o tratamento a altas temperaturas. 


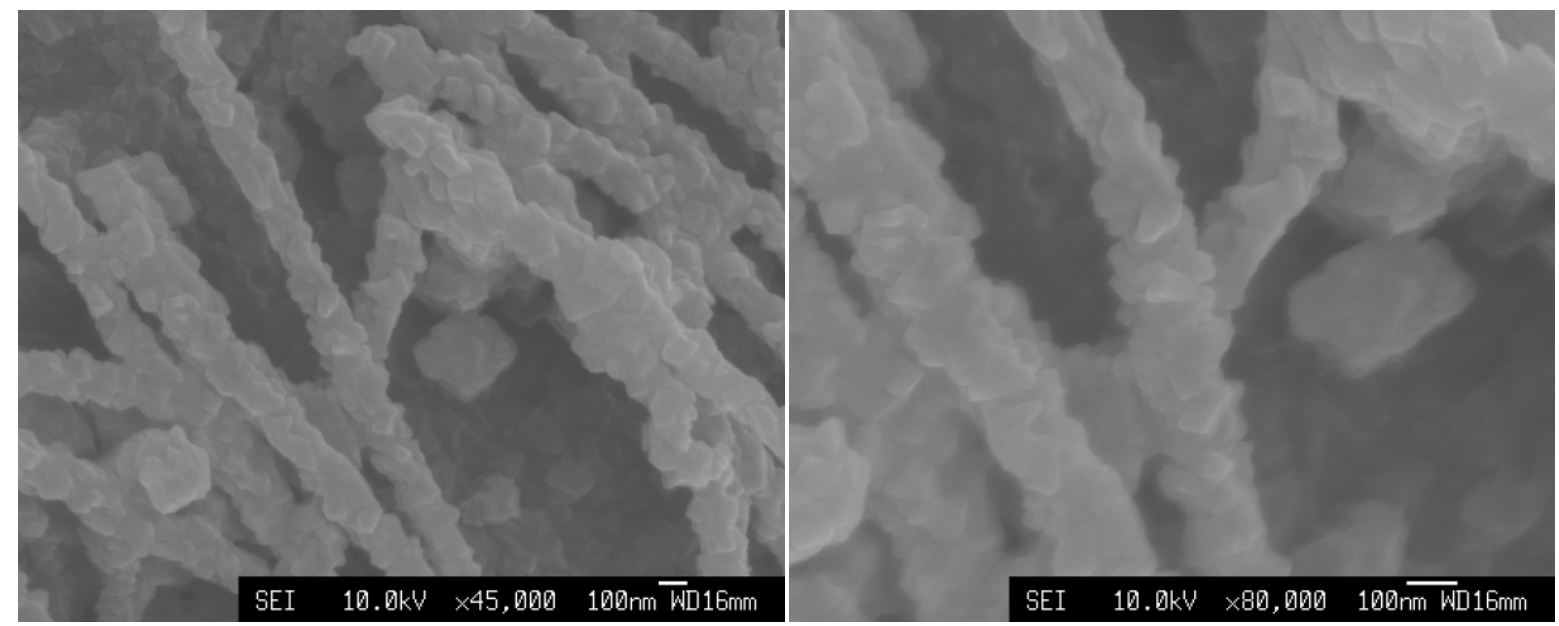

Figura 73: Estruturas de $\mathrm{CaCO}_{3}$ obtidas utilizando-se membranas de policarbonato, com tamanho de poros de $50 \mathrm{~nm}$, como template. A membrana foi modificada com 4 camadas de filme LbL, alternando-se quitosana e PAA. Remoção da membrana e do filme LbL inicialmente $\operatorname{com~} \mathrm{CH}_{2} \mathrm{Cl}_{2} \mathrm{e}$ em seguida por decomposição à altas temperaturas $\left(480^{\circ} \mathrm{C}\right)$.

O tipo de polieletrólito com o qual o filme LbL é terminado também influencia na morfologia dos cilindros formados com diâmetro de $50 \mathrm{~nm}$. Comparando-se as estruturas formadas na Figura 72 (4 camadas, terminando com PAA) e na Figura 74 (5 camadas, terminando com quitosana), nota-se que a presença de quitosana leva à formação de estruturas cilíndricas composta por cristalitos menores, como ocorreu com os cilindros de $200 \mathrm{~nm}$, nessa mesma condição. Estes cristalitos, por serem menores, fornecem uma superfície mais lisa. 

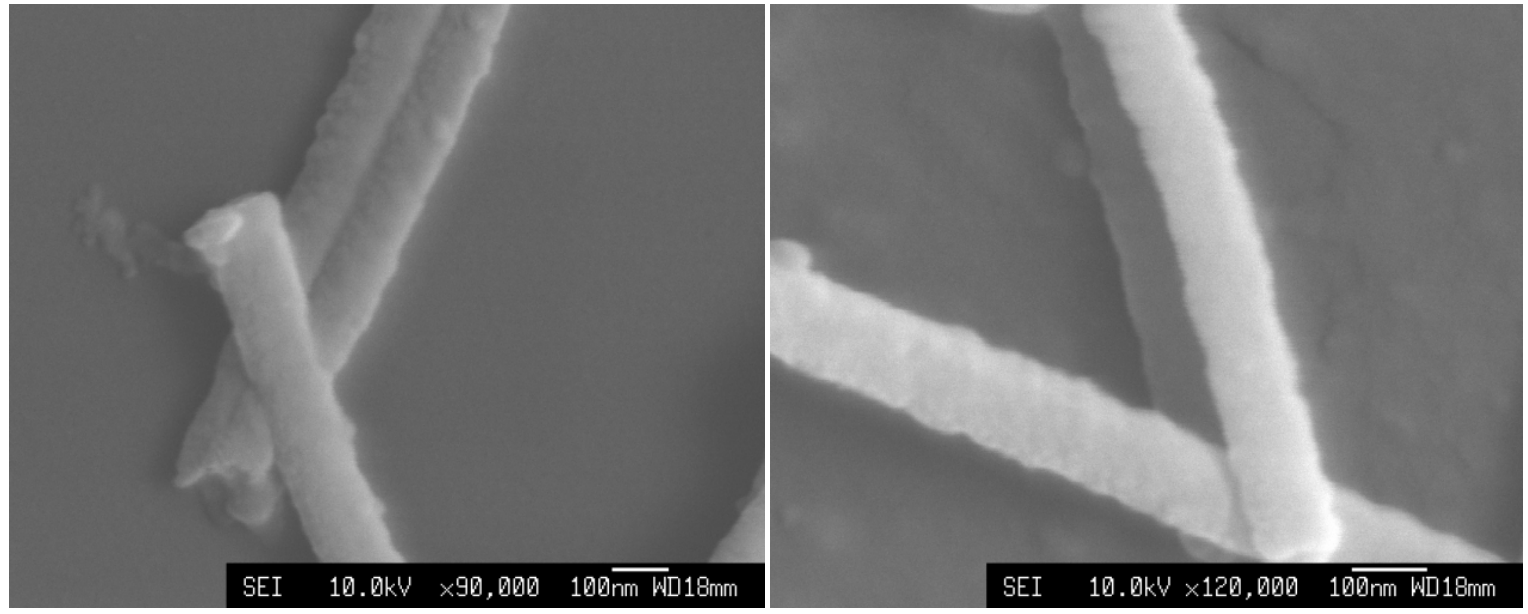

Figura 74: Estruturas de $\mathrm{CaCO}_{3}$ obtidas utilizando-se membranas de policarbonato, com tamanho de poros de $50 \mathrm{~nm}$, como template. A membrana foi modificada com 5 camadas de filme LbL, alternando-se quitosana e PAA. Lavagem para a remoção da parte orgânica 5 vezes $\operatorname{com~} \mathrm{CH}_{2} \mathrm{Cl}_{2}$.

A análise de preenchimento das estruturas cilíndricas, sob o efeito da adição de PAA, não foi realizada para as membranas com diâmetro de $50 \mathrm{~nm}$ pois, nestes casos a própria espessura do filme LbL já seria suficiente para o preenchimento do poro, eliminando-se o direcionamento da nucleação dada pelo efeito da ligação de íons cálcio ao poliânion. 


\section{Resultados e Discussão}

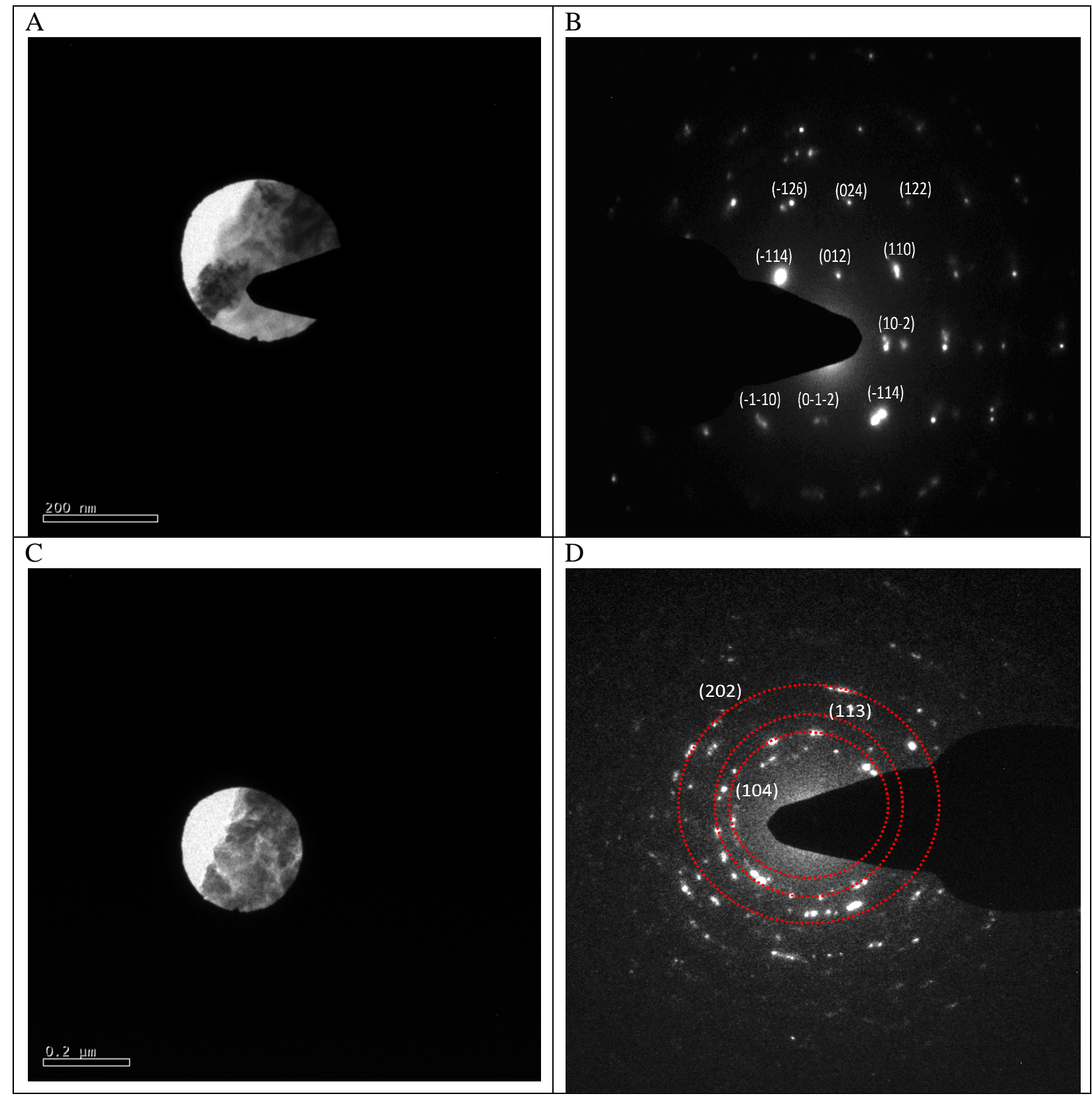

Figura 75: Padrões de difração de elétrons obtidos para as áreas selecionadas mostradas correspondentes às figuras 69 e 66. O padrão corresponde a um monocristal de calcita orientado em eixo de zona $<2-21>$. 


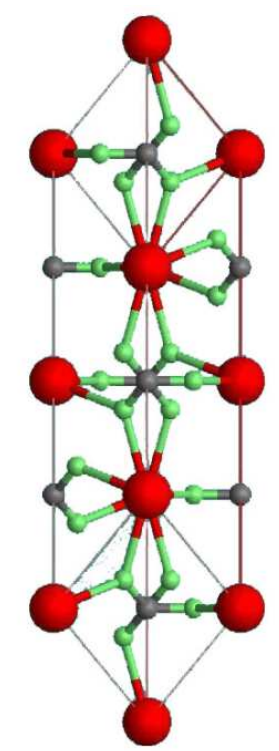

Figura 76: Estrutura hexagonal de $\mathrm{CaCO}_{3}$ orientado na direção cristalográfica $\langle 2 \quad-2 \quad 1>$. As esferas representam os átomos em suas posições: vermelho: cálcio, cinza: carbono, verde: oxigênio.

Padrões de difração de elétrons foram obtidos para as amostras com 200 nm de diâmetro. Estes, em sua maioria, correspondem a monocristais de calcita (Figura 75B). Porém, em alguns casos pudemos observar padrões que formam círculos concêntricos mostrando certa policristalinidade na amostra (Figura 75D). Estes padrões podem estar relacionados com a formação de diversos monocristais em uma mesma estrutura, ou ao crescimento de cristalitos de $\mathrm{CaCO}_{3}$ sobre os monocristais ${ }^{14}$. Além disso, estes monocristais devem estar orientados em diferentes direções cristalográficas gerando um padrão de difração com um conjunto grande de pontos, impossibilitando a determinação de uma direção preferencial. Os padrões da Figura 75B coincidem com a simulação realizada utilizando-se o programa JEMS (electron microscopy software- LNLS) para uma estrutura hexagonal $(\mathrm{d}(110)=4,00 \mathrm{~nm}-1 ; \mathrm{d}(012)=2,59 \mathrm{~nm}-1 \mathrm{~d}(10-2)=$

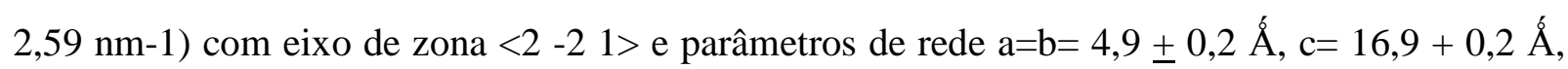
$\alpha=\beta=90^{\circ}$ e $\gamma=120^{\circ}$, como é de se esperar para cristais de calcita ${ }^{14}$. Para o padrão de difração 


\section{$\underline{\text { Resultados e Discussão }}$}

apresentado na figura 74D podemos calcular as distâncias interplanares $\left(\mathrm{d}_{\mathrm{hkl}}\right)$ correspondentes aos planos $(104) \mathrm{d}=3,4 \AA$, (113) d= 2,7 $\AA$ e (202) d= 2,1 Á por meio da obtenção do valor do raio do círculo, uma vez que cada círculo formado corresponde a um dos conjuntos de planos citados. Os valores obtidos experimentalmente estão em condordância com os valores calculados utilizandose a expressão que relaciona $d_{h k l}$ para o sistema hexagonal 3,1;2,3 e 2,1 $\AA$, respectivamente.

Nos estudos anteriormente realizados por Loste et. $\mathrm{al}^{14,98}$ onde este tipo de membrana foi utilizada como molde para a cristalização de $\mathrm{CaCO}_{3}$ em confinamento. Observou-se que o crescimento em meios confinados, em um primeiro estágio, leva à formação de estruturas cilíndricas constituídas por $\mathrm{CaCO}_{3}$ amorfo (ACC) que em seguida é convertido monocristais de calcita com estruturas cilíndricas também impostas pelo molde. Este tipo de meio permitiu verificar a importância da formação de ACC na cristalização posterior de calcita. A transformação de uma fase precursora amorfa em meios confinados pode ser uma rota sintética efetiva na manipulação da morfologia de monocristais. Por outro lado, mostramos com os resultados obtidos utilizando-se membranas modificadas por filmes LbL de polieletrólitos, que monocristais de calcita também podem ser formados sem a necessidade de passagem pela fase precursora amorfa. 


\section{Conclusões}

A nucleação e o crescimento de cristais de carbonato de cálcio são importanı̇s para estudos de biomineralização, entretanto, também é importante estudar características da matriz polimérica e dos filmes híbridos orgânico-inorgânico com relação aos fatores que afetam sua formação, estabilidade, a cristalinidade e morfologia das superfícies recobertas obtidas. Neste trabalho de tese foram obtidos filmes orgânicos através da técnica LbL utilizando-se diferentes tipos de poliânions e um tipo de policátion, e filmes híbridos contendo como parte inorgânica $\mathrm{CaCO}_{3}$ por meio da reação entre $\mathrm{CO}_{2}$ e $\mathrm{H}_{2} \mathrm{O}$ para formação de $\mathrm{CO}_{3}{ }^{2-}$. O tipo de formação do filme inorgânico, utilizando-se como meio reacional a água aprisionada na matriz polimérica é novo, uma vez que na literatura todos os trabalhos fazem uso de soluções onde suportes e membranas são imersos, com a sequiente precipitação da parte inorgânica. Ainda, outra vantagem em se usar este tipo de recobrimento é que não se faz necessário o uso de tratamentos térmicos. Quando depositados sobre suportes metálicos adequados, como em nosso caso, este tipo de material tem potencial aplicação em implantes de substituição óssea, os quais requerem superfícies quimicamente inertes e bicompatíveis, promovendo a osteointegração. Este tipo de material pode vir a oferecer uma alternativa às superfícies bioativas de hidroxiapatita, uma vez que demonstrou-se que as matrizes orgânicas formadas são suportes que podem viabilizar processos de calcificação.

As técnicas de análise utilizadas foram eficientes para quantificação e caracterização dos filmes formados. Existe uma versatilidade muito grande nos tipos de técnicas que podem ser utilizadas para análise dos filmes orgânicos e híbridos, tal como SAXS, difração de raios-X, espectroscopia Raman, FTIR e microscopias óptica, eletrônica e de força atômica. Essas técnicas 


\section{Conclusões}

de análise foram úteis e complementares nas análises dos filmes orgânicos, tal como, na análise das partículas de $\mathrm{CaCO}_{3}$ formadas. Por exemplo, a técnica de espalhamento de raios-X a baixo ângulo permitiu investigar a periodicidade dos filmes $\mathrm{LbL}$ formados e por meio da espectroscopia Raman investigou-se a presença de diferentes polimorfos de carbonato de cálcio.

Os experimentos realizados ressaltaram a importância do micro-ambiente onde a nucleação acontece. Os resultados dessa tese indicaram que os cristais de $\mathrm{CaCO}_{3}$ foram formados provavelmente em dois ambientes químicos distintos: $\mathrm{Ca}^{2+}$ ligado ao poliânion e $\mathrm{Ca}^{2+}$ presente na solução de $\mathrm{CaCl}_{2}$ utilizada no enxágüe das camadas poliméricas, uma vez que a matriz orgânica constitui-se por si só um gel capaz de aprisionar o solvente. Utilizando-se diferentes métodos de deposição, tal como, diferentes templates, observamos diferenças notáveis nas partículas formadas. Diferenças que vão desde tamanho ao tipo de polimorfo estabilizado.

Podemos então dividir as conclusões a partir dos resultados obtidos por meio dos diferentes métodos da seguinte maneira:

\section{1) Efeito da quantidade de solvente na vizinhança e rugosidade do suporte}

Para este estudo dois diferentes métodos foram utilizados, o método por nós denominado "a seco" que foi reportado pela primeira vez por Ramos et.al ${ }^{97}$ e o método no qual o suporte contendo a matriz orgânica é imerso em solução 0,01 mol. $\mathrm{L}^{-1}$ de $\mathrm{CaCl}_{2}$.

Quando os suportes planares são recobertos com filme LbL de 13 camadas alternadas de polieletrólitos, e o método de deposição "a seco" é utilizado, aparentemente a informação sobre a rugosidade do suporte é perdida, e filmes de $\mathrm{CaCO}_{3}$ formados sobre alumínio, aço inox e silício não exibem diferenças significativas em sua morfologia ou tipo de polimorfo formado. Porém, utilizando-se o mesmo tipo de modificação nas superfícies de suportes planares (filmes LbL de 
$\underline{\text { Conclusões }}$

PAA/Qt ou PSS/Qt) e deposição no interior da solução de $\mathrm{CaCl}_{2}$ com a face contendo a matriz orgânica virada para cima, resultou na estabilização do polimorfo termodinamicamente mais estável, calcita, sobre os suportes mais rugosos, ou seja, os suportes de alumínio. Já em silício, estabiliza-se preferencialmente o polimorfo cineticamente mais estável, vaterita. Já, em deposições realizadas também em solução, porém com a face do suporte que contém a matriz orgânica voltada para baixo, observa-se que as amostras formadas sobre os diferentes suportes não diferem morfologicamente, como mostrado nas imagens de MEV. Desta forma mostramos que a morfologia de filmes e/ou partículas formadas é dependente do conjunto rugosidade do suporte + processos difusivos, este último modificado pela disponibilidade de solução na vizinhança dos íons cálcio responsáveis pela nucleação do $\mathrm{CaCO}_{3}$.

Além disso, a adesão dos filmes aos suportes segue a tendência geral em relação à rugosidade: suportes mais rugosos (alumínio) propiciam maior adesão do que os suportes mais lisos (aço-inox). Para os suportes de silício não foram realizadas medidas de força de adesão pois, visualmente pode-se notar que a aderência é muito baixa. Os suportes de aço-inox modificados com a presença do filme LB foram os que apresentaram menor adesão filme/suporte. Este é um ponto que deve ser explorado e melhorado.

2) Tipo de grupo carregado negativamente no poliânion formador da matriz orgânica e conformação dos polieletrólitos

Foram utilizados poliânions com diferente grupos carregados: poli(ácido acrílico) (PAA) e poli(acrilato de sódio) (NaPA) que contêm grupos carboxilato, lambda-carragenana ( $\lambda$-car), e iota-carragenana (1-car) que possuem grupos ésteres sulfato e, finalmente, poli(sulfonato de 
sódio) (NaPSS) que possui grupos sulfonato. Como policátion foi utilizada quitosana (Qt) em pH 5,4 .

Observou-se que a nucleação e o crescimento dos cristais de $\mathrm{CaCO}_{3}$ estão intrinsecamente ligados ao tipo de matriz orgânica utilizada. Pode-se variar o tipo dos cristais formados, tal como sua morfologia, variando-se os tipos e quantidades dos formadores da matriz orgânica. Utilizando-se um poliânion que apresenta conformação helicoidal em solução obtivemos $\mathrm{CaCO}_{3}$ somente como partículas isoladas. Porém, em todos os casos, no qual se utilizou para formação da matriz orgânica, um poliânion com conformação "novelo-ao-acaso", formou-se um filme coeso e denso de $\mathrm{CaCO}_{3}$. Além disso, o crescimento dos cristais de $\mathrm{CaCO}_{3}$ se dá de maneira mais eficiente nos filmes LbL formados por PAA/Qt que se apresentaram mais densos e homogêneos do que os filmes formados por Na/PAA. Estas diferenças foram atribuídas a diferenças na supersaturação local, que pode ser alterada conforme a disponibilidade dos íons $\mathrm{Ca}^{2+}$ contido na última camada do filme orgânico.

\section{3) Tipo de fosfolipídeo que compões o filme LB e conformação dos polieletrólitos}

Foi estudada a influência de pré-recobrimento dos suportes sólidos com filmes LB sobre a formação dos filmes $\mathrm{LbL}$, tal como sobre o subseqüente crescimento de $\mathrm{CaCO}_{3}$ sobre essas matrizes. Para este fim utilizou-se fosfolipídeos contendo 14 carbonos em sua calda apolar, porém com diferentes cargas em sua cabeça polar: negativo ou zwitteriônico. Verificou-se que a presença do pré-recobrimento $\mathrm{LB}$ influencia na morfologia dos filmes de $\mathrm{CaCO}_{3}$ formados, porém quando aumentamos a numero de camadas do filme LbL a informação do filme LB é praticamente perdida. No caso do crescimento de $\mathrm{CaCO}_{3}$ sobre filmes $\mathrm{LB} / \mathrm{LbL}$ formados por um polieletrólito capaz de formar hélices (l-car) não houve a formação de filmes contínuos do 


\section{Conclusões}

composto inorgânico, mas sim a formação de estruturas que evoluíam em morfologia e tamanho em função da quantidade de DMPA presente no filme LB. Essas diferenças morfológicas observadas nas partículas também foram atribuídas às diferenças de supersaturação local gerada pela diferença de interação lipídeo-Qt dependendo do grupo polar do lipídeo e consequentemente no tipo de interação Qt-1-car que ocorre para a formação do filme LbL.

Para os filmes LB/LbL formados por polieletrólitos na conformação novelo-ao-acaso verificou-se a formação de filmes inorgânicos contínuos, compostos por partículas nanométricas que crescem em orientações diferentes em função do tipo de fosfolipídeo na matriz LB. Sobre os filmes formados por DMPE e $\lambda$-car observou-se a formação de $\mathrm{CaCO}_{3}$ como estruturas alongadas tipo agulha que cresceram orientando-se perpendicularmente ao plano do suporte sólido, formando estruturas semelhantes a flores. Já sobre os filmes contendo DMPA e $\lambda$-car observouse crescimento de partículas também alongadas, porém que se orientam paralelamente ao plano do suporte sólido. Desta forma, mostrou-se que o tipo de fosfolipídeo utilizado no filme LB direciona o crescimento do filme $\mathrm{LbL}$ criando diferentes interfaces que modificam o microambiente para a nucleação e crescimento de $\mathrm{CaCO}_{3}$.

\section{4) Crescimento em meio confinado tridimensional}

A formação de $\mathrm{CaCO}_{3}$ em meios confinados tridimensionais modificados com filmes LbL de polieletrólitos, exibe características peculiares em morfologia e preenchimento dos tubos, que podem ser influenciadas pelo tipo de remoção do template orgânico, pelo número de camadas de polieletrólito, e, assim, pela carga da superfície, e pelo tamanho dos poros nos quais os cristais foram crescidos. Membranas modificadas com filme LbL (Qt/PAA) $)_{2} \mathrm{Qt}$ são capazes de aprisionar 


\section{Conclusões}

quantidade maior de solução dando origem a estruturas cilíndricas de $\mathrm{CaCO}_{3}$ completamente preenchidas. Utilizando-se filmes LbL terminados em PAA (Qt/PAA $)_{2}$ ou adicionando-se PAA na solução de $\mathrm{CaCl}_{2}$ (método PILP) precursora dos cristais de $\mathrm{CaCO}_{3}$ ocorre a formação de estruturas cilíndricas ocas. A presença de PAA que pode se ligar à quitosana presente no filme LbL na parede da membrana deve direcionar a nucleação dos cristais às regiões das bordas, formando estruturas abertas. Os cilindros formados no interior de membranas de $50 \mathrm{~nm}$ são constituídos por partículas menores do que os cilindros formados utilizando-se membranas de 200 nm. A análise dos padrões de difração de elétrons para as amostras indicam que estas, em sua maioria, são constituídas por monocristais de calcita hexagonal. Certa policristalinidade foi observada para algumas amostras indicando que estas podem ser formadas por monocristais sobrepostos sem direção preferencial. 


\section{Referências}

[1] Conde, A., Durán, A., de Damborenea, J.J. Prog. Org. Coat. 2003, 46, 288.

[2] Baker, K.C., Anderson, M.A., Oehlke, S.A., Astashkina, A.I., Haikio, D.C., Drelich, J., Donahue, S.W. Mater. Sci. Eng. C-Biomimetic Supramol. Syst. 2006, 26, 1351.

[3] Chrzanowski, W., Armitage, D.A., Knowles, J.C., Szade, J., Korlacki, W., Marciniak, J. J. Biomater. Appl. 2008, 23, 51.

[4] Schwarz, F., Ferrari, D., Herten, M., Mihatovic, I., Wieland, M., Sager, M., Becker, J. J. Periodontol. 2007, 78, 2171.

[5] Sawase, T., Jimbo, R., Baba, K., Shibata, Y., Ikeda, T., Atsuta, M. Clin. Oral Impl. Res. 2008, $19,491$.

[6] Feng, B., Weng, J., Yang, B.C., Qu, S.X., Zhang, X.D. Biomaterials 2003, 24, 4663.

[7] Yang, J.; Welby, J.L.; Meyerhoff, M.E. Langmuir 2008, 24, 10265.

[8] Gupta, R; Kumar, A. Biomed. Mater. 2008, 3, 34005.

[9] Westbroek, P., Marin, F. Nature 1998, 392, 861.

[10] Mann, S., Webb, J., Williams, R.J.P. Biomineralization: Chemical and Biochemical Perspectives; VCH: New York, 1989.

[11] Meyer, H.J. J. Cryst. Growth 1984, 66, 639.

[12] Belcher, A.M., Wu, X.H., Christensen, R.J., Hansma, P.K., Stucky, G.D., Morse, D.E. Nature 1996, 381, 56.

[13] Sarikaya, M., Tamerler, C., Jen, A.K.Y., Schulten, K., Baneyx, F. Nature Materials 2003, 2, 577.

[14] Loste, E., Park, R.J., Warren, J., Meldrum, F.C. Adv. Funct. Mater. 2004, 14, 1211.

[15] Yue, W., Kulak, A.N., Meldrum, F.C. J. Mater. Chem. 2006, 16, 408.

[16] Park, R.J., Meldrum, F.C. J. Mater. Chem. 2004, 14, 2291.

[17] Glimcher, M., Nimni, M. Connect Tissue Res. 1992, 27, 73.

[18] Paine, M. L., Snead, M. L. J. Bone Mineral. Res. 1996, 12, 221.

[19] Sellinger, A., Weiss, P.M., Nguyen, A., Lu, Y., Assink, R.A., Gong, W., Brinker, C.J. Nature 1998, 394, 256. 
Referências

[20] Sampathkumaran, U.; De Guire, M.R.; Wang, R. Adv. Eng. Mater. 2001, 3, 401.

[21] Baker, K.C., Anderson, M.A., Oehlke, S.A., Astashkina, A.I., Haikio, D.C., Drelich, J., Donahue, S.W. Mater. Sci. Eng. C-Biomimetic Supramol. Syst. 2006, 26, 1351.

[22] Beppu, M.M. "Estudo da calcificação in vitro de quitosana", tese de doutorado, UNICAMP-Campinas, 1999.

[23] Ludwigs, S., Steiner, U., Kulak, A.N., Lam, R., Meldrum, F.C. Adv. Mater. 2006, 18, 2270.

[24] Rieger, J., Thieme, J., Schmidt, C. Langmuir 2000, 16, 8300.

[25] Arias, J.L., Neira-Carrillo, A., Arias, J.I., Escobar, C., Bodero, M., David, M., Fernandez, M.S. J. Mater. Chem. 2004, 14, 2154.

[26] Loste, E., Díaz-Martí, E., Zarbakhsh, A., Meldrum, F.C. Langmuir 2003, 19, 2830.

[27] Wada, N., Kanamura, K., Umegaki, T. J. Colloid Interface Sci. 2001, 233, 65.

[28] Wada, N., Yamashita, K., Umegaki, T. J. Colloid Interface Sci. 1999, 212, 357.

[29] Teng, H.H., Chen, Y., Pauli, E. J. Am. Chem. Soc. 2006, 128, 14482.

[30] Rudloff, J., Colfen, H. Langmuir 2004, 20, 991.

[31] Falini, G., Albeck, S.,Weiner, S.; Addadi, L. Science 1996, 271, 67.

[32] Kino, R., Ikoma, T., Monkawa, A., Yunoki, S., Munekata, M., Tanaka, J., Asakura, T. J. Appl. Polymer Sci. 2006, 99, 2822.

[33] Falini, G., Fermani S., Vanzo S. Eur. J. Inorg. Chem. 2005, 1, 162.

[34] Shen, Q., Wang, L., Huang, Y., Sun, J., Wang, H., Zhou, Y., Wang, D. J. Phys. Chem. B 2006, 110, 23148.

[35] Mao, C., Li, H., Cui, F., Feng, O., Wang, H., Ma, C. J. Mater. Chem. 1998, 8, 2975.

[36] Suzuki, M., Nagasawa, H.; Kogure, T. Cryst. Growth Des. 2006, 6, 2004.

[37] Manoli, F., Koutsopoulos, S., Dalas, E. J. Cryst. Growth 1997, 182, 116.

[38] Wedin, P., Bergström, L. J. Colloid Interface Sci. 2005, 281, 146.

[39] Aimoli, C.G., Beppu, M.M. Colloid Surf. B-Biointerfaces 2006, 53, 15.

[40] Wada, N., Suda, S., Kanamura, K., Umegaki, T. J. Colloid Interface Sci. 2004, 279, 167.

[41] Neira-Carrillo, A., Yazdani-Pedram, M., Retuert, J., Diaz-Dosque, M., Gallois, S., Arias, J.L. J. Colloid Interface Sci. 2005, 286, 134.

[42] Zhang, S., Gonsalves, K.E. Mater. Sci. Eng. C-Biomimetic Supramol. Syst. 1995, 3, 117.

[43] Lakshminarayanan, R., Loh, X.J., Gayathri, S., Sindhu, S., Banerjee, Y., Kini, R.M., Valiyaveettil, S. Biomacromolecules 2006, 7, 3202. 
$\underline{\text { Referências }}$

[44] Zhang, S., Gonsalves, K.E. Langmuir 1998, 14, 6761.

[45] Mann, S. Nature 1988, 119, 332.

[46] Kato, T., Hosoda, N., Sugawara, A. Adv. Mater. 2002, 14, 869.

[47] Manoli, F., Koutsopoulos, S. Dalas, E. J. Cryst. Growth 1997, 182, 116.

[48] Jayaraman, A., Subramanyam, G., Sindhu, S., Ajikumar, P.K., Valiyaveettil, S. Cryst. Growth Des. 2007, 7, 142.

[49] Mann, S., Heywood, B.R., Rajam, S., Sudara, J.B.A. J. Phys.D: Appl. Phys. 1991, 24, 154.

[50] Hacke, S., Möbius, D., Lieu, V.T. Appl. Surf. Sci. 2005, 246, 362.

[51] Küther, J., Seshadri, R., Tremel, W. Angew. Chem. Int. Ed. 1998, 37, 3044.

[52] Archibald, D.D., Quadri, S.B., Gaber, B.P. Langmuir 1996, 12, 538.

[53] Küther, J., Nelles, G., Seshadri, R., Schaub, M., Butt, H.J., Tremel, W. Chem. Eur. J. 1998, 4,1834 .

[54] Wedin, P., Lewis, J.A., Bergstrom, L. J. Colloid Interface Sci. 2005, 290, 134.

[55] Kim, I.W., Robertson, R.E., Zand, R. Cryst. Growth Des. 2005, 5, 513.

[56] Li, Q., Ding, Y., Li, F.Q., Xie, B., Qian, Y.T. J. Cryst. Growth 2002, 236, 357.

[57] Qi, R.J., Zhu, Y.J. J. Phys. Chem. B 2006, 110, 8302.

[58] Ercole, C., Cacchio, P., Botta, A.L., Centi, V., Lepidi, A. Microsc. Microanal. 2007, 13, 42.

[59] Yang, L., Zhang, X.Y., Liao, Z.J. J. Inorg. Biochem. 2003, 97, 377.

[60] Sakamoto, T., Oichi, A., Sugawara, A., Kato, T. Chem. Lett. 2006, 35, 3.

[61] Belcher, A.M., Wu, X.H., Christensen, R.J., Hansma, P.K., Stucky, G.D., Morse, D.E. Nature 1996, 381, 56.

[62] Falini, G., Albeck, S.,Weiner, S., Addadi, L. Science 1996, 271, 67.

[63] Xie, A.J., Yang, Y.F., Yao, C.L., Yang, Y.M., Yu, X.R., Rong, X., Zhang, C.Y., Zhu, X.M. Cryst. Res. Technol. 2006, 41, 1214.

[64] Lu, C., Qi, L., Ma, J., Cheng, H., Zhang, M., Cao, W. Langmuir 2004, 20, 7378. 
$\underline{\text { Referências }}$

[65] Wu, W., He, T., Chen, J.F., Zhang, X., Chen, Y. Mater. Lett. 2006, 60, 2410.

[66] Donners, J.J.J.M., Heywood, B.R., Meijer, E.W., Nolte, R.J.M., Roman, C., Schenning, A.P.H.J., Sommerdijk, N.A.J.M. Chem. Commun. 2000, 19, 1937.

[67] Naka, K., Chujo, Y. Chem. Mater. 2001, 13, 3245.

[68] Wakayama, H., Hall, S.R., Mann, S. J. Mater. Chem. 2005, 15, 1134.

[69] Backfolk, K., Lagerge, S., Rosenholm, J.B., Eklund, D. J. Colloid Interface Sci. 2002, 248, 5 .

[70] Wang, W., Wang, G., Liu, Y., Zheng, C., Zhan, Y. J. Mater. Chem. 2001, 11, 1752.

[71] Deng, S.G., Cao, J.M., Feng, J., Guo, J., Fang, B.Q., Zheng, M.B., Tao, J. J. Phys. Chem. B 2005, 109, 11473.

[72] Kjellin, P., Andersson, M., Palmqvist, A.E.C. Langmuir 2003, 19, 9196.

[73] Braun, P.V., Osenar, P., Tohver, V., Kennedy, S.B., Stupp, S.I. J. Am. Chem. Soc. 1999, 121,7302 .

[74] Mann, S., Heywood, B.R., Rajam, S., Birchall, D. Nature 1988, 334, 692.

[75] Heywood, B.R., Mann, S. Chem. Mater. 1994, 6, 311.

[76] Litvin, A.L., Valiyaveettil, S., Kaplan, D., Mann, S. Adv. Mater. 1997, 9, 124.

[77] Duffy, D.M., Harding, J.H. Langmuir 2004, 20, 7630.

[78] Duffy, D.M., Harding, J.H. Langmuir 2004, 20, 7637.

[79] Müller, H., Zentel, R., Janshoff, A., Janke, M. Langmuir 2006, 22, 11034.

[80] Hacke, S., Möbius, D. Colloid Polym. Sci 2004, 282, 1242.

[81] Gower, L.B., Tirrel, D.A. J. Crys. Growth 1998, 191, 153.

[82] Olszta, M.J., Odom, D.J., Douglas, E.P., Gower, L.B. Connect Tissue Res 2003, 44, 326.

[83] Ueyama, N., Takeda, J., Yamada, Y., Onoda, A., Okamura, T., Nakamura, A. Inorg Chem 1998, 38,475 .

[84] Ueyama, N., Kozuki, H., Doi, M., Yamada, Y., Takahashi, K., Onoda, A., Okamura, T., Yamamoto, H. Macromolecules 2001, 34, 2607. 
$\underline{\text { Referências }}$

[85] Ueyama, N., Hosoi, T., Doi, M., Yamada, Y., Nakamura, A. Macromolecules 1998, 31, 7119.

[86] Donners, J.J.J.M., Nolte, R.J.M., Sommerdijk, N.A.J.M. J. Am. Chem. Soc. 2002, 124, 9700.

[87] Naka, K., Tanaka, Y., Chujo, Y., Ito, Y. Chem. Commun. 1999, 1931.

[88] Naka, K. Top Curr Chem 228, 141.

[89] Feng, Q.L., Pu, G., Pei, Y., Cui, F.Z., Li, H.D., Kim, T.N. J. Cryst. Growth 2000, 216, 459.

[90] Lee, S.W., Lee, S.K., Belcher, A.M. Adv Mater 2003, 15, 689.

[91] Dujardin, E., Peet, C., Stubbs, G., Culver, J.N., Mann, S. Nano Lett. 2003, 3, 413.

[92] Deng, S.G., Cao, J.M., Feng, J., Guo, J., Fang, B.Q., Zheng, M.B., Tao, J. J Phys Chem B 2005, 109, 11473.

[93] Heywood, B.R. "Template-direct nucleation and growth of inorganic materials" In: Mann, S. Biomimetic materials chemistry, Wiley-New York, 143-173, 1981.

[94] Ramos, A.P., Nobre, T.M., Montoro, L.A., Zaniquelli, M.E.D J. Phys. Chem. B 2008, 112, 14648.

[95] Falini, G. Int. J. Inorg. Mater. 2000, 2, 455.

[96] Falini, G., Fermani, S., Gazzano, M., Ripamonti, S. J. Chem. Soc. Dalton Trans. 2000, 3983. [97] Ramos, A.P., Doro, F.G., Gonçalves, R.R., Tfouni, E., Zaniquelli, M.E.D. Thin Solid Films 2008, $516,3256$.

[98] Loste, E., Meldrum, F.C. Chem. Commun. 2001, 901.

[99] Fou, A.C., Onitsuka, O., Ferreira, M., Rubner, M.F., Hsieh, B.R. J. Appl. Phys 1996, 79, 7501.

[100] Onitsuka, O., Fou, A.C., Ferreira, M., Hsieh, B.R., Rubner, M.F. J. Appl. Phys. 1996, 80, 4067.

[101] Swalen, J.D., Allara, D.L., Andrade, J.D., McCarthy, T.J., Murray, R., Pease, R.F., Rabolt, J.F., Wynne, K.J., Yu, H. Langmuir 1987, 3, 932.

[102] Maoz, R., Netzer, L., Gun, J., Sagiv, J. J. Chim. Phys. 1988, 83, 1059.

[103] Conde, A., Durán, A., Damborenea, J.J. Prog. Org. Coat. 2003, 46, 488.

[104] Lvov, Y., Ariga, K., Ichinose, I., Kunitake, T. J. Am. Chem. Soc. 1995, 117, 6117.

[105] Blodgett, K.B. J. Am. Chem. Soc. 1935, 57, 1007.

[106] Langmuir, I. J. Am. Chem. Soc. 1917, 39, 1848.

[107] Decher, G., Hong, J.D. Makromol. Chem. Macromol. Symp. 1991, 46, 321. 
$\underline{\text { Referências }}$

[108] Ulman, A. An introduction to ultrathin films: from Langmuir-Blodgett to self-assembly, $1^{\mathrm{a}}$ ed., Boston: Academic Press, 1991.

[109] Ozona, F., di Megliob, J.M., cois Joannyc, J.F. Cond. Mat. Soft. 2002, 2, 1.

[110] Manning, G.S.; Biopolymers, 1970, 9, 1543.

[111] R. Netz, J. F. Joanny, Macromolecules 1999, 26, 2026.

[112] Xu, X., Han, T.J., Cho, K. Chem. Mater. 2004, 16, 1740.

[113] Lenahan, K.M., Wang, Y.X., Liu, Y.J., Claus, R.O., Heflin, J.R., Marciu, D., Figura, C. Adv. Mater. 1998, 10, 853.

[114] Decher, G., Hong, J.D., Schmitt, J. Thin Solid Films 1992, 210/211, 831.

[115] Raposo, M., Oliveira Jr., O.N. Braz. J. Phys. 1998, 28, 392.

[116] Sukhorukov, G.B., Donath, E., Lichtenfeld, H., Knippel, E., Knippel, M., Budde, A., Mohwald, H. Colloid Surf. A 1998, 137, 253.

[117] Donath. E, Sukhorukov, G. B., Caruso, F., Davis, S. A., Mohwald, H. Angew. Chem. Int. Edn 1998, 37, 2202.

[118] Schonhoff, M. J. Phys.: Condens. Matter 2003, 15, R1781.

[119] Decher, G. Science 1997, 277, 1232.

[120] Decher, G., Schlenoff, J. B. Multilayered thin films, Wiley-VCH, 2002.

[121] Hoogeveen, N.G., Stuart, M.A.C., Fleer, G.J. Langmuir 1996, 12, 3675.

[122] Schmitt, J., Grunewald, T., Kjaer, K., Pershan, P., Decher, G., Losche, M. Macromolecules 1993, 26, 7058.

[123] Lowack, K., Helm, C.A. Macromolecules 1998, 31, 823.

[124] Decher, G. Layered nanoarchitectures via directed assembly of anionic and cationic molecules in Sauvage, J. P. Comprehensive Supramolecular Chemistry, cap. 14, Oxford, 1996.

[125] Hoar, T.P., Yahalom, J. J. Eletrochem. Soc. 1963, 110, 164.

[126] Signini, R., Campana Filho, S.P. Polym. Bull. 1999, 42, 159.

[127] Liang, Z., Susha, A.S., Yu, A., Caruso, F. Adv. Mat. 2003, 15, 1849.

[128] Sauerbrey, G.Z. Phys. 1959, 15, 206.

[129] West, A.R. "Solid State Chemistry ans its Applications”, John Wiley \& Sons: Chichester, 1987.

[130]Arys, X., Laschewsky, A., Jonas, A.M. Macromolecules 2001, 34, 3318.

[131] Peaker, A.J.S., Czernuska, J.T. Thin Solid Films 1996, 287, 174. 
$\underline{\text { Referências }}$

[132] Kim, H.M., Miyaji, F., Kokuko, T. J. Mater. Sci: materials in medicine 1997, 8, 341.

[133] De Andrade, M.C., Sader, M.S., Filgueiras, M.R.T., Ogasawara, T. J. Mater. Sci: materials in medicine 2000, 11, 751 .

[134] Lazarevic, Z.Z., Miskovic-Stankovic, V.B., Kacarevic-Popovic, Z., Drazic, D.M. Corrosion Sci. 2005, 47, 823.

[135] Balamurugan, A., Balossier, G., Michel, J., Ferreira, J.M.F. Electrochim. Acta 2009, 54, 1192.

[136] Pedrosa, J.M., Perez, M., Prieto, I., Martín-Romero, M.T., Möbius, D., Camacho, L. Phys. Chem. Chem. Phys. 2002, 4, 2329.

[137] Souza, N.C., Caetano, W., Itri, R., Rodrigues, C.A., Oliveira Jr., O.N., Giacometi, J.A., Ferreira, M. J. Colloid Interface Sci. 2006, 297, 546.

[138] Kotachi, A., Miura, T., Imai, H. Cryst. Growth Des. 2006, 6, 1636.

[139] Manoli, F., Koutsopoulos, S., Dalas, E. J. Cryst. Growth 1997, 182, 116.

[140] Piculell, L., Nilsson, S., Muhrbeck, P. Carbohydr. Polym. 1992, 18, 199.

[141] Nilsson, S., Piculell, L. Macromolecules 1989, 22, 3011.

[142] Vagharchakian, L., Hénon, S. Langmuir 2003, 19, 7989.

[143] de Jong, S., van de Velde, F. Food Hydrocolloids 2007, 21, 1172.

[144] Dandeu, A., Humbert, B., Carteret, C., Muhr, H., Plasari, E., Bossoutrot, J.M. Chem Eng Technol 2006, 29, 221.

[145] Gerhard Herzberg, F.R.S.C. "Molecular Spectra and Molecular Structure”, VNR-New York, 1945.

[146] Weiner, S., Addadi, L. In Biomineralization; Mann, S., Ed.; VCH: Weinheim, pp 133-156, 1989.

[147] Cölfen, H., Mann, S. Angew.Chem., Int. Ed. 2003, 42, 2350. 